\title{
Viewing themes of teaching and learning with a phenomenological lens
}

\author{
Katina L. Sayers \\ West Virginia University
}

Follow this and additional works at: https://researchrepository.wvu.edu/etd

\section{Recommended Citation}

Sayers, Katina L., "Viewing themes of teaching and learning with a phenomenological lens" (2004). Graduate Theses, Dissertations, and Problem Reports. 2572.

https://researchrepository.wvu.edu/etd/2572

This Dissertation is protected by copyright and/or related rights. It has been brought to you by the The Research Repository @ WVU with permission from the rights-holder(s). You are free to use this Dissertation in any way that is permitted by the copyright and related rights legislation that applies to your use. For other uses you must obtain permission from the rights-holder(s) directly, unless additional rights are indicated by a Creative Commons license in the record and/ or on the work itself. This Dissertation has been accepted for inclusion in WVU Graduate Theses, Dissertations, and Problem Reports collection by an authorized administrator of The Research Repository @ WVU.

For more information, please contact researchrepository@mail.wvu.edu. 


\title{
Viewing Themes of Teaching and Learning with a Phenomenological Lens
}

\author{
Katina L. Sayers \\ Dissertation submitted to the College of Human Resources and Education at \\ West Virginia University in partial fulfillment of the \\ requirements for the degree of \\ Doctorate of Education \\ in Curriculum and Instruction \\ Patricia Obenauf, co-chair \\ Sam Stack, co-chair \\ Ron Ianonne \\ Ernest Goeres \\ Jaci Webb-Dempsey \\ Department of Educational Theory and Practice \\ Morgantown, West Virginia \\ 2004
}

Keywords: Phenomenology, Phenomenological Research, Image Based Research, Teaching, and Learning

Copyright 2004 Katina L. Sayers 


\title{
Abstract \\ Viewing Themes of Teaching and Learning with a Phenomenological Lens
}

\author{
Katina L. Sayers
}

The purpose of this qualitative study is to explore understandings pre-service teachers, in-service teachers, and college faculty hold towards learning and teaching, the types of classroom setting that best contributes to teaching and learning, and the kinds of experiences that are meaningful. These 'understandings' were compared to existing ideas in the literature to determine whether or not teachers are responding to post-modern thought related to the issues of concern.

Using common and not-so-common qualitative research methods, data was gathered from nine participants through face-to-face interviews, documents, observations, journal entries, and photo-elicitation interviews. For data analysis and interpretation, an inductive emergent design was utilized and consisted of three sub-processes: (1) data reduction, (2) data display, and (3) drawing conclusions.

Examination of issues of significance occurred from two perspectives. First, from that of the researcher where autobiographical renderings are woven throughout to expose a personal expose' of thought related to the issues of concern. Second, from that of the participants where personal narratives provide an in-depth view of the ideas and experiences that shape understandings related to the issues of concern.

Findings framed around the main research questions reveal teachers hold epistemological assumptions of mind congruent with post-modernism but teach in conditions that are antithetical to their understandings of meaningful classroom experiences. 


\section{Acknowledgements}

I wish to express my sincere thanks and gratitude to the members of my doctoral committee:

Pat Obenauf, Sam Stack, Ron Iannone, Ernest Goeres, and Jaci Webb-Dempsey. In my teaching, there is a part of each of you with me every time I step into a classroom. I pass on to my students what you have so graciously given to me.

I thank Pat for her infinite wisdom, love, and time.

I thank Sam for introducing me to the philosophy of John Dewey.

I thank Ron for asking more from myself than I thought ever imaginable.

I thank Ernest for always greeting me with optimism during the research approval process.

I thank Jaci for following me through from the very beginning of my qualitative research endeavors.

Other individuals involved 'directly' and 'indirectly' in the study and deserving recognition are the nine participants and hosting PDSs; and, Dr. Van Dempsey and Sara Steel of the Benedum Collaborative.

I wish to thank these individuals for their enduring love and tireless support during the study: my mom, Linda Jean Cameron; my aunt, Eula Fresch; my soul mate, Jeff Walker, for whom my love is so great that it inspired me to write; my best friend, Laura Adams; my graduate assistant, Melissa Brown; and for spiritual guidance, Caroline and Riley. 


\section{Table of Contents}

$\begin{array}{lll}\text { Abstract } & \text { ii }\end{array}$

Acknowledgements iii

Chapter I: Introduction 1

Problem Statement 3

Introduction to Areas of Concern 4

$\begin{array}{ll}\text { Purpose and Relevance of Study } & 8\end{array}$

$\begin{array}{ll}\text { Research Questions } & 10\end{array}$

$\begin{array}{ll}\text { Brief Overview Of Methodology } & 11\end{array}$

$\begin{array}{lr}\text { Concluding Thoughts } & 12\end{array}$

\section{Chapter II: Thinking about Phenomenology}

$\begin{array}{ll}\text { Introduction } & 18\end{array}$

$\begin{array}{lr}\text { Apart/A part } & 19\end{array}$

$\begin{array}{lr}\text { Overview of Phenomenology } & 28\end{array}$

$\begin{array}{ll}\text { A Brief History of Phenomenology } & 28\end{array}$

$\begin{array}{ll}\text { Consciousness and Intentionality } & 31\end{array}$

$\begin{array}{ll}\text { Meaning and Experience } & 34\end{array}$

$\begin{array}{ll}\text { Phenomenological Attitude } & 36\end{array}$

$\begin{array}{ll}\text { Perception } & 39\end{array}$

$\begin{array}{ll}\text { Intersubjectivity } & 43\end{array}$

Concluding Thoughts $\quad 45$ 
Chapter III: Doing Phenomenology, Part I - Past, Present, and Future Explorations of Teaching and Learning

$\begin{array}{ll}\text { Introduction } & 48\end{array}$

Defining the Eras $\quad 51$

The Modern Era

The Purpose of Education $\quad 52$

Epistemological Assumptions of Mind 55

$\begin{array}{ll}\text { The Classroom Setting } & 58\end{array}$

$\begin{array}{ll}\text { Meaningful Experiences } & 62\end{array}$

$\begin{array}{ll}\text { Teaching and Learning } & 64\end{array}$

An 'Unplanned’ Critical Reflection $\quad 68$

The Post-Modern Era

The Purpose of Education $\quad 75$

Epistemological Assumptions of Mind $\quad 84$

$\begin{array}{ll}\text { The Classroom Setting } & 99\end{array}$

$\begin{array}{ll}\text { Meaningful Experiences } & 107\end{array}$

$\begin{array}{ll}\text { Teaching and Learning } & 119\end{array}$

$\begin{array}{lr}\text { Chapter } 3 \text { Summary Table } & 133\end{array}$

$\begin{array}{lr}\text { Concluding Thoughts } & 134\end{array}$

Chapter IV: Doing Phenomenology, Part 2 - Researching the Lived Experience

$\begin{array}{lr}\text { Introduction } & 136\end{array}$

$\begin{array}{lr}\text { Problem Statement } & 137\end{array}$

$\begin{array}{ll}\text { Purpose and Relevance of Study } & 137\end{array}$

$\begin{array}{lr}\text { Research Questions } & 138\end{array}$ 
Justification of Qualitative Research Methods

$\begin{array}{lr}\text { Phenomenological Research } & 140\end{array}$

$\begin{array}{ll}\text { The Role(s) and Voice of the Researcher } & 142\end{array}$

$\begin{array}{ll}\text { Techniques within the Method } & 149\end{array}$ $\begin{array}{ll}\text { Interviews } & 150\end{array}$

$\begin{array}{ll}\text { Observations } & 153\end{array}$

$\begin{array}{ll}\text { Documents } & 155\end{array}$

$\begin{array}{ll}\text { Personal Journal Entries } & 155\end{array}$

Image Based Research and Photo Elicitation 156

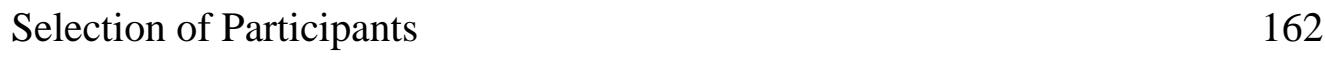

$\begin{array}{ll}\text { Permission to Conduct Research } & 163\end{array}$

$\begin{array}{ll}\text { Engagement with Participants } & 163\end{array}$

$\begin{array}{lr}\text { Data Collection } & 163\end{array}$

$\begin{array}{ll}\text { Data Analysis and Interpretation } & 164\end{array}$

\section{Chapter V: The Lived Experiences - Portraits of the Participants}

$\begin{array}{lr}\text { Introduction } & 167\end{array}$

Change in Teacher Education and the 5-Year Teacher-Education Program 169

$\begin{array}{ll}\text { Prelude to Lived Experiences } & 175\end{array}$

Section I: The Lived Experiences of the Pre-Service Teachers 177

$\begin{array}{ll}\text { Narrative I: Kerry } & 181\end{array}$

$\begin{array}{ll}\text { Narrative II: Lisa } & 196\end{array}$

Narrative III: Amy 208

$\begin{array}{ll}\text { Summary } & 221\end{array}$

Section II: The Lived Experiences of the In-Service Teachers 223 
Narrative IV: Kelly 226

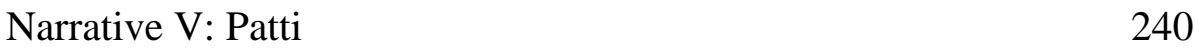

Narrative VI: Linda 253

$\begin{array}{ll}\text { Summary } & 265\end{array}$

Section III: The Lived Experiences of College Faculty 267

$\begin{array}{ll}\text { Narrative VII: Kathy } & 271\end{array}$

Narrative VIII: Jim 286

Narrative IX: Mike 300

$\begin{array}{ll}\text { Summary } & 314\end{array}$

\section{Chapter VI: Emerging Themes and Discoveries}

$\begin{array}{ll}\text { Introduction } & 316\end{array}$

$\begin{array}{ll}\text { Problem Statement } & 317\end{array}$

Question \#1 Emerging Themes and Discoveries 317

Question \#2 Emerging Themes and Discoveries 322

Question \#3 Emerging Themes and Discoveries 328

Discussion of Modern and Post-Modern Epistemological Assumptions of Mind Related to $\begin{array}{ll}\text { Problem Statement } & 334\end{array}$

Implications of Research Findings in Teacher Education 339

$\begin{array}{ll}\text { Recommendations for Future Research } & 340\end{array}$

$\begin{array}{ll}\text { References } & 342\end{array}$

\section{Appendices}

A. Approval to Conduct Research 352

B. Cover Letters to Parents 355 
C. Parental/Guardian Consent Forms 358

D. Student Assent Forms 363

E. Cover Letter to PDS Host Teachers 366

$\begin{array}{ll}\text { F. Cover Letter to Interns } & 368\end{array}$

G. Consent and Information Form for PDS Host Teachers 370

H. Consent and Information Forms for PDS Interns 373

I. Script to Participate in Study for College Faculty 376

$\begin{array}{ll}\text { J. Interview Protocol } & 378\end{array}$

$\begin{array}{ll}\text { Curriculum Vitae } & 382\end{array}$ 


\section{List of Tables}

1 Chapter 3 Summary Table:

Characteristics and Descriptors for the Modern and Post-Modern Era

133 


\section{List of Figures}

5.1 Mike’s Philosophy of Education 


\title{
Chapter 1: Introduction
}

\author{
A Time of Decay \\ After a time of decay comes the turning point. \\ The powerful light that has been banished returns. \\ There is movement, but it is not brought about by force.... \\ The movement is natural, arising spontaneously. For this \\ reason the transformation of the old becomes easy. \\ The old is discarded and the new is introduced. \\ Both measures accord with time; therefore no harm results. \\ --I Ching, \\ (cited in Capra, 1982)
}

Teacher education programs in the United States in institutions of higher education have been historically derived from criteria set forth by state departments of education to ensure uniform certification and licensing procedures. But following the publication of $A$ Nation at Risk (1983) and even more recently, the No Child Left Behind Act (2001), the quality and effectiveness of America’s teaching workforce have been scrutinized as never before as America’s public school children standardized test scores continue to lag behind their European counterparts.

With the burden of blame falling squarely on the shoulders of classroom teachers, promising interventions to improve teacher effectiveness and student learning were implemented. Since the publication of A Nation at Risk, random terms such as excellence, professional development, reflective practitioners, and accountability were tossed around in 
teacher lounges and institutions of higher education at such dizzying rates that evidence to determine efficacy would not be available until years later.

Almost 20 years later, Rod Paige, current U.S. Secretary of Education, called for raising standards in teacher education programs by requiring state examinations in the subjects they plan to teach and lowering 'barriers' in institutions of higher education through the reduction of number of methods courses required in a 2002 Annual Report to Congress on teacher quality (Page, 2000). Both goals aim to ensure qualified teachers in every classroom, a staple for improved student learning, and as called for in the No Child Left Behind Act.

At the state and local level, a maturing of certification procedures translated into continuing education units and workshops for teachers, mentoring programs, professional development schools, collaborative teaching partnerships, and action research projects in teacher education programs.

As A Nation at Risk explains, classroom teaching practices have become a matter of economic prosperity, civility, and national defense, but there are aspects of the teaching and learning processes that cannot be 'objectivized' and are not readily understood which need be taken into account. Teachers shape the learning environment and bring their identity and beliefs, into and through, their teaching practices, like the weaving of a braid. Teaching and learning are themselves mysterious encounters with materials, experiences, and humans within a socially constructed context (Pinar, et.al., 1995). Likewise, much of what teachers do is about going into the “unknown,” meeting the “stranger,” or journeying down previously unmarked paths. Just the simple lesson plan demonstrates an act of faith and a vision for what is worth knowing and learning. In actuality, though, the teacher never really knows what the learner 
learns or what will be remembered. They can only profess that they have instructed students by a set of prescribed standards and principles, and communicated information.

\section{Problem Statement}

Teachers have, for the most part, always had instructional programs 'handed-down' to them, but why has the teacher's voice been left out of the reform and change process when, on a daily basis, they, the pedagogues, implement and instruct the nation's children? Basil Bernstein contends that perhaps they accept that they are the "second site" of discourse with intellectualization beginning in an 'upper' authoritative site, and where, for reasons tied into their teacher identity, they have been viewed (and view themselves) as agents of implementation (cited in Kirk \& Macdonald, 2001). This present view of the teacher as secondclass citizen has for too long dominated teaching and learning practices and is deeply tied into the modern, positivist world view but this is changing as society transitions into the postmodern era. Evolving out of this transition are new ways of thinking, valuing, and viewing of the world. There is a crisis in education and there is resistance, as with any movement, to the cultural revolution taking place. New notions about teaching and learning are emerging and beginning to replace traditional ideas about teaching and learning but not without controversy. The American public school system has not kept up with changing societal views and still remains crudely positivist. The root of the educational problem lies in the epistemological assumptions of mind and then, the translation of the epistemological assumptions in classroom teaching and learning practices.

In this study, current teachers in the field will shed light on their beliefs towards the nature of teaching and learning practices, and these beliefs will act as a gauge in the portrayal of their understandings towards the cultural revolution. Do they view their classroom practices 
as changing and progressing to keep up with the societal transformation? Or, are their classroom practices more aligned with the modernist ways of teaching and learning?

Phenomenological research methods will serve as the method of inquiry for the in-service teachers, pre-service teachers, and college faculty who participated in the study.

\section{Introduction to Areas of Concern}

To provide a clearer picture and to distinguish the characteristics of educational practices more commonly associated with the modern era and the new, evolving practices of the post-modern, the following discussion introduces three elements that are pivotal in this study: (1) the classroom setting; (2) the type of learning and teaching practices that give meaning; and, (3) general understandings towards teaching and learning.

Recent literature related to post-modern thought defines the nature of classroom practices as a point of intersection with the subject, teacher, and student. What happens at that intersection is not well understood, but Parker Palmer (1998) conceives it to be, the meeting place of a "community of truth,” a place where teachers and students are equals and gather to pay reverence to the subject and build relationships with one another. Gone is the competition, the objectivism, and the separation of the knower from the known. Ron Miller (2000) in Creating Learning Communities writes classrooms of the new era will be democratic, participatory, emancipating, student-centered, and 'not held hostage' to accountability constraints. Both would agree that learning is dependent upon building a sense of community and need to belong.

Classrooms in the modern age of education are hierarchical - there is an 'object' to be studied; the teacher is the expert and transmitter of knowledge about the object; and students wait to receive the transmitted information about the object via a one-directional flow of 
information. For the student to make contact with the object, they must go through, around, or over the teacher (Palmer, 1998). Post-modernists would say the teacher is in the way of the student's learning. The first topic that is problematic and relevant to this study is related to the type of setting that best contributes to teaching and learning. What thoughts and understandings do teachers hold towards the type of classroom setting best conducive to teaching and learning?

Another issue of concern is the foundations of which most teacher education programs have traditionally stemmed from; that is, the Tyler Rationale (1949). Four basic criteria guided Tyler Rationale: (1) determine the teaching and learning objectives around the purpose the school seeks to attain, (2) design the program to attain the stated objectives, (3) organize the learning experiences for scope and sequence of procedures, and (4) evaluate the educational experiences. The implications of this are a sign of the modern era's mechanistic influence especially in the philosophic areas of realism and behaviorism. For example, course outlines in teacher education programs describe a "progressive atomizing of knowledge into discrete specialties and sub-specialties”; general strategies for information delivery as didactic, lecture based; topics subdivided into lessons and lessons into facts and formulas, as if to say, that the process of living entails breaking down the whole to understand the parts (Schubert, 1993). When matter becomes the dominant object for study, materialism and material wealth is valued over spiritual depth.

As post-modern ideologies creep into the classroom, the 'practical inquiry' status of the Tyler Rationale is losing ground to reconceptualized ideas of teaching and learning where a search for meaningfulness and lived connections matter (Pinar, et.al, 1995). Meaning can be found through one's learning, through one's teaching, as if to let one's life speak for itself. The 
next topic to be challenged and relevant to the study is related to the types of teaching and learning experiences that are meaningful. What is really understood about the types of the learning and teaching experiences that are meaningful?

The final area of concern is related to the general understandings teachers hold towards teaching and learning. What understandings do teachers have about teaching and learning? What are the origins and experiences that have led to these understandings?

The above discussion related to classroom environment and meaningful teaching and learning processes, sheds clues to the predominant ideologies of the modern era and postmodern era in the these areas. Much of the modern era's approach to learning and teaching gravitates around the idea of knowledge as a discrete group of facts or ideas and teaching and assessment methods, therefore, are reflected as such. During World War I, experimental testing of intelligence quotients (IQ) appeared and was the main mechanism of sorting military personnel for respective duties and responsibilities. Later, a similar type of testing appeared for high school students to test potential academic achievement in college bound students -- more commonly known today as the Scholastic Aptitude Test (SAT). In this present period of accountability and standardization, this is still the predominant mode of assessment for today's youth.

The modern era of teaching and learning has emphasized the quantitative gathering of facts; viewed the mind as a machine wherein information is passed on to the learner, similar to Freire’s (1993) “banking” concept of education; and linking the rational learning process to a straight line.

Moving beyond the modernist mindset, the post-modern approach to teaching and learning is strikingly different. The main factor in this equation is the human life and human 
potential. Not to say here that information is not important, but as William Doll (1993) elucidates in A Post-modern Perspective on Curriculum, the focus of teaching and learning in this era should be “polyfocal," that is, the human experience is not based on retention of the 'one way' or 'one best' concept to describe reality. The “"polyfocal” classroom would be a selfregulating system based on the needs of the students and include: studying change over time and looking for patterns and thematic connections in history; deconstructing meta-narratives and reconstructing personal narratives; and searching and living for social justice. The teacher would recognize the lived experiences each child brings to the classroom and value diverse opinions and consider cultural differences in their teaching practices. Assessment would take into account multiple intelligences and be true to authentic learning, described by William Ayers in To Teach (2001) as the 3-P method: projects, portfolios, and presentations. This study will explore common understandings about learning and teaching held by teachers.

In summary, three issues were explored in this study and examined with a phenomenological lens. The teacher's voice will serve as the guide through their sharing of what is, leading the researcher to juxtapose those thoughts on teaching and learning with those ideas most commonly associated with the post-modern era (Spiegelberg, 1975).

The three areas of concern in this study were:

(1) The ideas and experiences related to the kind of classroom setting that best contributes to teaching and learning.

(2) The ideas and experiences related to the kind of educational experiences that are meaningful.

(3) The ideas and experiences related to general understandings of teaching and learning. 


\section{Purpose and Relevance of Study}

In the opening pages of Ecological Literacy: Education and the Transition to a Postmodern World, David Ray Griffin describes the shift humanity is experiencing as one that will be freeing and liberating but nonetheless, a serious affair (cited in Miller, 1997):

Going beyond the modern world will involve transcending its individualism, anthropocentrism, patriarchy, mechanization, economism, consumerism, nationalism, and militarism...[T]he inclusive emancipation must be from modernity itself. (p. 73)

Is the paradigm change or shift so often written, spoken about, actually taking place? What clues or symptoms would shed light on these issues? Looking at these issues of change from a broader spectrum, changing worldviews have slowly permeated most areas of life. The traditional rules of modernity are lifting to expose eclectic, divergent paths of being in the world -- from the arts, literature, architecture, worship and spirituality, health care, technology, environmental concerns, science and the expanding universe, consciousness studies, honoring diversity and multiculturalism - with the core of the movement dwelling the meta-cognition of the "self-in-relation" (Slattery, 1995). In Acts of Meaning, Jerome Bruner (1990) provides insight to the world of self. Knowing self can only come through reflection but is defined by the kinds of experiences human beings use to "formulate their own concept of Self."

As I introduce my personal voice here, I make the following supposition: humanity is in the midst of change. But, I wonder how are teachers experiencing and responding to the dualistic energies floating around and within the school? Or, has the American educational system begun to grasp the ideologies related to post-modern thought? Has the school 
emancipated itself from the values of the industrial, modern era and begun to move towards the values and ideologies of the vision logic period?

The purpose of this qualitative study is to explore understandings teachers hold towards learning and teaching, the type of classroom setting that best contributes to teaching and learning, and the kinds of experiences that are meaningful. Examination of these issues of significance occurred from two perspectives. First, as my sense of self is tied into and within my identity as teacher, student, and researcher, autobiographical renderings will be woven throughout this study to expose (1) a personal expose' of thought related to my readings of teaching and learning and the concept of change especially as it relates to post-modernism; and (2) my experiences as a teacher, student, and researcher related to the issues of significance.

The second perspective is that of the participants. Phenomenology served as the philosophical framework and the central question of phenomenology is "What is the structure and essence of experience of this phenomenon for these people?” (Patton,1990). To study the phenomenon of teaching and learning, the study endeavored: (1) to describe the lived experiences and understandings pre-service teachers, in-service teachers, and college faculty have towards the concepts connected to learning and teaching; (2) to draw connections to the responses and experiences of the above stakeholders involved in teacher education programs; and, (3) to identify the emergent themes on teaching and learning. A final discussion compares and contrasts the identified themes of the study to the post-modern literature, with final thoughts on the implications of the research findings for teacher-education programs.

Too often as a professor, I hear my students voice their concerns and discontentment with the selected course readings on post-modernism. They remark of the 'fluff, 'the esoteric nature of the text and my discourse, and the 'un-practicalness' of the ideas. My students are 
primarily graduate students who are currently teaching in the public school classroom, returning to higher education to receive a Master's degree as required by the state. The most common objection I hear, “These are nice ideas, Professor Sayers, but in all actuality, it just doesn't exist," or “These sound like good ideas but I'm not tenured so I need to stick with the instructional plan.” There is a sense of fear I detect, but also, the pessimism and cynicism comes across even stronger than the fear. Even I question at times the ideas of the post-modern leaders in the field of teaching and learning - namely, that of Patrick Slattery, William Pinar, or William Doll - who’s ideas prompt the students’ remarks. But, my intuition, personal experiences and readings, lead me to believe that the change I read about and feel has its beginnings in the Civil Right's Movement and is quickening at a pace that cannot be described in numerical terms except to say, lives of 'busy-ness' is a constant theme and a constant pressure that pushes us to do more and accomplish more in less time or so it seems. This external, driving force has no face, has no name, except speculation exists that the global rates of information transmission via technological means has affected the perceived rate at which we live (Russell, 1998). I also recognize that some readers will discount and reject my personal thoughts woven throughout the writing of this research. That is to be expected but can be rationalized within the framework of the Innovation Diffusion Theory (1983) and supported in the classical text of Women's Ways of Knowing (1986). Dare I say we live in a time of fear and if so, where is fear moving us? The opening quote in this chapter is a reminder that the occurrence of change is a natural, flowing part of nature. So, where have we arrived in this transformation? Where has the educational system arrived in this transformation?

\section{Research Questions}

Three central research questions guided the study: 
1. What understandings do pre-service teachers, host teachers, and college faculty have about teaching and learning?

2. What understandings do pre-service teachers, host teachers, and college faculty have about the kind of educational experiences that are meaningful?

3. What understandings do pre-service teachers, host teachers, and college faculty have about the kind of classroom setting that best contributes to teaching and learning?

Answering these questions is especially difficult but essential to mapping out the present landscape teachers find themselves.

\section{Brief Overview of Methodology}

To explore the research questions and give power to the teacher's voice, traditional and not-so-traditional qualitative research methods provide the basis for data collection. The teacher's voice in this study includes three pre-service teachers, three in-service teachers, and three college faculty members. The participants had professional connections to one another: the pre-service teachers were under the guidance of the in-service teachers for practicum and student teaching placements; and, college faculty members were instructors to the pre-service teachers. The pre-service and in-service teachers were teaching at established Professional Development Schools (PDSs). Additional discussion of the history of PDSs takes place in chapter five.

To explore the research questions in depth, the following qualitative data collection strategies were favored: interviews, observations, document analysis, photo-elicitation, personal journal entries. In combination, these methods provided adequate measures for triangulation purposes. The interviews consisted of a series of three interviews and consisted of a total of 20 questions related to understandings of teaching and learning; two classroom 
observations were completed; two ‘take home’ questions per participant were used for document analysis purposes and when voluntarily offered by the participants, so did course syllabi; and, disposable cameras were provided to the participants to capture 'meaningful moments' in the classroom with the photographs offering the 'jumping off point' for the portion of the photo-elicitation interviews of the data collection. Interviews took place at times convenient for the participants and at multiple locations, e.g., at their respective schools, local coffee shops, and university libraries. Observations were scheduled at a time suggested by the teacher. This data was gathered during the spring of 2001 and analyzed by the researcher who used qualitative coding methods to answer the three research questions with further interpretation of the data based on phenomenological analysis.

Because I do not see myself as separate from the participants in the study nor the culture of education on which we base our patterns, rituals, beliefs, and standards by -- I, too, am a teacher and student - my role in the research methodology is that of the participant-observer because I share a common interest in the research findings. My voice, like the participants, will also be included in this study in autobiographical skits and renderings, as well as, for the elaboration of ideas related to modern and post-modern thought.

\section{Concluding Thoughts}

At present, education is struggling with the dualistic nature and identity of its profession. I better imagine the struggle described in this opening chapter in metaphorical terms as a game of tug of war, where at one end of the 'rope' are the traditionalists and at the other end, are proponents of post-modernism attempting to pull the modernists over to their side with idealistic dialogue of the nature of change. But, rather than taking place at the horizontal level, it is vertical. The post-modernists are attempting to pull the 'mainstreamers' up to their level, 
and attempting to lift them out of their present reality. The post-modernists are surrounded by others who think like them, talk like them, and are clearly outnumbered but remain steadfast to their beliefs. Passing back and forth between the camps is physical tension and tiredness, emotional struggles and anxiety, mental disbelief and challenges. There is no decisive winner. Each side desperately clings to its beliefs.

A dialogue takes place in my head of the exchange of words between the two camps. As I imagine it, the conversation resembles a similar conversation between the two central characters in the 1981 art-house film, My Dinner with Andre.' One character speaks of his catharsis with the living of the modern world and the soul-searching events that led him to be reawakened; while his dinner partner, provides the balance, the sounding board, for the oft times sounding incredulous accounts:

Post-modernists: Stop sleep-walking through life and re-awaken yourselves to the beauty and mystery of life. There's a cultural revolution taking place. Look at the world from another vantage point. There are multiple views of reality. In fact, there could be multiple, even parallel universes so explains "M" theory. Suspend your disbelief. There are experiences you have never seen because the old paradigm was structured in such a way that you could only learn, see, and feel in ways that defined your existence. Consider other possibilities.

Modernists: Everything is fine the way it is. I'm fine, look at me. There's no reason to change. There's no reason to try to fix something if it ain't broken. What's good enough for me, is surely good enough for my children. Cultural revolution? I don’t see anything going on.

Those of this new enlightenment thinking are no different than the 'radicals' who came before them. Galileo and Copernicus threatened the then existing belief systems; once their 
secretive experiments were made public, one was accused of heresy and imprisoned; the other, punished by death. So, where does anything new begin? Where do new thoughts and ideas begin and how are they manifested in the population at large?

The same argument resides in the field of education. Young and upcoming teachers on the edge of current thought are placed in classrooms with seasoned, veteran teachers. The preservice teachers bring new life, new energy, new ideas but what are they currently experiencing?

At this point, the reader has undoubtedly caught on to my preference of the post-modern over the modern and I want to clarify my thoughts. I do not mean to belittle or show disrespect regarding the contributions of the modern era - just the opposite. Out of the Enlightenment period grew cultural and political movements such as solidarity and democracy, and many technological innovations, which provide comforts to human daily living. Modernism provided these foundations and the beginnings of post-modern thought. If possible, I wish to find balance. My culture, my life, and my educational experiences, have the same roots as the individuals in the study. Too often the modern era is 'villified' and imagined as something that exists 'out there.' But, that is not the case. My students want to do the same when we study the ideas of Thomas Jefferson using the lens of critical theory. We are a part of the values, the culture of the modern era. It resides in us and is a part of us.

In my writing, I have also tried to balance and rebalance the ways of the modern era by emphasizing post-modern notions. I chose to purposefully expose the present dualities with the intent of re-connecting the parts later and discard the fragmented sense of reality created by 'either-or' thinking. 
As for myself, I have been led astray from the modern 'thinkings' of the world for reasons not clearly articulated except to say that I have personally experienced random, chance encounters that cannot be explained by constructs of the modern paradigm. For this reason, the modern paradigm is insufficient and I believe that the understandings of the world are only as good as the methods used to conceive of them. The modern paradigm is not my 'default' selection of my mental processor.

As this introductory chapter concludes, there are a few notes I wish to include here regarding the presentation and format of the study. Qualitative research has for too often been given a label by traditional quantitative researchers as 'soft research,' primarily because it does not adhere to the same rigorous procedures, and validity and reliability standards, so common to quantitative research. And, is, therefore, discounted as being 'good' research. Again, I will try to balance and rebalance this thought pattern. Yvonna S. Lincoln calls the doubting of the 'hard core' researchers a typical response because qualitative research poses a threat to the authoritative, privileged position quantitative research has obtained (cited in Tierney \& Lincoln,1997). But, in a post-modern context, doubt is reserved for all 'truths’ allowing “us to know 'something' without claiming to know everything." The creative format and qualitative techniques in this study should not be distorted as 'bad research.' Rather, qualitative research methods follow a different set of constructs and must, because of the intimate nature of human experience, necessitates an arena be built that invites the human voice. Creative freedom was granted in this study and further supported by the authors of Composing Ethnography: Alternative Forms of Qualitative Writing (1996), Writing the New Ethnography (2000), and Representation and the Text: Re-Framing the Narrative Voice (1997). Readers can fully expect the 'lines to be blurred,' the continual mixing of subjective and objective accounts, narrated 
stories, and the inclusion of images and photographs. The most difficult 'bump in the road' for myself was the inclusion of my voice and then, silencing my voice, my subjectivity, to not drown out the voice of the participants. What one must understand is no recreation of an event is ever the same as the actual event due to the 'lens' through which the world is viewed. The role of perception or the 'color of the lens through which the world is viewed' is discussed in later chapters but it is acknowledged that it does affect my writing, the stories of the participants, and, likewise, the readers as well.

\section{Overview of Chapters}

These issues of concern are systematically explored in the following chapters. Chapter one provides a brief overview of the study. Chapter two is entitled, "Thinking about Phenomenology,” and is the philosophical foundation of the study. The placement of this chapter represents its significance in the overall study. This chapter offers a brief history of phenomenology and discussion on some of the important aspects common to phenomenology to understand the role of perception and meaning-making. Chapter three and four share similar titles, “Doing Phenomenology” to illustrate the 'thinking and doing' of phenomenological research. Chapter three is sub-titled, "Past, Present, and Future Explorations of Teaching and Learning” and is divided into two main sections -- modern and post-modern era -- and further sub-divided by the areas of concern in the study. Chapter four is sub-titled, "Researching the Lived Experience,” and describes the techniques and methods for collecting and analyzing data. Chapter five is entitled, “The Lived Experiences - Portraits of the Participants” and is divided into three sections respective to the groups of participants - pre-service teachers, in-service teachers, and college faculty - and further sub-divided by areas of concern in the study. Chapter six is entitled, “Emerging Themes and Discoveries,” and summarizes the findings from 
chapter five to answer the main research questions of the study. Photographs and images of other cultural artifacts are included throughout to serve as documentation and representation of meaningful-moments.

\section{Post-Script to Research Study:}

Permission was received to conduct research following the University's Institutional Review Board (IBR) policies to protect human subjects. Under the conditions of consent/assent to participate in the study, it was agreed that photographs would not be posted to the Internet to protect the privacy of the individuals. Therefore, this version of the manuscript is void of pictures with the exception of personal photographs. I have left the placement of the photographs and captions in text primarily for the reason that I wanted future qualitative researchers to have an example of image based research techniques that relied upon a phenomenological foundation. I encourage readers to contact me to review the original manuscript. 


\section{Chapter 2: Thinking About Phenomenology}

And so it is "I," the person among other persons, alone yet inseparable from the community of others, who sees as if for the first time and who reflectively comes to know the meanings that awaken in my consciousness. I am the person who gives existence its essence, the one who returns essence to existential life

(Moustakas, 1994).

\section{Introduction}

The phenomena in question for this study are the understandings teachers hold towards teaching and learning, the type of setting that best contributes to teaching and learning, and the kinds of educational experiences that are meaningful. Problematic to this study are the epistemological assumptions of mind that conflict with emerging post-modern literature and practices related to teaching and learning. How are teachers experiencing and responding to the dualistic energies floating around and within the school?

To explore and distill the essence and experiences of teaching and learning held by teachers, phenomenology served as the philosophical foundation for inquiry. This chapter focuses on the phenomenological movement and the representation of phenomenological text, and acts as the 'building block' of discussion for the remaining chapters. Researching the lived experiences of the participants in this study will be discussed in later chapters.

The following chapter contains two main sections. The first section is devoted to personal reflections towards the nature of the representation of phenomenological text. As the self is exposed and committed to encountering the phenomenon privately and publicly, the writing of phenomenological research does not merely entail writing; rather, the writing is "self 
making or forming” (Van Manen, 1990). The writing process can take the writer to depths where thought and praxis become concrete acts. In this first section, I play with the representation of the text and the tone of the writing is casual, easy flowing, and allows for my 'inner voice’ to speak.

The second section is a general overview of phenomenology and takes on a more serious tone and writing style. Included in the overview is a brief history of the phenomenological movement, and a review of main concepts and ideas common to phenomenology with particular attention paid to the ideas of its 'founding father,' Edmund Husserl (1859-1938) and, French ‘perception’ expert, Maurice Merleau-Ponty (1908-1961). The ideas of William James (1842-1910) are featured in the discussion of consciousness.

\section{Apart/A part}

Phenomenology concerns itself with the often poorly defined structure of consciousness and the intentional receiving and perceiving of objects (Moustakas, 1994). But, that is not to say that consciousness exists only due to objective sense-datum; rather, it also takes into account, the mind's awareness of non-existent objects. As ideas, images, feelings, and memories, not singularly, but in a fluid fashion, stream through and into the mind's eye, awareness is paid to objects that are 'infused’ with meaning (Moustakas, 1994). There is a continuous dynamic weaving of the external environment with the internal mental environment brought on through perceptual responses, and 'decoded' and 'encoded' for ontological knowing. This 'bracketing of existence' is at the heart of phenomenology and such directedness is referred to as intentionality.

The phenomenological movement had its beginnings in Europe at the turn of the $20^{\text {th }}$ century -- at about the same time the U.S. public school system began to formally take shape - 
and resisted the claim of the separateness between mind and body, as espoused in Cartesian related thought. In the modern era, ways of knowing revolved mainly around objective practices; that is, it being necessary to 'stand outside' or 'away' from the thing being studied. The knower and the known were distinctly separate entities and subjective ways of knowing were dismissed as irrational or relegated to "the limbo of unredeemable private data" (Spiegelberg, 1975; Reason, 1994). Knowledge in the modern era was constructed through the atomistic act of breaking down the whole into parts, and was labeled, by the phenomenologists, as an “illusionary understanding” of truth (Moran, 2000).

Fritjof Capra (1996) in Web of Life succinctly identifies the dominant beliefs of the modern era that have and continue to shape epistemological, ontological, and axiological ways of being in the world:

...the view of the universe as a mechanical system composed of elementary building blocks, the view of the human body as a machine, the view of life in society as a competitive struggle for existence, the belief in unlimited material progress to be achieved through economic and technological growth, and the belief that a society in which the female is everywhere subsumed under the male is one that follows a basic law of nature. (p. 6)

The break-down of the world and the grasping for the control of knowledge was problematic to the phenomenologists. The Phenomenological movement sought to recapture the wholeness of life; that is, connect the objective world to the consciousness, which would be mediated through sensory perceptions, to explain the experiences of being in the world, primarily through descriptive means (Moran, 2000). As stated by Husserl, objectivity would be the achievement of “intersubjective confirmation and acceptance” (cited in Moran, 2000). 
Furthermore, Merleau-Ponty implied that phenomenology is best approached in terms of a 'holistic philosophy' -- a philosophy about everything, a philosophy to understand life as it is lived within the self and self with others (cited in Moran, 2000). So, what does it mean to experience unity or wholeness in this life?

As the research for this chapter began, I had random thoughts about 'wholeness' and how I might approach writing about phenomenology. The title of this chapter is thinking about phenomenology. Is thinking about phenomenology the one and the same as doing phenomenology? I am writing, I am thinking, I am reflecting, I am producing myself. If I am what I study because intentionality and my consciousness led me to the development of this study, then, I must be a part of which I study. I am the instrument. I am the product. I am 'united' with what I know (Van Manen, 1990). Like the spider in myth and lore that weaves, measures, and creates the silken threads of life, my past and present have come together and is embedded in the research. Within this study, my identity as a teacher and researcher are also present and unfolding.

At this juncture, the question remains -- what does it mean to experience wholeness and in what ways does phenomenology aid in 'seeing' the whole? As phenomenology studies the life-world of individuals and aims at gaining a deeper and richer understanding of human nature, every day acts can be re-experienced and re-appreciated when attention is paid to the direct participation of living (Van Manen, 1990). Therefore, phenomenology can respond to the issues that have arisen out of modernity because it can restore unity to the disconnected, fragmented world, brought on by the values associated with positivism and capitalism (Sokolowski, 2000). 
To better illustrate my point, a narrative, described in phenomenological terms as being 'a good description,' is one that reveals to the reader the significance of an experience in some 'unseen,' mysterious way; in that it intimately draws the reader into the psyche of the Other. Van Manen (1997) expressed the effect phenomenological text could have on the reader, “....the text....speaks to our cognitive and noncognitive sensibilities...thrives on certain irrevocable tension between what is unique and what is shared, between particular and transcendent meaning, and between the reflective and prereflective spheres of the lifeworld.” In a 'good description,' the reader undergoes a psychical transformation as the narrative acts on the consciousness in unexplainable ways. The mere act of reading itself does not always constitute change unless there is personal meaning attached to the experience. Perhaps, the change might bring about an understanding, compassion, or sympathy for the Other. A 'good description’ might be a “poeticizing” activity for the writer and reader, alike (Van Manen, 1990).

What follows is a narrative piece authored by Chief Seattle in 1892 in response to the U.S. Government's desire to buy tribal lands. In my opinion, this letter of reply 'is soaked in descriptive language' and could lead readers to a better understanding of the cultural values of the particular tribal nation. The first time I was exposed to the 'letter' was while watching a video series hosted by journalist, Bill Moyers, who interviewed, the now deceased, Joseph Campbell. Later, I came back to the letter through the reading of a book, The Power of Myth (1991). The thick beauty of the words and ideas resonated a lasting emotional response and regardless of the number of times I read and re-read this selection, I am brought to another level of emotion. I can still 'hear' Joseph Campbell reading these words in the video as I read 
them silently to myself. While it is lengthy, it does nicely bring together many of the preceding phenomenological ideas discussed thus far:

The President in Washington sends word that he wishes to buy our land. But how can you buy or sell the sky? The land? The idea is strange to us. If we do not own the freshness of the air and the sparkle of the water, how can you buy them?

Every part of this earth is sacred to my people. Every shining pine needle, every sandy shore, every mist in the dark woods, every meadow, every humming insect. All are holy in the memory and experience of my people.

We know the sap which courses through the trees as we know the blood that courses through our veins. We are part of the earth and it is part of us. The perfumed flowers are our sisters. The rocky crests, the juices in the meadow, the body heat of the pony, and man, all belong to the same family.

The shining water that moves in the streams and rivers is not just water but the blood of our ancestors. If we sell you our land, you must remember that it is sacred. Each ghostly reflection in the clear waters of the lakes tells of events and memories in the life of my people. The water's murmur is the voice of my father's father.

The rivers are our brothers. They quench our thirst. They carry our canoes and feed our children. So you must give to the rivers the kindness you would give any brother.

If we sell you our land, remember that the air is precious to us, that the air shares its spirit with all the life it supports. The wind that gave our grandfather 
his first breath also receives his last sigh. The wind also gives our children the spirit of life. So if we sell you our land, you must keep it apart and sacred, as a place where man can go to taste the wind that is sweetened by meadow flowers. Will you teach your children what we have taught our children? That the earth is our mother? What befalls the earth befalls all the sons of the earth.

This we know: the earth does not belong to man, man belongs to the earth. All things are connected like the blood that unites us all. Man did not weave the web of life, he is merely a strand in it. Whatever he does to the web, he does to himself.

One thing we know: our god is also your god. The earth is precious to him and to harm the earth is to heap contempt on its creator.

Your destiny is a mystery to us. What will happen when the buffalo are all slaughtered? The wild horses tamed? What will happen when the secret corners of the forest are heavy with the scent of many men and the view of the ripe hills is blotted by talking wires? Where will the thicket be? Gone! Where will the eagle be? Gone! And what is it to say goodbye to the swift pony and the hunt? The end of living and the beginning of survival?

When the last Red Man has vanished with his wilderness and his memory is only the shadow of a cloud moving across the prairie, will these shores and forests still be here? Will there be any of the spirit of my people left?

We love this earth as a newborn loves its mother's heartbeat. So, if we sell you our land, love it as we have loved it. Care for it as we have cared for it. 
Hold in your mind the memory of the land as it is when you receive it. Preserve the land for all children and love it, as God love us all.

As we are part of the land, you too are part of the land. This earth is precious to us. It is also precious to you. One thing we know: there is only one God. No man, be he Red Man or White Man, can be apart. We are brothers after all.

In the process of studying phenomenology, I come to understand myself as being intricately woven into the study and risk exposing my private thoughts. In doing this, my private thoughts intersect with the public domain. I am full of thought. Van Manen (1990) comforts me in this unstructured process and claims that to be full of thought means that the writer is transformed in the exploration and “recognizes....a lot of minding the Whole.” I am drawn into this mysterious realm of consciousness and want to lure the reader in, and together, we can wonder about these ideas. Where do I find wholeness in my human condition? Where do you find wholeness in the human condition? How do I participate in the world? How do you participate in the world?

There is personal journal entry I have decided to include here that reconstructs an ordinary shopping experience. What is of special importance in the entry, is the personal awareness paid to the moment about the interplay between the environment and other random conscious thoughts during my shopping experience. This is my personal example of a 'good description’ and I invite the reader to join me. 


\section{Personal Journal Entry:}

I am in a well-known New York college town and am pulled like piece of steel to a magnet to the nearest bookstore. Walking towards the store through the open-air market, there are tattooed young people milling around, some same gender couples walking hand in hand, and, others with matted dreadlock hairstyles wearing tie-dyed rainbow shirts. I am reminded of the acronym ROYGBIV from third grade science class. I catch out of the corner of my eye the motion of several youngsters walking on stilts looking more like they should be starring in a Dr. Seuss story with their 'cat in the hat' top hats, rather than this concrete setting. They have caught the attention of nearly everyone as they tower over us like giants and seem to enjoy basking in the stares. They are talking loudly to one another which further adds to their performance this cool, spring evening. Floating in the air, there is the all too familiar smell of patchouli, hippie stink, mixed with stale cigarette smoke and beer from a previous night's outings. I am enlivened by the energy within this space revealed to me through the sense of sight and smell as my mind is relating and decoding/encoding the messages to my past and present experiences.

I now focus my attention back to the bookstore and notice that my gait quickens and stride lengthens the closer I get. My purse is swinging from my shoulder and I clutch it hoping to stop the annoying to and fro motion that is opposing my forward movement. I am seamlessly moving through this space, a part of this space, through time all the while wondering what treasures I will find on this excursion. There are many others criss-crossing over my path but I am oblivious to them as I make a beeline approach to the hive. As I enter the bookstore, the musty smell coupled with the classical music, takes me back to my younger days as a child who used to beg her mother to leave her at the bookstore rather than having to play the puppy that 
follows the master. At that age, I loved books and bookstores. I could sit quietly for hours, flipping through pages of books, positioning myself on the floor, out of the way from the real money spending customers. I found solitude and could escape out of my life and into another's. I could be alone with my thoughts and just let my mind wander. I could be a character from the book; I could take a trip to a faraway place. Then, mom would summon me and my short mental excursion would end for the time being. Shifting my focus back to the present, I crouch down as if to pray to a worldly god and unceremoniously begin looking at the "new arrivals" cart. As a professor of education who is also in the midst of writing her dissertation, I look for texts and resources with a dual purpose -- items to share with my students and useful for my dissertation. There are books written by or about Foucault, Hemmingway, Weber, Jung, Erikson, James, Kliebard, Sontag, and many others. Glancing at my watch, I am conscious of my time constraints and decide to move on to the rest of the store. I am like a kid in a candy store. Where should I head first? The next two hours I meander around the store and pass into and through the philosophy section, religion and the occult, feminist studies, cultural studies, science, photography, American history, psychology, education, and Native American studies. I purchase two books and return to the outdoor commons and revel in my find. There is little left untouched by my hand and eye but much that is thought about (Sayers, April, 2003).

As I settle into my writing, it is more than just writing. It is a constant tossing of the ball back and forth between the words and the computer monitor. I stare at them and they stare back at me. Not only do they ‘tell’ me what I know, they ‘tell’ me what I don’t know. My private ideas become concrete, objectified understandings and forever immortalized on paper. For now, though, I turn away from my personal encounters and shift attention to the more formal writing about phenomenology. 


\section{Overview of Phenomenology}

In this section, a general history and brief overview of the field of phenomenology will be presented. Included are the following topics: A brief history of the phenomenological movement and a discussion of some terms common to phenomenology -- consciousness and intentionality; meaning and experience; phenomenological attitude; perception; and, intersubjectivity. While it is necessary to present clear distinctions in these areas, that is not to say that they exist independent of one another. In addition, the above topics were selected based on relevance to the problem statement, research questions, and qualitative inquiry methods.

\section{A Brief History of Phenomenology}

In its most comprehensive sense, phenomenology refers to the totality of lived experiences that belong to an individual, which is made aware through the presence of consciousness. Edmund Husserl (1859-1938) is generally credited with the responsibility of launching the phenomenological movement at the turn of the 20th century; however, there is some indication that the term phenomenology showed up in earlier philosophical writings dating back to 1765 . Husserl described in his groundbreaking work, Logical Investigations (1900-1901), the type of work that he was engaged in as “descriptive psychology,” and was later criticized by colleagues for appearing to confuse pure consciousness studies with psychologism, a field based on rationalistic principles (cited in Moran, 2000). In the first edition of Logical Investigations, Husserl wrote, "Phenomenology is descriptive psychology. Epistemological criticism is therefore in essence psychology, or at least capable of being built on a psychology foundation.” 
By the time a revised edition was published in 1913, Husserl better distinguished his ideas between psychology and phenomenology, and left little doubt of his expertise and alliance to his chosen field. More specifically, psychology was a field of study describing mental processes as events and real facts in nature; whereas, phenomenology was regarded as the contemplation of pure essences which included perception, judging, feeling, with other freely imagined experiences (Moran, 2000). Phenomenology was a science of pure description, in opposition to the analytical conditions found in the scientific method, that could be traced back to a priori knowledge, or what he called, intuition. Years later, Merleau-Ponty continued this line of thought by adding, “...the body is itself the original knowing subject from which all other forms of knowledge derive,” (cited in Audi, 1999). According to Husserl, intuition and essence precedes empirical knowledge (Moustakas, 1994).

In the introduction to the second edition of Logical Investigations (1913), Husserl wrote about his ‘revised' phenomenology (his emphasis included here) (cited in Moran, 2000): We are concerned here with discussion of the most general sort which cover the wider sphere of an objective theory of knowledge, and closely linked with this last, the pure phenomenology of experiences of thinking and knowing. This phenomenology, like the more inclusive pure phenomenology of experiences in general has, as its exclusive concern, experiences intuitively seizable and analyzable in their pure essential generality, not experiences empirically perceived and treated as real facts...

This phenomenology must bring to pure expression and must describe in terms of their essential concepts and their governing formulae of essence, the essences which directly make themselves known in intuition, and the 
connections which have their roots purely in such essences. Each such statement of essence is an a priori statement in the highest sense of the word. (p.107)

To believe that only one 'definition' exists for phenomenology would be counterintuitive to this discussion. George Hegel (1770-1831) approached the field of phenomenology in a similar vein, "Phenomenology referred to knowledge as it appears to consciousness, the science of describing what one perceives, senses, and knows in one's immediate awareness and experience (Kockelmans, 1967; Moustakas, 1994). The process leads to an unfolding of phenomenal consciousness through science and philosophy "toward the absolute knowledge of the Absolute.” Another contemporary, Martin Heidegger (1889-1976), added further to the field of phenomenology with the ontological question of, "What is the meaning of being?" in the everyday state of affairs of life (cited in Audi, 1999). He felt phenomenological ontology must return to the original data of "man's experience and the structures that make them" (cited in Kockelmans, 1967). And, more recently, in the opening pages of Phenomenology and Perception (1962), Merleau-Ponty, whose ideas were influenced by Husserl, began with the following:

What is phenomenology? It may seem strange that this question has still to be asked half a century after the first works of Husserl. The fact remains that it has by no means been answered. Phenomenology is the study of essences; and according to it, all problems amount to finding definitions of essences; the essence of perception, or the essence of consciousness, for example. But phenomenology is also a philosophy which puts essences back into existence, and does not expect to arrive at an understanding of man and the world from 
any starting point other than that of their 'facticity.'...it is also a philosophy for which the world is always 'already there' before reflection begins - as an inalienable presence; and all its efforts are concentrated upon re-achieving a direct and primitive contact with the world.....it also offers an account of space, time and the world as we 'live them.' (p. vii)

Looking across the various perspectives, common themes of phenomenology include: consciousness is recognized as a medium of accessing whatever is given in awareness; phenomenology takes into account the subjective and objective nature of existence; matter is a perception of mind and therefore, unity exists between the internal and external environment; intentionality reveals the 'aboutness' of entities within the structure of consciousness; 'onesided' objective, rationalistic claims of rigorous science are resisted as meaning is emphasized over matters of facts; and, one source of certainty exists -- the interplay of experience with self and others.

Husserl summed up his existence true to phenomenological doctrine, "For me the world is nothing other than what I am aware of and what appears value in my cognitions....I cannot live, experience, think, value, and act in any world which is not in some sense in me, and derives its meaning and truth from me” (cited in Moustakas, 1994).

\section{Consciousness and Intentionality}

A deeper probe into the aspects of consciousness and intentionality, seemingly draws more questions than answers and, at times, is ambiguous. The exact nature of consciousness is not known and continues to elude the modern scientific community due to the lack of 'hard' evidence but, early assumptions about subjective experiences are documented in Aristotelian philosophy with reference to the orientation of the mind to its object (Moustakas, 1994). Noted 
American psychologist and philosopher, William James (1842-1910), was one of the first to express that affective experiences are not absolute structures residing in a 'box' but better exemplified as functioning in a 'stream of consciousness,' or transitory mental events, where the relationship with mental entities are based, to some degree, on purposeful interaction or teleological (Audi, 1999; McDermott, 1967). Part of the telos, he reasoned, was due to 'corresponding feeling' but even he questioned the existence of feelings, “...if there be such things as feelings at all...” (McDermott, 1967). James’ working vision of this philosophy would be called 'Radical Empiricism,' and claimed that all science was built on the subjective nature of the scientist. In other words, every explanation about reality is based on a foundational or metaphysical paradigm. Bothered by the dominant paradigm of thought, James built an epistemology that encompassed the inner realities of a person with their experiences in the physical world (McDermott, 1967). A few years later across the Atlantic Ocean, Husserl would develop his related concept of intentionality, which he will use in a fundamentally different way than Franz Brentano (1838-1917), who is often credited with the original expression, and who was also one of Husserl’s teachers (Kockelmans, 1967).

Intentionality is often considered synonymous of consciousness and refers to the ontological construction of being (Moran, 2000; Moustakas, 1994 ). It is reasoned that humans are always 'intentionally conscious of something' and therefore, intentionality is the means in which the consciousness purposefully selects, chooses, and rejects 'something', e.g., real, imaginary, actual, or nonexistent (Moustakas, 1994). Husserl constructed two aspects of intentionality -- noema and noesis - which described the connection the consciousness has towards things (Audi, 1999). The phenomenon of the 'thing' appearing in the consciousness is the noema. For example, as I sit here working on this section, I put a music CD in the player. 
Printed on the jewel case is text that indicates that when I press the 'play button' I will hear Native American flute music. My ears, the auditory organs of my body, pick up the vibrations and perceive music. The 'hearing' of the music occurs through a series of neural events in my brain pathways, aided by the physical structures inside my ear. The noema in this example is not the music itself, but the perceived sound of the music in the background. However, there is still yet another dilemma for this discussion - why is attention paid to the music (or to the writing of this paper) when there are other distractions in my sensory perception field?

According to Husserl, for every noema, there is always a noesis which relates to the 'mingling' of the object in nature with the consciousness (Moustakas, 1994). The noema that appears in consciousness 'mingles' with the object in nature and is given a quality to determine the conditions of satisfaction, interest, or appreciation or, as Husserl labeled it, meaning. The degree of meaning or noesis of a phenomenon is affected by past experiences, memories, or emotions and it is not to say, that all meanings are seen in a favorable light (Sokolowski, 2000). But, it does mean that if the consciousness is always directed to an object, there must be an intrinsic relationship to the object allowing the consciousness to be open to something other than itself.

So, to continue with the above example, I hear the music because it awakens my spirit, conjures up soothing memories, it is aesthetically pleasing to my ears, and serves to inspire me during the writing process. (I digress for a moment and speculate that a discussion could ensure here over the reasons why I would choose this particular music CD over the others in my collection, but will avoid this for the time being.)

In the example, it may be inferred that intentionality takes place in a one-directional flow of information and transpires due to sense-datum but that would posit this example neatly 
in the realist category but there is an exception - not all mental states are intentional nor does intentionality always occur from objects presented in the external environment (Searle, 1983). In instances of anxieties and fears, which manifest in the psyche and could manifest into outward physical symptoms, intentionality would apply here only in the event that one recognized this state of being and would therefore, be conscious of the fear or anxiety. Additionally, intentionality can occur in illusionary and hallucinogenic states as well.

\section{Meaning and Experience}

In Phenomenology of Perception, Merleau-Ponty (1962) wrote, “Because we are in the world, we are condemned to meaning” and meaning, therefore, is at the heart of phenomenology and the description of the human condition. In accepting this assumption, I ask, what is the nature of meaning-making and in what ways do humans make meaning? Reviewing the phenomenological literature, there tended to be a common element - meaning is related to the lived experience (Spiegelberg, 1975).

In Doing Phenomenology, Spiegelberg (1975) implied that attempting to cover the field of phenomenological literature about the lived experience is nearly impossible but does sort through the common characteristics: (1) Experience is an 'intentional' act in which an experiencer is directed toward an experienced object; (2) A full experience is a synthesis of several intentional acts; (3) The experience of an object refers beyond itself; (4) Experience has temporary structure; (5) Experience extends to any type of individual objects; (6) Experience forms the pre-predicative stage of our cognitive life; (7) Experience constitutes the experienced; and, (8) Experience is a combination of receptive and spontaneous processes. At times, his position makes a circular argument but common to the previous discussion is the presence of intentionality 
In more specific terms, Marvin Farber, a U.S. student who studied under Husserl, put forth three features of meaningful experiences, “Acts are meaning-endowed and meaningfulfilling, which may blend together in fulfillment accomplished through intuition and fantasy; each act in itself contains a meaning; and each act is a reference to an object that is meant” (cited in Sokolowski, 2000; cited in Moustakas, 1994). Meaning, thus, guides the individual’s internal or mental gaze in the act of perceiving the object or experience, and is also an act of judging, and valuing. Likewise, the intent of judging and valuing is closely related to an 'ideal' concept that dwells in the perceived essence of the object (Moustakas, 1994).

Another contemporary, Hans-Georg Gadamer (b.1900) spoke of meaning as a selfinvolving encounter or understanding with the Other where a merging transaction brings 'unity of the significant whole’ or 'the totality of one’s self-understanding': “Thus when we respond to the statue of a god in a museum, even though it no longer is situated in its original context of the temple, it still has a claim on us and we respond to it by a kind of total self-involvement whereby the world of the object and the world of the subject merge " (cited in Sokolowski, 2000).

The founding father of the phenomenological movement, Edmund Husserl, gave precise meaning to the term experience but also incorporated as broader dimension with the inclusion of intuition, “Experience is the intuition of 'real objects,' that is, objects that are in space and time and regulated by causality, and thus are given in ordinary perception...” (cited in Giorgi, 1997). However, 'real objects' in this particular situation, can be without realistic reference.

Finally, Merleau-Ponty discarded the Cartersian dualisms of the time period in favor of a philosophy that sought to unify to the human lived experience through an “...immense 
complex weave of consciousness, body, and environment, best approached in terms of a holistic philosophy” and took into account the psychological and sociological aspects of being as well as the material and mental conditions of life (cited in Moran, 2000).

As this discussion on meaning and experience closes, I wish to reiterate and draw connections across some of the main characteristics. First, it is difficult to speak about the one and not the other simply because it would discount the inter-relatedness of the topics and likewise, immediately throw the discussion back into the Cartesian paradigm which I, for intentional purposes, have been arguing against. There seems to be a tendency in the literature to constantly take the reader into a reflective 'back and forth' exchange - an internal dialogue engaged with the text, between the internal and external life of the mind, the individual and the culture, and the public and the private domain -- which leads an interesting quandary. Is it possible to discuss meaningful experiences without looking to the more complex, contextual structures which define existence? And, if experiences are shaped by intentional states, are intentional states realized through participation? Using a phenomenological lens implores that the essence of experience and the structure of meaning, can never been understood in isolation because the life-world of individuals cannot be separated from the shared reality of living with other human beings. To return to an understanding of the life world, the phenomenological method requires viewing the world with a 'different colored lens,' i.e., a different attitude, for the purpose of setting aside existing beliefs which may interfere with engaging and describing the phenomenon.

\section{Phenomenological Attitude}

As the phenomenological movement sought to separate itself from the analytical systems of investigation common to the time, phenomenological practices set out to describe 
human experiences free from causal explanations and as free as possible from preconceptions and presuppositions (Spiegelberg, 1975). Merleau-Ponty would go so far as to reject any philosophical system rooted in Cartesian rationalism, and furthermore, any system that denied phenomenon occurring separate from the human mind (cited in Moustakas, 1994). This 'radical' way of doing philosophy necessitated a practice that would steer clear of misconstructions (such as practical concerns and folk assumptions), and impositions placed on the experience in advance, or what is referred to as the neutralizing of 'natural attitude' (Moustakas, 1994). Exercising natural attitude implied that there was an original, natural focus or 'default focus' that sets the stage for the understanding human experience. At times Husserl called it a pre-reflective, pre-theoretical, or pre-scientific mind, and at others, the normal worldly consciousness. To uncover the essence of the structure of an experience, exercising phenomenological attitude required recognition of the natural attitude (not negating the attitude) and the contemplation of intentionalities (cited in Sokolowski, 2000; cited in Audi, 1999). To study the meaning-making acts, Husserl recommended a special method of 'bracketing' natural attitudes towards the object and towards the psychological act to draw the attention to the pure essence of consciousness. (Husserl drew this metaphor from his mathematical background. Through bracketing the world, it is "given a different value" (cited in Kockelmans, 1967). Husserl named this process of 'letting go' of the natural attitude, as the epoche, and further suggested that approaching phenomenology in this manner would bring about the description of pure consciousness (cited in Audi, 1999).

At other times, though, the expression 'life-world' appeared in phenomenological literature and took on a similar tone to 'natural attitude' but just the same, presented myself with uncertainty. Early on in Husserl's career, he developed the concept of 'life-world' as the 
"realm of original self-experience that we encounter in an everyday sense" but it would not be until later when the idea matured into "the layer to be inserted between the world of nature and the world of culture (or spirit)" (cited in Moran, 2000). Further expanding on this, the lifeworld is "a general structure that allows objectivity and 'thinghood' to emerge in the different ways in which they do emerge in different cultures” (Moran, 2000). Later investigations led him to declare that there is not a single life-word but many, over-lapping worlds. The individual starts with the 'home world' and extends out towards other 'alien' worlds. To illustrate this point, in The Thesis of the Natural Standpoint and Its Suspension, Husserl wrote (his emphasis included) (cited in Kockelmans, 1967):

I am aware of a world, spread out in space endlessly, and in time becoming and become, without end. I am aware of it, that means, first of all, I discover it immediately, intuitively, I experience it. Through sight, touch, hearing, etc., in the different ways of sensory perception, corporeal things somehow spatially distributed are for me simply there, in verbal or figurative sense 'present,' whether or not I pay them special attention by busying myself with one of them, considering, thinking, feeling, willing.

But not even with the added reach of this intuitively clear or dark, or distinct or indistinct co-present margin, which forms a continuous ring around the actual field of perception, does that world exhaust itself which in every waking moment is in some conscious measure 'present' before me. It reaches rather in a fixed order of being the limitless beyond. 
Husserl reflected upon the suspension of natural attitude in the above passage and paid particular attention to perceptual acts. But, unlike the model of the modern era that viewed the body and mind as separate and defined perception as a precise series of events that took place through the receiving of information from the environment via sensory pathways, (e.g., sight, touch, smell, taste, and sound) Husserl would counter that argument and introduce the idea that perception is a source of primary knowledge that was the result of sensations coupled with meaning. He did not discount the accuracy or genuineness of sensations, but worked towards the unification of the physiological and psychological.

\section{Perception}

The role of perception in phenomenology is significant especially since it is at the root of epistemological assumptions. Merleau-Ponty (1962) explained in Phenomenology of Perception that perception is "access to the truth" and the "original act of consciousness." Moreover, he would take a similar route as Husserl in describing the perceptual act in a holistic fashion. But, common to both of their epistemological arguments is the direct insight or reflection into the essence things, could bring about a state of knowledge that also retained valuing.

Merleau-Ponty's The Primacy of Perception (1964) proceeded the publishing of Phenomenology of Perception (1962), however, his ideas of the body-mind relationship in the perceptual act, are demonstrated in the opening pages of the later writing:

We never cease living in the world of perception but we go beyond it in critical thought - almost to the point of forgetting the contribution of perception to our idea of truth...The perceiving mind is an incarnate mind. I have tried, first of all, to re-establish the roots of the mind in its body and in this world, going 
against doctrines which treat perception as a simple result of the action of external thing on our body as well as against those which insist on the autonomy of consciousness. (p. 3-4)

Advancing this idea, perception should be the starting point to understand any philosophical human inquiry into the 'life world' because it could provide a subjectiveobjective account of the nature of knowledge. "To perceive something is to live it," according to Merleau-Ponty (cited in Moran, 2000). In his phenomenological method, it had potential to combine scientism, idealism, rationalism and could delve into the meaning of language, science, culture, art, etc. It would be all encompassing and beneficial to scientists as well as philosophers. It would be the 'science of science' and return human life to research (cited in Moustakas, 1994; cited in Moran, 2000). While science was the leading mode to understand life during the time period and undoubtedly was adequate in many cases, it was problematic for the phenomenologists who claimed it suffered from a 'split' personality, that is, separated the senses from the internal human experience.

For Merleau-Ponty (1962), perception was the manner that individuals are 'projected' into the world where all sensory paths are experienced simultaneously:

I have no experience of the senses working separately; rather the senses overlap and 'transgress' each other's boundaries....we shall need to reawaken our experience of the world as it appears to us in so far as we are in the world through our body, and in so far as we perceive the world with our body. But by thus remaking contact with the body and with the world, we shall also rediscover ourself, since, perceiving as we do with our body, the body is a natural self and, as it were, the subject of perception. 
Merleau-Ponty would draw on the psychological principles of Gestalt theory to understand the totality of human experiences and bring back wholeness to the problems of the modern era. Gestalt literally refers to form or structure of perception. Gestalt theory, plainly expressed, states, "There are wholes, the behavior of which is not reducible to their individual elements, but where the part-processes are themselves experienced against the intrinsic background of the whole.” Helsen and Fehrer (1932), students of the Gestalt School, arrived at an early list of definitions for Gestalt. There was a total of ten sub-definitions and I have included the three which deal directly with perception: the form of an apprehended whole; some factor within a group that dominates the whole; and the totality of conditions determining a perception, memory, or behavior pattern (Zusne, 1970). In Phenomenology of Perception (1962), regarding Gestalt theory and perception, Merleau-Ponty disclosed, “The perception of something is always in the middle of something else, it always forms part of a field."

If one is perceiving, what is perceived? What are the essential features or phases of a perceptual experience that constitute the essence of an entity (Moustakas, 1994)? One of the key elements (that was addressed in a previous section of this chapter) that shed insight to this question is intentionality. Intentional states are linked to the conceptual framework through which ones views a phenomenon and instinctively, invoke feelings, memories, judgments, values, desires, etc., related to the noema of the object, and these meanings guide the choosing, selecting, and rejecting of certain things over others. Collectively, there is a merging and encountering of the thing to bring it into one’s existence (Moustakas, 1994).

Husserl took the position that when an object is initially perceived, it's meaning is 'intuitively given’ and upon subsequent viewings, numerous layers of meaning are added. There are limitless meanings associated with a perception, many of which change over time 
and with multiple viewings, which can further add multiple layers of meaning. Upon reflection of the perception, one comes to an understanding of the concealed meanings (cited in Moustakas, 1994).

In the case of misperceptions and illusionary states, perceptions are sometimes not as they appear, 'senses can deceive us,' and can look like other things and this could be due to an any number of causes, e.g., drug induced states, sensory-pathway dysfunction, pathological psychoses, poorly lit environment, etc., but are nonetheless, still perceptions. Furthermore, perceptions are never the same as the actual event.

I would like to come back to the notion of understanding. In phenomenological texts, less well-known, Hans-Gerog Gadamer (b.1900), is filed neared Martin Heidegger (18891976), and the proximity of the text also is reflective of their relationship -- Heidegger was Gadamer's mentor (Moran, 2000). Gadamer's kind of phenomenology is often characterized as hermeneutics and the central question of hermeneutical inquiry asks, "What are the conditions under which a human act took place or a product was produced that makes it possible to interpret its meanings?” (Patton, 1990). Gadamer freely described his phenomenology as, “a universal aspect of philosophy” (cited in Moran, 2000). Gadamer’s main influences were Husserl, Heidegger, and Dilthey (1833-1911) and like them, intended to describe the process by which meaning occurred but delved more deeply into the aspects of understanding as cultural and historical text with emphasis given to linguistics. As indicated by Gadamer, understanding had its genesis within the existing traditions of the culture and as such, the judgments, values, perceptions of an individual would be understood as a part of the larger whole. Hermenuetical phenomenology served to describe the essences and experiences of dialogue. 
Gadamer tended to freely interchange the terms 'meanings,' 'understandings,' and 'interpretation,' but for this discussion, I will mainly refer to the term understanding. According to Gadamer, understanding is always an on-going process, a give or take with others, where one is open to the Other. Dialogic exchanges would be built upon mutual respect and open to the truthful possibilities of another. There is some directedness in his writing with the repetitive use of the terms 'sympathy' and 'compassion'; both are essential aspects of understanding and, he made clear that "to attempt to get into the mind of the other is not reduce it to what is within one's experience” (cited in Moran, 2000). To come to a mutual understanding of one another, he put trust in human reason to recognize individuals first need to realize that they are different but accept that understanding, "comes through the overlapping of consensus, the merging of horizons, rather than abandonment by one of the interlocutors of his or her horizon” (cited in Moran, 2000).

Beliefs about the internal and external conceptions of the world have consistently divided phenomenology from realism with most of the disagreement residing in the processing of sensory sensations and then the construction of knowledge. In Phenomenology of Perception, Merleau-Ponty (1962), pointed out that his ‘dreams' are just as real his 'reality’ and to discount his dreams as imaginary, is because the idea of truth allows it to be so, "Perception is the background from which all acts stand out and is presupposed by them. We must not, therefore, wonder whether we really perceive a world, we must instead say, the world is what we perceive."

\section{Intersubjectivity}

Much of the previous discussion has revolved around the individual and neglected the presence of community (with the exception of Gadamer's ideas). However, it was noted (in a 
previous section of this chapter) that meaning and experience are closely threaded into intentional participation and the contextual structures, which define existence. So, as phenomenology is capable of describing the individual experience, it is also aware of the interconnection one life has to another and the shared environment, language, objects, and meanings that comes with living in community. In phenomenology, intersubjectivity is not interested in 'correlations' but in the relationships and shared understandings held about experiences (Sokolowski, 2000). Husserl affirmed this (his emphasis included), "I experience the world (including others) and, according to its experiential sense, not as (so to speak) my private synthetic formation but as other than mine alone (mir Frende), as an intersubjective world, actually therefore everyone, accessible in respect of its Objects to everyone” (cited Moustakas, 1994).

The ability for many individuals to experience an object, thing, or individual, will translate into varied perceptions, however, each perception is a private affair. For instance, my name is Katina and my students ‘know’ me as Professor Sayers; when I was younger, growing up my brother shouted “TEEENA"; my mother yelled, “Katina Lee” when I was young girl and would do something to her disproval; and, today, my loved one called me "Sweetie" and "Honey." All of these are perceptual acts of the same object. Each knows me through a different context and role, and each role has its limitations even though I always show up as "myself." What is portrayed in the role I 'play' are a set of behaviors and language that define their relationship with me and thus, their perception of me.

Husserl approached intersubjectivity in a language reminiscent to Gadamer's through the concept of empathy, "Empathy is not a matter of judgment, reasoning, or ideation in general. It is a founded experience" (cited in Moran, 2000). The Other becomes accessible 
through empathy, a "thereness-for-me-of others.” In the Fifth Cartesian Meditation (1967), Husserl further expanded on the topic: "The topic is not: how do I understand the other but how is the other constituted for me? How does the Other enter into my consciousness?" Later, his own experiences are factored in when he said, "My own experience gives me the possibility of understanding that there are other possible viewpoints on experience. When I experience another person, I apperceive them as having the kind of experiences I would have if I was over there."

\section{Concluding Thoughts}

Phenomenology is an extremely complex philosophical orientation that takes the writer into her own psyche. Furthermore, the writing about phenomenology is just as a difficult task as thinking about the philosophy itself. I have purposefully covered the following topics -consciousness and intentionality, meaning and experience, phenomenological attitude, perception (with additional attention given to understanding), and intersubjectivity - as they will be critical in setting up the remaining chapters in this study. Likewise, these topics will be of special importance when answering the research questions. This chapter provides the foundation for the remaining chapters.

Phenomenology is a philosophy orientation that has been at the center of much criticism, especially from fields deeply connected to positivism. It is no coincidence that phenomenology grew out of the same time period as modernization crept into all areas of life. The cost of abandoning the modern paradigm has led to questions of its legitimacy, but if we use the same argument that the phenomenology has provided for us, all life is open for interpretation and the modern paradigm is only one perspective, not the only, and 
phenomenology should not be defined by the conceptual framework set forth in the modern paradigm. Rather, it should have its own definition.

For clarification, I want to speak more about the term paradigm so to better explain the shared conceptual framework of the modern paradigm that most of society 'thinks and looks through.' (It does have special importance especially as it relates to perception here.) Thomas Kuhn in The Structure of Scientific Revolutions (1962/1996) is regularly recognized with coining the term, paradigm. Schooled in the sciences, Kuhn sought to explain the crisis being experienced in the field of physics where new concepts were forcing them to rethink their traditional views of reality. Kuhn defined paradigm as, "the constellation of achievements concepts, values, techniques, etc. - shared by the scientific community and used by that community to define legitimate problems and solutions." The paradigm is the 'net' (or set of beliefs and feelings) the captures, interprets, and defines the dominant worldview. It is the fabric that guides the epistemological, ontological, and axiological assumptions of existence. For the philosopher, scientist, and general population alike, the net is a sorting mechanism through which some things pass, while others are 'caught' and then, 'rejected.'

The modern paradigm that is predominantly influenced by the 'realist tale' is problematic to phenomenology for the reason that 'meaning' has already been chosen in a certain way. Phenomenology continues to challenge some of the most basic assumptions about the nature of knowledge, reality, and values in the modern 'net' but it is not to say that it is superior to the 'realist tale.' Like the phenomenologists, I also challenge some of the long associated beliefs of the modern era and more specifically, the influence of the 'realist tale' on educational practices. Problematic to this study is the American public school system's 
inability to keep up with changing societal views and therefore, educational practices are still crudely positivist.

So, how is it that I can wonder about the 'dual energies floating around and in the school' when I am a product of the modern era? Because I can envision the cultural transformation that is widely discussed and 'see' changes occurring in small pockets of society, especially in the areas of consciousness studies, Unified Field Theory, alternative health care practices, 'the variety of religious experiences,' and therefore, following phenomenological principles, it can be 'real.' 


\section{Chapter 3: Doing Phenomenology}

\section{Part I: Past, Present, and Future Explorations of Teaching and Learning}

\section{Introduction}

Building upon the ideas presented in Chapter 2: Thinking about Phenomenology and holding to the notion that phenomenology is a 'holistic philosophy,' chapters 3 and 4 both address the actual ‘doing’ of phenomenology. Both chapter 3 and 4 are entitled, “Doing

Phenomenology.” Chapter 3, Part I: “Doing Phenomenology,” systematically explored the past, present, and future of the issues in question while, Chapter 4 focused on researching the lived experience of the study's participants from a methodological standpoint with the intent to explain 'how' the essence and structure of 'everydayness' was revealed and explored. Both chapters pave the way for the remaining chapters in the study and offer a glimpse of the forces that shape the current state of affairs in education. The purpose was to bring together the ideas in chapter three and four to define what is and to better delineate the characteristics of the modern and post-modern energies 'swirling' within and around the school.

Bringing together the 'thinking and doing' of phenomenology is a novel approach in research; however, here it is my intention to bring balance and comprehensive-ness to research methods by nullifying the existence of dualities so common to research. American educator and philosopher, John Dewey, spoke in similar terms when describing his concept of 'experience.' For example, 'thinking and doing' are not two independent events occurring asynchronously; rather, both rely on the other to exist in a balanced, functioning system. In my personal life, as in my research, it has always been to seek balance and likewise, the counter-balance to 'thinking' about phenomenology is 'doing' phenomenology. 
The problem statement for this research study posits: The American public school system has not kept up with changing societal views and still remains crudely positivist. The root of the educational problem lies in the epistemological assumptions of mind and then, the translation of the epistemological assumptions in classroom teaching and learning practices.

Since phenomenology is primarily concerned with ways of being in the world, i.e., the essence and structure, this study focused on educational practices and I am drawn to investigating the characteristics that define the 'being' of the educational system from two perspectives - the modern and post-modern era. Phenomenological orientation to this issue indicates that being-in-the-world is due to intentional (or meaningful) interactions based on perceptual acts of judging and valuing that are also closely connected to other contextual structures of meaning. What I use to build my position in this chapter is an examination of the modern and post-modern assumptions of the purpose of education because there are tacit societal views embedded into the perceived purpose of education. These societal views likely originate in the Western paradigm, which dominate basic ways of thinking, feeling, and valuing. Therefore, the purpose of education is the underlying force that drives educational practices and thus, dominant ideologies are silently evidenced in teaching and learning practices, and the epistemological assumptions of mind where knowledge is most certainly value-laden. When these views are pre-defined and pre-determined, so are the teaching methods and likewise, so are the ways of exploring and knowing about the world.

To keep in line with the main research questions, characteristics of 'being' are related to: (1) the kind of educational setting that best contributes to teaching and learning, (2) the kinds of learning and teaching experiences that are meaningful, and (3) general understandings of teaching and learning. (In chapter one a brief preview of these characteristics was 
introduced, however the following discussion further elaborates on these topics.) The format of the following chapter is based on two perspectives - the modern era and the post-modern era and further sub-divided around the nature of the research questions. Each main section includes a general purpose of education built into contextual 'reminders' of society, epistemological assumptions of mind, and a literature review related to the research questions.

In post-modern discourses (which is where I 'index' myself and this study due to its phenomenological design), history is viewed as contextual, socially and culturally constructed, and autobiographical, and therefore, cannot be viewed as encompassing a single truth nor separate from the individual. A challenge to the modern era is for individuals to 'enter' into their own history and life stories instead of standing 'apart' from the history and traditions that have influenced their lives. One way I will 'enter' and 'participate' in this process is through the sharing of family photographs, personal artifacts, and professional projects to exemplify characteristics of the modern and post-modern era. In Questioning the Visual in the History of Education, Rousemaniere (2001) explained the inclusion of visual clues in historical research not only added to an understanding of the time period, but suggested that ideologies of past school practices may be gleaned. Furthermore, post-modernism is often defined as 'the crisis of modernism' and at a time when culture has become a visual culture, so should research practices. Nicholas Mirzoeff (1998) in The Visual Culture Reader defends this notion: Western culture has consistently privileged the spoken word as the highest form of intellectual practice and seen visual representations as second-rate illustrations of ideas. Now, however, the emergence of visual culture as a subject has contested this hegemony, developing what W.J.T. Mitchell has called 'picture theory'. In this view, Western philosophy and science now use a 
pictorial, rather than textual, model of the world, marking a significant challenge to the notion of the world as a written text that dominated so much intellectual discussion in wake of such linguistics-based movements as structuralism and poststructuralism.

My purpose of including images is two-fold: to 'live' in the history and to literally view themes of learning and teaching. First, though, I frame the time period in which I approached the issues of significance.

\section{Defining the Eras}

The modern era is characterized as having its beginnings during the middle of the $15^{\text {th }}$ century during the Age of Enlightenment but to focus the discussion with some clarity, I have chosen parameters to coincide with significant educational and societal events. For the modern era, the early $20^{\text {th }}$ century (at about the time the U.S. compulsory education laws went into affect) provides the lower range 'limit' and the upper range 'limit' is set during the decade of the 1960's. There is still some debate over when the post-modern shift occurred (historians have attached the years following WWI, WWII, and the decade of 1960's) but, again, to focus the discussion, the 1960's - 1970's will serve as the point of departure for the post-modern discussion. Part of my reasoning for choosing this decade to examine the paradigm shift was influenced by the publication date of Thomas Kuhn's The Structure of Scientific Revolutions (1962). It was in this publication that Kuhn gave characteristics to the changing values and assumptions guiding scientific research and likewise, it was at about the same time that other fields of study - natural sciences, social sciences (including education), humanities - also experienced a reorientation or reconceptualization. (There is still confusion and general disagreement when speaking about paradigm shifts, but for the sake of argument, I believe that 
humanity is in the midst of transition and will proceed from here.) One of the questions Kuhn wrestles with is whether or not paradigms develop one at a time or can different paradigms simultaneously exist within a given area of study? And, if paradigms do exist concurrently, is it a sign of 'immaturity' or a 'pre-paradigmatic' state (Schubert, 1989)? In terms of this study, this is of importance as I examined current ideas and experiences of teachers presently in the field. What paradigm do the ideas and experiences teacher holds towards teaching and learning fall into? Schubert (1989) wondered, "Do they reflect reconceptualization at the paradigmatic level? Or, do they merely represent tinkering within the dominant paradigm that is still wedded to analytic reasoning and empirical research of a neo-positivist persuasion?”

\section{The Modern Era}

\section{The Purpose of Education}

The purpose of education cannot be examined until it is put into a larger picture of the societal views which guides the process. In this section, I first offer a brief picture of American society at the turn of the $20^{\text {th }}$ century, and later, discuss the purpose of education in the modern era. (Special note: while completing this section on the Modern Era, it occurred to me that even though much of this was written in the 'past' tense, much of the same is still present in today's classroom; therefore, forcing me to also put a 'present' tense spin on the literature review at times.)

At the turn of the $20^{\text {th }}$ century, America's population was diverse in its ethnic, religious, and ideological makeup due to mass immigration, the growing industrial sector, and demographic shift from being primarily rural to being primarily urban in character. Capitalism was not only an economic system that supported industry but also became a way of life -- a culture -- that valued consumerism, materialism, and technology. As a worldview, capitalism 
defined (and still does define) human experience. Ron Miller (1997) in What are Schools For?, offered this account of the human experience:

...capitalism involves the belief that nature exists to serve human needs and wants; consequently inventiveness and audacity in taming nature are highly valued, and quality of life is measured in terms of how quickly raw nature is converted to human use - the gross national product. Furthermore, capitalism involves the belief that there are no inherent limits to human progress and comfort; therefore, the most ambitious and wealth-producing entrepreneurs are widely honored, and technological innovations are almost always welcomed. Another core belief is that in an open society there are no unfair barriers to opportunity; it is only one's own talent and initiative that determine one's status. (p. 16)

As 'big business' and industry grew, the 'cult of social efficiency’ was necessary to manage volumes of factory laborers. Fredrick Taylor devised a method, "scientific management" that formulated the working conditions to maintain order and stability in large factory settings. The scientific method specified, "not only what is to be done but how it is to be done and the exact time allowed for doing it" and later wrote a book of a similar nature about the scientific management of schools (Doll, 1993). The U.S. public school system was one American institution that accepted this model, as they, too, were attempting to manage massive numbers of school children. This technical efficiency model was translated into a pedagogical model that refined the responsibilities of the teacher, the hierarchy of school administration, methods of teaching and learning, assessment procedures, and structure of the 
school day. Furthermore, this method provided a 'one best way' or system on which all teaching and learning could be modeled.

The purpose of education in a society that valued materialism, consumerism, and technology, served primarily a technical, social, and practical interest to 'big business' in the preparation of competent workers and responsible citizens. A secondary purpose of education would be conveying this ideology to students. In support of this, Franklin Bobbitt in 1926 in The Twenty-Sixth Yearbook of the National Society for the Study of Education, wrote, "This school is not an agency of social reform. Its responsibility is to help the growing individual continuously and consistently to hold to the type of living which is the best practical one..." (cited in Joseph, Bravmann, Windschitl, Mikel, \& Green, 2000).

One way this practical message was conveyed to students (as evidenced in the following excerpt) is through publicly advertising the 'desires’ of business leaders (Miller, 1997):

The small businessperson actually is looking at the finished product of education, not what is actually going in. He wants the product to be someone who can read, who can listen, who is punctual, who can take instruction, who has the work ethic... (p. 66)

In the above passage, the language constructs a metaphor depicting the student as 'raw material' that is shaped and constructed through the educational process much in the same way that a piece of pottery is molded from a heap of clay. The value (or worth) per student is judged by their ability to fulfill these desired characteristics and likewise, it is assumed that students need to learn the 'work ethic'. Lakoff and Johnson (1980) point to a ‘causation’ and ‘manipulation’ metaphor typically grounded in 
capitalistic values as an explanation and function of educating students in such a manner but a more troubling aspect to this perspective, indicates that, "We have a cultural notion that if children were not engineered, if we did not manipulate them, they would grow up as beasts in the field” (Clark, 1997).

\section{Epistemological Assumptions of Mind}

Epistemology refers to the nature of knowledge and in the modern era, positivism is generally acknowledged as the method of 'coming to know.' Huston Smith characterized this modern ethos as being a 'blend of naturalism and control,' which corroborates the influence of Darwinism and positivism on social thought (Sloan, 1979). More specifically, Kincheloe, Slattery, and Steinberg in Contextualizing Teaching (2000, p. 57) presented ten characteristics associated with positivistic assumptions in teaching and learning practices:

1. All knowledge is scientific knowledge - Positivism relies on the assumption that all knowledge should be proven and verifiable; actions can be generalized to the whole of nature; and there are no exceptions to natural law.

2. All scientific knowledge is empirically verifiable - Scientific knowledge refers to knowledge that can be made known through the senses, e.g., sight, taste, sound, etc., and mathematically expressed.

3. The methods used to study the physical world are the same methods used to study the social and educational worlds - Scientific methods implied that order exists in nature and a key aspect of positivism involves predicting and therefore, controlling natural phenomena.

4. If knowledge exists, it exists in some definite, measurable quantity - Observable data can be measured and quantified through mathematical means to establish relationships.

Reductionistism explained phenomenon by breaking the whole into its parts. For instance, 
in the investigation of water, the properties of oxygen and hydrogen were studied separately.

5. Nature is uniform and whatever is studied remains consistent in its existence - Objects have an underlying natural order. For example, in the $19^{\text {th }}$ century, Newtonian Laws of Motion stated that the universe functioned as a 'large mechanical system' similar to that of a clock (Capra, 1996). The same forces of gravity that acted on objects on earth were the same forces that also stabilized the universe and likewise, this tenet translated into the view of the human body and mind as a machine with ‘machinelike’ qualities.

6. The factors that cause things to happen are limited and knowable, and in empirical studies, these factors can be controlled - Factors can be identified and isolated to study specific events. 'Cause-effect' explanations implied that for every action there is an opposite and equal reaction that can be identified. Linear sequencing provided a view that progression occurred in a specific order.

7. Certainty is possible, and when we produce enough research we will understand reality well enough to forgo further research - The quest for absolutes can fully explain the human experience and the scientific method provided a model to study the human experience.

8. Facts and values can be kept separate and objectivity is always possible - Facts are value free and knowledge resides 'outside' the self and is immutable and unchangeable. Furthermore, because reality is fixed and separate from the observer, when two people observe or measure the same phenomenon, they will come to a common agreement.

9. There is one true reality, and the purpose of education is to convey that reality to students - Teachers can rely on one teaching method to accomplish the learning objectives for all students. 
10. Teachers become 'information deliverers,' not knowledge producing professionals or empowered cultural workers -- Teachers rely information to students and learning is equal to memorizing.

Even though this discussion primarily focuses on the events of the $20^{\text {th }}$ century, there are two earlier perspectives from the $19^{\text {th }}$ century that further paved the way for the modern epistemological assumptions of mind. While both of these viewpoints are refutable today, they are nonetheless basic 'units' for understanding the development of thought in the era.

One of the main metaphors that arose out of the modern era (related to the epistemological assumptions of mind) gives clues to the conceptual understandings held towards the functions and structure of mind. John Locke's, mind as a blank slate, or 'tabula rasa,' is one orientation that beset the modern era (Doll, 1993). Locke conceived the mind of a child at birth as waiting to have the knowledge of the culture imprinted upon it through sensory experiences.

Likewise, the early faculty psychology movement of the $19^{\text {th }}$ century is linked to the idea of 'tabula rasa' with its attempt to understand knowledge construction as occurring through 'exercising' various compartments of the brain, similar to today's idea of exercising specific muscles groups to improve physical physique. It was believed that the power of the mind could be 'strengthened' through "memorization exercises and mental drills....which [the mind] could then accumulate more information, rearrange the data, and expand the knowledge base” (Slattery, 1995). In combination, Locke’s theory of mind and the faculty psychology movement paved the way for understanding epistemological assumptions of mind in the 
education of the modern era and gave rise to the dominant Behavioral movement, pioneered by the contributions of Edward Thorndike.

These 'rules' of knowledge provided the conceptual framework for the educational system of the modern era. To understand how the positivist assumptions affect(ed) educational practices, these assumptions will be applied to three areas: the classroom setting, the kinds of experiences that are meaningful, and general teaching and learning processes.

I will not speak to specifics, such as the elementary or secondary classroom, but to the more general characteristics of education of the period. Additionally, even though John Dewey's child-centered progressive education ideas were given birth in the early part of the $20^{\text {th }}$ century, they are not characteristic of the modern public school classroom and will not receive attention in this section; however, during this shift in eras, many of his ideas are being 'reincarnated' and evidenced in the post-modern classroom and given attention in that respective section.

\section{The Classroom Setting}

The modern classroom was appropriately designed and patterned after the workplace setting and generally took place between the hours of 9 a.m. to 3 p.m. (Rugg, 1955). Most schools had a division of isolated classrooms, usually under the direction of one female teacher, and most teachers were expected to instruct and maintain order (Dreeben, 1970). During the Cold War era, many buildings, including schools, were built with bomb shelters and equipped with emergency supplies in the event of a disaster. The number of students occupying the classroom varied and depended upon the community the school served and the size of the school. For instance, in larger urban settings, 100 students were a common sight; whereas, in smaller, rural areas, class sizes had potential to range from 10-30. 
The day, or in some cases, the school year, was arranged in units of study by specific increments of time and further sub-divided to cover more discrete concepts within a given subject area. Additionally, some subjects took precedence and were valued more so than others. Postman and Weingartner provided one student's perception of their school schedule (cited in Clark, 1997):

English is not history and history is not science and science is not art and art is not music. Art and music are minor subjects and English and history and science are major subjects. A subject is something you 'take.' When you have 'taken' it, you have 'had' it, and when you have 'had' it, you are immune and need not take it again. (p. 58)

As a young girl in $6^{\text {th }}$ grade, I remember having a similar type of schedule and during a recent trip home, I found the following document (which my mother had surprisingly kept) that illustrated a typical day in my classroom.

Judging by the date of this
document, it would appear that I
attended school at the beginning
of the post-modern era; however,
many of my experiences were
characteristic of the modern era.

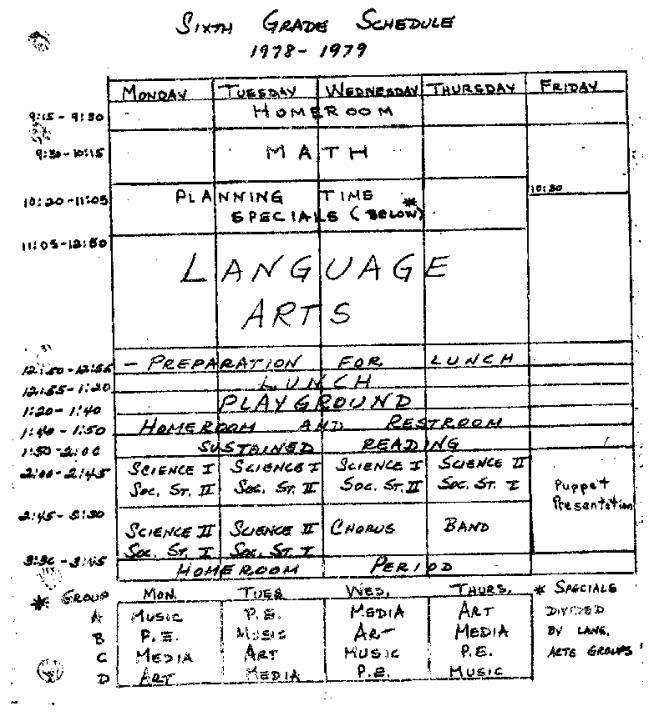


Student desks were lined up in straight rows facing the teacher's desk (some mention in the literature that at one point desks were bolted to the floor to prevent movement and preserve the classroom setup). Children sat, "head erect, eyes turned toward the teacher, hands or arms folded...feet flat on the floor” (Miller, 1997). As for the teacher's desk, it was commonly located at the front of the classroom, near the entrance of the classroom. Bells rang to signal the beginning and end of classes at which time, students either reacted by promptly picking up their personal items and moved on to the next class

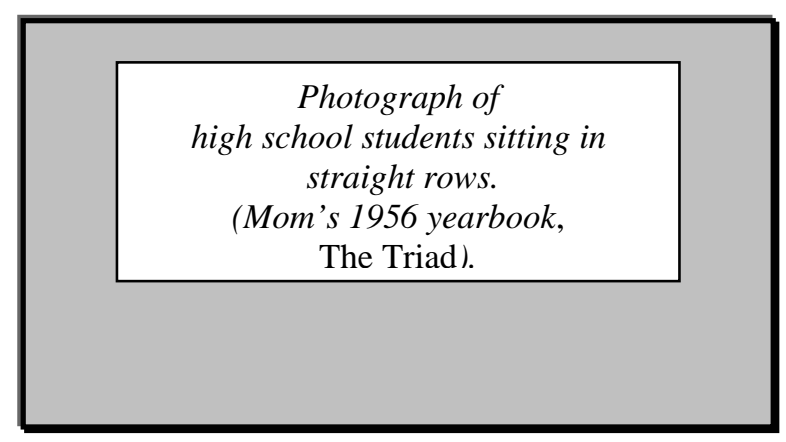
or at the end of the day, were excused.

Activities were monitored and initiated through teacher planning and approved by administration of their appropriateness. Students were expected to be quiet and obedient at all times. Michael Apple (1990) in Ideology and Curriculum witnessed this rigor in a contemporary kindergarten classroom:

The teacher made it clear to the children that good kindergarteners were quiet and cooperative. One morning, a child brought two large stuffed dolls to school and sat them in her assigned seat. During the first period of large group instruction, the teacher referred to them, saying, 'Raggedy Ann and Raggedy Andy are such good helpers! They haven’t said a thing all morning.' (p. 54) Turning back to a historical perspective, William Torrey Harris, superintendent of schools in St. Louis and later the U.S. Commissioner of education at the turn of the $20^{\text {th }}$ century, stressed particular ideals and characteristics of students as a chief aim of education. The student (Miller, 1997): 
....must be taught first and foremost to conform his behavior to a general standard... He must have his lessons ready at the appointed time, must rise at the tap of the bell, move to the line, return; in short, go through all the evolutions with equal precision...Great stress is laid upon (1) punctuality, (2) regularity, (3) attention, and (4) silence, as habits necessary through life for successful combination with one's fellow-men in an industrial and commercial civilization. (p. 51)

My grandmother shared a story from her girlhood that gives life to these words and relayed the history of the country and education in a much more personal way for me. She was born in 1911 in a small Ohio town and went to school through the $7^{\text {th }}$ grade. As a young girl, she had very long hair, which she spoke of proudly, as if it were a status symbol of sorts. One recollection that she shared with me prior to her death and initiated by my telling of a current research project at the time, relates to the orderliness of

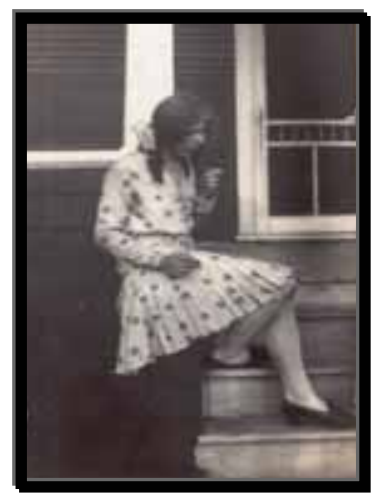

Grandma as a young woman during the 1920's. (Fresch Family Album) the rows. (While these are not her exact words, I hope to do justice to the story she told me.) On one particular day she wore her hair in braided 'pig-tails' and there was a young man who always sat behind her. As she sat and worked at her desk, there was a tug on one of her 'pig tails' and to her surprise, she turned around to see the young lad dipping her 'pig-tail' in the ink-well located at the end of the desk. She did not say what immediately ensued but based on grandma’s gentle nature, I speculate that she told the teacher and left well enough alone. However, she did say that she went home in tears to her mother who tried in earnest to wash her hair over and over to remove the ink but to no avail. For her hair, it would have to stand the test of time. 


\section{Meaningful Experiences}

Meaningful experiences were judged on the basis and quickness of 'climbing the steps' of the organization. The speediness, neatness, and overall accurateness in which activities were performed were a measure of success and the 'cult of social efficiency' rewarded 'good' behavior, as well. Those students who rose to the 'top of the ladder' demonstrated natural talent and superior intellect, and rewarded with leadership positions. Furthermore, it was believed that 'enlightened' students were conditioned to behave in ways in accord with 'technically correct strategies, with specific kinds of procedures' bound by a set of 'accepted values' and, likewise, by a set of social norms (Greene, 1978; Dreeben, 2002). To illustrate this point, the values associated with the 'cult of social efficiency' might be evidenced in the classroom through the student-to-teacher interaction in one of the following exchanges (Beyer \& Apple, 1988):

“Mark, let’s get busy here. Get your work done on time.”

“Nancy, I know you can do better. Sit down and recopy this so it’s neater. You need to turn in work you can be proud of...”

“Alexander, you have to be more responsible. You can’t leave your homework at home every night like this. Now, grow up. If you can remember your lunch, you can remember to bring your homework.” (p. 192)

Similarly, during this time period, 'rugged individualism' was valued and described a philosophy in which personal achievement came at any cost to 'move up the ladder of success.' In the classroom, competition was a mainstay of 'rugged individualism' where standard paper/pencil tests stood as the marker of achievement and in other cases, classroom debates served as a marker of intelligence where the ability to articulate ideas was of importance (Entwistle, 1997). Knowledge and/or intellect was measured against a set of behavioral 
objectives pre-ordained by the teacher. One national standardized test, the Scholastic Aptitude Test (SAT), grew out of the modern era and gained unprecedented importance by predicting academic collegiate success and also, portended to offer an unbiased selection process for the best and brightest students.

In a contemporary study, Michael Apple (1990) in Ideology and Curriculum claimed that meaning for kindergarten aged students was equated to knowing the use of classroom materials - either for work or play - with 'work' materials cited as more important items. Early on, children 'learned' that school was 'work' and therefore, work was valued over play and thus, productive activity was valued over 'non-productive' activity:

The categories of work and play emerged as powerful organizers in the classroom reality early in the school year. Both the teacher and the children considered work activities more important than play activities. Information which the children said they learned in school were all things that the teacher had told them during activities they called 'work.' (p. 55)

In fourth grade, I remember having a Friday math quiz involving the multiplication tables. My teacher stood in front of the room and recited arithmetic equations, "Ok, students,

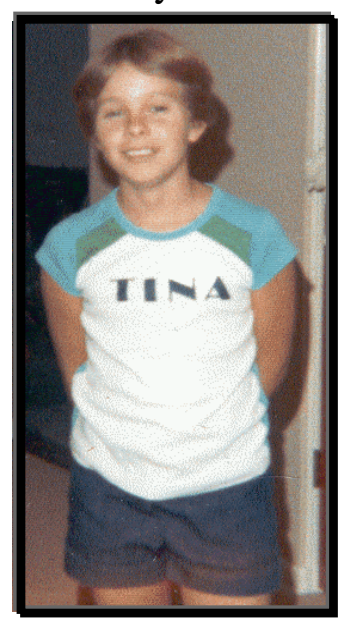
let's begin $. .4 \times 2 \ldots 4 \times 12 \ldots 4 \times 7 \ldots$ × Imagine each 'dot' in the preceding monologue as representing one second. We had to compute the answers on a sheet of paper to match her rate of request. She would not repeat an equation if someone asked and the entire quiz took less than two minutes. To earn a 'good' score, Thursday night memorization was key and when we earned a top score, we got stickers. I always felt as if my teacher liked me when I got a sticker but my brother never got stickers. (Family album) 


\section{Teaching and Learning}

Thomas Greene (1971) in The Activities of Teaching, wrote, "Teaching is almost always aimed at getting someone to learn. Indeed, it is hard to imagine any other motive for teaching" and furthermore, "...teaching is an activity primarily concerned with enlarging the manifestation of intelligence..." Teaching and learning are alike because both have to do with the beliefs held towards formation of knowledge and, likewise, it is hard to speak of one without referring to the other. For these reasons, teaching and learning are spoken about in conjunction in this study. But, that is not to say that learning always occurs with teaching or the activities of teaching is the only way an individual learns, but, generally, the positivist model assumes causal progression. In this section, this is a key characteristic.

General understandings about teaching and learning in the modern era supported a structural hierarchy in the classroom. At the top of the echelon, resided the teacher who practiced a technical craft in its broadest sense by communicating and transmitting ideas, and modeling desired behaviors (Epstein-Jannai, 2001). The teacher was expected to be the 'expert' of the subject matter and delivered the information via direct instructional strategies with time allotted for student questions. This slant towards teaching meant that teachers conceived their job having to do with the transmission of knowledge (Jackson, 1986). Metaphors of the era painted the role of the teacher as "Teachers on the front lines," or "Teachers in the trenches' (Grumet, 1989). A teacher's preparation and planning for daily lessons was documented in unit and/or lesson plans. The format of typical lesson plans included the following information to some extent: behavioral objectives with specific measurable and observable expectations to learning outcomes; introduction to lesson, procedures, line of questioning, assessment strategies, and needed materials. And, more specifically, various segments of the lesson were 
further broken down into time increments. Lessons were repeated consecutive periods and from one class to the next. The 'plan of attack' teachers utilized to prepare students for assessments consisted of repetition and memory recall exercises.

Learning required students to sit quietly at their desks, receive, and privately accept the information delivered from the teacher, take notes, memorize the information, and frequently reproduce the information on tests and worksheets (Clark, 1997). Student learning was conceived to occur much in the same way that radios or televisions received 'air signals.' In such instances, 'knowledge transfer' was a well-accepted and widely practiced theory in the classroom. Relying on Edward L. Thorndike's psychological research, teachers followed the premise that, "the best way to prepare a student for a given activity or goal was to have the student take a direct route: the study of the subject or the practice of the activity itself” (Tanner \& Tanner, 1990). This method proposed "habit formation" and "uniformity of response" across students, as if to say that learning purposes are the same across individuals but also reflected a commitment to objectivity (Tanner \& Tanner, 1990; Jackson, 1986). An explanation of student responses fed into a theory that "teaching is to cause another human being to change in a certain way, and that learning is the effect of causality” (Collins, 1970).

Both the teacher and the students relied on textbooks for information (Bolotin \&

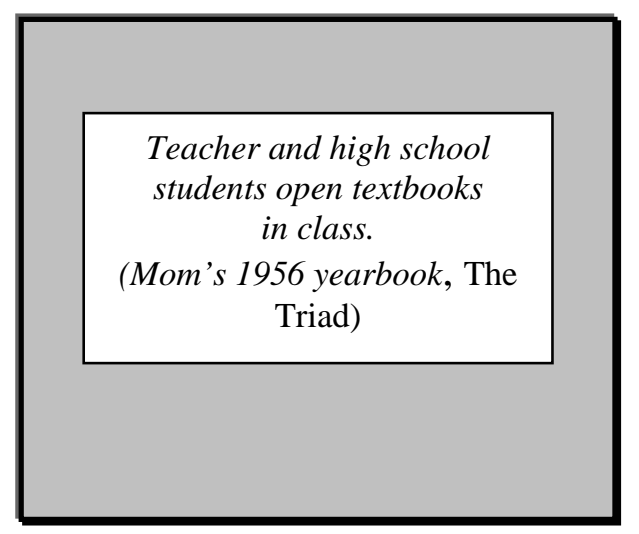

Burnaford, 2001). However, teachers benefited from teacher editions of textbooks or 'teacher-proof packages' where enlarged margins provided 'script' for teachers to ask questions and reminded teachers of observational cues to student readiness; teacher editions also offered assessment techniques in the form of suggested activities, handouts and 
tests/quizzes. These tests and quizzes were the medium of sorting and tracking 'winners from the losers' and further assisted teachers in labeling the deficiencies of students. Sorting and tracking 'directed' students to travel one of two general routes and was also determined by posthigh school aspirations - college bound or vocational preparation (Dreeben, 2002,). Therefore, distinctions were made that students either needed an 'academic approach' or a 'manual, handson approach' to their learning. In John Goodlad's educational study, A Place Called School (1984), he found that student tracking and ability grouping influenced teacher expectations on student performance.

Tests and quizzes were one method used to track and sort students but another method, a little less obvious but nonetheless just as important, were the implicit gender messages textbooks delivered. In other words, students 'learned' what it meant to be female or what it meant to be male through assigned readings and visual images in the text. They learned, “...girls and boys didn’t do the same kinds of activities...boys were strong, boys were masters, boy were active. Girls were sweet, girls were passive, girls watched, girls helped...” (Tyack, 2001).

Bloom's taxonomy of educational objectives, a theory developed during the 1950's, was one approach to student learning and provided a foundation of lesson plan construction and likewise, student assessment (Lasley, Matczynski, \& Rowley, 2002). Benjamin Bloom built a system of learning and teaching around five levels of cognition where the 'lowest' level, i.e., recall, was proposed to introduce new information and 'highest' level, evaluation, judged 'divergent' ways of knowing. The five levels were: recall, application, analysis, synthesis, and evaluation. 
In comparison to the early part of the century, teaching and learning by the 1950's took a dramatically different turn (at least in its philosophical underpinnings) and noticeable differences were apparent in terms of the roles of the teacher and student. Burrup (1960) in Teacher and the Public School System cited the Association for Supervision and Curriculum Development (ASCD) characteristics for 'better teaching': (1) fostering student security and satisfaction; (2) promoting cooperative learning; (3) helping students develop self-direction; (4) fostering creativity; (5) helping students develop values; (6) providing opportunities for social action; and, (7) helping pupils evaluate learning. Central to these tenets is the belief that classrooms should be democratic and students need to be treated and treat one another as democratic members, which is a radical departure from earlier but is still nonetheless, teacher guided. Furthermore, “...models that emphasize democratic process assume that the outcome of any educational experience is not completely predictable” (Joyce \& Weil, 1996). Ron Miller (2000) in Creating Learning Communities labeled this teaching model as 'transactional':

Knowledge is generated in relationships between people, through conversation and dialogue, and in relationships between the learner and the larger world through meaningful activities, experimentation, and adventure....This approach is generally concerned with strengthening democracy in education and society because only a democratic community encourages such dialogue and experimentation. Although the teacher is not treated as the authority figure....she or he plays an important role in students' learning by engaging in dialogue, questioning, and being a thoughtful and caring mentor. (p. 203) 
At the end of chapter three, there is a table summarizing the descriptors and characteristics of the Modern and Post-Modern Era. This summary table is a quick reference to compare and contrast the ideas in text from this chapter.

\section{An 'Unplanned' Critical Reflection}

In my original outline for this chapter, I did not plan for a reflective piece between the Modern and Post-Modern Era sections. I had carefully laid out the various topics and up to that point, followed the outline perfectly. In fact, in my planning stages, I assumed that I would end one section and immediately 'pick up' with the Post-Modern Era somehow believing that one section would flow into the next, the same way that a river flows into the ocean but instead, I felt like my 'flow' was halted bluntly at a manmade, concrete, dam. How was it possible that my plan looked 'good' on paper but I was struggling, feeling discontented, questioning, even though I had presented the information objectively, free from opinion (if there really is such a thing). I did what I was told was the correct way to present the information. It followed a natural logical, progression, but I admit, I mentally and emotionally struggled for unknown reasons throughout the writing of the Modern Era. I felt as if something was missing. I even offered personal accounts at the end of sections because the traditional literature review was considered more important than the ideas that initiated this research study (Grumet, 1989). It was too tedious, too precise, too orderly, too limiting for this gal who lives her life in unorthodox ways. That is, unorthodox in comparison to the modern mindset. Then it occurred to me, I was struggling to break free of the harness that bound my thoughts and was attempting to lift the weight of the modern barriers laid upon me in much of the same way that Kuhn described of his colleagues and the Reconceptualists questioned the human experience in education in the 1960's, and furthermore, like the students of today rebel against. I also detected 
the same so called 'rigor' of the era in my writing style -- very straight forward, without feeling, without passion, with the exception of the personal anecdotes where I became engaged at an emotional level.

There was even a tendency on my part that wanted to criticize and make inflammatory remarks against the apparent inadequacies and limitations of this paradigm. Many of the sources cited in this section, did just that - Kincheloe, et. al., Sloan, Huston -- but I refrained from doing the same. My thoughts were a bit more compassionate, This is a different time than when our grandparents were born and we live by a different set of cultural values, and the modern paradigm is now inadequate. Let's wake up and open our eyes to the injustices and inequities created by modernist underpinnings, and let's stop ignoring hegemonic practices that have dominated modern thought.

Now, society is in the midst of a paradigm shift and a new vision for society is emerging. As changes begin to ebb and flow within and around society, so will it too in educational practices, but a complete understanding of its structure is not yet determined. The counter-cultural movement to the modern era is resisting truths once accepted as truisms, i.e., consumerism, materialism, while looking to overcome the effects of other "-ism's" like racism and sexism, by questioning modern meta-narratives. Educational debates are situated in a socio-cultural context and re-examining the purpose of education under a critical lens. The critical lens I am speaking to here, is formally recognized in scholarly circles as critical theory and encompasses several perspectives -- feminism, critical pedagogy, post-structuralism, neoMarxism, symbolic interactionism, ecopedagogy, semiotics, etc.-- all of which question and analyze the link between historically privileged and oppressed groups, and social institutions (such as public education) that shape knowledge construction. The critical theorists put forth 
the doctrine of 'Do not let yourselves be deceived' because the visible and invisible social structures of society have been engineered to reproduce dominant ideologies. Robert Bierstedt (1974) defined social institution as "a formal, recognized, established, and stabilized way of pursuing some activity in society." Michael Apple discussed the appearance of some of these 'invisible' social institutions (cited in Slattery, 1995):

...the concrete ways that prevalent (and...alienating) structural arrangements - the basic ways institutions, people, and modes of production, distribution, and consumption are organized and controlled -- dominate social life. This includes such day-to-day practices as schools and the teaching and curricula found within them. (p. 191)

There is a personal story that I'd like to share here that creates mixed emotions because I expose myself in a very personal way and admit embarrassment and ignorance, both which are not easy to articulate because I am supposedly an 'educated' person. This is also a story where guilt and disbelief were original reactions but nonetheless, today, I use this 'learning experience' to help comfort my students as they are exposed to social injustices within the American public classroom and experience the same emotions. I am in my late thirties and am undoubtedly a product of the educational system of the modern era. Like many others (including the reader), I am sure that I grew up learning meta-narratives and did so, without questioning. The 'messages' I received from my teachers, parents, clergy, and friends, were all the same. There were messages about what it meant to be female, "Tina, good little girls carry poketbooks," or "Tina, good little girls don't get dirty and don't fight. They stay clean." There were also universally accepted historical stories, such as, "Columbus discovered America in 1492" and to this day, there is a date reserved on the calendar to observe and remember the efforts of this man. These 
are examples of the messages that influenced my female identity and the history that shaped my European-American experience.

Graduate school was an intellectual exercise and brought me into contact with critical theory. I was exposed to 'strange' concepts and 'strange' ways of looking at the world. Whattaya mean that education is an unfair enterprise and perpetuates social class distinctions? Look, education is 'free' in this country and if I can get an education, anybody can. People on the other side of the tracks just need to pull themselves up by their boot strings and get involved. Your education is what you make it. These critical theorists need to relax.

There were many assigned readings throughout my course work but the one that stands firm in my memory and transformed my way of thinking about education and social justice issues is Johnathon Kozol's, Amazing Grace (1996). Yes, yes, I get it now -- a child's environment, race, class, and gender impact their cultural capital. To this day, it is the one piece of literature that never left me and continues to influence how I teach.

As this course delved into the histories of traditionally marginalized groups and knowledge reproduction, the Columbus story was critiqued. Oh, you've got to be kidding...everybody knows Columbus sailed the ocean blue in 1492... what's with the analysis....my mom told me this, my brother studied this, my grandma asked me what I was studying in school and I said, Columbus, you know, he discovered America. We get a day off school for this. This guy was noteworthy historical figure. Then, it came to be understood that to every story, there are multiple views -- one view is only one piece of puzzle; to see the whole picture, all perspectives must be taken into account. What I had never been told my entire education was that there was a group of indigenous peoples, the Tainos, who welcomed Columbus and his crew as they made shore on a new world. Even as I sit here and write this 
reflection, there is a high school global history book with a 2003 copyright date in my line of sight. Just out of curiosity, I open it to see if mention is made of the Tainos. The Columbus narrative is offered but no story of the Tainos. Where is the story of the Tainos? Why was/is their perspective left out of history books? What history books fail to share is that on his return trip, Columbus captured and enslaved many of them and thus, the Tanios' voices were left out of history due to their enslavement status. In the final pages of Jane Yolen's (1992) children's book, Encounter, she provided an 'adult' historical account about the research she completed for the writing of book and claims that today that there are no full blooded Tainos left. I feel so guilty, so embarrassed, so foolish. How could I have not known this? So, there were lots of people in history -- blacks, women, individuals with disabilities, children, Latinos, Asians, Native Americans -- where is their story? There must have been black people in history besides W.E. B. DuBois and Booker T. Washington. I began to question my entire educational career, feeling as if I'd been 'mis-educated' and later, recognized that I was/am part of the privileged group and therefore, I pass judgment on the Other based on a set of cultural values/assumptions respective of my class position. Peggy McIntosh (1990) in White Privilege: Unpacking the Invisible Knapsack further informed me of the daily effects of my privileged life and the advantages of whiteness:

I can go shopping alone most of the time, pretty well assured that I will not be followed or harassed. When I am told about our national heritage or about 'civilization', I am shown that people of my color made it what it is. I can do well in a challenging situation without being called a credit to my race. I can choose blemish cover or bandages in 'flesh' color that more or less match my 
skin. I can easily buy posters, postcards, picture books, greeting cards, dolls, toys, and children's magazines featuring people of my race.

What should I do with this newly found knowledge? After these events, my attitudes towards teaching and learning were 're-configured' and I began to wonder about my own students, and my personal teaching and learning. Was this an explicitly stated objective of my doctoral program? Maybe, implicit? Furthermore, I wondered if I had contributed to the dominant ideology that I was raised with? Were the events in my classroom serving to further separate and segregate students from each other and from the content area? What are signs and symptoms of disconnection? When students asked, "What's this have to do with anything?" or "Do I have to know this for the test?," a 'red flag' went up to alert me that they didn't personally connect with the topic at hand. They weren't involved in their own learning and thus, promoting disempowerment and disinterest. But, a recently published book for social studies educators by Eula Fresch (2004) takes a novel approach to this too often heard cry for valued-based learning and is based on the premise that students studying history can connect to history when they learn about other children (versus the typical 'adult' history in books) and realize they can make an impact on society. For instance, 15 year old, Claudette Colvin, staged a similar 'sit in' as Rosa Parks only nine months earlier (Fresch, 2004). Children were there, too, but history books fail to mention this. Children do care and do want to connect because there is a natural human tendency to make meaningful connections, but developmentally do not connect with adults. This unique approach to connecting with the subject matter has the potential to change future classroom teaching and learning.

As I conclude this 'unplanned' reflection, it serves several purposes. As a phenomenological researcher, I must situate myself in the study to reveal the 'inner drama' of 
the research process (Mooney, 1975). Richard Wolff (2002) writes, "For the researcher, the lived experience is the process of phenomenological procedure itself -- the methodological movement among description, reduction, and interpretation....the researcher must engage in self-reflection to understand how the process in unfolding." What I have attempted to do is paint a picture of the path and the stepping stones that have led to the 'unfolding' of Tina and the study to this point, and to clearly situate myself in this study -- my public school education was built around the modern model; I was 'tracked' to college; I am a white woman, and come from a middle-to-upper class socioeconomic background. Likewise, there are values/assumptions I bring with me but what I have articulated offers clues to the transformation of my identity as a woman and as a teacher/research. (I'm not sure if I an can even separate these aspects of my being because they are all woven together.) But, the most important aspect of this 'unfolding' reflects a growing discontent and disenchantment with modern educational practices made possible by my graduate studies. I know that there are others who share the same experiences, and can understand my story and the participants of this study but even written language can be limiting at times (Wolfson, 1977). There are others who also seek to bring back subjective, value-based experiences to the classroom, create environments where all types of knowledge are valued and where the 'public' is in the public school, and approach teaching as a vocation, a moral enterprise, which serves to validate the identity and integrity the individual.

As I now cross-over into the post-modern portion of this chapter, it is structured similarly to the previous section -- first, a discussion of the purpose of education is built into a brief portrait of America over the last 30-40 years and epistemological assumptions of mind, followed by a detailed discussion of the types of classroom setting, meaningful experiences, 
and general understandings related teaching and learning. Likewise, personal images and artifacts will serve to illustrate characteristics of the discussion. Finally, because the structures of the post-modern era are not completely defined or well understood, the criteria used to select literature was based on the 'newness' of the ideas to the extent that they were the counterbalance to the characteristics associated with the modern era and furthermore, there is general disagreement about many of these issues ('no single truth'), leading to approximate explanations; however, there is one common component, the inclusion of the human experience.

\section{The Post-Modern Era}

\section{Purpose of School}

Much has happened in America over the past 30-40 years and to enable this discussion to be narrowed, this section is modeled to the previous analogous section. Therefore, I have given 'selective attention' to two aspects of society, which I believe are reflective of societal and ideological change. First, changing U.S. population demographics are briefly discussed in light of race, gender, and class inequalities, along with other historically marginalized groups, and contextualized with related historical events. The second aspect of society that is discussed focuses around emerging technology and information delivery systems, with additional discussion of the influence of popular media images and the growing need to be visually literate (Cushner, McClelland, \& Stafford, 2003; Schubert, Schubert, Thomas, \& Carroll, 2002).

There are a number of events and moments over the last 30-40 years that are the result of greater demand to close the gap on race relations, and other social injustices and disparities, that had in the past led to traditionally oppressed groups, i.e., women, gays/lesbians, individuals 
with mental and physical challenges, and individuals who are economically disadvantaged, but are also the result of the changing tide of population demographics and ideologies. Mentioned here are some of the notable events and moments of this time period that are related to my first argument (Tozer, et.al., 2002). Noteworthy events and moments of the 1960's include: the Civil Rights Act of 1960/1964 (a follow up to the enforcement of Brown vs. Board of Education, 1954), the federally funded Head Start program (1964), the Elementary and Secondary Education Act (1966), Paulo Freire's Pedagogy of the Oppressed published (1968), Sudbury Valley School in Massachusetts founded (1968), and Dr. Martin Luther King is assassinated (1968).

Notable events and moments of the 1970's include: Ivan Illich's Deschooling Society published (1970), busing to achieve racially balanced schools is upheld by the U.S. Supreme Court (1971), Title IX Educational Amendment and the Equal Rights Amendment (1972/1976), Bowles \& Gintis' Schooling in a Capitalistic America published (1976), and, PL 94-142, the Education for all Handicapped Children Act (1975).

Significant events and moments of the 1980's include: Jean Anyon's Social Class and the Hidden Curriculum of Work published (1980), A Nation at Risk is published and brings promise to educational reform (1983), Reverend Jesse Jackson is first African-American to challenge for a major party nomination for president (1984), stock market dives in worst oneday plunge in history (1984), E.D. Hirsch's Cultural Literacy published (1988), and Johnathan Kozol's Illiterate America published (1988).

Noted events and moments of the 1990's include: Johnathan Kozol's Savage Inequalities published (1991), Arthur Schlesinger's The Disuniting of America published (1991), Americans with Disability Act (ADA) guarantees equal access for disable people 
(1992), "Don’t ask/Don't tell" rule for gays and lesbians serving in the U.S. military (1993),

Supreme Court rules against Affirmative Action program (1995), same-sex marriages denied as Clinton signs into law Defense of Marriage Act (1996), IDEA amended (1997), and welfare reform legislation (1999).

Most recently, America 2000 (launched under the George Bush administration), later revised and entitled, Goals 2000 (under the Clinton administration), was a congressional act outlining future goals for America's public school system that sought to eliminate inequalities particularly in school districts attended by minority children (Urban \& Wagoner, 2000).

Mentioned in the opening pages of this study was NCLB Act (2001), which recently went into effect and follows in the footsteps of Goals 2000 and A Nation at Risk (1983). And, within the past month the states of California, New York, and Massachusetts are reconsidering passing laws to make same-sex marriages legal. These events and moments are signs of a changing social reality; reflect a growing cultural crises in addition to the changing purpose of education; and, represent a heightened public awareness to counter-culture ideologies through exposing how 'the other half lives' (Eduardo, 2002).

A closer look at the American 'face' reveals a society rich in diversity but the trend is not so much as to make everyone alike but to retain cultural identity; thus, the America once known for describing its patterns of socialization as a 'melting pot,' now looks to find its identity in the 'salad bowl' or 'stir-fry' metaphor (Grant \& Sleeter,1999).

While America has always offered the promise to immigrants to be refuge to 'the tired and the poor,' immigration in this country continues, but as opposed to the early $20^{\text {th }}$ century where immigrants came primarily from Europe, today's immigrants arrive generally from Latin American and Asian countries (cited in Cushner, et.al., 2003). Furthermore, according to the 
U.S. Census Bureau (2004), Hispanic/Latino populations have surpassed African-American populations as the largest minority group in the country with predictions that by the mid- $21^{\text {st }}$ century, people of color will make-up the majority of the country's population but the racial lines of previous eras are blurred due to recent scientific evidence generated from the Human Genome Project (HGP) that claims race is a genetically insignificant factor in overall DNA composition, therefore, making Americans more physically alike than previously believed (Adelman, 2003). Geographically, about 25\% of Americans live in big cities; half live in the suburbs; and the remaining live is small town America (Hodgkinson, 2000/2001). In the nation's schools, these changing racial demographics are also being witnessed, in addition, to spoken and written languages, and increasing rates of poverty and transiency (Nieto, 2004). Maxine Greene (1993) explained why it is necessary for schools to acknowledge diversity and the accompanying worldviews that students bring with them, "What is crucial is the provision of opportunities for telling all the diverse stories, for interpreting membership as well as ethnicity, for making inescapable the braids of experience woven into the fabric of America's plurality." But, even as society and schools are growing ever more diverse, the seeds of segregation and racism still exist. Desegregation has not brought greater economic equality.

The second aspect of society that reflects change is the use of technology and information delivery systems (Schubert, et.al., 2002). In this age of information systems, technological advancements and popular media images have inundated American life -- from television and cable systems, computers with high speed and remote Internet connections, online chat rooms, virtual reality, global positioning systems (GPS), cell phones with compatible wireless technologies -- with the rate of global information transmission greater than at any other time in history (Mirzoeff, 1998). Americans can access one another, news, and 
information '24/7' whereas only 30 years ago this was not possible. Historically, computer floppy disks and desktop computers were first introduced to the public in 1970 and 1974, respectively, and, the first e-mail message was sent in 1971, and it would not be until ten years later that microcomputers appeared in the contemporary classroom (Tozer, et.al, 2000). It was also in the decade of the eighties that saw compact disk (CD) players replace the eight-tract music cartridge and video-cassettes allowed people to record home videos and watch rented movies at home (Schubert, et.al., 2002).

Speaking about the effect of cyberspace on American life, John Perry Barlow, cofounder of the Electronic Freedom Foundation, states"..[it] is the most transforming technological event since the capture of fire," and Louis Rossetto, cofounder of the magazine Wired, described it as "a revolution that makes [the]

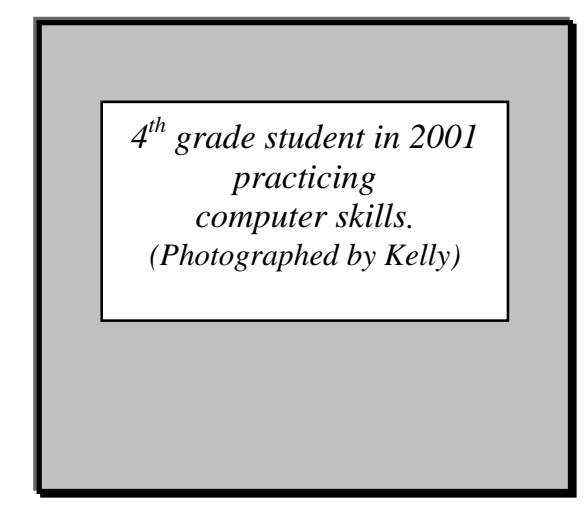
political revolution seem like a game" (Borgman, 2000). But, Albert Borgman writing about "Society in the Postmodern Era," suggests that there is also a downside to the technological revolution, "It has established an invisible zone of distance and disposability between us and our world. In allowing this zone to arise and by helping to establish it, we are deprived. We have deprived ourselves of the real resistance a person needs to acquire character....this condition generally inspires disengagement and disorientation..."

Students in the classroom now begin keyboarding skills as early as kindergarten, and graduate to word processing programs, database applications, presentation programs, and website construction. As rich as this scenario may sound, advancing technology has brought a 'digital divide' noticeable in economically depressed school districts. 
Corporate America has invaded the public school system through the buying of rights to sell company products in schools. Here are a few examples: Pepsi and Coke routinely compete for sole beverage rights; Pizza Hut rewards students with pizza for meeting reading goals through the 'Book it!' campaign; school fund-raisers often rely on Little Caesar's pizza kits; outdoor clothing company, Eddie Bauer, sponsored the final round of the national spelling bee; a 'mini-McDonalds' was installed at a elementary school in Michigan; and, market tests of various products -- from toys to breakfast cereals -- have been completed in day-care centers through the middle school grade level (Doll \& Gough, 2002; Molnar \& Morales, 2000). The Channel One television station offers today's youth with morning or afternoon news updates, and offers corporations advertising time slots (much like regular cable stations) at a premium. But, more importantly, corporate America knows that youth grow up and as adults, they become consumers and spend money on products, form habitual behaviors which often times have origins from childhood, and contribute to the overall economy, making name recognition the primary reason that the school-corporation merger pays off in the long run. The criticism towards 'schoolhouse commercialism' argues that children can by no means be considered 'rational consumers' because they lack the 'power, information, and freedom' of adults (who freely enter into contract with products) and therefore, these corporate acts are viewed as an 'immoral war on childhood' (Doll \& Gough, 2002).

The influence of popular media images -- on youth and adults alike -- cannot be disputed today especially as corporate visual communication experts understand the psychological impact of manipulating forms and structures that potentially translate into market gains. There are two main forms of images to be concerned with here. First, print media consists of primarily still images in magazines, newspapers and Internet graphics. The second 
form consists of moving pictures such as film, videos (music videos included), and television (Messaris, 1994). In light of the number of hours weekly that people are in contact with any one of these media individually or in combination, it becomes apparent of the need to be visually literate to break the 'message code' of corporate America. Visual literacy refers to a form of knowledge involving an understanding of applications of visual symbol systems such as, "...analysis and definition; the structural forces that exist in the interactive relationship between the visual stimuli and the human organism functionally, both physically and psychologically; the character of the visual elements; and the forming power of the techniques" (Dondis, 1973). Of the five sensory pathways, most Americans receive information about the environment through vision and 'decode' the messages for personal understanding, so subjectively, there are endless possibilities for meaning. However, visual literacy "can help us to see what we see and know what we know" because "what you see is a major part of what you know" (Dondis, 1973). One state that has recognized the importance of developing visual literacy skills in the classroom is New York. A set of student objectives has been devised for all grade levels addressing visual literacy skills.

The purpose of education in a society that is still mainly driven by values associated with capitalism -- consumerism, materialism, and technology -- and has perpetuated social stratification, economic inequalities and marginalized certain groups, and antithetical to individual meaning-making due to the overwhelming influence of corporate America, has been called into question in the post-modern era. This critical analysis of educational practices have led to demands to reform the public school system (especially during the 1970-1980's) to help bring relief to the cultural crisis and hegemonic practices where, "pseudo-communities based on consumption or the uncritical acceptance of a particular policy [policies] or point of view" 
have been created (Doll \& Gough, 2002). John Goodlad (1984), in his landmark study of schools, critiques the missing components in education, "Frequently missing were goals directed specifically to multicultural understanding and appreciation and to aesthetic development." Similarly, to counter-balance the effects of education of the modern era necessitates a new vision for the purpose of education and Kincheloe, et.al, (2000) propose that education:

Shift its focus from ideologically rigid programming and conformity to the sociocultural context that influences so dramatically the spirit and consciousness of those struggling to survive and flourish and amidst the trauma and marginalization of contemporary education. As Alfred North Whitehead recognized, the harmony of the whole will be secure only if we achieve the preservation of the individual.

By the same token, John Dewey (1916/1944) wrote in Democracy and Education that a new conception of education has no meaning until "we define the kind of society we need" and moreover, Ron Miller (2000), a self-proclaimed "Deweyan," affirms (his emphasis included), "....education and other social institutions need to be responsive to people's experience and understanding; the systems we set up to guide our lives need to be flexible and organic and relational." What follows is a compilation of various ideas about the purpose of education in the post-modern era that revolves around a new vision for society with emphasis given to the construction of self and personal meaning-making, the redistribution of power, and draws heavily from critical theory, phenomenology, and existentialism:

Education should honor, foster, and expand democratic life (Schubert, et.al., 2002).

Education should reconstruct a sense of moral purpose (Schubert, et.al., 2002). 
Education should provide communities of interested learners with opportunities to explore, create, and construct meaning (Schubert, et.al., 2002).

Education should offer a framework for understanding options for enacting multicultural education, ranging from providing compensatory education, to a human relations approach, to education for social reconstruction (Grant \& Sleeter, 1999).

Education is for living, learning, and growing individually and in groups. The quality of life and of human transaction in the school is central (Wolfson, 1977).

Education is a spiritual endeavor....dwelling on wonders, mysteries...encouraging students to engage their world with a sense of wonder through exploration and dialogue and creativity (Miller, 1997).

One of the first tasks of education...is to return man to himself; to encourage rather than stifle awareness; to educate the emotions, the senses, the so-called automatic systems; to help people become truly responsive and therefore, truly responsible (Leonard, 1968/1987).

Education should enable children to be well informed....to understand ideas that are important, useful, beautiful, and powerful. And, enable them to have the appetite and ability to think analytically and critically, to be able to speculate and imagine, to see connections among ideas, and to be able to use what they know to enhance their own lives and the desire to contribute to the culture (Eisner, 1998).

Education should shock ourselves into a new awareness of what we take for granted and often do not see and empower individuals to clarify and ground their own beliefs about the projects they have chosen for themselves to the end of creating themselves as thoughtful, articulate, critical, and human practitioners in a profoundly uncertain world (cited in Ayers, 1996).

The aim of education -- in fact the aim of life -- is to work joyfully and to find happiness. Happiness....means being interested in life......and responding to life not just with one's brain but with one's whole personality. Education must be both intellectual and emotional. Education must be geared to the psychic needs and capacities of the child (Neil, 1960).

Education is a constant reorganizing and reconstructing of experience. It has all the time an immediate end, and so far as activity is educative, it reaches that end -- the direct transformation of the quality of experience......what is really learned at any and every stage of experience constitutes the value of that experience, and in the sense that it is the chief business of life at every point to make living thus contribute to an enrichment of its own perceptible meaning (Dewey, 1916/1944).

Education is a quest to examine consciousness, a commitment to equality and tolerance, skepticism about established practices in education and government, and optimism regarding human potential (Shaker \& Kridel, 1989). 


\section{Epistemological Assumptions of Mind}

Drawing from the varied perspectives held towards the purpose of education for the post-modern era, epistemological assumptions of mind take on a radically different stance of the positivist model (from the modern era) but that is not to say that post-modern epistemology is built solely upon proving the 'falsity of positivism,' but, rather, offers an alternative or provisional paradigm. One of the main challenges to positivism will be to the objectivity of knowledge; that is, the 'real' world is known through the senses, which can be verified through observation and measurement, thereby disconnecting and discounting human emotional and spiritual ties to the object studied. Is it possible to think without feeling or feel without thinking? Modernist epistemological assumptions may quite possibly reject the authenticity of the human emotions of love, joy, or wonder, because neither can be measured on a scale or observed free from bias. But why would the existence of a thing be denied, when in actuality, it may be the methods that prove inadequate? Individuals adhering to positivistic principles often react to the possibility of knowing the world through subjective means with skepticism and fear rather than looking back at the paradigm that serves the worldview. Subjectivity has for too long been judged as 'unreal or less real' because it falls outside of the lines of the modern paradigm. The modernists failed to take into consideration the internal life of the mind or subjectivity where personal relationships to the object is vital to establish 'live encounters' with the known (Palmer, 1998).

As society transitions into post-modernity, one of the central questions that I am belabored with 'is how does anything new begin' or in the epistemological sense, how do new ways of thinking begin and how do new paradigms emerge? Paradoxically, though, I am reminded of this Platoian dialogue (which I cannot seem to remember the exact source of its 
origin and can only mention here because it is in my personal journal), "How is it ever possible to discover new? For in order to discover something, I must know what is it that I am looking for otherwise, I shall not know when I have found it." Will the new paradigm allow individuals to 'see' a new world in new ways? Or, is it just the same world seen differently?

In the following summary, epistemological assumptions of mind are presented, and similar to the above accounts on the purpose of education, also offers numerous perspectives to the construction of knowledge which Maxine Greene (1973) in Teacher as Stranger explained as a measure of a changing, pluralistic society, "...looking outward to the innumerable distinctive ways of life in the world, we cannot help being reminded of the necessity for a type of cultural relativism, of the importance of realizing that multiple ways of seeing the world exist." In schools, this pluralistic epistemology is of importance, states Elliot Eisner (1998) in The Kind of Schools We Need because, "...[it]....can....contribute to a less dogmatic view in our schools of what it means 'to know."' In the same manner, William Pinar (2004) in his recently published book, What is Curriculum Theory?, writes, "Subjectivity is cultural, and culture is subjective." Culture is of the self and of the public, and knowledge cannot be divorced from the self nor the public. Kincheloe, et.al., (2000) point out that post-modern assumptions of epistemology will likely focus on 'reuniting' the parts to form the whole which had in the past led to 'fragmented' or dualistic ways of thinking, e.g., incorporating rational and intuitive thought, science and spirituality; viewing change as a natural occurrence which replaces the idea that truth is Absolute or permanent; viewing knowledge as contextualized to one's life experiences and value-laden; and, invoking a re-appreciation for the dynamic, mysterious interrelationships of nature and the human experience. 
From the literature search, there emerged a general theme around knowledge construction in the post-modern era. I offer this theme an all-encompassing general description of a holistic and humanistic epistemology (for the main reason being that the theories are not dualistic in nature and do consider the human experience). Nearing the completion of this chapter, I came upon a book containing a chapter of a similar title, 'holistic intelligence,' published by the Foundation of Educational Renewal, that characterized holistic intelligence as, "the ability to distinguish between truth and falsehood....based on the principles that promote the common good...oriented towards developing the unlimited potential of humankind...the ability to perceive our interdependence and to recognize actions that would break down such interdependence" (Nava, 2001). This was a sign to me that my conceptual understanding of epistemology in the post-modern era was in agreement with others. However, there are numerous orientations under this general theme that carry similar messages, which I have decided to briefly summarize in the following discourse: John Dewey's concept of experience and nature, constructivism, metacognition, multiple intelligences, interpretative/understanding, problem-solving/critical, and systems view thinking. In the last decade, many of these theories have been generated from brain research (neuroscience) that studied extensively the working environment of the brain where learning and knowledge is seen as some function of memory, nutrition, genetics, culture, language acquisition, motor activities, exposure to the arts, emotions, and personal meaning-making (Jensen, 1998). Generally, though, constructivism is the dominant conceptual framework applied to the new era which describes knowledge production as occurring through personal meaning-making, i.e., "in terms of personal associations to other ideas," and systematically approaches aspects of reality as being interconnected (Davis, 1999). (Several of the other epistemological models, which are included 
in the proceeding discussion, have characteristics similar to constructivism, and at the risk of appearing repetitious, the other models should be considered 'the many faces' of constructivism.) The various orientations lead Ken Wilber (1998) to describe epistemology in the post-modern era as 'encompassing' and 'pluralistic' and additionally states that, "any way we slice the great pie....men and women have available to them at least the three basic eyes of knowing: the eye of flesh (empiricism), the eye of mind (rationalism), and the eye of contemplation (mysticism)..." All of which at some point are mentioned in this discussion.

\section{Holistic and Humanistic Assumptions of Mind}

\section{John Dewey's Experience and Nature}

John Dewey's ideas related to epistemological assumptions of mind lays the foundation for this particular section on holistic and humanistic thinking. John Dewey's life (1859-1952) was clearly situated in the modern time period but not representative of his contemporaries. Because his ideas towards epistemology and furthermore, progressive education, were atypical of the time period and in retrospect, better aligned with post-modern characteristics, I have elected to include him in this discussion.

Dewey's philosophy towards the nature of knowledge is generally considered an active or participatory epistemology, but seldom in his writings does he personally refer to it as such. Dewey will prefer the term 'experience' to most adequately describe his philosophy of knowledge where at the core of knowing was personal 'meaning,' which he referred to as the union of form and essence (Dewey, 1958). Knowing "was a mediating function capable of rendering judgments to guide actions that would transform problematic noncognitive situations into ongoing, unproblematic, noncognitive experience" and "knowledge is a perception of those connections of an object which determine its applicability in a given situation" (cited in 
Westbrook, 1991). Genuine knowledge "has all the practical value attaching to efficient habits...it also increases the meaning, the experienced significance, attaching to an experience" (Dewey, 1944/1916).

Dewey's ideas of experience are quite complex and well beyond the present scope of this study but should be briefly attended to because the meanings attached to the experiences give insight into the qualia of epistemology. First, speaking specifically to the concept of experience, he writes in Experience and Nature (1958), (his emphasis included), "...experience is of as well as in nature. It is not experience which is experienced, but nature....Things interacting in certain ways are experience; they are what is experienced." An experience describes a moment where an individual is at a constant and continuous point of intersection with himself [herself] -- both mentally and physically -- and the environment. So much so that as one experience ends in 'equilibrium,' it is immediately followed by another perplexing encounter that brings 'disequilibrium,' which Dewey will aptly depict as a series of 'to and fro' adjustments with nature. At the point of intersection is a seamless transaction of unity that occurs with the self, i.e., thinking, feeling, and doing, and with nature, that does away with dualities and demonstrates the interrelatedness of self and society, mind and body, and, thought and world, and continues until mental and physical equilibrium is re-established (Dewey, 1935). In Democracy and Education, Dewey (1944/1916) describes the 'experimentation' that one must go through to construct new knowledge in terms more commonly associated with the scientific method, and further insists that trial and error are part of the process, and more important than the 'product' of knowledge itself.

Dewey will lay claim that education fosters unnatural habits of mind by instilling 'faulty dualistic thinking' by following positivist methods that excluded personal ways of knowing and 
seeing the world (a priori knowledge); he was opposed to the idea that children arrive at school as 'blank slates,' and believed schools prematurely emphasized the 'basics' (cited in Westbrook, 1991). He further stated that theories of knowledge of the era contributed to "mark off social groups and classes within a group" (Dewey, 1944/1916).

Even though Dewey's ideas were published over 70 years ago, there are remarkable similarities to more recent theories of knowledge construction that can be also included in this section. More specifically, the theories of constructivism, metacognition, multiple intelligences, interpretative/understanding, problem-solving/critical, and systems view thinking. Each theory takes the position that knowledge is emerging and changing, rather than static, as well as, speculates that individuals draw on their own personal experiences and ideas (Joyce \& Weil, 1996).

Constructivism was first introduced and named by Jean Piaget, and is a theory of knowledge construction that finds its roots in the fields of cognitive psychology, physics, philosophy, and anthropology. It is, therefore, a philosophical and a psychological stance towards knowledge construction. It emphasizes students must take an active role in their learning by incorporating their own ideas and experiences; stresses that knowledge and understanding are 'highly social and cultural' and historical constructions of knowledge vary across culture; and, point out that students need to create and recreate knowledge for themselves which leads towards personal understanding (Perkins, 1999; Brandt, 2000; Clark, 1997). Henry Perkinson (1993) further elaborates this point, "Humans create their knowledge. We decode, or construct, or make sense of whatever we encounter.” If the intrinsic nature of mind and individual is to be active organisms, Dewey's concept of experience supports the idea of an interrelated active mind and an active body, then it follows that knowledge comes from 
"neither the subject nor the object, but more from the unity of the two" (Clark, 1997). In

Constructing Understanding, Mark Windschitl shares insight into the life of the constructivist learner (cited in Joseph, et.al., 2000):

A central aim of the constructivist culture is cultivating learners who believe that they can create knowledge themselves, and that knowledge does not exist outside them as some objective, universal entity. All students hold epistemological beliefs about whether or not they can learn how to learn, if there are alternative to knowledge being accepted from unquestioned 'authoritative' sources, and whether or not knowledge has contextual limitations. (p. 99)

Metacognition is another contemporary theory of epistemology and refers to 'thinking about thinking', an awareness of thought, and about the nature of learning. Jerome Bruner (1987) suggests that metacognition is an act of "self-monitoring and self-correction...varies according to cultural background, and....can be taught successfully as a skill." Numerous strategies fall under this category but, more specifically, Hilda Taba is recognized for her approach towards thinking wherein she believes that thinking is innate and can be developed primarily through inductive strategies particularly through subject-specific concept formation, questioning techniques and the questions should serve specific pedagogical functions, e.g., focusing, extending thought, and transition from one level of thought to another (Joyce \& Weil, 1996; Verduin, 1967). Inductive strategies are sought out to "make the student an insider to the learning process." Taba's orderly questioning techniques could lead to some discussion of whether metacognition is a linear process but Maturana \& Varela (1998) state, "Knowing how we know does not consist of a linear explanation that begins with a solid starting point and 
develops to completion as everything becomes explained....we are unable to locate a starting point...Recognizing this cognitive circularity, however, does not constitute a problem for understanding the phenomenon of cognition."

Howard Gardner's theory of Multiple Intelligences may well be one of the most widespread theories of intelligence in education in the last 10 years. But unlike his predecessors that measured intelligence via Alfred Binet's IQ test, Gardner sought a theory that would take into account an individual's 'talents', but did not want to underscore the value of such talents and therefore, chose the term 'intelligences' to depict the historical significance and logical reasoning of his findings. Intelligence in this framework is defined as the "ability to resolve problems and to generate products that are valuable for a given community" (Nava, 2001). Gardner (1993) posits that there are seven dimensions or intelligences: linguistics, logicalmathematical, spatial, musical, interpersonal, and intrapersonal, thereby, leading to a pluralistic and 'universalistic' notion of mind. Others who have followed in Gardner's theoretical footsteps and have looked in greater depth at 'single' intelligences (yet, make them out to be holistic in scope) are: Marsha Sinetar and Zohar \& Marshall who examines ideas of spiritual intelligence; Daniel Goleman who studies ideas related to emotional intelligences; and Rachel Kessler and Kathleen Kesson, who both speak to the inherent need to address soul and spirituality in the classroom.

Interpretative and understanding epistemological frameworks primarily draw from hermeneutical and phenomenological traditions, and rely on the role of perception to construct meaning which is central to knowledge construction (Sokolowski, 2000). In the opening pages of Philip Phenix's Realms of Meaning (1964), he states, "Human beings are essentially creatures who have the power to experience meanings. Distinctively human existence consists 
in a pattern of meanings." Meaning can be the engaging force that drives one to understanding or tacit ways of knowing, but, yet, is also intersubjective. Self is the primary tool for knowledge production but, Jerome Bruner adds, "It can never be the case that there is a 'self' independent of one's cultural-historical existence" (Doll, 1993; Bruner, 1987). Because individuals routinely interpret and make sense of the world, knowledge is a 'personal and private commitment' that comes through a reflective and recursive interpreting of history, thoughts, feelings, and, language/communication, mannerisms, and symbols common to everyday life (Doyle, 1989; Phenix, 1964; Conklin, 1970). Knowledge is a reminder of one's own history, language, and culture as it brings forth personal understandings about a given thing but "does not account for complete understanding" due to the intersubjectivity of experiences (Jardine, 2000). No interpretation is intrinsically better than another and all are equally valid ways of making sense of the world (Wilber, 1998). Polyani and Prosch refer to this type of knowledge as tacit or personal knowledge contained in the whole being of a person, and speculate that it brings forth 'relational insight' into living, as well as, a comprehensive understanding of the integration of 'forces' and 'motion' of living (cited in Phenix, 1964). Polyani further describes this comprehension of the whole in Gestalt terms, "....all meaning lies in the comprehension of a set of particulars in terms of a coherent entity -- a comprehension which is a personal act...the knowledge of a comprehensive entity is an understanding, an indwelling and an association..." (cited in Phenix, 1964).

Ken Wilber (1998) in The Marriage of Sense and Soul explains an interpretative postmodern epistemology is also an ontological orientation, (his emphasis included), "Postmodernism....may be credited with making interpretation central to both epistemology and ontology, to both knowing and being. Interpretation...is not only crucial for understanding the 
Kosmos, it is an aspect of its very structure. Interpretation is an intrinsic feature of the fabric of the universe.” To illustrate his point, he writes of two people meeting on the street. One is walking towards the other, sporting a frown. To understand the meaning of the person's frown, the other inquires into the state of the frown, "You will talk to me, and interpret what I say; and I will do the same with you. We are not subjects staring at objects, we are subjects trying to understand subjects -- we are in the intersubjective circle, the dialogical dance." Further developing his idea about meaning, he underscores the following rejection to modernity, "Meaning is context-dependent, and contexts are boundless (this is often called 'contextualism') much in the same way that the nature of reality can never be 'pre-given' and must be constructed as an interpretation of one's beliefs about reality."

Another orientation to post-modern epistemologies is the problem-solving or critical approach which rests on Freirian traditions and questions the equality of access to knowledge. This approach attempts to 'undo' the institutional barriers that have traditionally led to unequal power relationships, where power and class status is also some function of knowledge access and (re)production. This type of epistemology advocates that the emancipation or liberation of thought and self comes about by 'problematizing' or questioning information to complex issues, such as those that are historically-culturally grounded, to bring social transformation. Henry Giroux (1992) in Border Crossings explains the idea of 'problematizing', "Central to all of these positions is the importance of challenging, remapping, and renegotiating those boundaries of knowledge that claim the status of master narratives, fixed identities, and an objective representation of reality." Problem-solving and critical epistemologies view knowledge as political, historical, changing, uncertain, and value-laden but as complex as the situation appears, Laclau expresses, it is necessary (cited in Giroux, 1992): 
The important epistemological breaks have not occurred when new solutions have been given to old problems, but when a radical change in the ground of the debate strips the old problems of their sense. This is what seems central to me today if one wishes to push forward the political debate...it is necessary to construct a new language -- and a new language means....new objects, new problems, new values, and the possibility of discursively constructing new antagonisms and forms of struggle. (p. 3)

The final post-modern epistemological model that I am including in this section is systems view thinking which approaches knowledge as a construct of knowing the 'whole' and directly challenges the notion of reductionism and fragmentation. Like the previously discussed epistemological assumptions of mind (of the post-modern era), it shares some of the same features with the central tenet reinforcing the insight that, "no single, discrete entity can be fully understood apart from the complex whole of which it is an integral part" (Clark, 1997). Edward T. Clark (1997) in Designing and Implementing an Integrated Curriculum proposed six assumptions of systems view thinking: (1) Incorporates a 'both/and' rather than an 'either/or' logic; (2) assumes a living universe; (3) is ecological thinking; (4) recognizes that we live in a participatory universe; (5) is both global and, at the same time, local; and, (6) honors the longrange view often found in Native American cultures (in context of 'the seventh generation' vision). However, different from the previously discussed epistemological orientations, it deviates from the idea that thinking can be taught and rather, espouses, "It doesn't need to be taught. Indeed, it can't be. It can only be nurtured....it is no more than a potential which, like a seed hidden in a cave, has lain dormant waiting for its time." 
Drawing most of its theoretical base from the scientific community, especially that of quantum physics and quantum mechanics, systems view thinking poses that humans are closely connected to the universe and, likewise, many of the same principles that conduct and explain the universe, conduct the processes of being and knowing. It follows the train of thought that the human body is made of the same elements and compounds as those found in the universe, e.g., oxygen, hydrogen, carbon, etc., and similarly, is itself a living, open, and self-regulating system. Thus, like other living systems which go through chaotic, turbulent periods, and eventually, must 'negotiate' equilibrium to sustain life and evolve to new stages, systems view thinking is believed to occur through comparable processes that living systems also experience, a process that Piaget (who rooted much of his philosophical work in the biology of living systems) will describe as assimilation and accommodation. He emphasizes this point here, "We can observe a process leading from certain states of equilibrium to others qualitatively different, and passing through multiple 'non-balances' and reequilibrations" (cited in Doll, 1993).

In the literature review, there has also been mention of the application of principles of String Theory, Theory of Relativity, Unified Field Theory, Chaos Theory, and Heisenberg's uncertainty principle for understanding episteme, all of which dispute knowledge as static, certain, value-free, and, linear. Even more recently, there has been a trend to create a 'theory of everything', a theory which unifies disciplines of thought and practice, as all seek and search for unity in the universe. Renee Weber (1986) wrote a brief article for the then not well known journal, IONS Review, entitled, “The Search for Unity,” where she reflects upon the notion that a comprehensive law is somehow ideal and more beautiful than knowing the parts that make up the whole: 
The drive of scientists to achieve this ideal cannot be 'scientific' in the conventional sense. It seems closer to an aesthetic demand, the sense that unity is somehow truer, more beautiful and better than multiplicity. The scientific drive seems to me to border on Plato's vision that the good, the true, and the beautiful are the fabric of reality. Such terms as 'elegance' and 'beauty' recur regularly in philosophical scientists like Einstein, Heisenberg, Eddington, Jeans, Schroedinger, Bohr, Feynman, Wald, Bohm, Prigogine, Hawking, Sheldrake and others. Behind the aesthetics demand, I believe, lies a spiritual one.

A few years earlier, physicist, Peter Russell factored in consciousness as a function of intelligence, he explains (cited in Clark, 1997):

Intelligence itself is an organizing principle within human consciousness. In its most generalized sense intelligence can be thought of as the ability to abstract raw sensory data, organizing our perceptions into meaningful wholes, form relationships between them (concepts, expectations, hypotheses, etc.) and thereby organize action in a purposeful way. (p. 29)

I believe an epistemological assumption of mind for the future will subsequently lead into the realm of consciousness studies and I put forth such an assertion based on early evidence and research directed by the Institute of Noetic Sciences (IONS), the late Willis Harman, Edgar Mitchell, Rupert Sheldrake, Peter Russell, Ken Wilber, Fritjof Capra, and Antonio Damasio. This is just a small sampling of individuals who are on a quest to 'know more about knowing' but there are many others who go unnamed. One of the questions that has plagued humankind since recorded time is, what is the meaning of life? In this epistemological 
discussion, it may no longer be sufficient to merely ask about the meaning of life since humans live purposefully, and meaning, as well as, knowledge, is contextual.

As this section concludes, I wish to highlight a few of the aspects of the various epistemological assumptions of mind to explain how the theories fit into my larger, self-entitled category of holistic and humanistic. John Dewey's ideas about experience and nature take into consideration the growing and changing mental and physical states of the child, and links them to the larger world and in preparation of the adulthood. Constructivism is the new dominant 'active' epistemology, and relies on the individual's personal ideas and experiences to synthesize new concepts. Metacognition posits that thinking is an intrinsic activity that can be developed and taught. Gardner's multiple intelligences claims that individuals hold unique talents in the form of intelligences and each form of intelligence is a valid form of knowing. Interpretative and understanding epistemological frameworks focuses on personal meaning-making through the knowing of self and others where knowledge is objective and subjective. Problem-solving and critical epistemological frameworks strive to emancipate and liberate the self through 'problematizing' from hegemonic discourse and institutional structures that have historically marginalized groups. Systems view thinking holds to the idea that individuals have innate potentialities that can be 'released' and developed, in a similar fashion as that which allows living systems to change and evolve. In summary, holistic and humanistic epistemological assumptions envision the hidden wholeness of structures, where there was once thought to be separateness, there is now integration of mind/body, subjective/objective, self/others, order/chaos, and, rational/intuitive, and knowledge is a symbol of experiences in the world. 
Prelude to the Post-Modern Classroom Setting, Meaningful Experiences, and Teaching and Learning Sections

After presenting various perspectives on the purpose of education and the epistemological assumptions of mind in the post-modern era, attention is now paid to understanding how these views and assumptions influence more specific areas of educational practices, specifically, the classroom setting, the kinds of educational experiences that are meaningful, and general teaching and learning processes. Also, because there is general disagreement about the defining structures of the post-modern era, much that is written about the nature of education in the post-modern era is theoretical; at other times, there are actual accounts and events that are coherent with the theories. The actual writing of this section was particularly difficult as I attempted to illustrate these visionary thoughts with current practices that are 'different' from the traditional practices of the modern era and merge them with the ideas of 'post-modern' thinkers beginning with the 1970's through the present, never really knowing if I should write in the past, present, or future tense.

At this time, though, it is difficult to truly identify something as a post-modern practice or thought, with the exception that it is a counter-balance to modern era; on the other hand, many of the changes presently taking place in education should be acknowledged as signs and symbols of change; that is, signs of discontent and dissatisfaction, and signs of a countercultural movement. Some of the more concrete signs and symbols of change in education are the growing number of charter schools, free schools, private schools, home schoolers, and other faith-based schools, which are mentioned from time to time, but not in any detail since this study focuses primarily on public school practices. However, there is evidence that what was once thought to be 'alternative' educational practices are slowly creeping into the public school 
classroom. The following discussion will present theoretical and practical aspects of the selected areas of education, respective to the research questions of the study.

\section{The Classroom Setting}

In The Courage to Teach, Parker Palmer (1998) shares thoughts about pedagogical design, which he believes creates the conditions for learning and teaching. He stresses that these ideas embody not only a potential plan for the physical arrangement in the classroom but also, foster the 'feeling' of the classroom, and serve to 'ground' his teaching philosophy. William Ayers (2001) concurs and adds that anytime we enter into 'people's spaces,' "you are embraced with an identifiable feeling" whether it be one of tranquillity, calm, or nervousness, the space will set the tone for what is possible and what is not possible. Furthermore, he contends, "all human environments have some idea, some belief worked up in them, responsibly and self-consciously or not." Parker Palmer's (1998, p. 74) design of the space is best described as a tension of opposites or 'paradoxical tensions' which he sets forth, not as a prescriptive plan, but as a beginning point:

The space should be bounded and open.

The space should be hospitable and 'charged.'

The space should invite the voice of the individual and the voice of the group.

The space should honor the 'little' stories of the students and the 'big' stories of the disciplines and tradition.

The space should support solitude and surround it with the resources of the community.

The space should welcome both silence and speech.

Within these tensions of opposites, there is room to explore possibilities for the role of the teacher and student. But, looking back to the purpose of education and epistemological 
assumptions of mind, the classroom should carry the same 'message' and ideals in such a way as to present itself as a learning laboratory where 'ideals' come to fruition, which makes the role of the teacher especially important as they, first and foremost, determine the conditions for learning. George Leonard (1968/1987) asserts, "All environment has the capacity to educate." William Ayers (2001) claims, for instance, if the purpose of education is for students to experiment and explore, then the, "space...should say come 'Explore! Experiment! Correct! Re-correct!'" John P. Miller (2000) in Education and the Soul discusses the idea of a soulful environment that feels like a sanctuary, if nurturing the child's spirituality is central, "This environment is one of respect, caring, and even reverence. People in the soulful school feel validated as human beings and can speak authentically from their hearts. Love predominates rather than fear...Most of all, there is a deep sense of community." Progressive educator, John Dewey, believed schools to be the first introduction to democratic life and therefore, should be a "community where all members have responsibilities and obligations to the whole...it is a place where the child's own curiosity leads to active engagement with learning problems and to the challenge to solve them him or herself...schools are miniature societies (cited in Joseph, et.al., 2000). Furthermore, Bernice Wolfson (1977) indicates, "...I believe that a rich environment (varied and plentiful) is better for learning than a meager environment. But the kinds of materials in the environment are a reflection of the values and expectations of the designers (teacher, principal, central office staff, Board of Education)."

The design of the post-modern classroom is different, yet strangely familiar. At the turn of the $21^{\text {st }}$ century, public schools still primarily revolve around a 9 a.m. to 3 p.m. general schedule with the exception that high school students can be 'released' to work in the community where they receive course credit through 'school-to-work' programs, attend 
vocational training schools for a portion of the day, or fulfill volunteer hours. In 2003, the state of Colorado instituted a 4-day school week in about one-third of its school districts where the day was extended to 7.5 hours per day for 144 days per year -- roughly equivalent to the number of hours of a 180 day school-year at 6 hours per day (Colorado Department of Education, 2003).

Across the country, there is great variety in the school day schedule. Some school districts choose block-scheduling (one class or block is 75-90 minutes) and then, alternative "A-B" days ensure students are enrolled in the appropriate number of hours for graduation requirements. There is also grade 'looping' seem primarily at the elementary grade level which entails children remaining with the same teacher for 2-3 years while grouped with children of other grade levels, such as, "K-1" or "1-2" grade levels. Still yet, some high schools remain on a 7 or 8 period day.

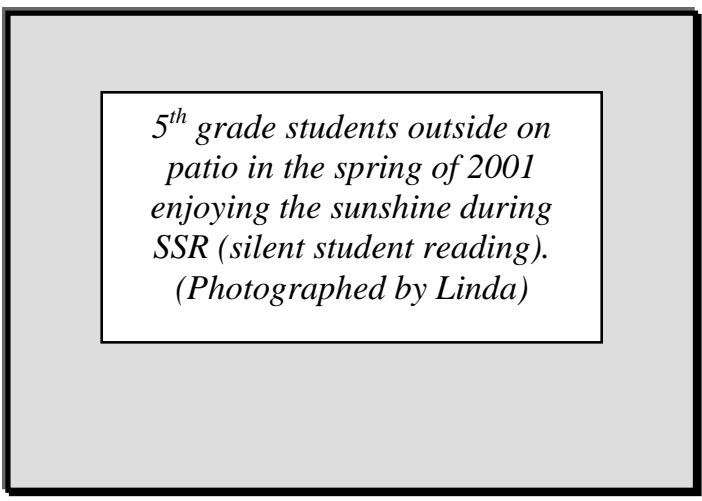

Many schools built in the early $20^{\text {th }}$ century still house today's children and districts make necessary renovations but, in these instances, the school's infrastructure maintains isolated classrooms. Growing populations have made it necessary for school districts to build new community schools and depending upon the tax base subsidies, students and teachers are privileged (or not privileged) to technological innovations in the classrooms, updated library systems, Internet access, playground and other recreational equipment, school gardens, open areas with comfortable seating and natural lighting, having access to the outdoors for natural classrooms, etc. But, it goes without saying that communities that are economically advantaged, enjoy the 'perks' and employ teachers at higher salaries, 
whereas, schools in economically disadvantaged areas, cannot afford to keep up with technology, and offer lower salaries. In instances where schools cannot afford to build new schools, schools districts opt to 'add on' wings or in other occasions, attach a mobile home like structure on the school grounds. Where, at other times, the decision to consolidate small schools into a larger school is enforced.

The direction of the classroom falls under the supervision of the teacher where, in general, female teachers dominate the elementary grades and at the secondary level, there is a combination of males and females. The students who make up the student populations now include many students with special needs, following the passage of PL 94-142 and other subsequently passed legislative acts. In the past, children with special needs were segregated from their peers in separate quarters of the school building, but it is now the norm for teachers to have inclusive classrooms. Recognizing the need for special learning accommodations for students with special needs, most classroom teachers are joined by a teacher's aide who actively works side-by-side with these learners. The number of students in any single class could range from 20-35 and at times, when classrooms are large, open spaces (one term that comes to mind here is 'pods') as many as 100 students in four 'separate' quadrants are contained in one area.

As much as teachers direct the activities within the classroom, as well as, discipline students, often collectively the students and teacher devise a set of classroom rules and a set of consequences, which tend to promote an atmosphere of democracy and more importantly, offer students an acknowledgment of 'voice' in classroom matters (Greene, 1978).

At elementary level, there is a tendency to make surroundings feel more like 'home,' whether that entails arranging 'quiet' and/or silent areas with floor rugs with pillows and big bean bag chairs or arranging desks and/or tables into places where students come around 'one 
table,' the classroom set up must somehow negotiate the actual learning of students and create a sense of belonging. In either case, students are provided with spaces for private thoughts and public interaction. Colorful surroundings add to the interior design scheme with student work

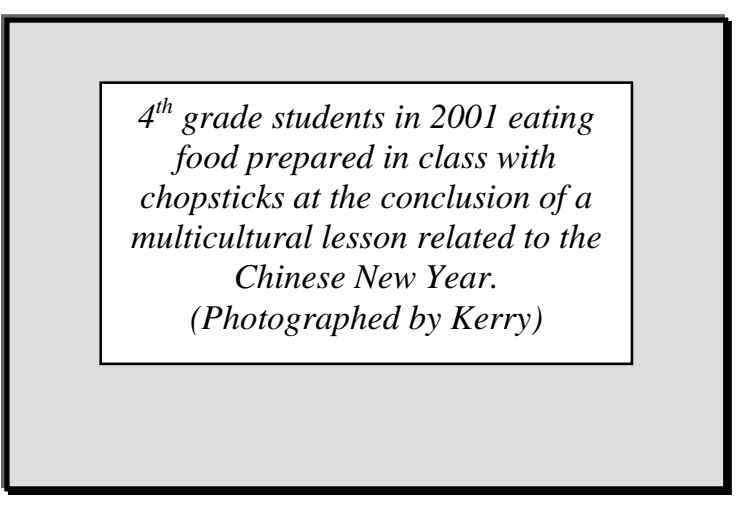

decorating the walls, mobiles hanging from ceilings, plants and 'growing' science experiments sit on window sills, and class pets are caged (or rolling around the floor in an exercise ball), all of which suggest the ideal of building a sense of pride and responsibility is important in building student character. Incorporation of multicultural artifacts displayed on bulletin boards complement like units of study complete with food and song to give students a taste of the nation's ethnic and racial diversity. Holidays that are typically recognized are Black History month, Chinese New Year, and, Cinco de Mayo (McCaleb, 1994).

The structural 'openness' and feel of the classroom also translates into the kind of interaction that takes place between students and students-to-teacher. Patrick Slattery and Dana Rapp (2003) write about the student and the mood in post-modern environment, "...the human condition and the cosmos are irreducible and irrevocably pluralistic, existing in a multitude of sovereign units and site of authority, with no horizontal or vertical order either in actuality or in potency. In this environment, knowledge and truth are contested, constructed, tentative, and emerging."

When opportunities present itself, field trips take students even closer to the 'subject' studied and provide them with live encounters of their interests (Greene, 1978). Other live encounters with subjects also entail parents and community members coming into the school 
and sharing personal experiences and ideas. The classroom "moves out of the school and brings the outside world in" providing shared experiences for teachers and students, making them colearners (Wolfson, 1977).

Learning communities is another novel concept related to the notion of democratic classrooms. Learning communities stem from a sociocultural approach to learning and development that emphasizes teachers and students take shared responsibility and management in the learning process (Matusov, 2001). Edward Clark (1997) and Sudia Paloma McCaleb (1994) both agree that learning communities are not natural fixtures in the schools and must be nurtured. Clark characterizes learning communities as interdependent environments; supports individual's self worth; reflects the interests and capabilities of students; is cooperative and synergistic; expands out beyond the four walls of the common classroom design; is consistent and responsive; utilizes 'appropriate feedback and assessment'; and, has a shared purpose. McCaleb will build the concept of learning communities by initiating communication and involvement in shared projects and vision with parents, children, and schools. They are places that are community-based, neighborhood-oriented, and cultural centers, which contributes to a sense of place. Both authors cite examples where they believe learning communities were born within individual classroom structures and later, gave rise to the larger school as learning communities. In St. Paul, Minnesota, there are four 'open' schools that come under the name of community learning centers, utilizing many of the same methods common to the Foxfire project, and accepts children ages 6-18, but does not have specific grade levels of study, nor are bells used to structure the activities of the day (Miller, 2000).

Since the 50 years since the Brown vs. Board of Education of Topeka Supreme Court decision, schools have tended to remain segregated essentially due to busing policies and lack 
of funding and in schools that have diverse populations, students tend to 'self-segregate,' which is witnessed through lunchroom observations. In Brian Willoughby's (2004) recently published article in Teaching Tolerance, entitled, "An American Legacy," he writes about the present state of education for people of color:

By the opening of the $21^{\text {st }}$ century, the nations most segregated public schools were not found in the South but in Illinois, New York, and New Jersey. There, and in other areas across the country, black and Latino students live in segregated, urban neighborhoods and attend overcrowded, under-funded, lowachieving schools, while most of their white counterparts attend, affluent, nearly all-white schools in suburban America. Separate and unequal continues: More than 80 percent of black and Latino segregated schools are in high poverty areas, compared with 5 percent of segregated white schools.

In an article by the same name, I wonder, "Where are we now?" which raises questions about the acceptance of desegregation/integration of schools (Orfield \& Frankenberg, 2004). The article points out that most Americans believe that "integration has improved the quality of education for both Blacks and Whites. This does not mean that most Americans do not also prefer neighborhood schools -- they do -- but it makes clear that most people would like integrated schools if they didn't have to do anything in order to get them."

Group photo of Tina, 'the professor,' with first class of college students during the fall 2001 semester. (Photographed by undisclosed source)
For the past 12 years, I have been in the classroom in some capacity, as either student teacher, teacher, graduate teaching assistant, and more recently, professor and during this time, have been exposed to different teaching 
philosophies from mentor and cooperating teachers. My classrooms were at one time very structured -- desks in straight rows -- with an occasional activity where students needed to work in groups or get up and move around to stations; for the most part, students remained seated, and I knew, in my heart, bored. But, there is one aspect that has remained constant in my teaching philosophy -- students need to talk, communicate, laugh, and, share. Students not talking, are not learning, whether it be the course information or from one another. It is natural for most people when gathered at an event to talk and converse, and I reject the notion that learning is incumbent upon silence. Quoting Martin Buber, "All real living is meeting," and I will personally extend that by adding, "All real learning is in living and meeting" (Buber, 1970).

Today in my college classes, we sit in a large circle. I like to call it the 'wisdom circle' or 'community circle', which has its roots in Native American traditions where elders came to sit and discuss important tribal matters. We sit in the circle to meet in communion with one another to discuss important issues in life, which cannot be separated from the life of the classroom. From the opening pages of a book of the same title, Wisdom Circles, there is a brief explanation, "That strength which sustains and renews each one of us also sustains and renews our communities, our organizations, our environment, the Earth. Gathering in wisdom circles enables us to move deeply into ourselves, into that core which continues to survive, hope, dream, and carry on" (Garfield, Spring, \& Cahill, 1998). When students are 'outside' the circle, I say, "C'mon on in and join us in the circle," and in doing so, I hope that they feel renewed. The circle is a sign of strength, longevity, and life's transits and cycles, and in my class wisdom circles, time and space is sacred. My hope is to promote a feeling of equity through the 
structure of the circle, but I know not everyone comes to class willing to listen equally to the other.

\section{Meaningful Experiences}

Meaningful experiences cannot be defined nor determined until students, communities, and teachers begin asking questions about what is worth knowing, worth sharing, and, worth experiencing, a similar sentiment shared by William Schubert (1995) when he explored the possibilities of coherent curriculum. But if lives worth knowing, worth sharing, and worth experiencing are somehow inexorably tied into the vision for the purpose of education in the post-modern era, meaningful classroom experiences are not based on the same characteristics associated with 'cult of social efficiency' of earlier years, that is, skills/tasks, proficiencies, timeliness, neatness, accuracy, etc. Indeed, these may be considered meaningful to teachers and administrators, but to the students, these are meaningless until the usefulness of these characteristics are connected into students lives. (Although the passage of NCLB has greatly impacted classrooms practices where teachers are expected in even greater detail to determine student achievement, which has led to some question if the rigor of present demands is greater than that of years ago due to necessary federal accountability requirements). But, what seems to be happening is that as demands upon teacher and student attempt to pull them away from the human interests of heart, there is resistance and struggle to retain and regain identity and meaning, since humans by nature are destined to make meaning. "Humans construct meaning as spiders make webs...this is how we survive, our primary evolutionary business," asserts anthropologist, Mary Catherine Bateson (1994). Meaningful experiences in the classroom have to do with significance, purpose, and intention for students, but can also evoke and support the same qualities in the teacher. As long as teachers and administrators pre-define and pre- 
determine the experiences within the classroom, students will continue to ask the perennial questions of 'what's this have to do with anything' or 'why do I have to know this?' and fail to comprehend the usefulness of their education. This is of concern because a survey from 2000 reports students have a dwindling interest in school and fail to see schoolwork and homework as meaningful, which is a significant drop in comparison to similar results 30 years ago (Scherer, 2002). Paying attention to autobiographical and phenomenological experiences is what Patrick Slattery (1995) in Curriculum Development in the Post-Modern Era supports as the way to bring back meaning thereby allowing students to connect and contextually interpret the events in their lives. In this, students recover intentionality and one's own history through lifting the veil of the past to expose the present context of their lives (Grumet, 1989).

Educator and philosopher, Philip Phenix (1964) in Realms of Meaning asserts that humans search for meaning, "a human being is in essence a creature who creates, discovers, enjoys, and acts on meanings" and further expands upon the kinds of meanings humans are engaged in -- symbolic, empirical, esthetic, synnoetic, ethical, and synoptic. Phenix further subdivides each realm of meaning to include the following areas: symbolic realms take the shape of language, speech, and other bodily gestures; empirical realms consist of mathematics, science, psychology and social science; esthetic realms include music, visual arts, movement, and, literature; synnoetic realms embody personal knowledge; ethical realms encompass moral knowledge; and, synoptic realms consist of history, religion, and philosophy. For humans to realize essential humanness, all areas must be "required if a person is to achieve the highest excellence in anything at all."

Meaningful classroom experiences can be related to meaningful knowledge or contextual

$5^{\text {th }}$ grade student in 2001 dressed up as pop diva, Britney Spears, as part of a language arts lesson.

(Photographed by Linda) 
knowledge, which entails students creating tasks they see as related to learning about things that have personal connection. One of the key components to meaningful classroom experiences are opportunities for choice and choice based on interests, "It begins with interests and concerns of students that grow out of their lives, and because it draws upon existing knowledge to illuminate those interests, it connects life with learning" (Schubert, 1995). Therefore, rather than the teacher deciding what is worth learning and knowing, which might be evidenced in behavioral objectives, meaning is self-defined as students search for their own meaning through interaction with the self and others. This could include encounters with parents, friends, community, and environment or relating personal experience they have related to the subject. In these instances, meaningful experiences are determined by discovering one's role while working as a member of a group, being self-directed, understanding the purpose of a task, being challenged despite fears of failure, receiving affirmation of acceptance, looking to the complex whole to ascertain if 'this is right or wrong,' and sharing knowledge of the experience with others (Collazos, Guerrero, \& Pino, 2003; Tomlinson, 2002). In these instances, 'thinking about thinking' and being aware of one's thinking plays an important role. Similarly, Don Trent Jacobs (2002) writes, "children who practice meta-cognition begin to know themselves in ways that allow for consistent application of spiritual values in any setting. This self awareness brings a degree of individual freedom which alone can bring true cooperation with others, with the whole." Additionally, accomplishments and assessments are judged, not against the class norm, but in introspective processes to study changes in personal understandings.

In The Soul of Education, Rachael Kessler (2000) claims that education has neglected a profoundly huge part of a student's being, the soul or the inner life, in these turbulent times. 
Kessler draws connections to drug usage, school violence, youth suicide, and eating and mental disorders as signs of 'soul-less' times and, furthermore, adds that perhaps it has something to do with the overemphasis of materialistic conceptions of life. Consider the following words penned by a classmate of the gunmen at Columbine High School following that tragic incident in 1998, as a testament to pay attention to students inner lives (cited in Miller, 2002): The paradox of our time in history is that we have taller buildings but shorter tempers; wider freeways but narrower viewpoints; we spend more but have less; we buy more but enjoy it less. We have bigger houses and smaller families; more conveniences but less time; we have more degrees but less sense; more knowledge but less judgment; more experts but more problems; more medicine but less wellness. We have multiplied our possessions but reduced our values. We talk too much, love too seldom, and hate too often. We've learned how to make a living but not a life; we've added years to life, not life to years. We've been all way to the moon and back but have troubled crossing the street to meet the new neighbor. We've conquered outer space but not inner space; we've cleaned up the air but polluted the soul; we've split the atom but not our prejudice. We have higher incomes but lower morals; we've become long on quantity but short on quality. These are times of world peace but domestic warfare; more leisure but less fun; more kinds of food but less nutrition. These are days of two incomes but more divorce; of fancier houses but broken homes. It is time when there is much in the show window and nothing in the stockroom; a time when technology can bring this letter to you, and a time when you can choose either to make a difference....or just hit delete. 
How might teachers begin to pay attention to soul in the classroom? What might it 'look' or 'feel' like? Kessler posits that when 'soul' is present in the classroom, the quality of attention shifts from a 'non-caring' to 'caring' because anytime soul is present, students intuitively understand, they are more important than the subject matter, and it follows that students do better in school, that is, if teachers care to listen. Likewise, she relies on the ideas framed by Howard Gardner and Daniel Goleman to legitimize her work. Ways that she 'introduces' soul into the classroom is through asking students to participate in activities and questions that revolve around matters of the inner life: silence and stillness, meaning and purpose, joy and delight, creativity, transcendence, and initiation. In these methods, students take serious journeys into and within self-knowledge, or spiritual stirrings, and return from a state of slumber to fully engage in the world (Tacey, 2002). Meaningful classroom experiences can occur when teachers listen and respect students; acknowledge the inner life of students; and provide reflective opportunities for them to relate to life, loss, meaning, and purpose (Kessler, 2002).

Progressive educator, John Dewey, often asked whether education is a function of society or is society a function of education? Dewey would optimistically reply the latter but the actual reality of this, is that for too long education has replicated and supported the status quo, rather than exposing injustices and the '-isms' in society such as racism, sexism, economic disparity, and environmental degradation (Slattery \& Rapp, 2003). Peter McLaren (1997) contends that "schooling has the responsibility to participate in the quest for critical voice, social justice, and individual transformation." I personally believe that schools can serve as the greatest source of change to reconstruct or transform society, much in the same way that George Counts spoke of in his short publication, Dare the Schools Build a New Social Order 
(1932). Students searching for 'voice' and concerned about social justices issues engage in dialogue about marginally oppressed groups, political and social inequities, technological vulnerabilities, the nuclear arms race, environmental degradation, and, the breakdown of community, which incidentally is the main theme of Robert D. Putnam's book, Bowling Alone (2000). But, dialogue does not stop in the classroom and students pursue emancipatory efforts to (re)construct and transform the classroom and society, where at some point, they discern the 'false consciousness' of their existence (Clark, 1997; cited in Ayers, 1996). Maxine Greene will ask whether the process of education makes us free or 'un-free', which is addressed in a classroom discussion chronicled by then student, William Ayers. Ayers (1996) writes about a classroom experience he had as a student with Maxine Greene in Teachers and Mentors that he referred to as a 'call to arms' to young radicals. He notes of Greene’s lecture in class, "We must -- each of us -- shed our privilege, reject our false consciousness, reinvent ourselves in complete opposition to war and racism and oppression. We must, if we are to live at all, live our lives as self-determined, rebellious, and free." Ayers responds with, "I was captivated."

In McCaleb's (1994) Building Communities of Learner's, she paraphrases Freire's notion of dialogue, "When the two 'poles' of dialogues are thus linked by love, hope, and mutual trust, they can join in critical search for something. Only dialogue truly communicates." bell hooks in Teaching to Transgress (1994) explains that student 'voice' is not just articulating one's thoughts about a matter, because rarely does language convey to the hearer the meanings the speaker intends, but about hearing, really hearing the Other's story, and coming to terms and grappling with one's own identity within political and social constructs:

...they learned that 'to hear' each other (the sound of different voices), to listen to one another, is an exercise in recognition. It also ensures that no student remains 
invisible. I wanted all of my students to become visible, to engage in tough but rewarding work of making articulations of personal experience and societal operation....coming to voice is not just the act of telling one's experience. It is using that telling strategically -- to come to voice so that you can also speak freely about other subjects.

What might be the purpose of dialogue? Of listening? In deconstructing the barriers and judgments that have led humans to view themselves as separate from one another or separate from the earth, it is hoped that students gain relational understandings to others, new found respect, greater tolerance, deeper caring, a sympathetic and compassionate attitude, and have an understanding for the invisible structures that have led to division, that is, if we are to become a more compassionate society. Existentialist Martin Buber (1970) describes a type of human relationship when persons are concerned for others and their well-being, that does not impose upon their freedoms, in holy terms, "I-thou." It is my belief that this concept embodies the type of relationship we should seek to have with others and with the earth if we are to embrace the god within, a sentiment expressed by Rene Dubos (1972) in a book of the same title.

As students find meaning through freedom and fairness in education as in life, and attempt to break free of institutional bondage, they must be free to question inequities and critically reflect on the human conditions created by the social structures of reality if they are to become individuals, not just of knowledge, but of vision. In summary, meaningful classroom experiences take into consideration the whole child -- body, mind, and spirit; is attentive to forms of meaning expressed in language and thought; is sensitive to the cultural and social experiences that contribute to knowledge formation; recognizes the inner life of students; provides opportunities and shared experiences where students can talk through and pursue 
efforts to transform societal injustices; and build and collaborate in classrooms that promote a sense of community. It is perhaps in this discussion on meaning where there is also a link to those situations that are valued or the need to 'feel' human in the classroom, in other words, to be looked upon as more than just a student sitting at a desk with minimal needs.

As a teacher, some of my most profound and meaningful moments in the classroom have come at 'unplanned' moments but, by the same token, have created lasting memories. The meanings attached to the memories are sometimes positive and sometimes negative, and inevitably, make me aware of my strengths and weaknesses as a person and as a teacher. This is the paradox in what we do -- neither would be complete without the other nor completely understood without reference to the other. In moments of prolonged silence, I am reminded that students do not want to engage in the subjects I love so dearly, or join me in 'dance', or worse yet, make me so uncomfortable that I make small talk to fill the room with something other than silence. There have been other times that I am abruptly reminded that students who receive good grades are not necessarily moral individuals, poison the atmosphere of the classroom, and challenge me to re-think my career as a teacher. Then, there are moments when I am honored to be a teacher. While few in number, these moments outweigh the negative and redeem my choice of career paths.

On the following pages, I am sharing personal artifacts that not only have meaning to me, but also give clues to the meaningful aspects of student's educational experiences. A brief explanatory piece accompanies each artifact to give contextual clues to their meaning.

Artifact \#1: A holiday card from a student and her husband Artifact \#2: An article from a college newspaper Artifact \#3: An excerpt from a student’s class reflection (a course assignment) 


\section{Artifact \#1}

\section{A holiday card from a student and her husband}

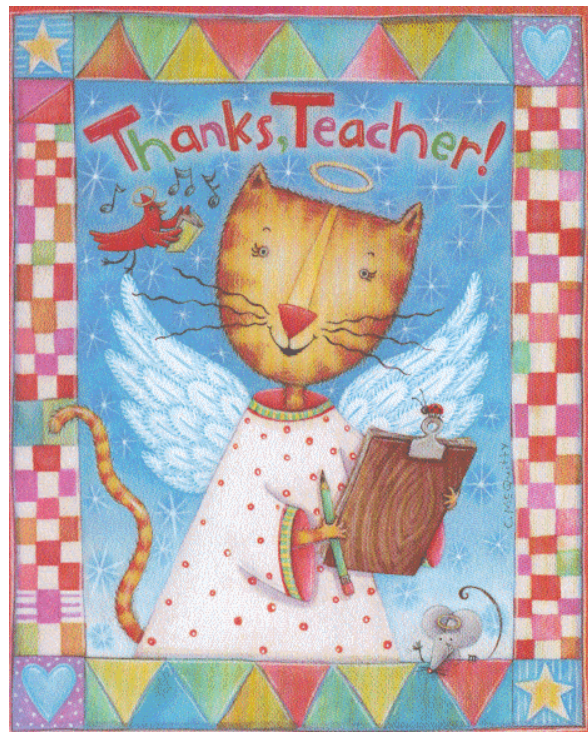

(Outside of card)

\section{Explanation:}

This card was given to me following

an exceptionally difficult semester, one

in which I doubted my abilities as a

teacher and advisor. I considered

leaving the teaching profession. This

is especially meaningful to me as I felt

my personal struggles affected the

classroom atmosphere. This card

reassured me that I retained my

professionalism even though I may not

have personally felt that way.

\author{
Oou deserve a lot of extra credit \\ for being such a great teacher!
}

Hope youp holidays ape terpific!

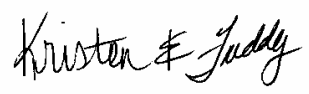

(Inside message of card)

Dear Kátina,

Thank you so much for all your help this semestor land all the other semesters). I would be lost without your advisement and gridance. My day 's always brightered with your smile and enthusiasm. Thank you! I hope your holidays are filled with joy-see you rext semester.

(A handwritten message of thanks) 


\section{Artifact \#2}

\section{An article from a college newspaper}

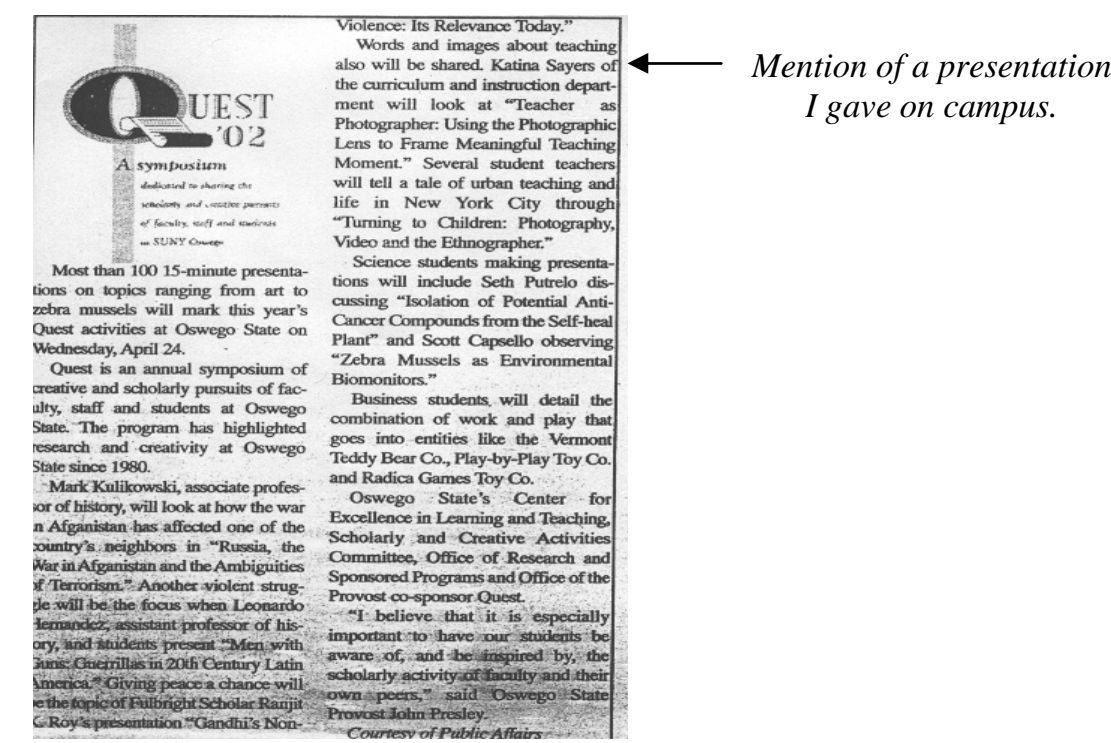

\section{Explanation:}

This article from a college newspaper highlights an on campus conference day where students and faculty present current research interests. I was especially proud of this, as, at that time, I was a fairly new faculty member. My research interests have rarely fit into the mainstream, which has been a negative and a positive, but in either case, often leaves me with anxiety and uncertainty. My research provides an outlet for my creativity and what is often seen as creative, is not seen as 'real' research. In addition, as the clipping states, there were over a 100 presenters in the conference and I felt honored to be mentioned in this write up as a junior faculty member. 


\section{Artifact \#3}

\section{An excerpt from a student's class reflection}

**In this excerpt, the student refers to readings from two assigned texts - "Tuesdays with Morrie” by Mitch Albom and "Let your Life Speak" by Parker Palmer

The closing chapters of Morrie was extremely powerful. I enjoyed reading the book; the themes that Albom covered looked at real questions and struggles that many people face in their lives. Mitch and Morrie’s story made me evaluate my own life and analyze the way that I live. A book that makes you look at yourself and question the choice that you have made and are making is definitely worth reading.

Your portfolio class set a good example for me. When I say example I mean model. This semester I learned that teaching is about helping students develop not only academically but also personally. Tying the two novels into your class was genius and made the experience a thousand times more beneficial for me. I plan to take the lessons that I have learned from your class and apply them to my own classroom.

I know that when I begin teaching I will make many mistakes and I also know that it is these same mistakes that will allow me to grow professionally and personally. Throughout my undergraduate and graduate work, I have paid attention to the various teaching styles of my teachers; I find it interesting to examine why students favor some teachers over others. Why are some teachers better or more remembered by their students than others? Is it a certain charisma, style that they encompass, or is it the way that they have made their students feel, grow and learn? I believe that it is a little of all of the above that makes a teacher a great one. I think that having made this fact known to myself will help me tremendously as far as awareness when I enter my classroom. I know that I will have my own style, apart from any teacher that I have had, but I plan to incorporate a little piece of all of those 'good' teachers into my own personal style. 
If you would have conducted your class with just assigning a portfolio and not adding in the extra trimmings, then I think that our portfolios would have reflected and been lacking in the area of “personality.” Let me clarify: without the intimateness that you incorporated into our class, many of our portfolios would have been dull, by the book models and not personal reflections of ourselves. From reading the novels I have grown personally. This personal growth has made my portfolio so much stronger. My reflection pieces, my theme, my classroom philosophy, etc., all of these artifacts are a lot more developed having read and discussed the novels in class.

I want to end my final reflection by telling you that your class has been awesome. I feel like I have learned so much, but in a way that I have not learned in any other class. Your class has had this weird way of teaching me things, personal things, without causing grueling stress through tests, projects, or papers. It is hard to explain obviously, but I just wanted you to know that you have done a great job this semester and have taught me about and made me consider a whole new side to the teaching profession.

(Student Reflection, written fall 2003 semester)

Explanation: It would be difficult to know what my students are learning as I am teaching. In fact, many students never know what it is that they learn, until years later. This personal reflection is meaningful to me for several reasons. Aside from the obvious complimentary aspects, which I am grateful for, this student was exceptionally quiet in class and it was difficult for me to ascertain where the student stood on particular issues. However, what is mentioned is the perceived 'feel' of the classroom that allows the student to feel safe in sharing these thoughts with me and furthermore, she understood the connection between the books and the process of portfolio development. This was never stated in class and I believe underscores the student's ability to make connections. 


\section{Teaching and Learning}

This final section of the chapter reviews general understandings about teaching and learning in the post-modern era with much of the discussion linking back to the discussion on epistemological assumptions of mind and meaningful moments. Relying upon constructivism as the main epistemological model and the need to find personal meaning in the events of the classroom, teaching and learning in the post-modern era is about providing experiences and opportunities for students and teachers to 'enter' into meaning.

General understandings about teaching and learning in the post-modern era do away with the structural hierarchy of the classroom from the modern era. Teacher and students enter into experiences and relationships as co-learners or equal partners in the process, and the teacher 'refuses' the role of the expert, acknowledging that collectively the class can offer much more to one another than the teacher could alone. Two metaphors which conceptually describe the roles of teachers in the post-modern era are 'sheep dog' and 'gardener.' The role of the sheep dog is to keep a watchful eye over the flock (or herd) as they spread out and roam about within a designated setting. The sheep dog will scout out the setting to ensure the safety and freedom of the herd. Even though the setting has been carefully chosen, in the event that members of the herd stray too far from the others, the sheep dog is alerted and makes its way out to the member to slowly guide and nudge them back to safer territory (Palmer, 1998). Teaching in this sense is much like that of a project director or travel agent, 'you tell me where you want to go and I'll do my best to help you get there.' Roles and responsibilities are set out before individual members and they are given the freedom to explore within a safe set of boundaries.

In the gardener metaphor, the role of the teacher is to nurture and sustain life that comes from the earth. Katherine Kersey (1983) paints the picture better, "Our job, like the gardener's, 
is to meet their needs as best we can: to give proper nourishment, love, attention, and caring, and to hope for the best. The gardener learns to be 'tuned into' the plant." Likewise, the gardener is also aware of the interconnectedness of his/her actions with the plant, and must know a little bit about the soil and climate, as well -- if plants are pulled too soon, the roots will fail to secure themselves into the earth; if the ground is flooded with water, the plant will drown; if too much topsoil is piled on the plant, it will suffocate. If the plant receives too much sun, it will wilt. If not given room to spread its roots, it will get root logged. At the regret of many, there are times when plants do not survive regardless of the gardener's effort. The gardener will want to blame himself/herself in nihilistic ways but, the amount of effort is not always a measurement of the outcome. In many ways, the role of the teacher is to understand that children hold unique talents or potentialities, and need to provide the learning environments and moments to help bring forth the not-yet-developed 'embryonic' structures of a system (Doll, 1993). In the words of Maxine Greene (cited in Ayers, 1996),

"Teaching...involves a sense of the possible, of seeing alternatives, of opening new landscapes."

One final metaphor for teaching and learning which I wish to develop here is based on the Madelbrot set where teaching and learning is consistent with the systems view. The language of this metaphor depicts teaching and learning as "a dance on the edge of chaos" where patterns emerge, disappear, and re-emerge in the classroom, with each movement interconnected and related to the whole (Fleener, 2002). In Curriculum Dynamics, Jayne Fleener (2002, p. 167) offers a rich description of the interconnectedness of the parts or 'bulbs' that make up the whole: 
As we move around the edges of the Mandelbrot set, we see infinite complexity, while at the same time common patterns and relationships continue to appear....This type of 'depth' offers the right amount of indeterminacy, anomaly, inefficiency, chaos, disequlibrium, dissipation, lived experience....Beneath what appears to be chaos are underlying orders that seem to re-emerge just as we thought we were in unknown territories. This kind of complexity is more suggestive of the interconnectedness and depth associated with relational meanings...

The 'dance on the edge of chaos' takes place at the point of intersection between the student, teacher, and subject matter. Patterns emerge where teachers and students are partners; both teacher and students question the inequities in education and in society, and enter into dialogue, understanding that in the beginning stages discussion can be messy and uncertain, even though, traditionally, uncertainty is not something that is typically rewarded in the classroom. Rather than relationships formed on the premise that one's knowledge is better than another's, constructivist views support the idea that knowledge is symbolic of experiences. For the teacher, this is significant because "our concept of knowledge also defines our concept of the learner, of the person we are educating" (Nava, 2001). I am inclined to add that it also affects the teacher's held assumptions and perceptions about their role as a teacher. In this scenario, the student and teacher hold equal status where it is hoped that caring and mentoring relationships are formed between student-to-teacher and student-to-student where at times, even children are mentors to teachers.

A teachers' daily preparation and planning still is in the form of a lesson plan, nearly identical to that of 50 years ago, but there is greater attention paid to turning over the 
responsibility of learning to the learner, taking into consideration the autobiographical and phenomenological aspects of a student's life. Patrick Slattery and Dana Rupp (2003) offer a personal account from one of their classrooms about a skeptical in-service teacher that doubted post-modern notions of teaching and learning, who takes a 'leap of faith' to put her students in charge of their learning. In the following account, the in-service teacher begins a new unit and voices her thoughts about the process:

Today we begin our next unit in social studies. Our topic is deserts....I do not know very much about deserts. I have never been to a desert. We are going to have to figure out how to learn about deserts together.' Immediately, one student raised his hand, 'I went to a desert in California last summer.' He described his trip enthusiastically, but he struggled to remember the name of the desert. Another student suggested they look at a map and find its name. The class moved to the map. Another student pointed to Africa and said that her father once went hunting on a safari. 'What's a safari?' another student asked....Over the next few days, students decided to divide themselves into groups to investigate deserts of the world....she had never seen such enthusiasm for a unit of study in her entire career. (p. 112-113)

In the preceding narrative, teaching and learning in the post-modern classroom can be interdisciplinary or thematic -- history can be studied with geography, life science with lifestyles, literature with geography, etc. Subjects are not studied in isolation or in a linear fashion because life events do not occur in isolation nor appear as occurring out of context of other events. But, what does appear as a recurring theme in the literature is the inclusion of arts, nature, and literature as subjects that 'invite' interpretative experiences, that is, these subjects 
are conceptually 'open.’ Likewise, this necessitates having an 'open' teacher -- one who is willing to teach with and work through and with open concepts. It is not to say here that every child will have artistic talent or appreciate a 'good' piece of classic literature but what it does consider is that an encounter with art, nature, or literature "can bring human beings in touch with themselves" through reflective processes or what Maxine Greene (1978) more specifically calls as bringing "wide awakenness." These open subjects have the ability to awaken the inner landscapes of the student where perceptual differences shed light on the understandings and emotions associated events and objects. This perceptual process includes mental picturemaking activities, as well (Sloan, 1983). Dewey (1935) writes in Art as Experience, "Emotions are attached to events and objects...emotion belongs of a certainty to the self. But, it belongs to the self that is concerned in the movement of events toward an issue that is desired or disliked." The inclusion of arts in the classroom takes many forms -- dance, drawing, painting, performing, handcrafts, pottery, music, etc. -- all forms of 'doing' and 'thinking' but, referring back to Dewey (1935) to support the inclusion of the arts as a method to find meaning:

The process of art in production is related to the esthetic in perception organically...Until the artist is satisfied in perception with what he is doing, he continues shaping and reshaping. The making comes to an end when its result is experienced as good -- and that experience comes not by mere intellectual and outside judgment but in direct perception. (p. 46-57)

Similarly, Douglas Sloan (1983) also calls the arts a 'doing-knowing' combination and further comments on participative knowing, "...this participative doing-knowing of will-activity is taken up and guided by feeling-perception, and finds expression in the creation of meaningful 
patterns, forms, and images. And, finally, all of the arts require a joining of skills, form, and individual style in one interrelated, unbroken whole."

Nature is another subject common to post-modern teaching and learning. Native American cultures have traditionally had tacit knowledge of the importance of the earth to human survival. For Native American cultures, nature provides the mysteries of life where a spiritual life is analogous with learning. Don Trent Jacobs (2002, p. 17) offers this account of the spiritual life, learning, and nature:

To be spiritual is to learn about the significance of things, seeking deeper and deeper levels of meaningfulness in all that we do, see, and create. Finding meaning in such things as childbirth, the spawning of salmon, the sound of thunder, the joy of love, or the pain of injury calls for a very personal approach to learning....Defining spirituality as that which is significant in the most sacred sense means realizing truth about our relationship to Nature. We see ourself as a part of Nature and see Nature as a part of us. Through deep concentration, meditation, ritual, observation, art, music, and stories, we can achieve an appreciation of the great complexities of Nature...This leads to a sense of oneness with rather than separation from the source of life that is Nature....Infusing the Nature connection back into our classrooms can reconnect us with Spirit and with the wisdom of our indigenous ancestors....we know that Nature as a teacher is a factor in why wilderness treatment programs for troubled youth tend to succeed, why pristine wilderness vacations can renew your spirit.... 
Incorporating nature into teaching can take

many forms -- field trips, nature walks where

students are young naturalists observing and

recording sights, smells, and sounds, caring for

school gardens, or holding class outside -- each

having the potential to create a felt relationship to

the earth where things and events can be looked at

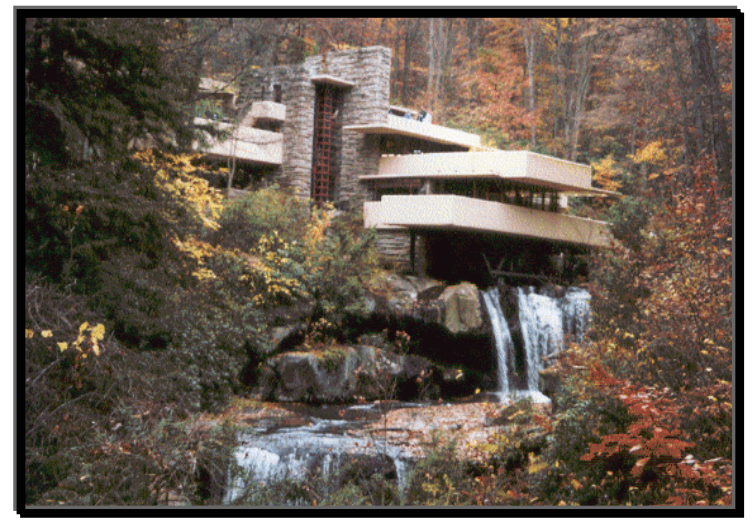

At the end of a unit on leaves, a fall field trip is taken to one of Frank Lloyd Wright's homes, Falling Waters, by elementary school students in 2001. in conjunction to larger patterns and relationships.

In terms of literature connections, multiple opportunities for creative expression of thoughts can take the shape of myths, fairy tales, poetry/creative writing, and storytelling, and can honor individual and group voices, as well as, hint to moral lessons and the practical wisdom of ancestors (Miller, 2000). Bringing in popular media and critiquing the hidden messages behind the words and images is a way to bring attention to social mores and values that are found in images.

The question of whether children are open to 'wide-awakenness' is disputable especially when the confines associated with NCLB tends to be antithetical to meaning making; however, there are ways to cover the standards, as well as, pay tribute to the inner lives of students. Liberating and emancipating teaching depends upon curiosity and questioning the 'what' and 'why' of life. For instance, a question posed as, "In the developing fetus, why do some cells turn into lung cells, others into eyes, and still yet, others into fingers and toes? More provocative questions can direct discussions on moral and ethical dilemmas, and lead to even more intriguing questions about human existence (Simon, 2002). In "The Blue Blood is Bad, Right?," 
Katherine Simon (2002) offers some of the following examples of how moral and existential questions can be built into units on literature, social studies, and science classes:

What, if anything, constitutes a just war?

How should a society distribute its wealth?

What is the impact of particular technological innovations on the environment?

What forces gives rise to cruelty among human beings?

What does it mean to be a 'good' human being?

How does human life differ from other kinds of life on earth?

What typically is the result of such questions are discussions, and additional questioning and 'problematizing' of about the purpose of life (assuming that there is a question and problem) and the perceptual structures that define existence where connections are drawn to the economic, social, and political organizations. In addition, I especially like these types of questions for their ability to invoke 'thinking' and 'feeling.' William Schubert (1993) in Towards Lives Worth Sharing makes the following observation about these types of discussions, "I found that when students are enabled to share their interests, concerns, and wonderings with each other, they begin to see that they are not alone."

In addition to teaching traditional subjects, e.g., math, science, language arts, etc., the role of the teacher has become quite complex and dynamic, which is a sign of the changing needs that public schools must serve. Aside from the traditional activities of teaching, teachers are also responsible for most of the following on any given day and as a former public school teacher, I wholeheartedly agree with this 'litany', as I, too, have felt teaching was a secondary activity of a teacher. While it is absurdly lengthy, the length should not downplay the 
importance of carrying out these many functions and likewise, should serve as a reminder that much of what teacher's ‘do’ goes unnoticed by the common person (Allison, 1995):

Give specialized instruction for the hard of hearing, the blind, the developmentally disabled, the mentally challenged, and the gifted; develop special programs for at-risk students; build respect for the worth and dignity of the individual; do eye testing; schedule inoculations; assist in bladder control; keep health records and age certification data; attend faculty/grade/departmental meetings; attend professional workshops; work on advanced degree; volunteer to supervise extra-curricula activities; participate in fund-raising; collect money to rebuild the Statue of Liberty; stress the prevention of drug, alcohol, and tobacco use; promote physical fitness and good nutrition habits; eradicate head lice; inculcate morals, ethics, and values; maintain order and teach self-control to the undisciplined children of undisciplined parents; provide pregnancy counseling; monitor restrooms, playgrounds, hallways, parking lots, and the cafeteria; discourage food fights; break up fist fights; pray that there are no knife fights; develop individual and civic responsibility; eliminate gender bias and sex discrimination; promote ethical and racial tolerance; develop an appreciation of other people and other cultures; protect civil rights; help develop political know-how; teach sex education and AIDS prevention; provide suicide counseling; give First Aid instruction; train students in CPR; teach the principles of free enterprise; teach management of money, property, resources, assist in career planning; develop skills for entry into a specific field; teach etiquette and telephone manners; do 
job placement; serve hot breakfasts and lunches; dispense surplus milk; teach driver training; stress bicycle, automobile, and pedestrian safety; keep up with the latest trends and developments in education and be ever ready to implement these new program; know the latest education 'buzz' words; assist with bilingual language development; instruct in speed reading; encourage metric education; promote computer literacy; purchase enlightenment materials with your own money; counsel students with small problems; counsel students with major problems; protect student privacy; communicate with parents, detect and report child abuse; follow due process procedures; unteach the 4 food groups; teach the pyramid; announce that broccoli is good; build patriotism and loyalty to the ideals of democracy; encourage an understanding of heritage of our country; develop the ability to reason; promote curiosity and thirst for life-long learning; develop skills in the use of leisure time; build a feeling of self-worth and self-respect; teach pride in work; avoid religion; and teach reading, writing, and arithmetic.

In the post-modern classroom, teaching materials are not as important as they once were even though many textbooks and worksheets/handouts still drive the practices of the classroom. However, there is greater emphasis on utilizing differentiated teaching strategies with the purpose to ensure student's learning styles and multiple intelligences are incorporated into lessons since classrooms are rich of students of varying abilities and cultures. Seldom are there 'right' answers since learning is a highly individualized matter that recognizes that there are multiple realities, provisional truths, nor is learning based on a fixed theory or set of principles (Baker, 2002; Reiss \& Tunnicliffe, 2001). "Pairing and sharing" groups and cooperative 
learning groups are a norm for many classrooms and tend to better mimic the patterns of social life, in contrast to the modern era where learning was an individual affair.

Traditional assessment techniques of paper/pencil tests are growing obsolete as assessment (which may be a word that has outlived its usefulness, but for lack of a better word, it is used here to refer to evaluation procedures), emphasizes 'process' over 'product', delves into observing changes over time of thoughts, feelings, and actions, therefore, necessitating reflection and time for self-inquiry, better referred to as self-study. The idea is that self-study is an introspective process that can be freeing and liberating, yet a disciplining investigation, into self development (Bleakley, 2000). A practical example of self-study is in the form of a contract or verbal agreement where both teacher and student negotiate the type of activities the student will engage in to fulfill goals that students have personally set. Furthermore, in a chapter entitled, "Keeping Track," Ayers' (2001) introduces the chapter by reminding the reader that, "the root of the word 'evaluation' is 'value' and authentic assessment includes understanding first what students value and then building from there." I believe that he is asking that not only should teachers inquire into what students find valuable in their learning, but also for the reader, i.e., the teacher, to reflect upon what is valued, as well. By understanding the value of teaching and learning experiences, also makes assessment more student-centered, which leads to forms of assessment that are connected to real world matters, or often called, authentic assessment. Authentic assessment "understands learning as a selfregulating process of resolving inner conflicts that become apparent through concrete experience, collaborative discourse, and reflection" (O'Brien, 2000). Ayers (2001) offers alternatives to standardized testing through the "3-P" method: projects, portfolios, and performances. Another important aspect of authentic assessment is its expanded attention to 
culturally relevant learning where students are seen as social and cultural constructs of experiences, and teachers are mindful of the beliefs and traditions of the culture, to make learning meaningful.

Maxine Greene (1978) in Landscapes of Learning takes a phenomenological stance to learning and points out:

Learning...is a conscious search for some kind of coherence, some kind of sense. Learning is also a process of effecting new connections in experience, of thematizing, problematizing, and imposing diverse patterns on the inchoateness of things.....learning must be in some manner emancipatory, in the sense that it equips individuals to understand the history of the knowledge of structures they are encountering, the paradigms in use in the sciences, and the relation of all of these to human interests and particular moments of human time. (p. 19)

In this process, student learning focuses on self-development and self-discovery; it is relational to the world and the student's interpretation of the world. Ron Miller (2000) in Creating Learning Communities more specifically describes this process as transformative and what is especially interesting is that in his language, he does not speak of definitive barriers between what teacher's 'do' and what learner's 'learn'; that is, transformation occurs simultaneously for teachers and students alike:

To educate is ....to help each person discover the deeper meaning of his or her life. Who are we? Why are we on earth? What is our relationship to other living beings, and to the evolution of the cosmos itself? Holistic educators do not supply answers to these questions but they believe that every person is at heart a spiritual being who thirsts for insight and wisdom about such questions. To 
ignore the questions is to diminish our education as well as our humanness.

Transformation occurs when people are able to see through their own cultural conditioning and limited ego identities, and realize their connections to the unfolding universe itself. Education should be practiced in such a way as to encourage young people to pursue this understanding. (p. 203)

Because I believe in the 'power’ of images for evoking feelings, random thoughts, and memories, I often incorporate art and other forms of images in classroom assignments, even though I am not an art teacher. To the best of my knowledge, I do not know of other teachers doing the same in the field of education, and am presenting what I believe to be 'original' ideas here; but that is not to say, that others have not done the same since my reading and research is limited. I present my students with opportunities to interpret pieces of art or photographic images and then ask them to connect ideas from class discussions and readings to the interpretations they have envisioned. What follows are two 'mid-term' reflections I give in graduate courses. I encourage readers to take time to visit the listed websites, view the images, and consider making your own connections.

\section{Sample \#1}

1. The first part of this reflection, necessitates you go to the Norman Rockwell Collection website to view a piece of his artwork. Go to http://www. rockwellsite.com $\gg$ Prints to order $>$ Color prints $>$ Scroll down the page and click on " 2 ". "The Golden Rule" is coded as Art.12. (If you want to view a larger version, click on the image.) In "The Golden Rule" Rockwell struggled to give each figure its own character while having each one contribute to the overall conception, in effect, achieving a representation of the motto, "From many one," ( $E$ pluribus Unum). 
Likewise, John Dewey, one of the curriculum theorists we have studied in this course, is well known for his concept of 'communication.' In Democracy and Education (1916) he writes, "Not only is social life identical with communication, but all communication (and hence all genuine social life) is educative. To be a recipient of a communication is to have an enlarged and changed experience.... The experience has to be formulated in order to be communicated. The formulate requires getting outside of it, seeing it as another would see it, considering what points of contact it has with the life of another so that it may be got into such form that he [sic] can appreciate meaning...All communication is life art. It may be fairly said, therefore, that any social arrangement that remains vitally social, or vitally shared, is educative to those who participate in it."

(a) As you look over the picture, what message(s) does it hold for you?

(b) Based upon your understandings of Dewey's "communication," how does it relate to "The Golden Rule?"

(c) How do these understandings relate to curriculum development?

\section{Sample \#2}

1. Slattery ( $p$. 74) writes, "Recent scientific discoveries by physicists viewing graphics transmitted from the Hubble Space Telescope (HST) reveal images from the very seconds after the Big Bang. Using these images, scientists are beginning to explore the mysteries of creation and eternity."

To view a small but extraordinary collection of these images, go to the following website: http://hubble.stsci.edu/gallery/ >> Collection >> Select a category to begin viewing these images.

(a) As you look over these images, what messages/meanings do they hold for you?

(b) How might these understandings contribute to our own lives?

(c) How do these understandings relate to curriculum development within a post-modern ideology? 


\section{Table 1}

Chapter 3 Summary Table:

Characteristics and Descriptors for the Modern and Post-Modern Era

\begin{tabular}{|l|l|}
\multicolumn{1}{|c|}{ Classroom Settings, Meaningful Experiences, and General Understandings of } \\
Teaching and Learning
\end{tabular}




\begin{tabular}{|l|l|}
\hline Dualistic thinking -- 'either/or' 'this/that' & Both/and logic \\
\hline Paradigm of simplification & Paradigm of complexity \\
\hline Based on bureaucratic organizations & Based on communities of learners \\
\hline Scientific-dogmatic & Secular-spiritual \\
\hline Teacher provides knowledge & Teacher creates context \\
\hline Teacher promotes competitive values & Teacher promotes human values \\
\hline Teacher favors uniform learning approach & Teacher favors multiple learning approaches \\
\hline
\end{tabular}

\section{Concluding Thoughts}

Writing this chapter was exceptionally challenging, as it is basically two separate chapters combined into one with a 'transitional' reflection marking the movement that might be traveled from the modern into the post-modern era. For this reason, the perspectives in this chapter offered glimpses of 'what is', 'what might be,' 'what should be', and 'what will be' as evidenced in the changing tense forms of verbs. Another observation I make is the length of the various sections. Sections in the modern era are more succinct and to the point than sections in the post-modern era, which I believe, is a sign of the move away from meta-narratives in the modern era to the pluralism associated with the post-modern era. But, that is not to say that one is any more important than the other; instead, it means nothing other than what it is.

As this chapter concludes, I find myself in an odd place -- I am optimistic about the changes presented in the post-modern era and believe that the philosophies and practices of the post-modern era is exactly what is needed to bring students back to life; it is exactly what is needed if education is to be an enterprise that helps reconstruct society, because children do grow up and will carry educational experiences with them. My optimism is often labeled as 'seeing the world through rose colored lenses.' However, C. Wright Mills (1959) in The Sociological Imagination discusses the lenses through which people 'see' the world. I make the analogy that what if a lens is cracked, what if a lens is dirty, how might this affect a person's view? What if the lens is fixed? Or wiped off to reveal a clearer perspective? No answers, just 
rhetorical questions. If it is at all possible for education to be the mode to a clearer lens, then what might be in store for society? What messages will students carry with them? How might society be different? In light of this, I am reminded of a class discussion I had with my students following the tragic events of September $11^{\text {th }}$. What triggered this particular discussion was a newspaper article from a Sunday edition "Parade" magazine article in the local newspaper. On the front cover were individual snapshots of each 'terrorist', patterned very similarly to a school yearbook where head-shots are taken of each student. I looked at the front cover and tried to imagine each terrorist as a young child growing up and thought to myself, 'what if someone told these children that compassion and understanding of differences is a better way to resolve conflict?' How might the course of history be different? Or, what if someone told little Hitler that is it better to love than to hate Jewish people? How might the course of history be different? The point being is we never really know what could happen or what 'potentials' someone holds. We must overcome fear and fearful ways of living in this world, but most of my students resist change, they are no different than other living creatures, but change presents its own set of challenges -- uncertainty and fear. So, fear silences us.

At present, education is at a cross roads between the positivist practices and philosophies of the modern era and the non-positivist practices and philosophies of the postmodern era. In chapter five, it will be determined if the practices and ideas of today's teachers are different or the same from the modern era, and will provide an understanding of the swirling energies around and within the school from a phenomenological viewpoint. 


\section{Chapter 4: Doing Phenomenology}

\section{Part II: Researching the Lived Experience}

\section{Introduction}

This chapter turns away from the past, present, and future ideas of teaching and learning and now approaches "Doing Phenomenology" from a methodological standpoint with the intent to explain the process of gathering and exploring the essence and structure of 'everydayness' in the classroom.

This chapter, sub-titled, Researching the Lived Experience, follows suit to Max Van Manen's (1990) book of the same title based on phenomenological research methods, which he personally described as human science research. William Dilthey originally coined the phrase 'human science research’ to mean “investigation concerned with those areas of human existence involving consciousness, purposiveness, and meaning” (Brown, 1992). For clarity, I prefer the phrase 'phenomenological research methods' and for the remainder of the study, refer to my methods as this.

What follows in this chapter is a re-statement of the: problem statement, purpose and relevance of study, and three main research questions. Justification is provided to support the research methods utilized in the exploration of the phenomena in question. Detail is given to the techniques within the methods, data collection procedures, data analysis and interpretation, the selection of the participants, permission to conduct research, and the engagement with the participants. Particular attention is paid to image based research (IBR) located within the ‘techniques within the methods’ section. Additionally, personal narratives and journal entries will be sprinkled throughout the chapter to chronicle the experiences of this participantobserver. 


\section{Problem Statement}

The American public school system has not kept up with changing societal views and still remains crudely positivist. The root of the educational problem lies in the epistemological assumptions of mind and then, the translation of the epistemological assumptions in classroom teaching and learning practices.

\section{Purpose and Relevance of the Study}

The three phenomena that are examined in this study are the ideas and experiences teachers held towards: (1) the kind of classroom setting that best contributes to teaching and learning; (2) the kind of educational experiences that are meaningful; and, (3) the general understandings of teaching and learning.

Examination of these issues of significance occurred from two perspectives, which are interwoven at times but clearly represented to leave no question of ownership. Like my participants, I am also a teacher and for this study, the participant-observer. First, my perspective and identity is exposed through a personal expose' of thought related to my personal and professional readings as well as to my teaching and learning experiences.

The second perspective is that of the participants. To study the phenomenon related to teaching and learning, this research study endeavored: (1) to describe the lived experiences and understandings of pre-service teachers, in-service teachers, and college faculty have towards the concepts connected to teaching and learning; (2) to draw connections across the responses and experiences of the teachers; and (3) to identify emergent themes on teaching and learning. A final discussion ensues to compare and contrast the identified themes with that of the postmodern literature with final thoughts on the implications of the research findings and future recommendations for teacher-education programs. 


\section{Research Questions}

Three main research questions guided the study:

1. What understandings do pre-service teachers, host teachers, and college faculty have about the kind of classroom setting that best contributes to teaching and learning?

2. What understandings do pre-service teachers, host teachers, and college faculty have about the kind of educational experiences that are meaningful?

3. What understandings do pre-service teachers, host teachers, and college faculty have about teaching and learning?

\section{Justification of Qualitative Research Methods}

After reviewing the problem statement, purpose and relevance of study, and research questions, qualitative research methods were chosen to explore and distill the essence and experiences of teaching and learning held by pre-service teachers, in-service teachers, and college faculty for the following reasons:

- Qualitative research methods can study human phenomenon and nature from multiple perspectives - participant, observer, and researcher - using multiple methods.

- Qualitative research methods provide opportunities to freely explore opinions and feelings of participants in depth -- free of predefined categories.

- Participants can be purposefully chosen to explore their context-specific experience of phenomenon. A small number of participants is useful as long as it provides the reader with an understanding of the phenomenon and a 'recognizable reality' of the topic of significance (Entwistle, 1977).

- Qualitative research is open to emerging issues. 
- Qualitative research methods provide a unique picture of the 'whole' phenomenon and the interacting parts that make up the phenomenon in question.

- My personal view of knowledge, reality, and values favor qualitative research methods.

Under the larger 'umbrella' of qualitative research methods are numerous philosophical orientations, e.g., ethnography, phenomenology, heuristics, semiotics, systems theory, symbolic interactionism, etc., that more clearly define the research process (Patton, 1990). Denzin and Lincoln (2000, p. 20) in the Handbook of Qualitative Research describe five 'phases' that clarify the 'type of activity' researchers engage in, which can aid in the identification of the philosophical orientation: (1) The researcher as multicultural subject, (2) theoretical paradigm and perspective, (3) research strategies, (4) methods of collection and analysis, and (5) the art and politics of interpretation and evaluation. For this study, phenomenology defined my role as the researcher, and the strategies of data collection and analysis. The central question in phenomenological research asks, "What is the structure and essence of experience of this phenomenon for these people?” and likewise, the research methods should adequately reflect a medium to gain access to and then, describe, the essence of experiences. The ultimate goal (of phenomenological research) is "the fulfillment of our human nature: to become more fully who we are" and in terms of the usefulness of this type of information that is produced by the research, Martin Heidegger, asks another question in reply, "The more important question is not: Can we do something with phenomenology? Rather, we should wonder: Can phenomenology, if we concern ourselves deeply with it, do something with us?” (Van Manen, 1990) 


\section{Phenomenological Research}

In chapter two, some of the main theoretical concepts of phenomenology were detailed with special attention give to the ideas of Husserl and Merleau-Ponty. Now, the application of the theoretical concepts 'steps in' to explore the ideas and experiences held by teachers related to teaching and learning with methods that 'trigger' the consciousness to reveal perceptions about the issues at hand.

So, what does it mean to engage in phenomenological research methods versus standard qualitative methods? There is not a set of investigative procedures but there is a history of thinkers and a body of knowledge that constitutes a set of guiding principles. The methods themselves are qualitative in nature; however, to qualify as phenomenological based research, it must be guided by phenomenological orientation and be a medium to access to whatever is in consciousness. That is, to qualify for phenomenological research, it must take a “Husserlian” approach. According to Giorgi (1997), this entails communicating ‘lived experiences' through descriptive narrative; viewing the experiences of the Other with a phenomenological attitude; and, seeking contextual meanings of the experiences.

Van Manen (1990) spoke in a similar tone when he described the six activities of phenomenological research: (1) turning to a phenomenon which seriously interests us and commits us to the world; (2) investigating experience as we live it rather than as we conceptualize it; (3) reflecting on the essential themes which characterize the phenomenon; (4) describing the phenomenon through the art of writing and rewriting; (5) manipulating a strong and oriented pedagogical relation to the phenomenon; and, (6) balancing the research context by considering the parts and whole. 
In Phenomenological Research Methods, Clark Moustakas (1994, p. 21) distinguished between five models of phenomenological design - ethnography, grounded theory, hermeneutics, Duquesne University’s Phenomenology, and Heuristics - and ascertained the commonalities of the models include: (1) Recognizing the value of qualitative designs and methodologies, studies of human experiences that are not approachable through quantitative approaches; (2) Focusing on the wholeness of experience rather than solely on its objects or parts; (3) Searching for meanings and essences of experience rather than measurement and explanations; (4) Obtaining descriptions of experience through first-person accounts in informal and formal conversations and interviews; (5) Regarding the data of experience as imperative in understanding human behavior and as evidence for scientific investigations; (6) Formulating questions and problems that reflect the interest, involvement, and personal commitment of the researcher; and, (7) Viewing experience and behavior as an integrated and inseparable relationship of subject and object and of parts and whole.

Michael Quinn Patton (1990) in Qualitative Evaluation and Research Methods wrote that often times there is confusion about what makes a phenomenological study but coyly admitted that this is his interpretation of the issue:

...conducting a study with phenomenological focus (i.e., getting at the essence of the experience of some phenomenon) is different from using phenomenology to philosophically justify the methods of qualitative inquiry as legitimate social science research. Both contributions are important. But a phenomenological study (as opposed to phenomenological perspective) is one that focuses on descriptions of what people experience and how it is what they experience. One can employ a general phenomenological perspective to 
elucidate the importance of using methods that capture people's experience of the world without conducing a phenomenological study that focuses on the essence of shared experiences (at least that is my experience and interpretation of the phenomenon of phenomenology). (p. 71)

Phenomenological research is discovery oriented and in this, one realizes that there endless potential to pursue research interests, however, the aim is to grasp and communicate patterns of meaning constructed in an intersubjective community. The role of the researcher is just as significant as that of the participants as they must paint a picture for others to 'see' the range of human experience and the worlds in which people inhabit.

From the preceding ideas, my interpretation and application of phenomenological research procedures were as follows:

1. Investigate the lived experiences of the participants through formal and informal qualitative research methods.

2. Search for meanings and essences of experiences in transcript passages and other data sources that stood out as significant.

3. Create narratives that are rich in description and give 'voice' to the essence of experiences had by the participants.

4. Reflect on emergent themes.

5. Compile themes into a meaningful 'whole.'

\section{The Role(s) and Voice of the Researcher}

\section{The Author/Researcher}

Moustakas and van Manen, whom I rely upon for support and guidance in this unstructured process, regularly write about the role of the researcher in phenomenological 
research. Their words are subtle and mysterious, and draw me in. They are messengers from an uncommon research dimension. They have looked at the world from angles that others seldom do. They speak of a holistic philosophy that engages the participants, the researcher, and the cultural environment - holistic referring to the unity of being itself (Van Manen, 1997). The phenomenological researcher does not favor a single method to discover the lived experiences of individuals but should set out to uncover the historical stories and personal interpretations of the present.

The work of the phenomenological researcher is to embellish description and often is done so through artistic means. Many researchers include photographs, images, artwork, poetry, classical literature, and flourish in first person narratives and anecdotal interjections as a way to sensitize readers; but the stylistic impression should not substitute for 'data.' Rather, the inclusion of such pieces function to clarify meaning, to help the reader 'see' meaning, and to make intelligible “feelingly understanding” (Van Manen, 1997).

For myself, who primarily considers herself a teacher first and foremost, the greatest hurdle for me in this study is to write in such as way to express myself and the views of the participants (van Manen and Moustakas nearly demand this of the researcher if they are to consider themselves phenomenological researchers), that is informational and yet, evokes feeling in the reader, unlike 'normal' research that lacks sympathetic tone or intensity. How is it I can be 'author' and 'researcher' in the same document when my identity is truly that of a teacher? My sense of self is not that of author, let alone researcher, still yet, research is the work of writing, and Roland Barthes (1977) in Language-Music-Text adds to my anxiety, “...[referring to research] its is the language which speaks, not the author.” The lack of procedure further contributes to my fears because if I want to remain true to the 'informational' 
aspect of phenomenological text, writing becomes a secondary act. Barthes (1977) writes about the paradox the phenomenological researcher finds herself in:

Method becomes a law, but since that law is devoid of any effect outside itself (nobody can say what a 'result' is in 'human sciences') it is infinitely disappointed; posting as a pure meta-language, it partakes of the vanity of all meta-language. The invariable fact is that a piece of work which ceaselessly proclaims its determination for method is ultimately sterile: everything has been put into the method, nothing is left for writing; the researcher repeatedly asserts that his text will be methodological but the text never comes. No surer way to kill a piece of research and send it to join the great waste of abandoned projects than Method. The danger of method (of a fixation with method) is to be grasped by considering two demands to which the work of research must reply. The first is a demand for responsibility; the work must increase lucidity, manage to reveal the implications of procedure, the alibis of language, in short must constitute a critique (remember once again that to criticize means to call into crisis). Here method is inevitable, irreplaceable, not for its 'results' but precisely or on the contrary, because it realizes the highest degree of consciousness of a language which is not forgetful of itself. The second demand, however, is of a quite different order; it is that of writing, space of dispersion of desire where Law is dismissed. At a certain moment, there, it is necessary to turn again Method, or at least to treat it without any founding privilege as one of the voices of plurality as a view, a spectacle mounted in the text, the text which all in all is the only 'true' result of any research. 


\section{Self-Analysis}

The writing of phenomenological text is a twisted process for the researcher. One aspect of the process refers back to Husserlian traditions, which indicates that the researcher must exhibit natural attitude to identify presuppositions they bring to the research process. Doing this necessitates a self-critical, reflection upon the reflection process - a self-looping or 'mind looping' -- that Peter Reason (1988) in Human Inquiry in Action claims is "the root of insanity.” The researcher tries to "become the data, live the data" and in doing so, the self risks becoming transformed in the process. The researcher is in the process of being and becoming, new relationships are formed. To conduct this type of research, the researcher must have patience and a time commitment. They must be willing to admit that they are personally attached to and care for the research, and involved in the lives of the participants. But, the irony in Reason's, Moustakas', and van Manen's words, and referring back to the intentionality of doing such research, is this is where the self has led itself.

\section{Responding to the Call}

Where do I stand on the issues that were identified as problematic in this research? In a phenomenological sense, it would not be useful to identify my position because it should be apparent by now (as demonstrated through the Purpose and Relevance of the Study and main Research Questions). The value of this research undoubtedly rests in the implications it may have in future teacher education programs and furthermore, in the public school classrooms. Again, this may prompt another question, why invest time and energy (a metaphor Lakoff and Johnson (1980) cite as being indigenous to our capitalistic society based upon the value system) in a study such as this, when the 'real players' in this story, may never 'show up' or read this. This study not only ignites a deep seeded passion in me but greater than that, this study is for 
the human beings who spend 12-13 years in the classroom and who too often, are afflicted and inflicted with values too closely associated with the modern era which denies truth found in experiences and perceptions.

How do teachers view teaching and learning? For too long, teaching has been reduced to technique and method. But what if I shared a secret here and said I 'listen' to my students (who are presently teachers in the field) and they are discontent with current practices and that they 'feel' something is wrong with what is being imposed on them at a state and national level but could not justify their feelings because they are 'doing' what is being asked of them. They mechanically go through the actions long associated with teaching but never have opportunities to talk with one another at an intimate level. Part of their self has been denied and likewise, they deny it in their students as well. Yes, 'the nation is at risk' because in the field of education, we have forgotten what really matters. Ron Miller (1997) in What are Schools For? cites Douglas Sloan regarding the type of education that is currently taking place, "If we impose only quantitative concepts and mechanical images on the world in our attempt to know her, a quantitative and mechanical world we shall have. And eventually, thinglike, mechanical selves to go with it.”

\section{Going into the Womb}

We complain that something is seriously wrong not only in education but in routine affairs. We feel the monotony in our lives, we watch the evening news and wonder what has gone wrong; we see it in the faces of those we pass everyday in larger urban centers to the smaller rural communities. We hear it from students. We blame school systems, teachers, teacher-education institutions, the federal government, parents, etc., all of which was highlighted in A Nation at Risk over 20 years ago. 
In chapter one, I talked about the crisis in education that is occurring at the same time as this cultural transformation; it is no coincidence. There is a paradigm shift occurring, a change in thought. The problem of change is not a relatively new phenomenon but the process of change is. Over the course of history, change is slow to take place and Lewis Mumford in The Transformation of Man (cited in Reason, 1994) discussed the process of change, "Every transformation of [the human species]....has rested on a new metaphysical and ideological base; or rather, upon deeper stirrings and intuitions whose rationalized expression takes the form of a new picture of the cosmos and the nature of [humanity].” In this transition, the educational system will either be re-born or exist no longer, and in either case, it is symbolic of change. Likewise, Alvin Toffler (1970) in Future Shock wrote that one of the greatest obstacles to humankind in the future will be the individual unwilling to change. He writes, "The illiterate of the $21^{\text {st }}$ century will not be those who cannot read and write, but those who cannot learn, unlearn, and relearn.”

The role of the researcher in this type of research is found in her voice. Voice gives recognition to the researcher's values, philosophical orientation, relationship and involvement with the study and participants. Husserl speaks of phenomenological attitude, but I doubt if it is ever possible to purely approach one's research of this nature, and of the magnitude that he suggests, that is completely devoid of voice. Is it possible to remain neutral while at the same time, clarifying one’s thoughts on the matter (Spiegelberg, 1975)? It will be through my writing and the tackling of issues from many perspectives and angles, that I hope readers will form an empathetic relationship with the participants, come to new understandings related to teaching and learning, connect life experiences, and see themselves in the life of another. Throughout, I will be appearing and disappearing, and always reflecting. 


\section{Participant-Observer}

Qualitative methodologies have long relied upon observation as a mainstay for data collection but unlike the process where the researcher sits 'apart' from the participants, there is another level of involvement which designates the researcher as 'participant-observer.' Michael Quinn Patton (1990) in Qualitative Evaluation and Research Methods wrote about the extent of the participant-observer's interaction in the field. At times they are fully submerged and participating, at other times, not at all. There could be times when a non-participatory observation is planned but unexpectedly, the researcher is 'pulled in’ and becomes part of which she is studying. Patton (1990), citing Denzin, reflected upon implications of participant observation, “[it]...simultaneously combines document analysis, interviewing of respondents and informants, direct participation and observation, and introspection.” It can privilege the researcher with an insider's perspective so they can get a real 'feel' for the experience; however, in the process, it may challenge the researcher to remain objective unless they become enculturated and 'go native.' One of my many roles in this study was that of participant-observer. At times, I participated in the field I was observing; and, other instances I withdrew from interacting and 'looked on' clearly feeling like I had invaded the personal space of the classroom.

I can identify with the participants. At one time or another, I have been in their 'shoes' and walked the same path. I received a teaching certificate, taught in the public school system, taught in a private school; I have a Master's degree; I am completing the requirements of a doctoral degree while teaching full-time at the college level. I am the participants; they live in me. I desire to understand their feelings and experiences; they are my colleagues and I want to 
include my experiences in this study and ‘jump in' to let them know that I do understand. I’m not the outsider here.

\section{Techniques within the Methods}

The purpose of this study is to explore understandings pre-service teachers, in-service teachers, and college faculty hold towards learning and teaching, the type of setting that best contributes to the teaching and learning, and the kinds of experiences that are meaningful. The phenomenological design of the study sets out to discover 'what is' in the everyday classroom. Upon discovery of these understandings, connections will be drawn across responses to identify emergent themes of teaching and learning. To explore these understandings and the structure of the 'life world' of the participants, common and not-so-common qualitative techniques were selected: interviews, observations, documents, personal journal entries, and image based research $(I B R)$.

Taking a phenomenological perspective on the techniques, gives insight to the potential application of the techniques. For instance, interviewing is a method of dialoguing with the Other; it can promote understanding and empathetic connections (Frank, 1985). Observations provide contextual meaning to behavior and events. Documents are artifacts of understanding and show engagement with a subject. Journal entries record personal reflection. The discussion of images and photographs illustrate perception of meaningful experiences. The purpose of using a multitude of techniques is for building a comprehensive picture and story of the participants.

This section includes a summary and description of how each these techniques were utilized with a more in-depth explanation presented on IBR. In combination, these methods provide adequate measures for triangulation purposes. In qualitative research, the strength of 
the study's design can be assessed through triangulation. Patton (1990, p. 187) identified four types of triangulation: data triangulation, investigator triangulation, theory triangulation, and methodological triangulation. This study relied on data and methodological triangulation to support its findings.

In subsequent sections of this chapter, attention is given to the procedures of Selection of the Participants, Permission to Conduct Research, Engagement with the Participants, Data Collection, and Data Analysis and Interpretation.

\section{Interviews}

Beginning with the three main research questions as a foundation, a list of semistructured, open-ended interview questions were devised around the concepts of teaching and learning. There were a total of 20 questions in the interview guide.

These interview questions were related to research question number one, What understandings do pre-service teachers, host teachers, and college faculty have about the kind of setting that best contributes to teaching and learning?

5. Think of yourself as a learner, how do you learn best?

6. How do you make decisions about what you do in the classroom? What do you take into consideration?

11. How (or in what ways) do you connect student's lives outside of school with classroom learning experiences?

14. Tell me about an ideal learning environment - what would it look like elementary students, secondary, and higher education? 
These interview questions were related to research question number two, What understandings do pre-service teachers, host teachers, and college faculty have about the kind of educational experiences that are meaningful?

1. What is satisfying about being a student? What is dissatisfying about being a student? 2. What is satisfying about being a teacher? What is dissatisfying about being a teacher? 3. Tell me about some of your personal learning experiences - begin with your earliest memories and work forward.

4. Tell me about some of your personal teaching experiences.

5. Think of yourself as a learner, how do you learn best?

6. How do you make decisions about what you do in the classroom?

7. How are the issues of race, class, and gender taken into consideration in the classroom? 8. Thinking about classroom practices, how do you prepare (or teach) while keeping in mind the best interests of the students? The best interests of the interns? [for host teachers only] 11. How (or in what ways) do you connect student's lives outside of school with classroom learning experiences?

13. What things have significantly influenced the way you teach? 17. The purpose of education is...

These interview questions were related to research question number three, What understandings do pre-service teachers, host teachers, and college faculty have about teaching and learning?

1. What is satisfying about being a student? What is dissatisfying about being a student? 2. What is satisfying about being a teacher? What is dissatisfying about being a teacher? 
3. Tell me about some of your personal learning experiences - begin with your earliest memories and work forward.

4. Tell me about some of your personal teaching experiences.

5. Think of yourself as a learner, how do you learn best?

6. How do you make decisions about what you do in the classroom?

7. How are the issues of race, class, and gender taken into consideration in the classroom?

8. Thinking about classroom practices, how do you prepare (or teach) while keeping in mind the best interests of the students? The best interests of the interns? [for host teachers only] 9. What helps you to best meet the needs of the students?

10. What are the barriers that keep you from best meeting the needs of the students?

12. What is important to know about students when you teach?

13. What things have significantly influenced the way you teach?

15. What role do textbooks have in your classroom?

16. What role do grades have in your classroom?

17. The purpose of education is...

18. My role as a teacher is...

19. What does teaching mean to you?

20. What do learning mean to you?

Interviews consisted of a series of three face-to-face interviews of about seven questions at each sitting. Each interview was approximately one hour in length. However, at times, due to time commitments of the participants, the length of the interview was altered as were the number of questions discussed. To maintain accuracy of participant's thoughts, interviews were 
audio-cassette recorded with their permission and later, transcribed. During the interview, there was frequent note taking, as well.

Two main aspects were taken into consideration when developing the interview guide past history and memories, and present experiences and ideas. The first perspective was memory recall of past personal experiences. For instance, “Tell me about some of your personal learning experiences. Begin with your earliest memories and work forward.” The other angle was that of current classroom practices to explore what currently takes place. For example, "How do you make decisions about what you do in the classroom? What do you take into consideration?” Probing questions were also part of the interview to give greater depth to responses.

Phenomenological techniques imply that the interview can serve two purposes: (1) "It may be used as a means for exploring and gathering experiential narrative material that may serve as a resource for developing a richer and deeper understanding of a human phenomenon and (2) the interview may be used as vehicle to develop a conversational relation with a partner (interviewee) about the meaning of an experience” (Van Manen, 1990, p. 66).

\section{Observations}

Two classroom observations were planned for each participant and occurred at times convenient for the teacher. Each observation was approximately 1-1 1/2 hours in length for a total of 2-3 hours. In the elementary school setting, observations of the participants spanned over several content areas, such as, math and science, and observations occurred at the beginning and end of the school day. Of special mention, observations were of the teacher with same group of students on each occasion. Furthermore, on certain occasions, I was purely an observer and at other times, I was a participant-observer in the field. In my observations I 
recorded the layout of the classroom, colors and other decorative designs, the placement of the students’ desks, the teacher's desk, the number of students with the ratio of males to females, racial makeup of the classroom (this judgment was made on outward appearance but should not be considered a valid source of information due to theories on identity construction), teacherto-student interaction and communication, tone of response and comments, etc. In the field notes, I also included my feelings and reactions towards classroom experiences and in the phenomenological tradition, recognize that observation is referred to as 'selected perception.'

A final word on 'observer effect' indicates that when an 'outsider' intrudes the field setting, in this case, the classroom, the situation being observed may not always appear as it really seems. “Atypical behavior' can be noted as 'typical behavior' in field notes and distort data analysis.

Here is a sample of my 'uncooked' field notes:

Observation \#1 -- Linda

April 10, 2001

There are 29 students = approx. 10-11 boys and 19 girls, all white.

It's Hat Day! Linda tells me as I enter-as I look around I can see that most students have on different types of hats. Linda has on a gold/silver visor.

She has an enclosed classroom unlike many of the other teachers who must teach in a cluster (there are 4 classes in one large room).

This is a very busy classroom - there are mobiles hanging from the ceiling, posters on the walls, maps, computer area, shelves on books, construction paper, supplies, students are counting out lunch money. This looks like fun.

Linda is walking around the classroom and she is kind to her students, “Yes, dear...” “Hon...'

As I walk in, they are working on a language arts spelling lesson.

The lights are out and the overhead projector is on - Linda is using transparencies for lessons. 
Students are working independently with little direction from her. Once they get done with the lesson, they are permitted to go to the computers. There is so much here. I just want to walk around and look at everything. There are snacks outs on tables, paints, brushes. Students walk by and ask me questions (Sayers, Spring 2001).

\section{Documents}

Two ‘take-home’ questions per participant were used for document analysis purposes.

Full confidentiality and anonymity was assured to the participants. The questions were:

(1) If you could design your own teacher-education program, what would it look like? How would you learn to teach?

(2) What is your educational philosophy? If I sat in your classroom, what would I see as evidence?

Several participants had a prepared statement of philosophy of education, which was printed off from the computer; others did not and submitted hand-written responses. These artifacts served document analysis purposes and were not part of the interviews. In addition, two of the three faculty members voluntarily offered course syllabi. These documents were a key source of information and provided conceptual frameworks about proposed course activities, course goals and objectives, and assessment and planning procedures. Course syllabi served as cultural artifacts.

\section{Personal Journal Entries}

My personal journal entries signify my relationship to and perception of the study, and also provided a 'spot' for my voice. In my entries, I shared feelings and thoughts about the research process and about the same issues that is asked of the participants. Entries were not regularly scheduled events but more or less, chronicled the more personal difficult circumstances of being engaged in research. Here is a sample journal entry, entitled, "My Methods and My Fears,” written near the beginning of the dissertation process that more or less 
in my 'confessional tale' with coming to grips with the 'messiness' and often times, complex nature of qualitative research.

\section{Personal Journal Entry:}

Many talk about the messiness of 'doing' qualitative research. There are generic approaches such as taking observational notes, document analysis, interviewing, (all of which are included in this study) but what happens when the qualitative researcher crosses over the already unclear, murky boundaries within the 'doing' into a new territory or method even further from the mainstream approaches. One is only left with common sense, some hesitancy and trepidation, and the philosophical framework to guide the thought process for building the rationale for 'doing.'

The beginning phases of this study left me with many questions and uncertainties. It wasn't until I began reviewing the literature in the area when I found that there were others 'out there' who experienced the same conundrums but in their words and stories, I found that much of what I had planned and did, was similar to others. I found some relief and solace. The process of doing image based research is not step-like process but it seems I had covered my ‘bases’ (Sayers, December, 2000).

\section{Image Based Research and Photo Elicitation}

Building upon previous qualitative research projects that utilized photographs, this research project further advanced my use of photographic images in research. For this study, participants were provided with a disposable camera (supplied by the sponsoring University’s PDS Collaborative) and instructed to “take pictures of meaningful classroom moments.” These simplistic instructions were based upon the phenomenological aspects discussed in chapter two. I anticipated participants would select and choose to photograph certain classroom moments 
over others for phenomenological purposes, and also assumed that participants would photograph 'ideal' or 'celebratory' moments which is common in this culture. Following the development of the film, the photo elicitation portion of the interviews followed. Photoelicitation is a method using photographs as an interview device to collect information where individuals are asked to reflect upon the nature of the image and is considered highly phenomenological due to the associations one makes with the various elements in the photographs. Roland Barthes (1981) in Camera Lucida referred to the nature of photographs (his emphasis added), “...all we can say is that the object speaks, it induces us, vaguely, to think.” Some photographs leave the viewer 'unmoved' and others ‘communicate' webbed layers of information and an assortment emotional responses; but, at any rate, photographs are instrumental in exploring perceptual acts (Harper, 1988). In About Looking, John Berger (1980) wrote, "Photographs are perhaps the most mysterious of all the objects that make up and thicken the environment we recognize as modern. Photographs really are experience captured, and the camera is the ideal arm of consciousness in its acquisitive mood.”

In this study, some of the participants requested if they could use existing photographs and this was accepted, as well. Questions from this portion of the interviews included:

- What photos have most meaning to you?

- What does this photo represent to you?

- Which photo best represents you?

- How do the photos represent your pedagogy?

- How do the photos represent the views and roles of the students?

- How do the photos represent the views and roles of the teacher? 
Similar to the 'observer-effect' during fieldwork observations, cameras also have potential to produce 'unnatural behavior' but with photo-elicitation, the distortion of data is lessened through interviewing process.

Much has been written about the use of photography in research but primarily from a sociological and anthropological standpoint. IBR is a form of research comprised of "moving images in the form of film and video, and still images, such as photographs, cartoons, and drawings” (Prosser, 2003). Traditionally, images and photography have been used in four ways: as data, as images to elicit data, as documentation, and as a mode of representation or interpretation. Psychology has routinely relied upon images for therapeutic and diagnostic evaluations, such as the Rorschach Inkblot test; whereas, the 'hard sciences' have utilized images for documentation of evidence to support the 'realist tale' (Harper, 1981).

In the social sciences, IBR currently serves a much different purpose even though in its infancy it originally provided documentation or 'proof of observation.' One of the first anthropological studies recognized for using still photographs as documentation, is Mead and Bateson’s study, Balinese Character in 1942. In this ethnographic study, images served to document the traditions and customs of a South Pacific culture in the 1930's. 'Natives' were photographed participating in 'exotic' trance-like rituals, celebratory rites of passage, and images recorded village living conditions and artifacts indigenous to the culture. The images in Balinese Character were presented to expose the 'objective reality' of the culture (Harper, 1988). Today, post-modernists challenge the use of photographs in these types of situation as it is a display of power of privileged groups and further contributes to the marginality still experienced by traditionally oppressed cultures, which is explained by the absence of images of the power elite in research settings. 
Closer to home, the photography of Lewis Hine and Jacob Riis provided a means for social reform in the 1920's as they captured images of the living and working conditions of marginalized groups, specifically that of manual laborers, working children, and immigrants (Trachtenberg, 1989). These images portrayed social injustices and proved to be emotionally moving so much so that Hine and Riis were criticized for "pandering to the low tastes of the public or trying to persuade readers to accept shaky conclusions by using illegitimate 'rhetorical' means” (Prosser, 1998).

Today, there is little agreement about the appropriateness of using photographs in social science research even though it has become a more acceptable trend for generating contextual understanding. Jon Prosser, one of the leading image based research scholars in the United Kingdom, claims IBR has limited status for a number of reasons: lack of organization and definition of purpose, and methodological framework, as well as, little attention has been paid to it in research textbooks, and therefore, few teach about the techniques or possibilities. Furthermore, he writes, “....few role models of acceptable ethical practice have been debated let alone established for others to follow” (Prosser, 1998; Prosser, 2003).

One research study Prosser cites in Image-Based Research: A Sourcebook for Qualitative Researchers (1998) that has similarities to this study, is a case record of a school, entitled, The Hathaway Project. In this study, teachers, as a part of a professional development requirement, were given cameras and asked to take pictures of classroom events. Teachers discovered that during the photo elicitation process, they began to understand more about their teaching as they articulated the 'messages' in the photographs.

For this study, the photographs were a form of data but because photographs are not capable of talking for themselves, the information must be teased out of them, interpreted, and 
decoded for socio-cultural contextual meaning (Prosser,1998). Image based research may provide the medium to best capture the many dimensions of life not just for its ability to visually depict events and happenings, but because it provides the 'stepping off point' to recreate and uncover feelings, thoughts, memories, awareness, perceptions associated with the image and furthermore, for its ability to transgress the researcher to the participant's consciousness and for the consciousness to interact with the researcher.

Sorting through books and journals to support my use of IBR in this context, I found there was a 'gap' in the literature in supporting IBR performed within theoretical frameworks. However, the written descriptors of 'doing' IBR were similar to the descriptors of 'thinking' about phenomenology. My initial reaction was "IBR brings unification to doing phenomenological based research.” My thoughts swirled around perception, meaning as epistemology, Gestalt theory, visual thinking, aesthetics, intentionality, and causal theory of perception. Dancing with each idea was inadequate in this case. Therefore, to study each concept alone (which would be a paradox in and of itself), was insufficient to understand the interconnectedness between phenomenology and IBR. Then, true to Glaser and Strauss’ (1965) work on emerging themes to create grounded theory and in a moment of revelation and gratification, it came to me -- it's not what phenomenology can bring to IBR research, but it's what IBR can bring to phenomenology.

To illustrate my line of thinking, I am including a journal entry that gives clues of the path that led me to these conclusions (it is the original rough draft but should serve the point):

$\boldsymbol{D}$ IBR is a trigger to unlock and study consciousness - it triggers memories, emotions

The mind creates a concept/metaphor of captured object 
2 People see 'life-sights' and speak of the conditions, sounds, smells, colors, involvement, feelings, of the 'life-sights' (my original term) - speak of the properties associated with the image; language is symbolic of the culture; intentionality - the mind reaches out and interacts with the image 'out there'

(3) 'Life-sights' are sense-datum to the consciousness - not necessarily real.

4 What people relay in their speaking of images are their perceptions.

5 Perceptions and sensory experiences tell us about the personal characteristics of the individual and their experiences because the mind models the world by projecting its own experience 'out.' Perceptions are private matter to each individual but some publicly shared.

6 We perceive what we know - could be a provisional epistemology.

(2) What we know is some function of consciousness.

$\boldsymbol{8}$ Ideas are real; perceptions are real.

$\boldsymbol{\Theta}$ To study consciousness, research must be phenomenological in its broadest sense. (Sayers, April, 2003)

In terms of IBR and participant photography, first, it is acknowledged, that not all images captured by the participants were 'meaningful.' But, this is not to say that there was not intentionality when consciously choosing to photograph certain events and behaviors over others. Looking through a camera lens is in essence the 'bracketing' or 'framing' of physical life but is done so for a particular nature. The researcher cannot understand this physical reality unless photo-elicitation is implemented to reveal the photographer's psychical reality and their encounter with the image. The researcher may even find out that they are not the 'expert' in this situation. However, since phenomenological research methods seek to understand the structure and essence of an experience of others, the 'expert' should be the participant and not the researcher (Winston, 1998). 


\section{Selection of Participants}

Nine participants were purposefully selected to represent and facilitate three levels of 'understandings' that teachers hold towards ideas and experiences of teaching and learning. Three pre-service teachers were selected to represent a beginning teacher's understanding of teaching and learning. Three in-service teachers were chosen to represent a veteran teacher's understanding of teaching and learning. Three college faculty members were selected to represent an instructor's understandings of teaching and learning that taught in a teachereducation program. All individuals were associated with the University’s 5-year teacher education program. The three pre-service teachers were in their $5^{\text {th }}$ year of a 5 -year teachereducation program and were all females. The in-service teachers were 'veteran' teachers with a minimum of 15 years of teaching experience each and all were teaching in well-established professional development schools (PDSs) associated with the University. The in-service teachers acted as host teachers for the pre-service teachers student teaching placements. The inservice teachers all taught in the elementary school setting and were female. The three college faculty members taught at various levels of a 5-year teacher-education program and in various disciplines. There were two males and one female who had a range of teaching experiences in the public school setting to their current position in higher education.

College faculty were chosen based upon their various levels of involvement in the teacher-education program. One faculty member instructed junior level students $\left(3^{\text {rd }}\right.$-year students) in the teacher education program; another faculty member taught students in the semester prior to student teaching; and another member, taught a professional seminar course to student teachers and a methods course prior to student teaching. 


\section{Permission to Conduct Research}

Permission to conduct research was approved at two levels - exempt and expedited - as per University Institutional Review Board (IRB) requirements for the protection of human subjects. See Appendices A-I for necessary forms to participate in study.

\section{Engagement with Participants}

Initial contact with the participants in this study began with the in-service teachers and college faculty members. I had developed relationships with the in-service teachers and college faculty through my 'membership' as a graduate assistant with University’s sponsored PDS training workshops. After discussing the possibility of participating in this research study with the in-service teachers, contact was made with the respective pre-service teachers and all agreed to participate. Engagement with college faculty members took a similar path. Many of my informal relationships with faculty members were made possible through the PDS programs, which permitted me to approach faculty members at ease. All nine participants were provided with an overview of the study detailing the general purpose and relevance, the main research questions, and the proposed time commitment.

\section{Data Collection}

Data collection began in February 2001 and ended June 2001. During this time, participants were interviewed every 3-4 weeks. At the beginning of the first interview, participants were read a short script detailing the purpose of the study and conditions of participation and demographic information was recorded: gender, age, educational degrees earned, number of years teaching, various grade level of instruction, and course/content areas. Interviews were conducted with only the participant and myself present. There were a total of 20 questions in the interview guide (see Appendix J). Interviews consisted of a series of three 
face-to-face interviews of about seven questions at each sitting. Each interview was approximately one hour in length. After the first interview, participants were provided with disposable cameras and asked to take pictures of meaningful classroom moments. The photoelicitation portion of the interviews occurred at the third interview session. Photographs were given an identification number (for example, \#1, \#2, \#3, etc.) for organizational purposes. During the photo-elicitation portion of the interviews, special attention was paid to identifying the photograph participants specifically mentioned. In doing so, I noted the number previously given to the photograph and interjected this number during the conversations. To maintain accuracy of participant responses, interviews were audio-cassette recorded with participant permission and later, transcribed. Subject anonymity was guaranteed and upon reporting out the study, participants were told that subject names would be changed to protect their identity. Interviews were scheduled at times convenient for the teachers. Likewise, upon consent to participate in the study, observations were scheduled at times convenient for the teachers.

Two ‘take home' questions were given to participants upon consent to participate in the study. Questions were returned at the participant's leisure through either e-mail or written, hard copy exchange for document analysis purposes.

During the entire study, I kept a personal journal and other writings to document and reflect upon my experiences in the research process.

\section{Data Analysis and Interpretation}

In this study, data and transcripts were analyzed and interpreted using an emergent, inductive design. Detailing this process, Norman K. Denzin and Yvonna S. Lincoln (1998) in Collecting and Interpreting Qualitative Materials wrote this type of design consists of three sub-processes: data reduction, data display, and drawing conclusions and verification. 
Due to the enormous volume of information that the researcher collects during a qualitative study, the data must be made manageable. In this study, data for each participant consisted of three face-to-face interviews, photographs, written documents, and observation notes. The various data collection strategies were useful to corroborate stories and to link words to action. Data analysis began with the first reading of the interview transcripts. I did not transcribe the interviews but to re-familiarize myself with the data, I read over the interview transcripts while listening to the audio-cassette tapes. A second level of data analysis consisted of re-reading the transcripts with the inclusion of coding notes in the margins, which were preliminary units for emergent themes. As similarities emerged, broader themes were developed which were instrumental in answering the research questions. Observational notes and document analysis additionally proved to either support or contradict the data in the transcripts.

In chapter five, data were displayed first by individual case within sub-group by research question. That is, there are three main groups of participants - pre-service teachers, inservice teachers, and college faculty - and each sub-group will be sub-divided by individual case and more specifically, narratives are formatted around research questions.

The final way data were analyzed is through drawing connections across case and then across the overall larger group to establish patterns of relationships. In drawing connections, I looked for similarities and differences in the responses of these individuals whom are all associated with the 5-year teacher education. Findings cannot be generalized but can provide an understanding of the issues of significance. Photos are included in participant narratives and served two purposes - the documentation of actual events or display contextual evidence of meaningful events. 
Always being conscious of the theoretical framework, which guides this study, i.e., phenomenology, the primary purpose of data analysis is to explore the essence and structures of human experience. Through data analysis, perceptions and understandings provided clues to the experiences that are individually meaningful but also explain how experiences are socially organized (Ball \& Smith, 1992). In this type of analysis, the researcher (Denzin \& Lincoln, 1998):

...does not move toward abstraction, away from life, but back to experience. It aims not to foster the growth of knowledge but to restructure experience; not to understand objective reality, for that is already established by common sense, nor to explain how we understand, for that is impossible, but to re-assimilate, to reintegrate the self in society and to restructure the conduct of everyday life.

In other words, in 'doing' phenomenological research, the goal is not to concretely answer the research questions but to give a greater understanding and awareness of the issues so that one may learn to live in a more tactful way. 


\section{Chapter 5: The Lived Experiences -- Portraits of the Participants}

\section{Introduction}

Chapter 5, "The Lived Experiences: Portraits of the Participants," presents nine minicase studies based on data gathered and accumulated from the recorded interviews, observations, journal entries, document analysis, and photo elicitation interviews. The chapter is divided into three main sections: (1) the lived experiences of the pre-service teachers, (2) the lived experiences of the in-service teachers; and, (3) the lived experiences of the college faculty. These three sections not only provide a description of the lived experiences had by individuals associated with the teacher-education program but may reflect the influence one group has upon the other due to the interconnectivity of experiences and activities in-service teachers have with pre-service teachers; faculty have with in-service teachers; and, pre-service teachers have with faculty, which are built into the teacher-education program. Individual narratives within sub-groups offer descriptions of personal experiences and also, provide an understanding of the similarities within the sub-group. At the end of each sub-group discussion, understandings held towards respective research questions were collectively summarized to identify the patterns and themes of the lived experiences of the individuals. In chapter 6 comparisons are drawn across sub-groups to answer research questions and likewise, to characterize the lived experiences some where along the modern-post-modern continuum, as portrayed in chapter three.

Prior to presenting the case studies, a brief overview and history of the sponsoring University's teacher-education program is provided. The purpose of this is two-fold -- first, the teacher-education program (in which the participants of this study are all involved with at varying levels and functions), is the product of 1980's school reform efforts following the 
publication of A Nation at Risk (1983) where, in this publication, teachers were blamed for American students' poor showing against their European counterparts. Many U.S. teachereducation institutions revamped requirements with the hope that higher admission and graduation requirements would translate into better qualified teachers in the classroom, therefore, with the underlying purpose that American children would 'catch up' to the Europeans (Eisner, 1998). While it is important to build the foundation to anchor the proceeding case studies on, the other purpose of providing an overview of the teachereducation program, goes back to questions initially posed by Schubert (1989), "Do paradigms develop one at a time or can different paradigms simultaneously exist within a given area of study? And, if paradigms do exist concurrently, is it a sign of 'immaturity' or a 'preparadigmatic' state?” In terms of this study, this is of importance as I examined current ideas and experiences of teachers presently in the field. What paradigm do the ideas and experiences teacher holds towards teaching and learning fall into? Schubert (1989) wonders, "Do they reflect reconceptualization at the paradigmatic level? Or, do they merely represent tinkering within the dominant paradigm that is still wedded to analytic reasoning and empirical research of a neo-positivist persuasion?”

Returning to the teacher-education program, it originated from the reconceptualization period of education in the 1980's, following the publication of A Nation at Risk, and philosophically aligns itself with post-modern practices. After the University accepted an invitation from the Holmes Group to initiate a teacher-education reform effort, a University wide advisory board was established to begin collaborating on a new vision for education. Three sub-goals were established with the overall goal (A New Vision for Teacher Education at 
West Virginia University -- Report of the Participants of Partners for Progress: A

Collaborative Project for Educational Improvement in West Virginia, June 12, 1992):

...we believe that establishing high quality programs for pre-service and

practicing teachers in West Virginia is a vital ingredient in bringing educational

reform to the state -- reform that is essential to meeting West Virginia's urgent

needs for economic development, improved employment opportunities, and

enhanced quality of life.

But, now the question is whether the program has influenced the ideas and experiences

of the participants more befitting of the modern or post-modern era? While this is not a focus of the study, it is important to mention since educational reform efforts were mounted to counter problems of the modern era. However, I take caution in making that statement because then it might be assumed that a model of direct causation might explain that the result of such teaching and learning experiences may be due solely to the influence of the teacher education program but, that may not be the case when it comes to how individuals privately experience their roles and responsibilities as teachers. So, in light of a teacher-education program based on postmodern assumptions, where do the lived experiences (of this group of teachers) fall along the modern-post-modern continuum, as portrayed in chapter three?

\section{Change in teacher-education and the 5-year teacher-education program}

Historically, teacher education has taken place at normal schools, then later within an university setting. In contemporary teacher-education programs, the route to becoming a teacher typically involves enrollment in 4-year undergraduate teacher education program, completing general university courses and courses of study related to the nature of education, 
e.g., history and/or philosophy of education, general method courses, educational psychology, and a student teaching placement (Goodlad, et.al.,1990).

One argument that mounted against existing teacher-education programs was lengthening 4-year programs, by an additional 1-2 years. In the 1980's, Hendrick Gideonse, then Dean of Education at the University of Cincinnati, was one of many others, who pushed for this change. He defended his notion at a speech given at a conference of the American Association of Colleges of Teacher Education (AACTE), "In no way can the levels of proficiency we must come to demand be achieved in four years...we must do more than merely expose teacher candidates to the wide knowledge they need; we must require that they becomes masters of how to use that knowledge" (Lucas, 1997). Gideonse offered a 6-year plan that included meeting the requirements of a 4-year degree, plus the addition of foundation courses during the junior and senior year, a progressive series of field placements with observations, concluding with student teaching at a designated school that "operated cooperatively by the teacher-training institution and a local school district (what shortly thereafter came to be called a professional development school)" (Lucas, 1997). Later, in a chapter published in Dynamics of Change in Teacher Education, Gideonse (1986) envisioned four images of 'what teaching might be' as a catalyst to think about the kind of future teachers created in teacher education programs -- teacher as artist, teacher as moral craftsman, teacher as applied scientist, and teacher as decision maker.

A few years later, following the release of A Nation at Risk, two task force groups, the Holmes Group and the Carnegie Forum on Education and the Economy, simultaneously studied 'teacher deficiencies' and put forth the following practical recommendations in a series of reports about teacher-education programs: "More stringent admission standards, better 
screening of teacher applicants, an increase in the number of academic courses required, more - or, alternatively, fewer -- prescribed professional education courses, a beefing up of the number and quality of clinical experiences, and possibly, standardized testing of teaching and subject matter competence prior to certification” (cited in Lucas, 1997, p. 90).

As the idea teacher-education reform and professional development schools grew, the Holmes Group (1990) in Tomorrow's Schools: Principles for the Design of the Professional Development School defined the characteristics of PDSs:

A regular elementary, middle, or high school that works in partnership with a university to develop and demonstrate -- fine learning programs for diverse students; practical, thought-provoking preparation for novice teachers; new understandings and professional responsibilities for experienced educators; and, research projects that add to all educators' knowledge about how to make schools more productive.

A professional development school will be a center of responsible innovation where new programs and technologies can be tried out and evaluated. It will be a place where faculty of the school and of the university both experience the 'whitewater' feeling of working at the edge of their knowledge. It will be a place where new teachers, just forming their knowledge and technique, taste the reality of classrooms similar to those where they're likely to get their first jobs, and where they also see the skill, hear the counsel, and feel the support of expert teachers.

From the same executive summary report, the Holmes Group proposed six guiding principles of design for a professional development school: 
1. Teach for understanding so that students learn for a lifetime.

2. Organize the school and its classrooms as a community of learning.

3. Hold these ambitious learning goals for everybody's children.

4. Teach adults as well as children.

5. Make reflection and inquiry a central feature of the school.

6. Invent a new organizational structure for the school.

This vision for teacher-education programs is one that not only that reforms teacher education but is also one that embraces a "progressive vision of the purpose of education in a democratic society," coherent with critical theory and practice, as evidenced by the following characteristics: (1) the replacement of the education major with an arts and sciences major; (2) the recruitment and retention of people of color in the teaching profession; (3) the empowerment of teachers; and (4) the expectation of a clinical experience much more substantive than current student teaching (Fraser, 1992). However, Fraser (1992) cautions that it actually depends a:

Great deal...on who is implementing any specific reform. In the wrong hands, all of these reforms can support an undemocratic profession in an undemocratic society. But in the right hands, these proposals can be the basis for a broadbased reform effort that will help move the process of teacher education in directions more progressive than either the status quo or the changes being adopted by others.

Despite resounding criticism to lengthening teacher-education programs, could building relationships between public schools and teacher-education units serve to not only change the atmosphere of the university, but also that of the public schools? In 1994, Judy Swanson (cited 
in Lucas, 1997, p. 163) profiled three public school and university partnerships that had undertaken comprehensive teacher-education reform initiatives that were singled out as exemplary programs, and the sponsoring teacher-education program of this study, received mention. Swanson noted that the connection between the public schools and the teachereducation units was based on "genuine collaborative efforts, one encompassing team teaching, jointly developed curricula, shared student teacher supervision, and program assessment" and Ken Zeichner (1996) added "represents a philosophical approach that values lessons of practice, and invites experienced teachers to help prepare aspiring teachers, both on site at the college.

The participants of this study were all associated with a 5-year teacher-education program at mid-Atlantic public university, designated as Research One Comprehensive Institution. Upon graduation, pre-service teachers receive a Masters of Science degree in education. The teacher-education program is self-identified as a 'Collaborative' that offers PDS partnerships to its pre-service teachers, public schools, and university faculty. The goal of PDS networks is to "provide new models of teacher education and development by serving as exemplars of practice, builders of knowledge, and vehicles for communicating professional understandings among teacher educators, novices, and veteran teachers” (Darling-Hammond, 1994).

The Collaborative's curriculum is based on the Interstate New Teacher Assessment and Support Consortium (INTASC) characteristics for novice teachers, which also sets the standard for evaluating students in the program. The following belief statements of the Collaborative reveal the anticipated 'characteristics of the novice teacher' (Benedum Foundation, 2000):

1. The novice teacher should have a commitment to and skills for life-long learning. 
2. We believe that the novice teacher should be an effective communicator.

3. We believe that the novice teacher should recognize that teaching is a professional, moral, and ethical enterprise, should understand moral issues and ethical practices in educational environments, and should have developed ethical frameworks which facilitate effective teaching.

4. We believe the novice teacher should be a facilitator of learning for all students.

5. We believe that the novice teacher should have in-depth knowledge of pedagogy.

6. We believe the novice teacher should have in-depth knowledge of content.

7. We believe that the novice teacher should effectively integrate content and pedagogy.

8. We believe that the novice teacher should be a reflective practitioner.

9. We believe that the novice teacher should be aware, of and have respect for human diversity.

10. We believe that the novice teacher should be liberally educated.

A break-down of the 5-year program illustrates a program that is extremely full and challenging however, the Director of the program responded with, "These student's don't have much free time, or even much opportunity to take elective courses...but neither do students working to become lawyers or doctors. This is what you do to prepare for a profession" (Benedum Foundation, 2000). Here is an overview of the program:

- Years 1 and 2: Pre-education for four semesters, with courses in liberal studies, the discipline to be taught, and pedagogy; completion of 60 hours of volunteer work with children in the age range to be taught, and completion of a portfolio about the experience; and completion of the Pre-Professional Skills Test required by the State before contact with schoolchildren; evaluation of students for continuation in the program. 
- Year 3 ("Tutor" Year): PDS experiences begin: two hours per week (for the entire academic year) tutoring students at the assigned PDS; academic program continues; education courses focus on learning theory, psychology of learning, children and adolescent development; and, professional portfolios are begun, organized around Characteristics of a Novice Teacher.

- Year 4 ("Participant" Year): PDS experiences intensify: 5 hours per week the first semester, 14 hours per week second semester; academic program continues, education courses focus on instructional design and evaluation, and on organizing and managing a classroom; and, students are evaluated for continuation in the program.

- Year 5 ("Intern" Year): Students spend the first semester full-time at PDSs -- teaching, managing a classroom, working with a mentor/host teacher, attending faculty meetings and parent conferences; students implement 'action research projects' at PDSs, along the way learning to assess the impact of an initiative, get parent permission for research, gather and analyze data, etc.; students takes a 'teacher as leader' course; second semester is the Professional Development semester -- students undertake special projects at their PDSs, give 135 hours to their PDSs, complete portfolios, and complete academic course work (Benedum Foundation, 2000).

\section{Prelude to The Lived Experiences}

The participants in this study included three interns (or pre-service teachers), three faculty who teach at various levels in the program, and three in-service teachers who hosted the interns throughout their program of study. The following mini-case studies of the participants 
are divided into three main sections: (1) the lived experiences of the pre-service teachers, (2) the lived experiences of the in-service teachers; and, (3) the lived experiences of the college faculty. Narratives revolve around the main research questions of the study and similar to previous discussions, include photographs to illustrate 'visible' and 'invisible' understandings held by the participants. I am choosing to let participants 'introduce' themselves. Introductions are a composite of statements from their respective interview transcripts and it is my hope that the reader will come to know the participants, as I did. For participant and PDS anonymity, pseudonyms have been used in place of the participant's surname and names of schools.

First, I am including a personal journal entry to reveal my thoughts as I struggled to make sense of the huge volume of data collected during the study that cluttered my living room floor that had to be transformed into narratives. Prior to this entry, I completed viewing photographs in Robert Frank's The Americans (1969), slated as one of the first photo journalistic efforts with phenomenological undertones, and likened my role of researcher to that of an artist.

\section{Personal Journal Entry:}

In making a film I continue to look around me but I'm no longer the solitary observer, turning away after the click of the still-camera shutter. Instead I am trying to recapture what I felt, saw, and heard at 24 frames a second; and it's not just happening in front of the lens. I've got to do everything to make it happen...talking....running....cutting....explaining....recording ....erasing...directing....distorting....lying....telling the truth. What a mess until it's done (Robert Frank, “The Americans,” Continuation, 1969). 
Oh, my sentiments exactly. Like Frank, I am solitary in this endeavor now. I am not making a film but I would equate it to a piece of art -- a timely project that consumed many hours as I walked from side-to-side, looking at it from many perspectives, often asking others to look at it and tell me what you see. His photos and my writing, over 30 years apart, but we are not separated by time because in some odd way, researchers are artists. They want people to come see their work, they want people to take time to critique, they want public admiration, while others don't want any of this and just want to complete the task in their own way not worrying about the 'field' they are a part of. In the beginning, there were many of us. Committee members, subjects/participants, friends, and now, there is just me left with an amassed heap of papers and books. As a researcher, I have never known such confusion, angst, and uncertainty. I gave up part of my power to my subjects.... who's lying now? Who's telling the truth? Who's talking? Who's running? Cutting? Explaining? Recording? Erasing? Directing? Distorting? I am. It's not the pictures, it's not the participants, it's me. 'Take some pictures,' I said. I want to see how you make sense of your classroom. But, now, look where I am. I still can't give up my power, still can't seem to let the words come through. What I write is intentional, meaningful, so lost in the interpretation are perhaps some of their best moments; maybe moments I don't like or maybe moments I didn't 'hear' when we were doing the interviews. But, it's still my perspective. How do I get past this? How do I go against interpretation? (Sayers, February, 2002)

\section{Section I: The Lived Experiences of the Pre-Service Teachers}

One PDS, "Bedford Elementary," hosted two of the pre-service teachers, "Amy" and "Lisa," and the third pre-service teacher, "Kerry," completed her placement at a PDS, "Cold 
Springs Elementary," in an adjacent county. These particular PDSs were located within a 20 mile radius from the university and primarily served children from families of middle-to-lower socioeconomic status in rural to suburban areas. 


\section{Meet the Pre-Service Teachers}

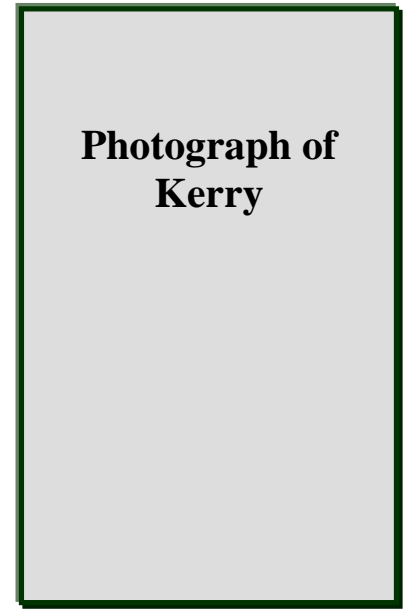

"Kerry"

Age: 23

Major area of study:

Elementary Education

Minor area of study:

Language Arts

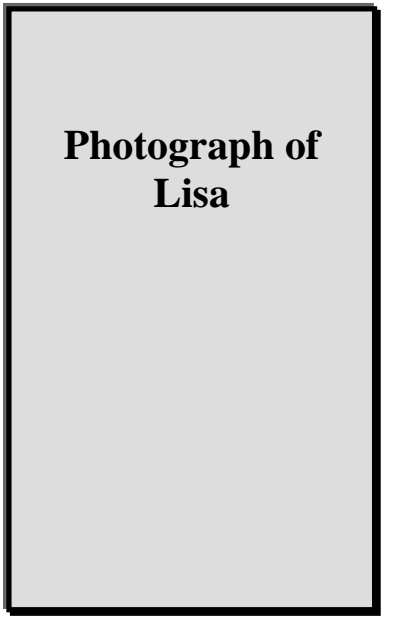

"Lisa"

Age: 22

Major area of study:

Elementary Education

Minor area of study:

Elementary Childhood Education

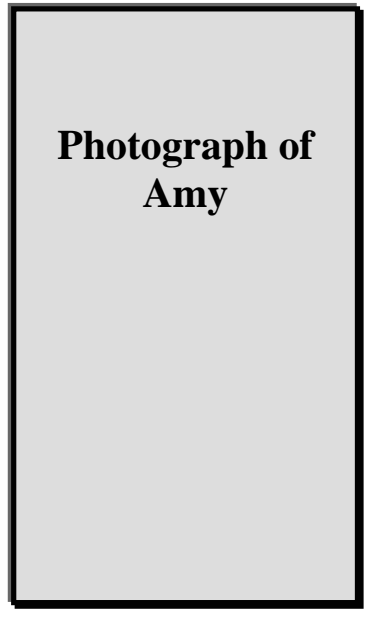

"Amy"

Age: 23

Major area of study:

Elementary Education

Minor area of study:

Social Studies 


\section{The Professional Development Schools}

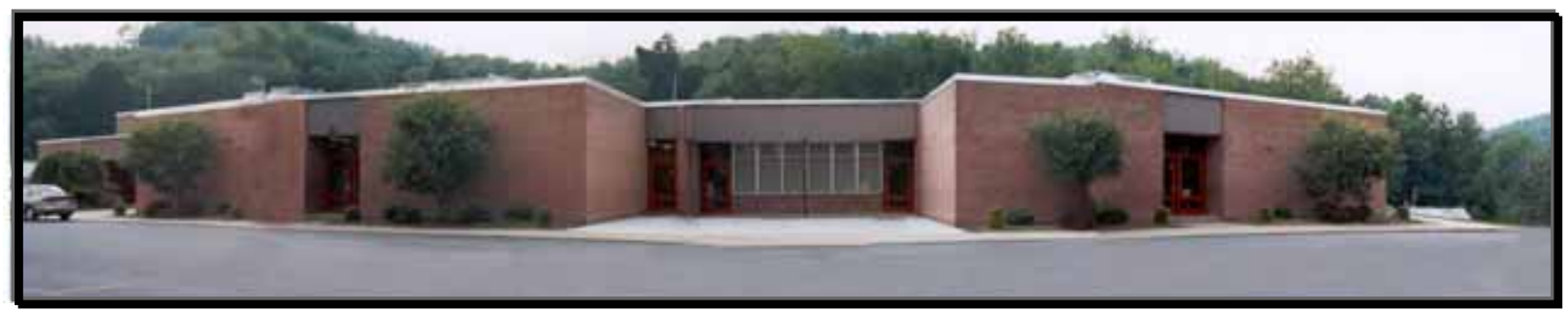

Bedford Elementary School,

A National School of Excellence, hosted Lisa and Amy.

Mission statement: Our task is total commitment to the students

of our school. Through this commitment, we encourage students

to perform to the best of their capabilities and to push for excellence on an individual level so that they will be prepared

to face and respond to a rapidly changing world and its challenges.

(front view)

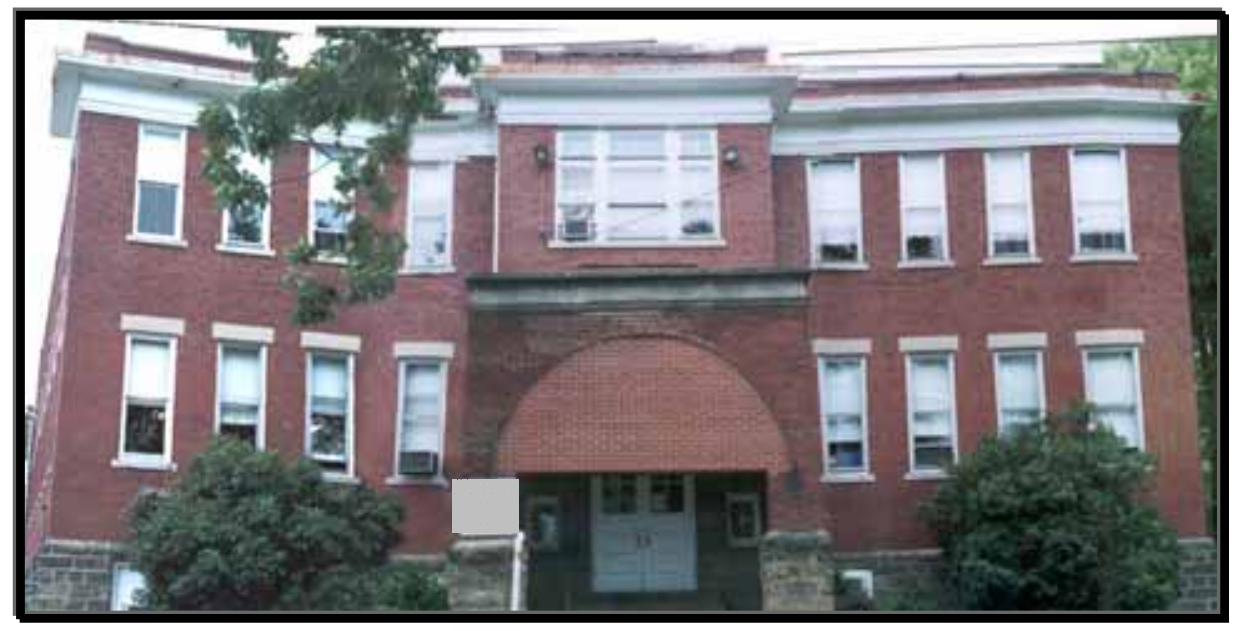

Cold Springs Elementary School

hosted Kerry and is the oldest school in the county.

Mission statement: "To empower all students to achieve their academic potential, to recognize and accommodate individual differences, and to assist the students in the development of self-worth."

(front view) 


\section{Narrative I: The Lived Experiences of Kerry}

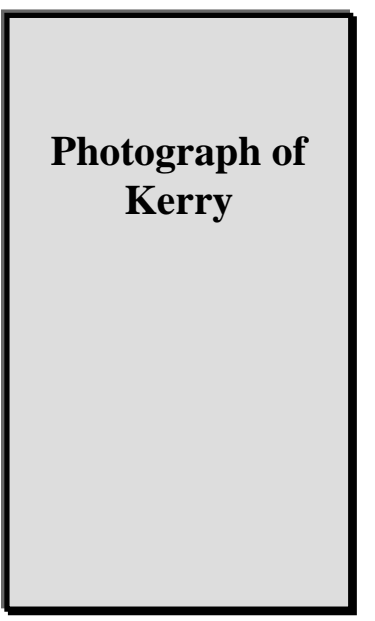

...where I was working...children [were] coming from really low socioeconomic status....bringing interesting hands on activities in the classroom and hearing them go 'Wow! This is fun.' This is interesting and wanting to do more. That was really satisfying. That was really rewarding being able to reach kids who maybe would have gotten lost in the shuffle otherwise...My role as a teacher is to guide students towards new ideas and new knowledge and to be supportive so they can believe that they can do whatever they choose in the end when they become adults (Kerry, spring 2001).

When Kerry and I sat down for our first interview, I had memories of Kerry as a student in a course where I was the graduate teaching assistant a few years back. She was young, charismatic, and stood out from the other students of the course, which was early on in the preservice teacher's program of study. Unlike many of the other students, Kerry participated and asked questions. Now, as she is quickly moving towards me, I am witness to a maturing woman and teacher who has recently accepted her first teaching position for the upcoming school year in Georgia. She is excited but anxious as her final semester in the teacher-education program was coming to an end. She still needed to complete a final research paper for graduation and begin making plans to relocate to larger metropolitan area.

After we exchange pleasantries, we talk about her past educational experiences as a young woman growing up, present ideas and experiences as a student and a pre-service teacher, and about visions of 'what could be' in education, as a means to create the context for 
understanding what has led Kerry to where she is today as a student and pre-service teacher. One of the significant influences that has affected Kerry’s outlook on teaching is her mom, "My mom is a teacher, she teachers pre-school so I think that has always given me a confident outlook on teaching and respect for teaching...” Other influences include memories of "good" and "bad" teachers that she had as a student and likewise, teachers she has interacted with during her pre-service experiences. The final factor that influences her teaching reflects Kerry's ability to see herself in the Other, or as she states, “seeing myself as a student.” These experiences and ideas form the basis for her philosophy towards the purpose of education. She writes in her philosophy of education:

....to guide students towards further knowledge so that they can become productive citizens and members of society and they are knowledgeable in different areas so they can pursue the different areas that they choose eventually.

\section{The Classroom Setting}

Bright colors and nice environment....lots of literature books...for secondary [classrooms] it should be fairly similar and I feel like kids go to elementary school and it is very nurturing and very enthusiastic and then they go to [the] secondary level and it is nothing on the walls, no enthusiasm. That is why students drop out of high school... [in higher education] instead of having several white walls, maybe have rose colored...a little 'pinkier'(Kerry, spring 2001).

Kerry's present classroom is her host teacher's classroom and for this reason, we talk about her current situation and then an ideal vision of a classroom at various grade levels. In the 
Three $4^{\text {th }}$ grade 'young scientists' hard at work in Kerry's classroom in 2001. (Photographed by Kerry) elementary grades, she believes the classroom should offer students a warm, 'homey' feeling and in the same respect, is nurturing, and provides comfortable surroundings. The mood of the classroom must also promote a feeling of safety so students can feel like they can experiment, take chances when trying things over and over, "children are born

inquisitors...they are miniature scientists," as stated in Kerry's philosophy of education. There are cloth curtains on the windows that can be drawn at times of direct sunlight and at other times, opened, but also add decoration. To circulate air in the classroom, there is an overhead ceiling fan. Bright colors, such as orange, can also create an enthusiastic mood in the classroom, "...orange is supposed to make you more energetic and more active," she claims. The lighting in the classroom should not be overhead fluorescent lighting. Kerry also believes that secondary grade classrooms should be set up in a similar manner. Likewise, adds that the 'sterileness' of the white walls in higher education, should be replaced with a "pinkier" color, "so people can focus and be relaxed."

In this particular classroom of 22 students that I observed, male students made up twothirds of the group and according to Kerry, there is one black, African-American student and one Asian-American student; the remaining students are white, European-American. Approximately one-third of the students have been identified as 'inclusion' or special needs. On one occasion, "Sam," a child with special needs who is accompanied by an aide, approached me while I was making observation notes and wanted to know what I was doing and why I was 
here. I explained to him the purpose of my visit and asked with a kind smile, if it was 'ok' with him. He replied, "Yes," and seemingly satisfied, returned to his seat.

Kerry explains that desks in the classroom should be arranged in the shape of a "U" where in the center, activities, movement, and talking occur, and on the 'outside' of the "U," quiet work can be done at desks. In Kerry's classroom, the teacher's desk is located at the lower portion of the " $U$ " and near the 'open' portion of the " $U$ " is an original slate chalkboard of the school, which is part of the history of school. There are resource centers filled with materials in bins, books of a variety of subjects which students can personally choose if done with an assignment early, art supplies such as cardboard, colored paper, scissors, ink markers, etc., several world globes, and bell chimes. Other equipment I noticed around the room includes an audio-cassette/CD player, an overhead projector, and two computers with Internet access located in a far corner of the room. A clock sits over the entryway and on a connecting wall hangs the U.S. flag and a state flag. Student art and posters with educational messages were hanging on the walls. Kerry says that in her future classroom will be of "different pictures of genders in not stereotypical roles," 'chain link' art work is slung diagonally from one corner of the room to the other, and several medium sized bulletin boards. One bulletin board is dedicated solely to the behavioral management plan of the classroom, where in the event students are not following directions or acting out, they are instructed, "Pull a card." Each student has a card with his/her name printed on it. Kerry admits she is the main disciplinarian, "I am fairly strict when it comes to management and I make sure I have specific rules that are laid out in the beginning of the year and students are well aware of them and I don't really budge... of course, I am a little flexible for specific incidences..." 
Kerry acknowledges that due to variety in student learning styles, the classroom set up should be given careful consideration to ensure that students are offered with the conditions conducive for learning. There should be materials and supplies for auditory, visual, tactile, kinesthetic, etc. learners. To illustrate this point, she emphasizes, "The environment should offer opportunities for different types of learning. Not just sitting at your desks but opportunities for different activities. Maybe an area where you really paint and get your fingers dirty...."

The class schedule is based on state requirements interpreted by school administrators:

These are the blocks of time and they decide what you are teaching within those blocks of time...it doesn't leave much time to be flexible...I feel like when I was teaching, we would just get into something and it was time to switch....it was so difficult.

At the school where she has recently accepted her teaching position for the fall, she says: You don't have to teach every subject every day. You can plan it the way you want...so if we are doing a social studies activity and I feel we need more time or there are students who are really getting a lot out of this, you just keep going...I think that allows you to get more in depth of the things if you want to...

\section{Meaningful Experiences}

I remember really enjoying school and really being fascinated by the things I could learn in school...not just book work. Not just answer these questions and the teacher is going to read the answers from the book and expect specific answers. Really going deeper into critical 
thinking and more meaningful activity, more hands on, being active in your learning... (Kerry, Spring 2001).

One of the over-riding themes that emerged from Kerry's conversation, related to meaningful classroom experiences, is the need to always relate the topics of the classroom to the lives of the students. First, activities that are connected to students' lives in a personal way are perceived as interesting and usually well received, especially in terms of student enthusiasm and motivation. Kerry offers this account about a literature unit that focused on a very popular and best-selling Harry Potter book:

...I did my literature unit using the first Harry Potter books in the fifth and sixth grade, it is like pulling teeth to get them to read and to get them to answer questions and to get them interested and I asked the kids not to jump ahead [because] I was going to read aloud everyday because it wasn't on all their ability levels...so we could do our predicting and questions...I would say half the class finished the book early and started the second book because they loved it so much and these are kids who don't like to read generally so that was really exciting.

Second, it goes without saying that students tend to display greater joy when engaged with a subject they are interested in and like, and furthermore, might even think learning is fun and exciting. Next, experiences that are woven into the context of the students' lives are thought of as useful or applicable. Finally, experiences that are useful are experiences that are also memorable. Memorable activities take on two characteristics, according to Kerry, that is, activities need to combine head and hands. There must be thinking and doing opportunities, "through hands-on investigation, inquiry, and manipulative materials." To honor the Chinese New Year, Kerry's class participated in several activities, which she describes with pride: 
I would pull aside groups one at a time and we started with a brown paper box and we made this Chinese Dragon mask...the mouth flapped like this...I looked at several books about Chinese New Year celebrations and the dragon dance and the lion masks...at how they were constructed...How they danced...I guided them and gave them some suggestions but they chose how to do it all....they took turns getting underneath it [the dragon]...They also learned how to make Chinese letters, the words, the symbols, say 'Happy New Year' in Chinese... at the end of the last week, the two third grade classes come together in one classroom and we cooked in a wok Chinese food....They got to practice with chopsticks and then they ate their food with chopsticks. They had fortune cookies. It was really neat and they really liked it and it was a real hands on experience that I think they learned from it and they will always remember. I think it's important for lessons to be 'rememberable' because I remember when I was in school if the lessons were 'rememberable,' I would remember the activity first and then thought [about] the concept we learned from the activity.

The relationship between the student and teacher is especially important and a vital component to understanding the needs and likes of students. Kerry believes that teachers need to talk with students about their social lives, personal lives, and extracurricular activities, as well as, recognize that the student is a human being and being a student is only one aspect of their life:

I make sure I ask my students personal questions...I know your brother was in the hospital. How is he doing?...If their parents are going through a divorce. Things like that can affect their work in school and if you are not aware of that 
then you might think this student is not smart. They are not paying attention, they are slacking.

Kerry tended to value relationships with students and is of the thought that if students believe that the teacher has a personal interest in the student, it leads them to be more interested, "in you and what you have to say." Interwoven into this mixture of the studentteacher relationship is also the sense that if the person cares enough to ask about the events in another person's life, the environment is supportive yet, respectful, and brings awareness to the differences or in some cases, the 'baggage' that children carry with them each day to school. One of the ways that Kerry practices this is by reminding herself that teachers, "should not treat them [students] as though they have had the same life experiences." However, these 'differences' should not always be viewed in a negative light because, "Our country is extremely diverse.... Our job as educators is to remember students come to us with varied viewpoints, talents, and abilities." But, rather it should be a beginning point through which students and teachers share stories about their personal culture or their concerns about social injustices. "It is important for students to learn from an early age to respect different cultures, races, and lifestyle." Kerry allows students to tell stories of their personal lives with the hope that through sharing of stories, students come to see classmates in a personal and compassionate manner; furthermore, she hopes this could be a route to incorporating issues of social justice and multiculturalism in the classroom. It is important to honor and celebrate the diverse experiences and backgrounds of students for them to feel the pride in who and what they are. The diverse range of student needs becomes apparent to students and teachers alike, as they tackle the sensitive issues together. 
Kerry described a recently completed social studies unit on the Civil War. She was aware that the African-American students in her class might respond differently to issues of slavery but used it as an opportunity to discuss sensitive issues:

You bring up these discussions and you were talking about how people were mistreated and talking about things that happened...they [African-American student] are members of our classroom and they are going to feel differently than the rest of us because we still can't completely identify the way they can because maybe their ancestors were related...

Kerry believes that it is important that students should be given a voice, given choice in their education; without such, they would be disempowered for twelve or more years of their life. Kerry makes this point, "...it is frustrating being a student because you don't feel like you have any power. You feel like many things are beyond your control. You don't really have a big say in your education and you don't get to really choose what things you need to study."

In Kerry's philosophy of education, she writes, "I believe that education can work towards the good of both society and the individual, since the two go hand in hand," which has a reminiscent ring to it, similar to the Social Reconstructionists of the 1920-1930's. Kerry reminds us that she approaches her teaching position, as not only that of an instructor, but as moral agent, as well, which is telltale of some of the values she associates with the enterprise of education. She believes that purpose of education is, “...to guide students towards further knowledge so that they can become productive citizens and members of society...” In this, not only was Kerry defining her role as a teacher, but this is also a statement about the type of individual schools should seek to produce. Student 'work ethic' (or lack of work ethic) was noted several times in my notes and appears to be understood as a function of class status and 
furthermore, becoming (or not becoming ) a productive citizen. Kerry discusses this in light of her frustrations:

...children were coming from really low socioeconomic status. They came to school not really being interested in school...they really had no work ethic...because of their background, they come in with different points of view from home like lack of work ethic or parents not wanting them to go to school...They don't' value education.

In one of my observations, I recorded the following remark Kerry makes towards a student (which is in reference to the student completing a class assignment earlier than others), "I like the way Heather is reading a book since she is all done early." I wondered about the message this sent to other students? Does it mean that Kerry appreciates students who take initiative to keep themselves busy? Who are quiet? Who do not bother others? I do not make further inquiry into this but jot a few notes to myself.

\section{Teaching and Learning}

We must attempt to reach all our students in ways which they are best suited for by including as many instructional methods into our practices as possible.... At the same time, not all children can be taught in the same manner. Students have different learning styles, and as educators it is our responsibility to provide students with equal opportunities for growth (Kerry, Spring 2001).

During a visit to Kerry's classroom, one of the first things that grabbed my attention was the energy that filled the classroom, which I attributed to the flurry of activity of these young bodies. Kerry was moving from one student to the next; she was in front of the room, then in back of the room; children were up and down from their seats, some working alone, some 
working in groups -- a constant raising of hands with questions, concerns, and need for bathroom breaks or the water fountain. The flurry of activity was complete with overlapping voices, the 'creaky' wooden floor produced by small tennis shoe clad feet, and the occasional sound of other nearby classrooms. At one point, Kerry's contact lens pop outs on her cheek, she catches it, and pops it back in, not missing a beat. Amazing, I write in my notes.

Other items that catch my attention are the daily reminders written on the chalkboard for students. One of the announcements states that today students have physical education class. Other items written on the chalkboard included a "Sponge" activity, which appears to be a review of concepts from the previous day's lessons. I later inquire about the "Sponge" activity which Kerry then confirmed my suspicions. When children arrive at school in the morning, they are to complete the "Sponge" activity prior to morning announcements, which come through a building wide PA system.

Kerry's presence as a teacher is felt, but is not reflective of a time when the teacher dominated all aspects of the life of the classroom. She believes that at this grade level the classroom should not be teacher-centered but, on the other hand, recognizes that teachers do need to have the final say in classroom matters, especially when a classroom, such as hers, has so many hands on activities.

Kerry approaches teaching as an endeavor "to inspire life long learners who will have a strong desire to contribute their talents to society” and part of this endeavor is enticing 'audience members' to join the performer in an odyssey. She remembered teachers who were “...really charismatic. Really characters. They were almost like they grew up in a theater...they really put on a show for us.” One specific memory she shared was about a first grade teacher who had students construct a city in her name, "Mrs. See who was Asian and we created See 
City." On another occasion, the audience members got involved in the performance, "We were learning about ancient Egypt and we had to act out scenes about things we had learned...” Other attributes that Kerry includes as vital to the act of teaching is establishing rapport with students by extending a smile or welcoming students to class, "She would say, 'Hi. I am so glad you are here. Thank you for joining us today.' She just seemed so happy at what she was doing."

Creating lesson plans is a part of Kerry's everyday planning for the activities of teaching. When planning, she takes into consideration students "abilities and areas of weaknesses that need strengthened,” prior knowledge, class dynamics, various learning styles, the various multiple intelligences, and issues of race, class, and gender. The state's Instructional Goals and Objectives (IGO’s) are included at the top of every lesson plan. But, she also makes adjustments to the lesson following the cues of the students:

...I write up a lesson plan...but if we take a detour and we go off but it is pertinent to the lesson or the sequences in your lessons gets mixed up, that is what is suiting the needs of your students the best. If that is the questions they are bringing up at the time then that is how it is flowing...

Textbooks play a role in Kerry's teaching and are further supplemented by other tools such as information packets, manipulatives, flash cards, and student journals for note-taking purposes. The role that textbooks play is related to the state's IGO's and what textbooks provide is the "structure and progression of order" of information. Kerry indicates that she tends to follow the information in textbooks more so when teaching math and social studies than with the other subjects, and likes the set up of "skilled practices." Even though Kerry is, 
in general, against reading straight from the text, she expressed that in social studies, she read "off and on straight from the text even though I know the kids get really bored with that."

In the area of literature, Kerry prefers using children’s literature that students are especially interested in or excited about. The class voted upon the enormously popular children’s literature series about the adventures of the young wizard, Harry Potter, after Kerry came upon a list of best children’s books. Likewise, in a unit recently completed on the Civil War, Kerry mentions that a book about children during the Civil War era provided a glimpse of children’s history, "We had a story that told about the Civil War from a children’s point of view and so that helped because it broke it down to their level....so they can more identify with it...so it is not all these old people...”

A common theme in Kerry's teaching is a strong belief towards hands on, active learning; this translates into a teaching and learning processes that are creative and engaging. Kerry includes a number of creative lessons in her teaching repertoire by combining art and social studies, movement and science, and multiculturalism and literature. For example, from a lesson that demonstrated the election process, students were elected for 'offices,' gave campaign speeches, created a voting ballot, and created campaign posters. In another lesson,

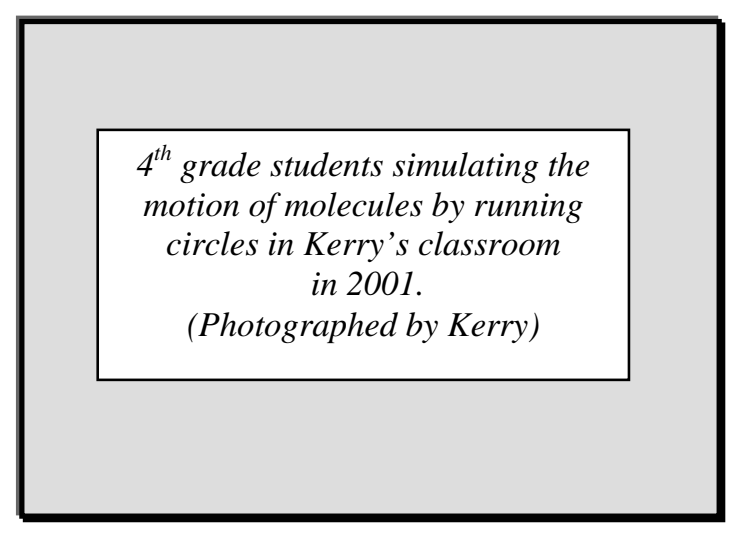
students were investigating molecule movement in various forms of matter, and were placed in "small groups of three, four, or five people...they had to act out the ways of molecules in the solid, liquid, and gas...in liquid molecules, they spread apart but they are also able to slide pass each other...the gas

[molecules], they moved really quickly...” 
Based on my interactions with Kerry, much of her teaching revolves around student 'doing' and 'thinking.' To my surprise, she sheepishly admitted, “The students did really well on the assessments after these lessons were implemented and so it shows that they weren't just having fun. They were really learning as they went so that is what was important.”

Kerry's attitude towards assessment could be described as humanistic and practical. She understands that as a teacher, she is bound to a practical side of assessment as required by the school and to some extent, the state; however, from a humanistic standpoint, she believes that some children do not test well on standardized test formats, which is a reason why she offers other ways to help children feel successful. She stresses, “I am supportive. I don’t strand kids up at the board and 're-kill' them in front of the class.” Theoretically, if she had the power to choose a format for grading, she prefers a "Pass/Fail” system:

...because so many kids get discouraged by their grades even if they are working hard, you know if they get a ' $\mathrm{C}$ ' and they are doing just fine and they are discouraged...but if they are really smart and I know they are not trying and are being lazy then that is not going to be as good a grade from me.

Kerry defines learning as the potential to "acquire knowledge about a broad range of things. You can become successful in skills that may be varied and in the skills you are interested in.” In support of this, she writes in her philosophy of education, "I believe it is very important for our students to have a well rounded education. Students should be taught in a wide variety of concepts and ideas, whether or not they apply directly to the students’ lives.”

One activity that I witnessed, that incorporates many of the themes presented in this narrative, was the "Sparkle" game, which is a spelling review activity. Students lined up in front of the chalkboard and Kerry announced a word for the group to spell. The first person in 
line, spoke the first letter of the word; the next person, gave the next letter, and so forth until the word was spelled. If a letter led to the misspelling of a word, the child sat down and the game would then continue.

Kerry: "The word is wonderful."

Student \#1: "W"

Student \#2: “O”

Kerry: "I don’t know if I could spell these words.”

Sam: "Maybe I should be the teacher."

Kerry: "Maybe one day you will be.”

Sam: "I'll be a basketball player."

The physical education teacher arrives to pick up the students for gym class. Most of the students are wearing tennis shoes. 


\title{
Narrative II: The Lived Experiences of Lisa
}

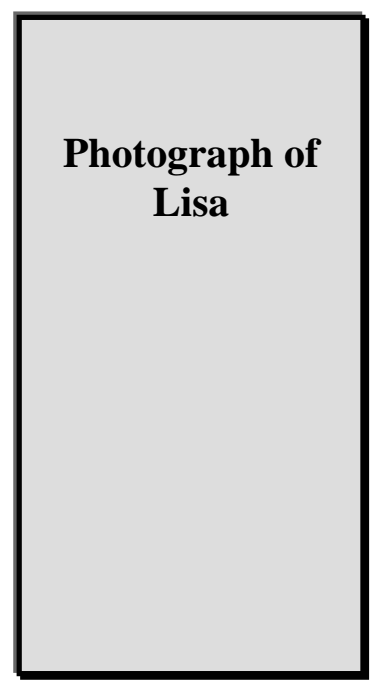

\author{
In my elementary years, I always looked forward to \\ going to school for social activities. Junior high I \\ didn't like school. I didn't like my classes and I \\ was just a changing teenager. In high school, this \\ changed again. I started to enjoy school. There were \\ more activities. I was given some choice and I had \\ to get ready for college. I enjoy learning again and \\ reflecting now, I've gotten a lot out of my teacher
} preparation program (Lisa, Spring 2001).

Near the end of the spring semester, Lisa and I met late one afternoon at a local café for coffee. She has recently returned from jogging a few miles and still dons her jogging apparel for our meeting - a pair of nylon jogging pants and a matching hooded jacket. Even in this 'athletic state,' she is glamorous. As we sip on our coffee, I notice that she is wearing a necklace, bracelet, earrings, rings, and her nails have been professionally polished. I had never seen her in this capacity but she carries herself with confidence and as we are making informal conversation, there are many individuals who Lisa recognizes and makes eye contact with, which I mentally note as a sign her social nature. What is so uncanny about this picture is that Lisa reminds me very much of her host teacher (who is introduced in Section II: The Lived Experiences of the In-Service Teachers) and at times, even the conversation, especially in terms of language and tone, reminds me of her host teacher. Now, in retrospect, there were times during the interviews with Lisa that I felt as if the conversation was superficial. Her answers were quite generic - not the way that a generic pill resembles a brand name drug and can guarantee its user the same effect per dose but in the sense that she spoke of teaching in such 
overly used bookish terms that I almost believed that she must have read a book right before we met for her to come out with such straight forward answers. In fact, she used all the right 'buzz words' about teaching and learning but the conversations 'felt' as if they lacked depth.

Sometimes teachers become so close to their craft that I think it is difficult, at best, to verbally articulate what it is that they do every day for all their students.

Looking back at some of the influences that have shaped Lisa's beliefs towards her role as teacher and the purpose of education, she shares a touching story about herself and a kite that wouldn’t fly in third grade. Her teacher "brought in a kite to help me, for me only...she went out of her way. We all went outside and I flew my kite.” The generosity of the teacher and her desire to want Lisa be successful, influenced Lisa to enter the field of teaching. Another not so positive influence on Lisa was an event, which she witnessed, wherein a classmate answered a question incorrectly and was instructed by the geography teacher to stand up for the remaining class period. Lisa empathetically explains, “I will never do that to my students.” These experiences, as well as, other experiences and ideas, form the basis for her philosophy towards the purpose of education. She writes in her philosophy of education:

Through education, it is our goal as teachers to provide an education for the students that will be beneficial someday. There are many important aspects that help create a warm environment in the classroom. With the help of parents, friends, community volunteers, and tutors, students are on their way to becoming strong life-long learners....you have to start somewhere and education is the first step in everybody’s life.

\section{Classroom Setting}

What I normally do is involve the community. I had guest readers come in, guest speakers come in from the community and read to the class 
to try and involve other people than teachers or people that they're familiar with...So I try to involve the students' lives outside of the classroom in the classroom (Lisa, spring 2001).

Lisa feels strongly about inviting community members and other guest speakers to read to students, talk about work-related experience, or expose children to different viewpoints. Unlike some of the other participants in the study, Lisa believes that the community is a valuable resource because, "I try to involve the students' lives outside of the classroom, in the classroom." She will be one of the first in this study to recognize that the public needs to be in the public schools because "education is a societal issue."

Lisa’s present classroom is her host teacher's classroom and for this reason, we talk about her current situation and then an ideal vision for a classroom at various grade levels. In the elementary grades, Lisa voices a similar opinion as Kerry, and explains that "vibrant colors make a classroom warm and inviting for students, lots of pictures on the walls, things that they could look at, like posters, things that they can relate to, things that they're interested in, a lot of materials, activities that they could do hands-on inside or outside the classroom...a literacy corner surrounded by books...” The importance of creating a pleasant atmosphere is for students to 'feel' as if they can forge bonds with teachers, which at this grade level can impact their learning. According to Lisa, the classroom environment at the secondary level is not as important because the child's attention is turned away from the physical environment to other “distractions” which she speculates is a by-product of the student's changing attitudes towards school.

The day I went for an observation, Lisa’s classroom was one-quadrant of a ‘pod,’ i.e., an open classroom housing four separate groups of students. There were 23 students -- six boys and 17 girls -- sitting at six round dining room like tables, complete with center floral 
arrangements. There are mobiles hanging from the ceiling of an Easter theme, posters, bulletin boards, and prior to classes beginning in the morning, another teacher from the 'pod' makes morning announcements -- weather forecast for the day, birthday announcements, and then, the teacher sings Happy Birthday to students. The moral lesson of the day is 'Two wrongs don’t make a right.' Also, the day’s “body machine checks are for nails, shower, wash and brush teeth, use deodorant...use Young Teen Spirit... and don't forget, this is the best country in the world.” I make a note to myself about the promotional slant of the deodorant product. Not only were there pod announcements, but also school-wide announcements are made on the PA system. One morning during an observation, I counted three interruptions. This school is privileged to have computers in every classroom, TV/VCR combinations, overhead projectors, whiteboards, and a larger screen in open sitting areas for projection purposes.

Lisa mentions several times how students like to sit on the floor - either working as an \begin{tabular}{|c|}
\hline $\begin{array}{c}4^{\text {th }} \text { grade students in Lisa's } \\
\text { classroom in } 2001 \text { move } \\
\text { towards the front of the room } \\
\text { prior to the start of a reading } \\
\text { lesson. }\end{array}$ \\
(Photographed by Lisa)
\end{tabular} individual or in groups - and how they especially enjoy coming up front to sit on the floor when she is in the rocking chair because, "they like to be close to the teacher.” Most of what I observe one day consists of just that. During the time I was there, a language arts lesson and a health lesson on bones took place and each time, Lisa asked for children to join her up front. She sat in the rocking chair with the text situated on her lap while the children gathered around her feet. Some of the children, I noticed, furthest away from her, were slowly working into a prone position, while the one's closest to her, sat upright with legs crossed. 


\section{Meaningful Experiences}

Diversity is one of the most important aspects that is learned in the classrooms throughout the country. Each student in the classroom may learn different and their needs may be accommodated in several ways. It is important that teachers recognize the many different unique characteristics that each child may portray. Students need to be exposed to the many different traditions and ways people live (Lisa, Spring 2001)

The above quote is cited from Lisa's philosophy of education and I am initially led to believe that diversity encompasses issues of race, class, and gender, but as I read on, I realize Lisa approaches issues of diversity in terms of meeting individual student needs, that is, needs based on learning styles and making accommodations for children with special needs. She explains that each child is different and one way that she begins learning about children and their interests at the beginning of the year, is an activity, which entails children making individual slides on a PowerPoint program. A digital photograph is taken of students, uploaded onto the computer, and students input five pieces of personal information, which is later shared with the entire class in a presentation. Lisa records the information and from time to time, will refer back to the slides to create activities that are related to something they like outside of textbooks. In a similar fashion, another way she attempts to bridge the gap between herself and students, is through a personal student inventory that she passes out at the beginning of the year, "it gave me a feel for what they enjoy doing, their favorite subjects, why they like school, why they don't like school. I think it’s important to get to know them because you have a whole year with them....” 
Because it is personally important for Lisa to learn about the kind of lives that students lead outside of school, she incorporates assignments into her teaching where students do research at home, "like family background or family trees," where they need to talk to family members to gather information. She finds this especially useful when certain situations present themselves and she needs to be familiar with the home lives of students “...if there's a death in the family and it's happening to somebody in our classroom, you can discuss these kinds of situations that occur outside the classroom and you can tie that in with health or social studies." The other side of this type of activity indicates that when children's learning involves things they are interested in, they become more involved.

As for dealing with issues of race, class, and gender, Lisa explains, "I’ve never had a problem to deal with. I've never dealt with that. All my students are white but I do try to put a diversity strand into my lessons, for instance for sight impaired. I move them up front and make modifications/adjustments.” It must have been my own way of not feeling satisfied with her answer, but I further probed into this area by asking her to think about her students when they go to high school - how do you prepare students for high school knowing that it is more diverse? She responds, “Students are 'given’ a fact and each day, newspaper articles are brought in. That is part of their reading assignment. We write something on the board and this helps to keep them abreast of world events.” The multicultural reading program she is referring to includes the story of Rosa Parks and from my observation notes, they have also read a story about baseball great, Jackie Robinson, in which the main character is a young woman from China who wants to learn more about American baseball. Lisa claims, "I mainly use literature and recognize that each child is unique.” As an elementary education pre-service teacher, Lisa 
must be able to teach all the subjects but regularly weaves children's literature across the content areas.

Building relationships and rapport with the students is an important aspect of Lisa's teaching. She takes a caring approach towards her students and shares several recollections of events that provide evidence of the types of relationships. On Monday mornings, she takes time for the class to share events that happened over the weekend. She feels comfortable talking about her personal life because she wants students to know that she is a human with feelings and emotions, and does not spend all her time at school, as many elementary children often tend to think about teachers:

I like to know about them as much as they like to know about me. I'm very open with them and let them know what I did over the weekend....I let them know that I'm human, too...they don't realize that until you actually tell them, make them aware of that...

Another story she recalls, that is especially touching, is about a going away party students gave for her at the end of her student teaching experience. The 'gift' she received at the party is perhaps a gauge of the types of relationships she established with students. One of her students created a storybook "from the things we did every day....from day one to the Christmas pageant. In the book, the student wrote me a letter and in it, it said, 'go and show the world what you're made of.'”

I witnessed the following interactions of Lisa with her students which I believe is reflective of the type of relationship she has established and furthermore, the qualities she values in relationships, more specifically -- caring and respect - and, nonetheless, the qualities she values in students: 
Thank you...you're welcome.

I am ready to start...everyone please look up here.

Please listen, boys and girls. I am going to pick the 5 quietest people to help me pass out snacks.

I like the way Chris is working and the way Vickie is working.

While building relationships with students is important, she also expresses frustration when her efforts to help students be successful prove fruitless. I am inclined to believe that she wants students to be successful and will go to any length to help them, which is illustrated here, “...if they need extra help or something I will provide help for them extra worksheets, extra practice. If I can stay with them before or after school, you know, anything to help them succeed in a classroom situation.” But, often times her efforts do not translate into student success and this is where she becomes frustrated, "I work so hard to help students, motivate students, get them involved and sometimes they just don't want to learn...they just give up on school...They're just there because they have to be there.” But, looking back to Lisa's past, we are reminded of a time when she didn't like school either, where she alluded that many of her frustrations as a student was due to "lack of choice" and she was "forced to take certain classes.”

\section{Teaching and Learning}

Never more so in history than today, have we begun to see the necessity for a lifelong learner. Today, one can witness a CEO of a company going back to work to learn how to use computers, as well as, mothers dropping her children off at school and then going to class on her own (Lisa, Spring 2001). 
The above statement, cited from Lisa's philosophy of education, is a unique perspective in this study. In addition, she writes, "I believe in promoting life-long learning for students.” On this and other occasions, Lisa mentions change as a part of human development -- more specifically, once when she was speaking about her own experiences, then about students in the secondary grades, and the above statement - which is an appealing thought, especially in terms of this study, as 'change' is one of the focal points.

One important factor that she attributes to some of the changes she has made in her teaching style is due to interacting and collaborating with other teachers. She strongly believes that pre-service teachers need to see other teachers teach because pre-service teachers need role models. "I think it's important to get out there and to observe as many teachers as you can so you get ideas from them and then expand on that...I've been very fortunate to have worked with outstanding teachers and exemplary models.”

Lisa philosophically defines the nature of teaching 'through' student learning and the inner qualities a teacher should reflect, which she describes in the following, "teaching is the importance of what the students learn and being a good teacher means the teacher is caring, compassionate, and enthusiastic.” Furthermore, teaching should incorporate "hands-on activities as much as possible as opposed to the activities in the textbook.”

$4^{\text {th }}$ grade students in Lisa's classroom acting out their interpretation of a poem in 2001.

(Photographed by Lisa)

During my time in Lisa's classroom, I observed several lessons and some of what I witnessed would not be characterized as 'hands-on' but I also take into account here that this is merely one day and this could not fully represent her teaching to its fullest extent. Over a two- 
hour period, I observed a language arts lesson focused on parts of speech and a health lesson related to the skeletal system. Much of what I saw consisted of Lisa posing questions to students and students responding. Lisa sat in a rocking chair positioned at the front of the room, stationed directly in front of a chalkboard where she would occasionally turn around and write examples on the board. Children moved up front to be near her. The textbook lay on her lap and likewise, as students sat cross-legged on the floor, they, too, had the textbook cradled on top of their legs. She asked for students to volunteer to read a sentence out loud and then fill in the blank with the appropriate answer. After which time, students were instructed to fill out the corresponding worksheets to the lesson - they could choose to work alone or in groups. The other lesson I observed as a health lesson on the skeletal system. The lesson began with a quick review of the systems they studied the day previous and then continued on to the bones of the body. As a teaching device, Lisa uses a song to the tune of 'Row, Row, Row Your Boat,' to memorize and later, recite the bones in the body. After learning the song, Lisa adds gestures to match with the respective bone they are singing about. In my notes, I write, very cute. Of course, the children turn towards me as they are singing. I nod, to let them know I am listening. Lisa is attentive to the individual needs of students and in her preparation, she reviews student records and talks to teachers students had in the previous year because, "it is important to know some of the background that the students have prior to getting the student.” As she systematically moves ahead in her planning, she takes into consideration the state's IGO's and any other needed modifications to the lesson. However, outside of the traditional acts of planning, Lisa brings in a personal component, "I usually do what I feel is right. I put myself in their shoes" which seems to suggest that she is trying to be compassionate and empathetic towards her students. Early on during her student teaching experience, she admits that she 
relied heavily on the advice of her host teacher for planning class activities, and eventually gained confidence to “try out new things on my own. If it works great, if it doesn't, it fails, and I then I just talk with other people.”

The lessons I witnessed relied on textbooks and workbooks but, in general, Lisa feels textbooks are:

...good to have, it teaches the basics but I think there are so many more activities that you can do beyond the textbook. I think that students get bored reading...I think they can make the activities so boring and that kind of turns kids off...they're helpful but not the prime source when teaching.

Lisa speaks of herself as a college student and confesses, "by the time you get to college, it's like you don't even want to read anymore....that's one of the most important times that you need to be reading a textbook."

Lisa's attitudes toward grades and assessment is similar to Kerry's - she understands that as a teacher she is required to assess students and give them a letter grade at the end of a nine-week period, but she does not solely rely on tests, “I don’t think it’s fair to base a student’s performance on a test.” Rather, she incorporates ample opportunities for students to feel successful and hopes that by reviewing the student's efforts in class participation, homework, and group involvement (where she factors in creativity as well) will help students feel successful if they are not 'good' test-takers. However, if students are not doing well, she points out that this may mean that she needs to change her teaching style and strategies.

Continuing with the theme of change, Lisa believes it is the teacher's responsibility to promote life long learning in students and furthermore, believes that "children are constantly learning and growing.... learning is an everyday thing. You will learn whether you want to 
learn or not.” In this statement, there are hints that Lisa recognizes that children grow and change, likewise, learning takes on an 'informal' slant, that is, learning takes place away from the classroom, but this type of learning is just as valuable. Later on, when I asked Lisa about the nature of learning, she says, "Learning involves a variety of things and I think it is the importance of the teachers speech and the activities they provide with the lesson to get the message across to the students...." Interestingly, the nature of learning is defined 'through' the act of teaching. Lisa claims that she learns best with "engaging lectures, discussion, and a quiet atmosphere to study.” As a teacher, she believes that the times when students are truly learning are characterized by students working in groups; groups working towards a set of common goals which she will describe as a 'team effort'; and, when students are conferring with one another to answer questions.

$4^{\text {th }}$ grade students in Lisa's classroom read to one another while working in small groups in 2001.

(Photographed by Lisa) 


\section{Narrative III: The Lived Experiences of Amy}

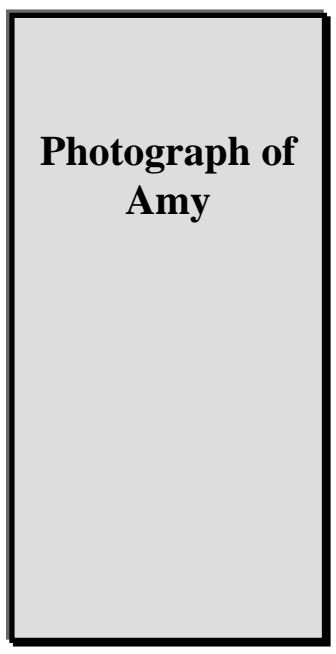

I feel it is the responsibility of parents, grandparents, guardians, and teachers to encourage children to investigate what life is offering and convince them that they are able to triumph over environmental limitations.... I had poor school experiences...I actually took the idea that nobody wanted me to succeed...they didn't expect me to do well. I was from a lower class family...school trained me to be a drop out... they expected me to fail (Amy, Spring 2001).

Amy and I met at a pre-arranged location and as we approached one another, her blonde hair was pulled back, and she was wearing a pair of faded blue jeans, a white t-shirt mainly hidden by a hooded sweatshirt, and sandals. By first appearance, her round face, blue eyes, and big smile do not give the impression that she is nearly at the end of a challenging 5-year teacher-education program. Unlike the other participants of the study whom I had previous relationships with, Amy's participation was questionable and it would not be until we had met a few times, when I realized that her stories and life experiences contributed a perspective to this story different from the others.

Similar to Kerry, Amy is also in the midst of finding a teaching position for the upcoming fall semester, but, unlike Kerry, she has yet to secure a position. She has focused her job search in the states of Virginia, Maryland, and Pennsylvania, and researched the teaching certification requirements for these states. One of the first topics of conversation we 'bounce back and forth,' as we attempt to overcome the awkwardness of not knowing one another, is the uncertainty of finding a teaching position for the fall. She is concerned that her low test scores 
may negatively influence administrators and affect her chances of attaining a position, but she believes that the strength in her teaching abilities rests in her creative approach of involving students in their learning.

To gain an understanding of Amy’s past and present educational experiences and ideas related to teaching and learning, this story could be better understood as a personal journey to overcome the odds stacked against her which she spoke about with anguish and pride. Furthermore, this story that does not end at her graduation because she continues to witness the disparities and injustices in the educational system where, she, herself, hopes to serve as a role model to struggling students in the classroom. The irony of the story is that even though, "nobody wanted me to succeed in high school...I thought what was the one thing I could do to save people's lives who were in the same position? I wanted to actually make a difference in their [students] lives so I went into teaching.” Her first positive experiences in the classroom came in her senior year of high school as a result of volunteering time in a teacher's classroom "to check out teaching.” The teacher who invited Amy into the classroom is the individual whom she credits with being one of her significant influences. She described her memories of this teacher, “...she was great. She could play the piano...she was creative...she was everything. I watched her and was completely in awe.” Other influences included "good” and “bad” teachers, which served as reminders of “the things I did and didn’t want to do. I didn’t want to stand in front of the classroom and constantly preach. They say you 'preach teach.' I wanted my students to have input and I wanted to make the class lighthearted...” The final influential figure in Amy’s life is her husband -- he is Korean - which she quickly interjects into the conversation. 
These experiences and ideas form the basis for her philosophy towards the purpose of education. She states:

To prepare youth to go out into society and be productive and efficient citizens. Therefore, I believe that it is essential for teachers to represent and model morals and values within the classroom in order to educate students. I also feel that a well-developed curriculum provides passageways for teachers to subtlety educate students about the importance of their role in society.

\section{The Classroom Setting}

.... if the teacher stands at the door on the first day of class and invites those students into the classroom... They will set the tone for the rest of the year.... Whenever the students come into the classroom the first day should be filled with 'who are you' and 'who am I' kinds of activities. No matter what grade they are in.... I think then it sets up the roles, guidelines, boundaries and I think that sets it [curriculum] into smooth sailing... (Amy, Spring 2001).

The opening statement in Amy's philosophy of education reads, "I believe that the nature of a child is deeply rooted in their environment," and what is especially interesting about my conversations with Amy is she will be the only individual who includes the home-life of the child as being equally important to that of the classroom setting. The foundation for learning rests on an environment that is a positive, warm and loving place that encourages children despite limitations placed upon them through social class distinctions. One memory she shared related to this is about her parents who taught her to read and write at an early age but when she arrived at school, she learned she was 'poor' because she was placed in a lower reading group despite knowing how to read: 
I go back and look at my parents and those situations there in socioeconomics

[sic] and that has encouraged me to continue and show the students who, they may be poor but they may not realize it because their parents who show them so much love...I never knew I was that poor...I never thought of myself that way until I went to school.

Amy reminisces about her childhood and claims that positive learning experiences can be fostered through an environment rich in communication, that is, rich in verbal and nonverbal forms of communication. Likewise, the classroom setting can also foster positive learning experiences and the one thing teachers can do, according to Amy, is to learn about a child's history prior to coming into the classroom. Amy expresses that teachers need to be concerned with, "how am I going to present myself...review student records..." or when "the teacher stands at the door on the first day of class and invites those students into the classroom it means that the teacher is concerned already.” By showing concern and 'asking' students to "be part of a learning environment," this is a cue to students that "their teacher is willing to work hard to make sure that all of her students understand.” In addition, other forms of communication that teachers can utilize to reach out to students, parents, and community members, include "phone calls, newsletters, one-on-one meetings, e-mail, and web pages.”

As I enter Amy's classroom for one of the observations, she and another Intern are coteaching a language arts lesson to a group of $5^{\text {th }}$ graders. Both of them are substitute teaching for PDS host teachers, who are out for a professional development meeting, on this particular day. Her classroom is one-quadrant of a 'pod' and I am constantly noticing the noise level coming from the other three adjacent quadrants. In this area, there are 28 children who are sitting at tables arranged in a straight line so that when they look up, the chalkboard is in direct 
sight. There are snack foods and water bottles scattered around the desktops. Printed on the chalkboard are the events and assignments for the day. They all appear to be oblivious to the activities and noise going on around them. In a few minutes, the students file out for a 'specialty' and Amy and I have time to talk. Because the circumstances are such today, we talk about her classroom during her student teacher experiences, her experiences as a student, and then, visions for her future classroom. She must have caught me looking at the chalkboard and tells me, "on your board, you should write something always, everyday, have at the beginning of the day what you are going to do through the whole day.” As for the physical environment, the layout of the room and the arrangement of student desks should be so "teacher is never with her back to the class.....and the best design...is to actually have a place that you teach at and a place that you work at but you should never be at your desk whenever the students are in the classroom.” Amy mentions that children's attention span is limited and their eyes and minds will wander. Following that assumption, she asserts, “...the walls should have "something stimulating on them...like parts of speech or the constitution or a list of presidents....” Other resources should be available to students such as books and she relates what she has learned from a recently attended action research conference, "Always have books on hand, trade books, too...label books as easy, medium, and hard reading for students....put them in a huge zip lock bag with a check form for students to review.” As for classrooms in higher education, she expressed frustration about the lack of creativity in light of the fact that she is required to make the classroom an exciting place for learning, but does not offer concrete suggestions for improvements, “...there is nothing on the wall...if they wanted to teach us as novice teachers how to make an interesting design...they should do it in their own classroom." 
In the elementary education setting, classroom management is important, and Amy admits that she is strict, "I am the person who has the most control of my classroom," but setting boundaries is important, so “students won’t cross them but, on the other hand, let students have input,” as well. However, from another perspective, rather than blame students for disruptive behavior, Amy emphasizes that disruptive behavior could be the product of boredom, the teacher's inability to engage with student learning styles, or the failure to relate the lesson to a student's life. In these scenarios, Amy accepts the possibility that her teaching strategies may need modified before students are disciplined. The following statements are examples of interactions I observed between Amy and the students:

Zack, you are not paying attention...pay attention... which one are we on?

You do not get up and wander around the classroom.

I am going to count to 10 and you need to have out pen, pencil, paper, and spelling book.

The classroom is also a place where Amy values the community as a resource, "inviting parents to participate in classroom activities such as diversity week also motivates students to work harder and communicate better with parents” but she cautions, that some parents shy away from such events "because maybe they had a traumatic experience [in school].” Welcoming community into the school and offering them a comfortable environment to read stories to students or talk about events in their lives are ways that the classroom setting can also help students determine their role in society.

\section{Meaningful Experiences}

An effective classroom teacher appropriately addresses diversity and special needs within the curriculum. I believe that activities relating to both areas should be implemented in the classroom in 
order to reach all children. And as they learn about the differences that exist among people, I think that they will become more understanding and tolerant of differences (Amy, Spring 2001).

The main theme that emerged from Amy’s conversations, related to meaningful classroom experiences, is the importance of incorporating issues of diversity and social justice in the classroom, much more so, than, for instance, honoring Black African-Americans one month out of the year, which entails American students studying the contributions of selected individuals for 30 calendar days. Amy professes, “I think it’s a problem that there’s black history month. I think it needs to be cut up throughout the year....in this country, diversity is overlooked because socioeconomic status overshadows it [diversity].” Now, more than ever, since Amy is married to a gentleman from Korea, she has realized in her personal life that prejudices and racism still run rampant so much so that she has been made to feel uncomfortable in social situations. She believes that building respect and learning acceptance and tolerance must begin in the classroom to improve human relations, that is, if future generations wish to change the existing structures.

After witnessing students, during her student teaching experience, refer to people in Asia as 'ching-chongs,' Amy became aware that merely discussing the information from the textbook was insufficient for students to grasp an understanding of another culture. Amy felt that one way to overcome this 'mis-interpretation' (or lack of understanding) and to create longer lasting impressions, was to invite her husband into the classroom to share personal insight into Korea's relationship with China and Japan. Even though she was unsure of how he would be received by students, Amy judges his impact as positive and adds, "I like the idea of keeping my student's open minded, keep their minds clean from corruption like false ideas and perceptions....I think all teachers should have an open mind if they want to reach all their 
students.” But, that is not to say that Amy takes on the responsibility of change herself, but rather she understands that as children encounter society and society encounters children, that the nature of the child is “ultimately affected by society’s acceptance of them.”

Another incident she relayed of a similar theme relates to a teacher 'mis-identifying' a student of color. The student preferred to be identified as Cuban but a teacher insisted upon referring to the child as black even though his heritage was not. Amy was deeply troubled by this and used the opportunity for a 'teachable moment' but confesses she struggled with how to sensitively address an issue of race in a state that is $97 \%$ white, European-American and does not 'see' diversity, when this is not representative of the country. While the complete details of this story were not fully disclosed, Amy mentioned that she spoke directly to the class, relaying, "We are all something different....one day my children will be Irish, English, and Korean...”,

Building a classroom atmosphere revolving around student needs can be difficult if channels are not put in place to foster open lines of communication. Open lines of communication are the mainstay for constructing relationships between teachers and students. For teachers, the difficulty rests in providing channels for open communication even when some students are not comfortable publicly discussing needs for fear of appearing 'un-cool.' In these types of circumstances, teachers should have ways that students can indiscriminately express concerns. Earlier, Amy spoke about having a classroom 'rich with communication,' and one way that she found that was especially helpful to students to privately communicate with her, was through the creation of a 'suggestion box' where students would write concerns on a piece of paper and later, deposit. She took ten minutes a day to sort through the suggestions and opened the discussion to the entire class: 
We would talk to the whole class about issues....and we would ask if anyone would like to add a suggestion so we can help out classmates....it worked....that helped a lot of students release a lot of pressure and tension they were feeling and I think it also instilled that they could talk to teachers and not be afraid to share their ideas with teachers.

It is important to Amy that students feel safe, have a 'voice' in the classroom, and be a participant in their learning. Times when she 'senses' this occurring the most is when students are in groups, having fun, and involved in lessons where 'creative dramatics' is the focal point and she is not "really teaching" in a traditional sense. Examples of creative dramatics are role-

$5^{\text {th }}$ grade students in Amy's classroom participate in a creative dramatics activity while outside on the patio in 2001.

(Photographed by Amy) playing, miming, singing, simulation activities, movement, creating models, and using 'props.' Some of the unexpected 'side effects' of creative dramatics were students, who in the past had been labeled as 'trouble makers,' became involved in class activities in a positive way. Amy discloses this

account, "They [other teachers] said he will never listen. He is so loud. He is so rude. He will interrupt you and his grades will be awful. His grades were good. He loved me. He did really well.”

Teaching and Learning

.... once we get started into the school year and everything becomes very mundane just from day to day to day. I think the teacher has to always reflect. What is going on in my classroom? How can I keep the zeal? How can I show them that I am interested as they should be? (Amy, Spring 2001). 
Amy approaches teaching and her role as a teacher in terms perhaps more familiar to the relationship that a parent has with a child - it is a process where children are still dependent upon adults; however, it is also a time when children are beginning to seek independence and need guidance:

Teaching is being responsible for 28 kids, their learning, their happiness, their stability, their everything...teaching is life... I have to provide the basic necessities and that would be their parent. I have to be their mother and their dad and their friend, their judge, and their counselor...I need to be aware of the changes children are going through.

Somehow in this process, she accepts that teaching entails preparing youth for the future and she believes that, "my role as a teacher is to prepare the youths to fulfill the requirements that society may have.”

During Amy's student teaching, she appreciated teaching and collaborating with other teachers. She met with other teachers and interns on a regular basis, which provided her with additional information on students, offered her ideas for incorporating different teaching strategies, and would make arrangements to observe teachers so that she would be exposed to other teaching styles. This collaboration was especially useful to ensure that the $5^{\text {th }}$ grade 'team' was covering similar information but also, important to the professional development of the pre-service teacher. One story she communicated related to this was a conscious decision on her part to learn more about children with special needs and the opportunity to observe another teacher in an area she felt she was lacking in:

...I know so little about special education. What I have learned has been through observation. I took it upon myself to go into a MI classroom....I 
observed a phenomenal teacher....He came here from Delaware and he really just brought this whole sense of teaching special education to children with special needs. I would watch him and talk to him all the time. He really gave me some good insight...

Another aspect to Amy’s planning entails attention to long range goals as a pre-cursor to daily planning, as well as, reviewing individual student needs, an inventory of available resources, all in conjunction with the state’s IGO’s. Working with at-risk students, she incorporated more hands-on activities but she believes that setting high goals and expectations for the students and herself enlivens that atmosphere as all must work together to achieve similar goals.

Textbooks play a role in her classroom by providing an outline of information but interestingly she adds:

You need to make a connection from the very start and then, you need to know when to pull away and bring in other stuff, like technology because it is important to teach students that there are many ways to go about learning...books are only one way.

When working with at-risk students, she will not rely on textbooks and incorporate more hands on activities.

In terms of learning, Amy considers learning an individualized process that is equated to "growth and the position of the learner" but the element of time becomes apparent in this process as she includes that students must "look back" or reflect upon the process to remember what it is that they remembered, or took from a lesson. Learning is not a static process but is 
viewed as, "a constant and a continuous process and it should be met head on with enthusiasm.”

One event that significantly influenced Amy’s philosophy of teaching and learning was a trip she took her junior year of high school to Italy and Greece. She felt like a stranger who could not read the signs nor understand the language. "I was not in the classroom but I knew I was learning, there was constant learning everywhere I turned.” If she was able to concretely hold something, feel something, and talk to someone about the 'thing' then, this is how, "I learned how I learned best...” It was also this trip that “turned me onto social studies.” For these reasons, her minor area of study is social studies and she believes that children need tactile objects and must be 'doing something' to learn.

Many of the activities of learning that Amy describes are not only rooted in creative dramatics but are thematic. For instance, literature and social studies were combined to create lessons on tornados; social studies and language arts were combined for a lesson on the judicial process; and, a lesson that focused on Native American cultures involved students creating adobe homes and then performing a rain dance outside.

An especially sensitive issue for Amy was the topic of

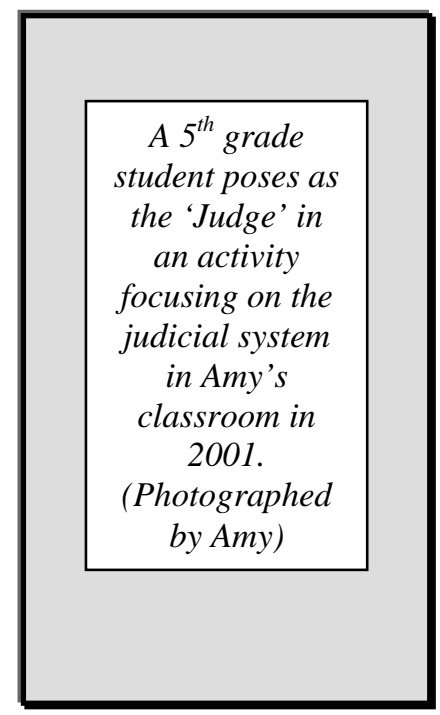
assessment. Just mentioning the word, 'assessment,' she interjected, “I despise it...absolutely detest testing.” Knowing Amy’s history gives insight to this position but as part of her degree requirements, she took a course on assessment techniques and upon further research, feels that testing gives children from the upper class an unfair advantage due to test bias. She shared a few insights she gleaned from the course such as, "we try to trick students with tests...that is 
not assessment," or "grades should be based on how you have advanced...how far you have come in a semester.” One of the things she did the first day at her student teaching was to review student grades. Upon reviewing the grades, she realized that thirteen students were failing and emphatically states, "I was horrified.” She understands that children who are failing are set up for failure in the educational system, “Because if you give a student a 'F' and don't tell them you are showing improvement in some way, you have created yourself an at risk student....they are going to fall to the wayside...they are going to think I am so dumb.” For this reason, she believes that implementing creative dramatics in the classroom can 'pick up' students from the wayside and get them involved in their learning in alternative ways and get them interested again in their learning. She puts forth, "If students are interested in what they're doing, their grades will go up. Children need encouragement and opportunities to feel successful.” 


\section{Section One Summary:}

Pre-Service Teachers Understandings Related to Main Research Questions

- The Classroom Setting As...

Nurturing

Rich in human diversity

Rich in resources and materials

Rich in communication

Community members

Behavioral management

Bright

- $\quad$ Meaningful Experiences As...

Freedom to choose

Self-expression

Contextualized

Caring relationships

Exposure to diversity and multiculturalism

- $\quad$ Teaching and Learning As...

Teaching as learning and learning as teaching

Collaborative

Active

Flexibility

Lesson plans and IGO’s 
Thematic

Thinking and Doing

Meeting needs

There’s grading but.... 


\section{Section II: The Lived Experiences of the In-Service Teachers}

Two of the in-service teachers, "Patti" and "Linda," taught at "Bedford Elementary" and were the host teachers for "Lisa" and "Amy," respectively. The other in-service teacher in this study, "Kelly," taught at "Cold Springs Elementary” and was the host teacher to "Kerry."

Prior to introducing the in-service teachers, I am including a personal journal entry. To set up this entry, it is a spring morning and I am walking across the parking lot adjacent to Bedford Elementary, following a morning rain shower and the sun is beginning to break through the clouds. Earthworms cover the sidewalk and I begin to think about the life of the earthworm being similar to that of a student.

\section{Personal Journal Entry:}

It had just gotten done raining. The air was heavy, damp, the ideal setting if you're an earthworm who finally appears after a long winter's slumber. My hair was frizzy and like the earthworm, I, too, emerged from my car after a long slumber from the night before. There were earthworms slithering, sliding, making their way somewhere, sliding all over the paved lot and side walk leading to the school's entrance. I thought how ideal for these elementary education students. All these living creatures to study and play with - it was if there was a natural science lab waiting for them right out side the physical confines of the school. The children could come out here rather than stay inside the building to learn. Why does "learning" always take place within the physical confines/barriers of cement?

When I was done after 11/2 hours, the sun was out, the heavy clouds of earlier had given way to blue sky. The sun shone brightly down upon the pavement. The sun's baking UV rays are a welcome sign of spring for this human but for the earthworm that 90 minutes ago emerged believing that this must be heaven, the sun would be their 
demise. I gingerly avoided the already dried up, baking carcasses of the earthworms. Sometimes hopping side to side, like the students who played hopscotch only yards away,

Where were the earthworms going when I first came to the school? There were so many - some fat, some thin, some long, some short - each one unique and each one on it's own agenda. But, when I was leaving the school, the sun was out and the earthworms looked like they were getting baked, or had they reached the school (i.e., the sun) and lost their vigor, loss their passion for the journey. They looked old, worn out by the time the sun had turned its fierce rays onto the once young, skins of the earthworm. Consider a first grade child as they anxiously await the first day of school - so alive, so full of energy. Where is it they think they are going? What drives them? What happens by the time they leave school? When the heat gets turned up, what happens to their once vigorous ascent into the halls of learning? (Sayers, April, 2001) 


\section{Meet the In-Service Teachers}

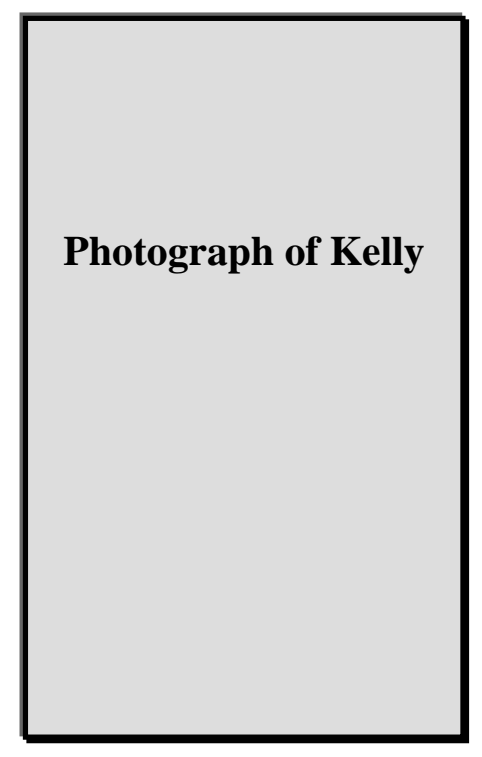

"Kelly"

Age: 38

Degree: $M A$

Years teaching: 16

$4^{\text {th }}$ Grade Teacher

Certified Elementary

Education

Specialization: Language

Arts, grades 4-8

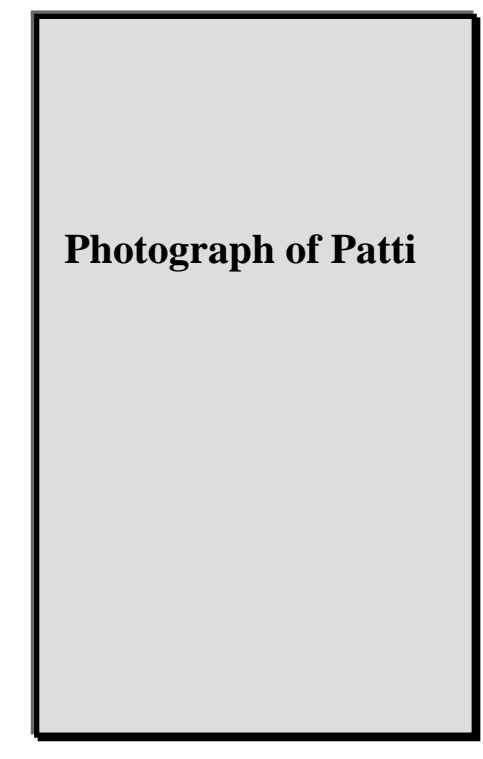

"Patti"

Age: 44

Degree: $M S$

Years teaching: 21

$4^{\text {th }}$ Grade Teacher

Certified Elementary

Education

Specialization:

Special Education

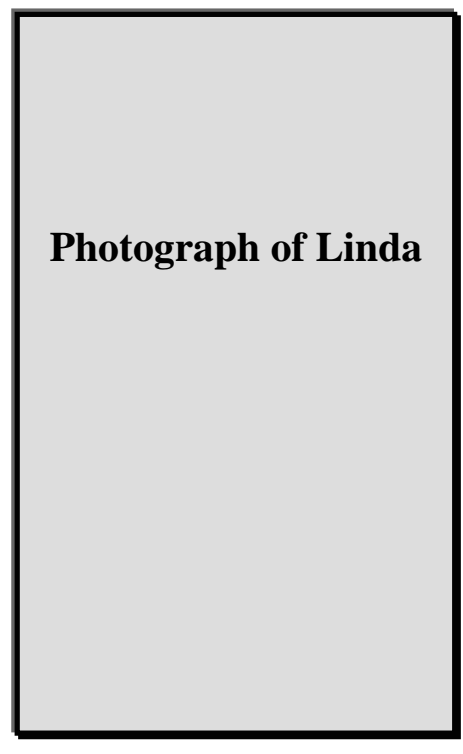

"Linda"

Age: 49

Degree: $M S$

Years teaching: 25

$5^{\text {th }}$ Grade Teacher

Certification Elementary

Education

Specialization:

Health \& Physical

Education 


\section{Narrative IV: The Lived Experiences of Kelly}

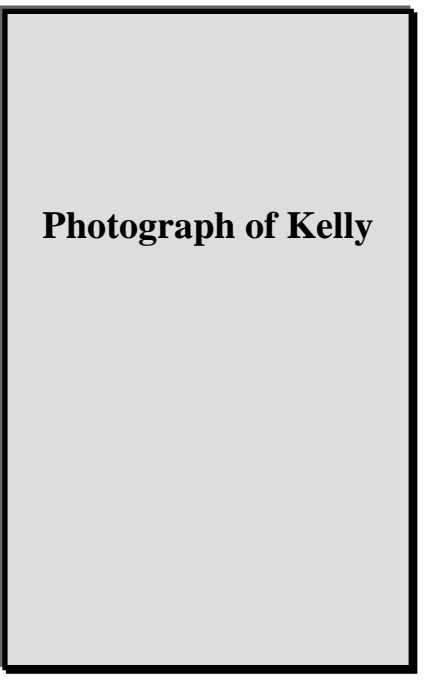

The paperwork just eats you alive. It's like I'm being sucked in by it sometimes. It's amazing the amount of paperwork. I think that if I didn't have to do so much of it, I could probably spend more time on constructing materials....it cuts into my life at home with my family. You just make do because you know in the end the kids are who benefits from it.... Kerry was really easy because she was exactly like me. Our teaching styles are right in synch...we balance each other $100 \% .$. This was by far probably one of the best experiences I had with an intern (Kelly, spring 2001).

Kelly and I first met when I was a graduate assistant with a technology project. She was one of 25 teachers participating in a three-week intensive summer technology program that was co-sponsored by the PDS collaborative at the university. Teachers participating in the program received 'on loan' laptops for the upcoming school year and developed classroom materials using the 'latest and greatest' in technology, and learned how to incorporate technology into their teaching. What separated Kelly from the others was her enthusiasm and willingness to take risks. She, like many of the other teachers who attended the program, were educated during a time period where technology was not a 'strand' of teacher-education programs and are now forced to 'catch up’ with recent graduates in the field. And, unlike some of her colleagues during the program, she expressed a desire to find out as much as she could and was not afraid to 'push buttons’ in fear of damaging equipment. I found her attitude refreshing and positive, not yet tarnished with the cynicism too often heard in teacher lounges. In this study, 
she carries the same attitudes as when I first met her and these attitudes are convincingly inherent in her stories about teaching and learning. Yet, she is realistic in terms of what she is faced with on a daily basis in the classroom. She is brutally honest at times, “...this year’s been my toughest year....I'm worn out. I thought I was going to have a breakdown by the end of this year.”

Some of the events that Kelly recalled that influenced her methods and styles of teaching goes back to her experiences as a first grader. She labeled herself a "talker” who knew her limits. However, one day she was wrongly accused of talking when in fact, she claims, it was another student. Her punishment entailed moving her desk out of the classroom into the hallway where she remained "for what seemed like hours....I just sat there and cried and cried.” Now as a teacher, she attempts to demonstrate understanding towards her students through listening because she believes that the teacher's perception of a situation may be different from the actual events.

A positive influence on Kelly was a teacher she had in $4^{\text {th }}$ or $5^{\text {th }}$ grade - she could not remember with certainty - in the 1970's. Kelly remembers building a cave in the back of the schoolyard complete with stalactites and stalagmites. Other activities that students participated in were campfires, cooking crepes, and creating passports. Kelly described this teacher as a "pioneer” in the field of teaching that motivated students to learn and made learning fun. These experiences, as well as others, have influenced Kelly’s beliefs towards teaching and learning, “I guess in a way I am influenced by the teacher’s I’ve had - the good teachers and the bad teachers," and gives insight towards the ideas stated in her philosophy of education: Every child can learn in a fun, positive way although some children need more time or an alternative way. Education should aim to prepare children for the real 
world so learning experiences must have a definite purpose and should be linked to life lessons. Children need to learn to be flexible and open minded in order to adapt to an ever-changing society and technology has a very important place in this. Students need to be able to read, write, communicate, and be able to do math as well as be a problem solver.

\section{Classroom Setting}

.... I teach in a building that's a very old school. What we lack in facilities we make up for in curriculum and content, but at the same time, I think the physical part is important. I think its needs to be attractive for the children. Organized, so that the children know where the things that they need are (Kelly, spring 2001).

At the risk of repeating myself, I will not describe in great detail the physical structures of Kelly's classroom (which was the classroom described in the respective section in Kerry's narrative), but instead, I will bring to light the events and activities I witnessed, as well as, the types of classroom settings Kelly recalls from her personal experiences and ideal visions of the classroom, prompted by the interview questions.

“I don’t think of my room as colorful because I hate the color of my room,” Kelly responds to my compliment of her room, "They only give us certain choices. We call these institution walls because of the color. Most of the schools [classroom walls] in the country are painted blue, green, and yellow.” As we begin to discuss the ideal learning environment, two central features Kelly includes at all grade levels, that is, elementary, secondary, and higher education, is the need for schools to be attractive to the students and having available technology for the students and teachers. At the elementary level, she describes individual learning areas, which she calls, “cubbies,” where each child has a personalized space, “do 
away with desks," and as an after-thought, she interjects, "maybe have them seated at tables.” In her present classroom, children sit at individual desks, which are arranged in the shape of a “U.” Because of the large amount of resources and materials needed to teach across the content areas, storage space is important, as well. In addition, the physical structure of the building should include a gym, art room, media center, and music room. To make the environment attractive, she believes that the color of the walls should be bright, and carpeting adds a 'homey' touch, “looks more warm - warmer.” In the classroom, young children should have "little library corners,” computers, and learning games. As for computers, “I think that if I had a computer sitting on my desk and one on every child's desk that would be the best thing because I think there’s so much we can do with technology.”

At the secondary level, attractiveness of the school is mentioned again, "more bulletin boards and student work up," and Kelly will re-emphasize the importance of technology as she speaks about a recent article she has read, “I think everyone of us should have a laptop that's hooked to the Internet. I read an article where the whole school's set up so where they carry these laptops around...the whole school was wireless...”" Because high schools are typically larger than elementary schools, she believes students can benefit by teachers who "work in clusters within their respective discipline.” Following along the same train of thought from the elementary grades, students should not be sitting at desks in rows but desks should be arranged in the shape of an "U” because, "I think that that is more informal and they feel more comfortable, more welcoming." Similarly, in addition to the gym, media center, library, students should have several computer labs available to them. Deviating from the technology aspect of secondary education, she is also concerned about safety at this level: 
I think there needs to be some kind of system...that if somebody comes into the building that's not supposed to be there... a camera system to track and watch people...so they're caught right off the bat. The schools are not just so open that they can just walk in at free will.

In higher education, the attractiveness of the classroom is still an important feature as she mentions bulletin boards and posting student work, and the need to get away from desks set up in rows. In her graduate classes, she mentions that the configuration of desks lead to students feeling as if they could discuss topics, "we sat in a circle and it allowed for an interchange.” One criticism of current classrooms in higher education is the large number of students in a single class which she believes takes away from the instructors ability to know students and likewise, for students to feel as if they are known and not just a social security number, as if to say, the instructor's familiarity with the student somehow promoted learning: They need to be smaller - not a class of 300. I was just a number on paper. I was just a face. I wasn’t known. And I think that that's really important....as you move up in the secondary and higher education you become so far removed and I think the classrooms need to be smaller.

Technology is the final feature she mentions. She is aware that some universities 'loan out' laptops to incoming freshman, which remains with them throughout their college career while, other universities, require students to have personal laptops. She wonders out loud, "I wonder how successful the schools are that have the laptops?”

The day I perform an observation, there are 20 students in Kelly's classroom and within this group are children labeled with behavioral problems, eating disorders, autism, EMI (educatively mentally impaired), learning disabled and, two gifted students, and usually, one 


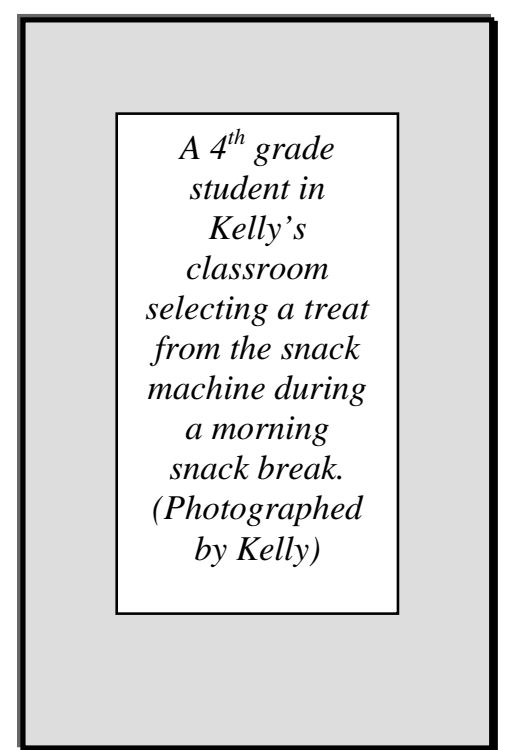

aide accompanies the students on any given day, although, I

notice that it is not always the same aide. As I set up my

'observation station,' I hear 'munching and crunching' and ask

Kelly about the voracious appetites of her students, "a highlight

of the day for the students is snack time sometime between 10-

10:30....It's been a long time between breakfast and lunch so this

is part of their day. They bring their snack [after purchasing from

the vendor machines] and they eat or they can bring something

from home.” A child sitting beside me looks up. He’s missing his front teeth. He flashes a big smile, as his powder-sugar coated lips give clues to the donuts he is happily chewing on -there's also a bag of potato chips sitting on his desk. Kelly turns on the music when students are individually working on class assignments. I believe it is the soundtrack from Walt Disney’s animated film, “The Lion King.” I recognize Elton John’s voice. The music is kept at a low volume and as I look around, I spot some students quietly singing to themselves, while others are silently 'mouthing' the words to the songs.

The behavioral management system described in Kerry's narrative, is the same system utilized, and I witnessed Kelly calmly instruct students to "Pull a card," that is then followed by an explanation for her directive, such as, "Ryan, we do not get up when someone else is talking.”

\section{Meaningful Experiences}

I'm always looking for what's the best, meaningful way to get it across to the children. Plus, I want it to be fun. I want them to see it tied to the real world. I want them to realize that sometimes it's hard work but it does pay off and this it can be fun. They can enjoy 
learning and that $I^{\prime} m$ willing to work with them as much as they are. And I want to be close to them. I want them to see me as human (Kelly, spring 2001).

One of the main themes that comes through in Kelly's time spent with me, is her desire for students to see her 'as human' and connected to this, is also for students to respect individual differences, which is a theme of a newly created year-long literature unit. Kelly returns to these connected themes unexpectedly throughout our discussions, and it will be at times when I believe that the discussion should be focused on other aspects her teaching and learning, that she inserts vignettes (into the discussion) based on these themes. I begin to understand that her teaching is inexplicably tied into the human-side of life, more specifically, living respectfully. One such instance is when we were discussing her role as a teacher and she states:

...to facilitate the learning environment in my classroom. My role would also be that the children see me as a human but as the same time someone that can be their...friend but also a person that's in charge. To teach children respect for one another and for myself and for adults because I don’t think they get enough of it at home in today's society.

I sense, though, that this need for students to see her as human is not narcissistic but rather, a way that students should treat all individuals. One memory Kelly recalls where she believes that students did get to observe her as 'human,' (which is prompted from sorting through her photographs) relates to a school-wide event where a local community group that rescues injured birds of prey and nurses them back to health, brought birds in for an assembly. Kelly explains that she was very nervous, "jumpy," around these large birds, which were taken out of their cages during the assembly. Kelly was given an opportunity to pet one of the birds and 
The Raptors assembly showcases healing birds of prey to children at Cold Springs Elementary. The assembly turns out to be a special moment for Kelly in 2001. (Photograph taken by undisclosed source) when she approached it, “....[the bird] she

gave me this look and started making this noise and I was afraid she was going to attack me, but they said she’s harmless.” The students teased her about this, even though she found it very exciting, but believes students

viewed her in a light they had not before. Through these stories, Kelly emphasizes that modeling respect and courtesy to others is necessary in the classroom, as well as, outside the classroom, but more importantly, by viewing others as we see ourselves, "as human," we begin to treat others as we would like to be treated.

Another especially touching story Kelly tells (again, prompted through the photo elicitation portion of the interviews) is focused on an infant who "they weren't even sure if the baby was going to live last year when it was born...” This infant is the sibling of one of her students and likewise, the daughter of a parent volunteer that regularly comes into the classroom to assist with 'fluoride rinses.' What transpires is an especially heart-felt story that Kelly's shares about the type of relationships she formed with the student, the parent, and with her students, during this tenuous time. Once the parent was able to return to school following the birth of the child, she resumed her role of 'fluoride rinsing,' but due to lack of money was unable to afford a sitter to watch the infant. Kelly would take the infant, as Kerry was student teaching, and the infant would fall asleep on her, “...the class just loved that. They were fascinated by the baby laying on my chest while they were still working. And they were real quiet. 'You've got to be quiet. The baby's sleeping.'” In her words, it became evident to me that some of her most meaningful moments occur when she is not only in the role of a teacher, 
but exposes a vulnerable side of herself, perhaps more commonly associated with being a parent.

The other part of this thematic equation is for students to also model respectful behavior and attitudes towards one another. In a year that has been especially mentally and physically challenging for Kelly due to the diversity and neediness of this particular group of students, she worked closely with the county's ESL coordinator to develop lessons encompassing 'respectful' themes across the content areas. It is not to say here that children were 'disrespectful' to one another prior to this, but rather, that the diversity of the group was such that she purposefully set out to use the opportunity for learning. In her classroom, she has witnessed random acts of kindness where students have actively taken a role to help out a fellow student who is identified as ESL with autism, “The kids help her...They take her under their wing. They steer her, literally. They'll say, 'go this way or that way.'” Another precursor to Kelly pursuing a classroom that promotes respect was due to an increasing number of international students. Another school in the county merged into her present one and the “population was different.” A year-long literature unit which incorporated issues related to diversity would be the guiding premise for addressing these issues. Lessons included reading books about other children from similar and different backgrounds or grouped by issues that children in her class were personally struggling with such as divorce, bullies, and violence. Activities within the unit included students researching and sharing with the class family history and ancestry, writing/journaling, and taking photographs of one another. "The one thing I think that the children need to take out of here is a respect for one another. I think that if you have respect for other people I think that you're going to go places in this world.” 
The final theme that became evident is related to student success. But, according to Kelly, success is also a function of teacher effort plus student effort, and assessed over time, ...you work with that same student day in day out and they finally get it. Or they question you on something that you've just been trying to get across to them for weeks and it's like the light bulb comes on....It gives me a great feeling to know I've made a difference in a child's life, so I think that's part of the meaning, to make a difference in a child's life.

\section{Teaching and Learning}

Teaching means a lot to me...I think it's one of the most important jobs there is. It gives me a great feeling to know I've made a difference in a child's life. Learning means flexibility. I think learning is fun. I don't think you can ever know enough. I think that you're continually learning throughout your life no matter what job you hold or what place you hold in society. I think it's a means to an end. I think that you need to learn to be able to be a productive member in society (Kelly, spring 2001).

Kelly’s years of experience as a teacher and a parent, meet at a point of intersection in her classroom. As a parent, she is privileged to ‘insiders knowledge’ about the developmental issues of children and their concerns about school, as well as, the other conscious acts of living; as a teacher, her 16 years of experience come through as confidence, but not arrogance. Watching over her, she has flow as activities transition one into another, asking questions of her students, disciplining, "Pull a card,” moving from child to child with raised hands, and, yet she is thoughtful, “Slow down...I want you to think about what you're reading...Let's take turns reading this. Let's look at the clues in the sentence.” She has 'student helpers' who assist 
in picking up completed work, moving the overhead projector closer to the screen, and passing out materials. She will personally describe her style of pedagogy as packed with "cooperation, active learning, non-traditional....students are busy and involved and it’s organized. It may be a little chaotic at times....I'm indirectly directing things.” But, that is not to say that her classroom was always structured like this. In order for these types of 'chaotic' methods to work, Kelly stresses that the teacher needs to know and have an understanding about the students, and how they behave with one another. Kelly shares a personal story about her first year teaching that supports this realization, however, in relaying the story, she admits embarrassment, because she did not know about her students:

It was my first year. I taught at second grade classroom. I was at a school in the outlying areas in the county. I was very naïve and limited in experience at this place - and I stood up the first day of class and started to write on the chalkboard, and I was writing in cursive. And the children raised their hands and said, 'We can’t read that.' And I thought, 'This must be a school where the kids are just like illiterate or something. I can’t believe they can’t read.' And finally one of them said, ‘No, you don't understand. It’s because you're writing in cursive. We don't know how to read cursive. We have to print.' So, I thought to myself how dumb, dumb, dumb....

Now, as a host teacher to a pre-service teacher, she is again reminded of the experiences that new teachers have and where some lessons, can only be 'learned' through experience. Her roles when working with the pre-service teacher are that of confidant, guide, apprentice, and trainer, "I want her to know that I'm here and I'm their safety net but yet at the 
same time, I don't want to make them dependent on me. I want to give them enough freedom to spread their wings...”"

Kelly’s planning is focused around the lesson plan and must include the state’s IGO’s, and she must consider county and state policies before final administrative approval is granted. However, prior to planning, there are many details she pays attention to - student IEP's, state test scores from previous year - while, she must always keep in mind the best interest of the learner, "what do they need.” There is a fine line, though, she insists, between knowing too much, which could put the child at disadvantage because the teacher builds up biases; whereas, knowing too little, which could lead to “missing your mark,” that is, not knowing individual needs and teaching in appropriate ways to meet those needs:

I kind of want to feel my way on my own....I try not to look at previous grades because that could depend on their home life, the previous year's teacher, that sort of thing....after I meet the children and spend some time with them, then I go and look at that [their files].

For an experienced teacher, such as herself, Kelly does not rely on textbooks but approaches their usefulness solely as a guide or resource. Nevertheless, for novice teachers, she suggests that textbooks can help familiarize them with the information of the curriculum.

Kelly is a self-described 'technology hound' and teaching and learning with computers has become a normal part of her classroom practices. She has taken class virtual fieldtrips to Ellis Island, China, and created a thematic weather unit where students daily check the weather conditions in a city throughout the world from an computer connected to the Internet, graph the weather changes, and further research other aspects of the culture. Much of her interest in computers and technology has come about the in past year as she continues her education 
through workshops and on-line courses, and she believes that the role of technology in education and in daily living, is part of keeping up with the changing world and being a lifelong learner.

Assessment and grades are a frustrating subject for Kelly and since her planning is based on the IGOs, which is a statement of evidence to administration about the preparedness of her students for statewide testing and furthermore, guides her teaching practices and what students learn, she must document and keep accurate records of performance, while still keeping in mind the diverse needs of the children. She explains that this is an especially difficult task and as of recent, the county has switched to a new report card system, which necessitated her finding an alternative way to document student work due to extensive "check lists of student skills." Students in class want to talk about what makes an "A" or a "B" and she believes students need to take time to do a self- assessment, “Are you putting forth your best effort? Or, are you fooling around?” A relatively new system of assessing student work was recently introduced in the county, better known as, portfolios. There are two types of portfolios in place for students, an assessment and a celebration portfolio, and "at the end of their career here in elementary school they're awarded the portfolio and they can take it with them and keep it. They’re good.”

Kelly bases many of the activities in the classroom around literature that also incorporates hands-on activities, some of which she attributes to her own learning styles, “I'm a do'er...I have to have my hands on it, writing it as I'm listening...I'm visual as well...I don't hear very well....” She believes, “Children learn best when they read the literature books....when they read literature books on their level” and the literature unit based on respect (discussed in the preceding section) is the basis for the types of books chosen. She mentioned 
several books - the Jackie Robinson story, Fitting

In, There's a Boy in the Girl's Bathroom, and a series of books for children about the events of the

Holocaust. Some of the hands-on activities she mentioned includes cutting sentence strips and linking the sentences together in a chain; a selfcreated lesson, "Picture Perfect Spelling” which

A male 4th grade student in Kelly's classroom cuts out shapes in construction paper while participating in an enrichment activity which Kelly entitles, "Egg Art," in 2001. (Photographed by Kelly)

incorporates spelling words, writing a sentence with the spelling words, and then illustrating the concept of the sentence; and, an enrichment activity where students research a famous individual of the state and "take egg shapes and make heads...they create faces....I mean Barney Fife was absolutely beautiful - the big red lips and the bow tie.” Kelly talks about the amount of planning that goes into some of these activities, but what's interesting is that once she gets the students moving, she removes herself from the picture which allows them to move ‘up' into a different role, not quite as dependent upon her. One memory she recalls from the previous year is students saying, “...this is just too hard.” They negotiated the requirements of the assignment and the students redesigned the activity to where it is today. Kelly remembers another time when she was giving students topics for journaling activities and they told her, "They didn’t need my topics. They wanted to write on things on their own." 


\section{Narrative V: The Lived Experiences of Patti}

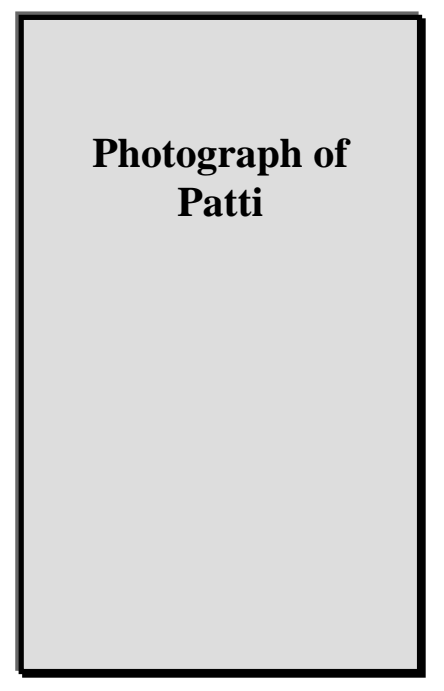

I always had a love of literacy and my parents always taught me the love of reading - not just books but newspapers, magazines, and I always felt like if things were not going quite well socially or academically, I could just lose myself in a book... lack of respect from the public is I trend I see now. I still have the respect of my students but I've seen a lack of support from the parents.... I see that they're not supporting what I did in the classroom during the day at night (Patti, Spring 2001).

Like Kelly, Patti and I share a similar beginning - we met at a summer technology program, and very quickly, it become apparent that Patti is one of the most celebrated host teachers in the PDS collaborative. If one were to pick up literature about the collaborative, her image is a common sight, and she regularly confers and meets with the directors of the collaborative. When I first met her, I was immediately attracted to her energy and positive upbeat personality, as I believe others were, too, so much so that when she entered a room, she was like a beacon of light. One could not help but sense her presence. People looked, people listened to Patti when she spoke and she moved across the room.

On top of her regular teaching responsibilities, she also directs summer workshops on basic computer skills for adult learners in the community and in the past, has co-taught courses at the University in the teacher-education program. What she keeps in mind when teaching at any grade level is, "if somebody's excited about something, then I'll get probably get excited, 
too.....right now, I'm trying to learn about the stock market...I have people that are helping me....they're excited about it and they make it seem...real world for me.”

Even though Patti enjoys celebrity like status due to her involvement with the PDS collaborative, her journey in the field of education has not been without its own trials and tribulations. At one point, due to money struggles, she contemplated leaving teaching. Upon accepting her first teaching position, she received her paycheck over a nine-month period, not knowing she could opt to have it spread out over a twelve-month period. By the time summer arrived, "I spent it all practically," and had to find a summer job to pay bills. She was able to secure a sales position with Xerox and seriously contemplated staying with Xerox once the fall school year arrived. What changed her mind was a phone call that took place between Patti and the newly appointed school principal. The principal was, "talking about the Collaborative and different things that would be involved.” Something that the principal said convinced Patti to stay and she remembers, “I called Xerox and said, 'I'm not going to work for you. I'm going to be a teacher.' They thought I was crazy....I can’t say I’ve ever looked back.”

One negative aspect of teaching that Patti has come to realize, after being in the field of education for 20 years, which she believes is a gauge of the value that the American public places on education is, "that you're not appreciated by society because your paycheck and your public support is not real special....the public does not think you're an important cog by your salary.”

The money aspect is secondary to the satisfaction she receives when students, whom she has had in years past, remember her with an invitation to graduation or when they are grown and invite her to weddings, “....you have that satisfaction in knowing that you made 
some sort of positive impact....especially when you see what they’ve become and knowing that you've been some part of that.”

Some of these experiences and many others, provide insight and understanding towards Patti’s philosophy of education, where she writes:

...all students can learn through enriching and challenging experiences that enable students to apply their classroom experiences to real-world scenarios. Students must be able to see the purpose and practical application for their classroom studies.

In order to achieve these goals, I feel that the presentation method of the teacher should be highly motivating and geared toward the individual learning styles of each child. Many opportunities for real-world applications should be provided through the usage of in-class guest speakers, as well as, out of classroom field trips.

Parents should be given the chance to take an active part in their child's learning. I feel this should be addressed by frequent parent teacher conferences, and opportunities for volunteerism in the classroom.

Students should take an active role in self and peer assessment. The student should be able to choose topics that interest them to study and apply concepts learned. Portfolio assessment should be utilized in order to emphasize self and peer evaluations.

All students should be enabled to see themselves in a positive light during their educational experiences. Numerous opportunities to succeed should be an integral part of a child's classroom experience. Every child can 
experience success in learning, and it is my goal to enable and facilitate

him/her towards educational excellence.

\section{Classroom Setting}

....an ideal secondary classroom would look like an elementary

classroom.... where they are not just taking notes from the board or the

overhead but where they are more actively engaged....but with more

technology, more experimentation... I would love to have more

technology. I would really like to have a laptop for students. I know

it used to be a dream [to have a] laptop on every teacher's desk but

I am lucky I have that now... (Patti, Spring 2001).

Similar to Kelly's narrative, I will not describe in great details the physical structures of Patti’s classroom (which was the classroom described in the respective section in Lisa's narrative), but instead, I will bring to light the events and activities I witnessed, as well as, the types of classroom settings Patti recalls from her personal experiences and ideal visions of the classroom. One general observation I make about our conversations, entailed Patti reflecting upon her present situation, and then, adding items to improve upon her current state -- for instance, "I'd like to have more computers or I'd like to have a door [in my classroom, leading] to the outside..." however, she never specifically states the implied message, 'children need to have access to nature.' While I do not pursue this nor do I want to speculate about the meaning of this, I do make note of it in my personal journal and share it with the reader.

Two of the main themes that emerged from my conversations with Patti were the need for classrooms at all grade levels to make technology widely available for students and teachers, and for students to participate in hands-on activities: 
I think [about] an ideal learning environment. I try to do that in my classroom would be where students are taking an active role in their own learning and education. That would mean they would be very actively engaged in meaningful lessons but they wouldn’t be afraid to get out of their seat and move around or get up and do something. Of course....for me, there would be technology...I'd like to have more of it.

In her present classroom, there are five computers for 25 students and hanging above each computer, is an address (URL) for an Internet website. The Internet addresses appear to be links to chocolate companies - I catch sight of 'Hershey.com' and ‘Cadbury.com.' Patti does have a laptop computer (courtesy of the technology summer workshop she attended), which I witness her using to connect to the Internet and present a related PowerPoint presentation on chocolate, via a cable hook-up to a larger monitor for student viewing. Other

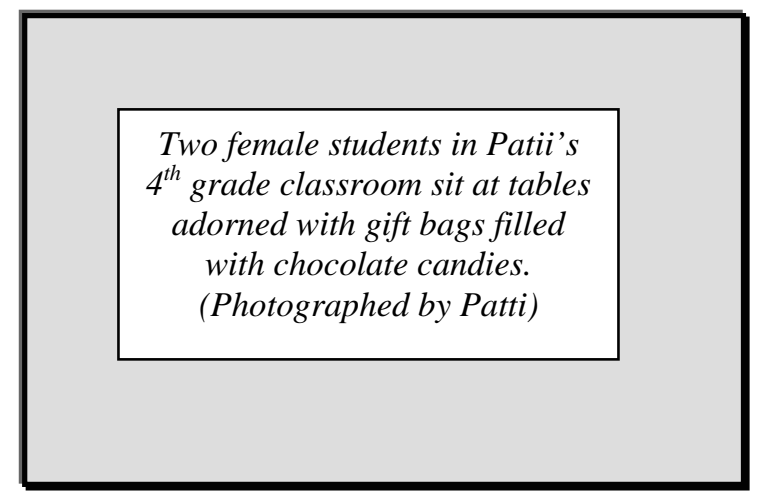
small changes I notice during one of my observations is that Patti has changed the floral center arrangements that once graced the center of the tables students sat at, with chocolate themed gift bags complete with colored tissue paper and chocolate candies.

At the secondary level, she believes that the classroom should resemble the elementary classroom set-up but students should be provided with opportunities for more experimentation and more technology because, "they are more mature to handle it.” Similarly, in higher education, she shared a sentiment that many others did in the study when she states, “...the walls are so blaah...” and the learning atmosphere could be improved if changed to, “....look 
like elementary, too....” Unlike the other participants in the study, Patti expressed dissatisfaction with the teaching arrangements in higher education:

One thing that I see in higher education that I don't really like is a turn towards less teaching by the teacher and more group work and projects by the students. I almost feel like the students are doing so much of the teaching....I think that when you're at that level, you want to hear experiences from professors....you want to hear about research presented.

Furthermore, in the teacher-education program (in which she has co-taught courses with director of the collaborative), she believes that pre-service teachers are better served when professors at the university level are accompanied by in-service teachers out in the field, "I think in our field of curriculum, if you could have the team teaching with an actual classroom teacher and a professor, I think you got the best of both worlds there...I think it would be so much better than all this group work.”

\section{Meaningful Experiences}

...I was really having a bad week because my attitude towards that [the Stanford 9 test] and worrying about the children, whether they'd be prepared, and my children gave me this huge 'Thank You' card and it was just the sweetest thing. I don't know how they could sense that you needed that but they did...(Patti, Spring 2001).

Patti tells a story about herself as a young girl where she says, "I could tell that my teachers thought I was a good reader...I got a lot of praise” and one of the defining characteristics about Patti and her relationship with students, is her constant attention to providing positive feedback and praise. Patti's relationship with her students and interns is especially important to her and evidenced when she explains that her role as a teacher is, "to 
encourage each child to reach their [sic] fullest potential....to bring out the best in them that I can.” Likewise, she echos this same message when speaking about her relationship with her intern, Lisa, “ I believe in nurturing them along....bringing out the best in them, just like the children....show them ways that they can showcase what they do best....” During one of my observation visits, I recorded the following exchanges, which gives a clue to Patti’s caring and loving nature. The first statement is directed at myself:

Hi, Darlin', c’mon on in....

I am so proud of the way you worked today.

Thank you, my love...

Interestingly enough, she explains that some of her most affirming experiences as a teacher are moments when students show love and respect towards her. One such instance is in reference to the opening quote of this section and another story she recalls occurred at the end of the 6-month long thematic chocolate unit where she briefly left the room to get a knife to cut up the ten pound Hershey bar that was the highlight of the unit for the students, and when she returned, students wrote on the chalkboard, “Surprise, \#1 teacher. You're so great....”

Patti and Lisa embrace at the conclusion of the Action Research Conference for Bedford Elementary Interns. Standing to the right is Amy. (Photographed by undisclosed source)
As a host teacher in the PDS collaborative, she regularly hosts pre-service teachers each fall semester and understands the role she plays in their development as a teacher and as a professional. She proudly shared with me many photographs of herself and Lisa at the Action Research Conference held at the end of the spring semester at Bedford Elementary where $85 \%$ of the faculty attend; a newsletter put together by the interns focused on technology and recent technological developments at the school that was sent home to parents; and, when looking over the photographs, she relates a 
story that other teachers in the school wanted to 'loan out' Lisa and another intern who endearingly earned the nickname, “The Writing Pair," to team teach other fourth graders, the basics of writing, “...they did such a stellar job on that and that was very meaningful in the life of the school as well as to me personally.”

As positive as these relationships are, she expresses frustration over the lack of parental involvement and support in children's education today, which, she believes, is an important component in the child's overall educational experience but, is also symbolic of a changing family structure and demands taken on by parents, “...the home life’s so different....there’s not a stay at home mom or somebody there all the time....they're exhausted because by the time they get started it's nine at night...” These 'parental' barriers complicate some of what she believes goes into meeting the best needs of the child and also affects the types of assignments implemented in the classroom, “...the parents don’t cooperate or give you the support you need....” In turn, she relies upon administrative backing if she believes that certain activities are 'risky.' Another change she observes over the last 20 years, which she believes is related to the changing dynamics of the home, is that students of today are more "mature" and "streetwise" than previously and often question her about the purpose of lessons. More than ever, she must contextualize lessons to the children's life so that they can make connections between the activities in the classroom to events occurring outside the classroom.

Patti states that her role as a teacher, "is to facilitate the most diversified education I can for the children" and as the country's population demographics diversifies, the student population at Bedford Elementary, is not representative of the nation's. However, one way that the school does address issues of diversity for the future citizens of the country, is through year-long and school-wide units. She admits, “At Bedford, we’re not too good on 
diversity...we don’t have too many races out there.” Individually, Patti claims in her classroom that she tries to treat everyone equally but recognizes that at times that the boys feel outnumbered by the girls, "I don’t try to do a special thing for the girls, a special thing for the boys, special thing for the racially diverse. I try to just not even look at that.”

School-wide there is a program that has been implemented to address issues of diversity. Patti asks me if I am familiar with E.D. Hirsh’s work, “Cultural Literacy,” and I reply that I am. E.D. Hirsh’s work is controversial especially within critical pedagogy circles, but I do not mention this during our conversation. She claims that the program, based on Hirsh's book, was translated into an elementary education program about cultural diversity. The theme of the program this year is based on ancient civilizations. Because I am curious, I asked her to describe the program:

First, you usually try to go into the history of some of the races - how did it start or maybe...like, they were the first people here, we're really new on the scene, and they have so many things to be proud of. And then the reason why America became a country so that we would all be equal. And how we're all equal and we all have so much to be proud of...

\section{Teaching and Learning}

To be a life-long learner is one of the most important things to me, and I think it makes you feel young. I've determined that's why I like to take all these classes and do all these things because it makes you feel young if you're constantly learning and if you can still get excited about learning something new. And my dad always had a saying, 'Learn something new every day,' and I guess that kind of stuck with me (Patti, Spring 2001). 
Entering Patti's classroom, she is hard to find amongst the students. She is a small, petite woman and is just as active as the students but according to how she describes her pedagogy, “...I want them [the students] actively involved in their own learning and not just me standing up there preaching," this is a befitting scene. But, more importantly, there is a sense that she is right 'there' with them learning; likewise, not only is she learning from her students, but she heavily depends upon colleagues, as well. Teaching in a 'pod' atmosphere means that others are always within sight or hearing distance. During one of our interviews that took place at the end of a tiring day, she offers details of the teaching conditions:

I think they [colleagues] influence the way I teach and I think lots of times I would never sit at my desk and teach because I wouldn’t want anyone to see me in an open classroom and that influences my principal, too....sometimes I wish I could do it. I would be less exhausted. I like to be more actively teaching and learning along with them.

One aspect of Patti's involvement with the PDS is continuing professional development workshops and conferences for teachers. For instance, she recently returned from Atlanta, Georgia in which she attended a conference and "saw the way other teachers teach.” Also, she speaks with pride when she describes ‘team teaching' tactics and relying on her colleagues and building principals for support and new ideas. She points out that team teaching is more than collaborating with other teachers - but, rather it is teaching that involves two teachers in the same classroom, at the same time. Within these constructs, she has been provided with role models and exposed to many innovative ideas.

Patti defines the nature of teaching as, “...to make an impact on the future of the nation by encouraging and enabling each child to reach their fullest potential.” Considering the task at 
hand, Patti takes into consideration many variables during her planning phase to move towards this goal. She begins with familiarizing herself with student needs by identifying learning styles and interests, similar to what Lisa described, through the interest inventory. Because her students are an 'accelerated group,' knowing their interests and then, creating activities related to their interests, is a motivating factor. Also, because $4^{\text {th }}$ grade is a pivotal year for state testing, she must review the IGOs, and admits, “I know that my teaching will be judged on my test scores, so that's a sad twist." Within the classroom, she reviews physical resources such as the needed materials, supplies, and technology to create an active learning environment. This is followed up in a formally written lesson plan that breaks down the day into discrete units of time, and further divided by subject, skills, IGOs, procedures, materials, and a section for teacher notes. Patti is immaculate in her planning and during one of my observations, she handed me a lesson plan from which she was teaching. I noticed various sections on the lesson plan had icons or symbols pertaining to particular IGO’s. She also gives consideration to students' home lives (which was mentioned earlier), which may or may not affect their ability to complete assignments. She prefers not to review to student test scores from years past or personal files because:

Two male studentathletes from a local state college read to students in Patii's classroom. Students learn reading is 'cool.' (Photographed by Patti)

I don't like to stereotype children by saying they come from a bad home so I know they are going to have problems or then they didn't get their best score on their Stanford 9 last year so they are not going to be a good student. I try not to get too much of that. 
Other valuable resources include members from the community, which from time to time, are invited in to read to students or volunteer to speak to children about work experiences.

Over the 20 years that Patti has been teaching, she observes that textbooks "are having less and less of a role which also makes you go crazy too because it is more work.” While she has many textbooks available in her classroom for students to review, the main information resource she relies on is in the form of resource packets. In the event that textbooks are used, “they must tie into the IGO’s, which tie into the almighty Stanford 9 test.” Any time new textbook series is selected, the books must be demonstrative of the IGO's and for this reason, she discloses that textbooks can be limiting.

One of the sample resource packets she shares with me is based on a 6-month long, thematic chocolate unit. She seems to be especially proud of the chocolate unit as it encompasses a good portion of our conversation. The unit incorporates many subject areas -

A learning station in Patti's $4^{\text {th }}$ grade classroom is a place where students learn about chocolate. (Photographed by Patti) math, history, geography, cultural studies, art, computer technology - and most of what I observe while spending time in her classroom, are bulletin boards of a chocolate theme, learning stations, website addresses of chocolate companies, students working on worksheets

that necessitate them using candy M \& M's to compute fractions (which they later eat), and “Merry Maid” helpers who distribute chocolate products to students each day.

Patti is required to give "percentage grades” to students but adds, "more and more I am seeing rubric grading” which she explains as, “more work than doing just averages.” An alternative form of assessment she incorporates across the content areas is rubrics but she cautions that giving grades is becoming more challenging than in years past. However, what 
rubrics account for that percentage grades cannot, are skills and sub-skills that students have (or have not) attained. Another alternative form of assessment she has recently included are portfolios but she does not offer an explanation of their use. As teachers search for alternative forms of assessment that better describe student mastery, Patti is concerned because "students are still geared up, 'what is my grade?’ Even today with that activity they asked, 'Is this going to be graded?' Grades are always on their minds.” 


\section{Narrative VI: The Lived Experiences of Linda}

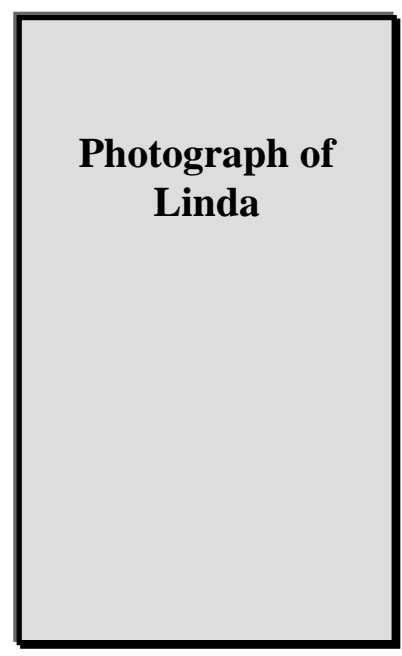

You never stop being educated. You don't even have to go to school to be educated. Read newspapers, read books, go to movies. Education is a life-long learning process. It means that your brain will not die. Keep it active.... Sometimes the rewards of being a teacher aren't right there in front of your nose everyday but when kids hug you or tell you how much they will miss you, that is great to hear because there are struggles along the way (Linda, Spring 2001). Linda is a colleague of Patti's at Bedford Elementary and my first interactions with Linda were at the summer technology program. Linda and Patti share common characteristics and appear to be not only colleagues, but friends, as well, judging by their noontime lunch activities, friendly banter, and proximity to one another while working on their technology projects. Like Patti, she is energetic, up beat, and passionate about teaching. Without knowing Linda, one would be hard-pressed to guess that she carries 25 years of classroom teaching experience with her (more than any other participant in this study) and is a mother of a collegeaged student, due to her youthful appearance and attitude. Not to take away from her youth-like appeal, but she is also reflective and thoughtful of her time in the classroom and will be the only individual in the study to describe her chosen career as something other than a job, “Teaching’s not just a job...it is my life...it is something I enjoy.” In this light, it appears that Linda has found her true calling or vocation.

Looking back at some of the experiences that have shaped and influenced Linda's thoughts and ideas about teaching, she recalls stories that offer brief glimpses of a young 
woman who perhaps valued the social aspect of school over the academic. When she speaks about the students in her present classroom, she is also mindful of their changing nature at this age and the importance of the child's social life. Some of what she shares about being a young schoolgirl are incidents where she was reprimanded for putting on make-up while class was in session; being moved to the corner of room in $2^{\text {nd }}$ grade for talking too much; joining extracurricular clubs in high school to meet new people; and, trying out for the cheerleading squad. As a sign of the changing fashion trends and social acceptance of appropriate teaching apparel, she also remembers wearing mini-skirts the first few years she was teacher fresh out of college, and lets out a small laugh of disbelief, as she shares this tidbit of personal information. Another change she has witnessed over the span of her career is the public's changing thought about disciplining students. When she obtained her first teaching position, the school's assistant principal told her to buy a paddle. She was informed, "As a teacher, you need to have control," and she noticed that children who did "act up" and threatened with the paddle, were more fearful of the repercussions, than students of today when they are informed that they will receive a demerit for inappropriate behavior.

In Linda's philosophy of education, some of the same elements are apparent and give understanding to the assumptions and beliefs that guide her teaching:

Teaching is the most important profession in the world. All tasks must be learned; therefore, all tasks must be taught. Teachers are not found only in the classroom. Until the world realizes that education is the key to everyone's success, we are at a huge disadvantage to be successful. Every job, no matter how simple or how complex, must be learned. Teachers are learners and learners are teachers - it is a continuous cycle. Discipline is the key to learning. 
Discipline includes self-discipline of organization, manners, time, and most important, behavior.

\section{Classroom Setting}

I just think 'clusters' are bad...they were good at one time but now with the way things are and we have so many computers and cooperative learning... When I taught in a cluster my way of teaching was much different than it is in this [enclosed] classroom. I have to admit that the cluster stifled my teaching because I couldn't do a lot of the current activities...(Linda, Spring 2001).

In the preceding narratives of the pre-service teachers, the host teacher's classroom was described since that was the physical environment where instruction took place. However, due to a schedule conflict, I was unable to observe Amy in Linda's classroom and for this reason, will provide attention to the classroom setting and environment in this section.

Linda appears to be especially pleased with her current situation. Not only does she compliment Bedford with being an "ideal school to teach in," she furthers that statement with, “Everyone should have a room like I have.” Linda’s classroom is an isolated classroom

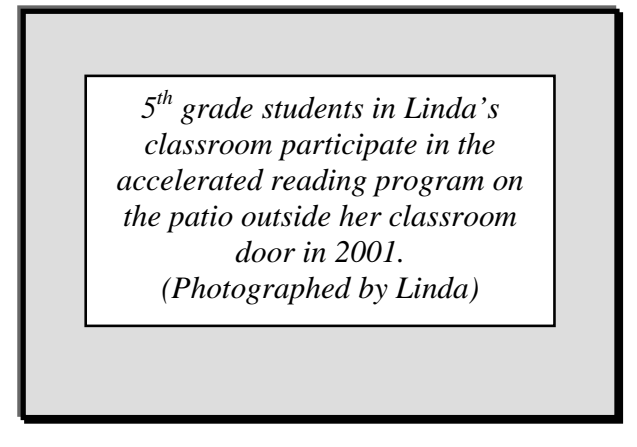

enclosed by three walls with the outer wall facing the outdoors, completely glassed in. Natural light fills the room and it is not often that Linda resorts to overhead lighting. There is a door from her classroom that leads to an adjacent patio where students in good weather can venture outdoors for activities. Rolling hills surrounds the school and the countryside provides picturesque scenes. Unlike many of the other classrooms at Bedford that are arranged in 'pods,' or 'clusters,' Linda expresses gratitude for her situation because the physical 
environment does influence how and what she teaches which only came as a realization after she moved to her present room. At one point in her career, she did teach in a 'cluster' environment but due to noise limitations and amount of space, her teaching and planning revolved around the limitations of the classroom, “I couldn’t do a lot of the current activities that I liked to do and I like the students to read aloud together or teach songs, or do cute little skits because it disturbed the other teachers....” All of which are regular activities of her classroom today.

Careful to not take away from overall pride she feels teaching with colleagues at Bedford, she is aware of the advantages of teaching in clusters and mentions that colleagues tend to nurture one another part of which she attributes to the closeness of the cluster set-up. The other aspect she includes in this conversation about classroom setting is connected to the influence of administration and the 'feel' that each school creates that one might sense upon entering the building, “...you can tell when you walk into a school probably how each school is different...that's due to the principal...is it positive? Is it negative?...It just feels different so that influences that way you teach.”

During one of my visits to Linda's classroom, upon entering I am greeted with, "It's Hat Day!” and as I look around, not only are students sporting 'head gear' from baseball caps

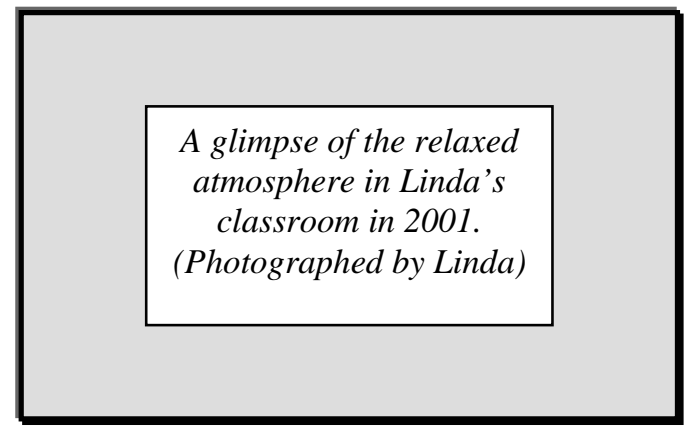

to handkerchiefs, but also Linda is wearing a metallic colored sun-visor. There are approximately 29 students, she tells me, but at any one time, that is difficult to ascertain, due to the flurry of activity in the classroom. Students are 'coming and going' to I don't know where. Of the 29 students, there are about 19 young ladies and the rest are young 
men. This is an accelerated group of $5^{\text {th }}$ graders, which has something to do with the activity since they are granted greater freedoms than others. Linda is complimentary when she says, “This is a good group.” By appearances, this group is mainly white, European-American. Similar to other elementary classrooms, this one is no exception - very colorful, decorated with student art-work, posters, numerous bulletin boards, a chalkboard, shelving to hold books and other needed materials, a sink, nine personal computers across one wall with half the number of printers, TV/VCR ensemble, an overhead projector, and, a pull down screen. Linda's desk is located off to the side after entering the classroom from the main hallway and students sit at tables arranged in two parallel rows at opposing sides of the room.

The 'feel' of the classroom is very relaxed. As I look around the room, some students have their legs up on chairs, some are sitting in groups around tables that have the remnants from snack time, and some are sitting on the carpeted floor, which Linda describes as opportunities for students to “choose their comfort zone.” Linda is constantly moving around, but at no time during my observations, does she ever take 'command' and demand attention with the exception of when a student asks where a particular book can be found and Linda's voice calls out above the rest, asking for help from the class to locate a missing item. Somehow, though, everyone seems to know what they are doing and where they are going. The only time that her presence is a greater than the students is when the class transitions into a different activity.

\section{Meaningful Experiences}

We have a lot of discussion with the students in the morning...That is when they have an opportunity to share things that they do outside of the classroom. If they went on a trip on the weekend or if they are in a ballgame or cheering, then they share that with us and they are 
glad to do that...I allow them that opportunity to share and that helps me to get to know them a whole lot, too (Linda, Spring 2001).

When Linda describes her role as a teacher, she begins with, "Not enough time to tell you that," and as the conversation unfolds, in a more serious tone, Linda talks about the many ‘roles’ she plays throughout any given school day, “Teachers are nurses. Teachers are referees. Teachers are psychiatrists...” What one comes to understand is the types of relationships Linda forms with students are based on student need and aside from student need, there also seems to be a tendency on her half, to ask students to open up a part of their lives to let her 'in' so that she may best meet their needs in the classroom. Building relationships with students is the foundation of what she does as a teacher. Some of what Linda shares from her early school experiences give clues to the type of teacher, she does not want to be - that is, a teacher that stands in front of the room, lectures, or walks up and down the rows snapping a ruler on student desks for intimidation purposes. Rather, Linda values the types of relationships with students that begin in informal conversation. Every morning prior to the start of classes, Linda allows time for students to talk about events and happenings in their life and says, "I think my students feel the freedom that they can say, 'well, I did this or I visited with somebody...'” She tenderly adds, “...I wish I could go there or I wish I could see them do stuff...” but acknowledges that as a teacher, she must step back from the 'parent' role.

Other occasions that are outlets for getting to know students less formally from the structure of the classroom are fieldtrips. Linda explains, “you get to know them [the students] differently...they are more free to talk like when you are on a bus trip, sitting together, and they talk to you like a friend almost, not a teacher.” One specific account that Linda shares is from a recent field trip to a local business where students bowled to disco music and strobe 
lights, played laser tag, and earned tickets to purchase trinkets. Students and teachers participate in individual and team activities and eat lunch at the same table.

The types of relationships she forms with students seem to be 'faith based,' that is, she has faith in students that if they are granted some freedoms and discipline is fair, they will find a place in her classroom that is safe to learn, and in a round about way, this also fosters a sense of community. To illustrate this, during one of my observation visits, I witnessed the following - students are participating in an individualized reading program where individual goals are determined after students complete a computerized questionnaire. Goals are met when students complete certain books that have been previously categorized at a certain levels and given rewards for meeting their goals. One student completes a book while I am there, makes his way over to Linda so she can record his progress, where she immediately announces to the entire class that he has completed two Harry Potter books. The class looks at him and collectively says, "Whoooooa."

The times when Linda feels as if she has failed at making connections with students is troubling to her and she directly points to lack of discipline and lack of respect that she has observed in students over the years. But, at the same time, feels that, as a teacher, “....my hands are tied...” She explains:

I want to say our system has failed certain students. I hate to say that but I think we as teachers don’t always have the freedom to do what we feel would be best for them because discipline wise we are not able to discipline them...especially if they need to be disciplined to learn. 
Without mutual respect, students and teachers cannot establish relationships which Linda says is detrimental to her teaching because she is unable to learn the interests of the students. With an uneasy sigh, Linda adds, "Our system is failing them.”

The other main theme that emerged from our conversations related to meaningful classroom experiences is creating lessons and classroom activities that allow students to creatively express what it is that they have learned and then, 'perform' their understandings

Three $5^{\text {th }}$ grade students in Linda's classroom dress up as a cheerleading squad and demonstrate their understanding of spelling words in 2001. (Photographed by Linda) through creative dramatics. Amy (Linda’s pre-service teacher) was a proponent of creative dramatics and likewise, Linda also finds creative dramatics an especially valuable learning device in the classroom. I am unsure if it was Amy’s influence over Linda or vice-

versa, but both spoke of creative dramatics. The other aspect of creative dramatics is the 'way' it enables students to connect their personal lives with the subject. On numerous occasions, Linda spoke about spelling and vocabulary lessons where students 'taught' one another through a variety of made-up scenarios, such as simulated game shows complete with ‘celebrity’ guests and TV commercials, to express highlights of learning. Students incorporated 'props,' costumes, music, and dance steps in the presentations, as well.

The faith Linda has put her students seems to be not only a reflection of her philosophy towards the nature of learners but, I believe, also a sign of her creative tendencies. More importantly, it is a sign that if students are given freedom to create or "just let go and be themselves...they can be active and happy learners.”

\section{Teaching and Learning}

Today we just received our new reading series and our new spelling series for next year and every year we get a new textbook. Another 
teacher and I were just saying this is really neat because it keeps our interest in teaching because we have new textbooks that we have to learn how to use and new ways to teach. So learning is an on-going field. We are always learning, not about textbooks, but we learn about students (Linda, Spring 2001).

Linda's first years of teaching were fraught with nervousness, she recalls. Newly graduated, she went into $4^{\text {th }}$ grade class of 37 students and relied on her student-teaching experience and theories of learning. Today, the demands to keep up with new ideas and new theories, do not greet her with the nervousness that once accompanied her in the classroom, but is perceived as an opportunity to continue to learn. However, she does admit that her role has diversified into more than just a teacher -- that is, nurse, referee, and psychiatrist - which she finds frustrating because, “We don’t have enough training to cover everything that a teacher is supposed to do. And every year the list keeps getting longer and longer...”"

Now, a well-established teacher in her own right, Linda is what I would say as nothing less than remarkable. Every fall she hosts an intern and in the event that an intern's experience at a particular school is not a good 'fit,' University supervisors turn to Linda, like a foster parent that intervenes when the original parent is unable to properly care. Her approach when working with interns is to be a positive role model and helping them to find their 'voice' in their teaching style, “I don’t ever want the interns to feel they have to teach like I teach. I want them to be able to know themselves as a teacher so I usually give them that open floor to explore.”

Linda's planning is primarily focused on blocks of time that correspond to the importance of items on the state's Stanford 9 test. As an elementary education teacher, all subjects are taught throughout the day and likewise, align with the state's IGO’s. After formally 
A female $5^{\text {th }}$ grade student stands beside a 'waterfall' she created for an enrichment project in 2001. (Photographed by Linda) considering these items, Linda moves on to a more individualized approach in her teaching where she stresses the importance of "knowing" students, which entails being aware of interests, motivating factors, and learning styles. For instance, she claims:

Some students have a real hard time listening...You can give them an assignment, they can read, they can find the answers...but if you are talking then of course, they have a tendency to daydream so you as a teacher have to be aware of the learning styles...

To familiarize herself with students, she reviews student files and test scores from previous years but is cautious to form preconceptions of students, “And, sometimes I don’t always read those reports because it tends to sway my thoughts of them....After the first month of school, it is pretty evident for the most part who needs the extra attention....” Another reason why she tends to not review student files is because she recognizes the changing nature of students at this age and understands that their interests in school changes, as well. Linda is required to create lesson plans but stresses that she cannot use "patented" lesson plans because class 'personalities' differ from year to year. Other considerations are medical problems and legal issues which are revealed to her through private student folders.

Her teaching techniques could be best described as teacher-facilitated where students are participating in activities that are hands-on, cooperative, creative, and self-paced. During one of my classroom observations, Linda and I were privately chatting and with a grin she asked if I wanted to see some 'real' teaching, which she clarifies with "direct instruction.” Obviously, she must have somehow sensed that I was attempting to take notes on her teaching 
but was unable to exactly pinpoint 'teaching' due to the chaotic nature of the classroom. But that is not to say teacher nor learning was occurring.

As a $5^{\text {th }}$ grade teacher, Linda needs to have textbooks related to all the subject areas to cover the many subjects that she teaches but, the exact role that texts play in her classroom is left somewhat vague when she responds, “I use textbooks a lot but I don’t use them...” which seems to indicate that the usefulness of textbooks varies depending upon the objective she sets forth. Over the last 25 years, Linda states that the quality of textbooks have dramatically changed and now, offer a host of ideas, activities, and resources, which are supported by educational research. At times, she will rely on textbooks especially for selecting lessons that are specific to learning styles, while at other times, "I do a lot of just my own thing....I could probably teach without them...but if I were a new teacher, I don’t know.” However, one must keep in mind that this statement of confidence is based on years of experience. Looking back, as a new teacher, she relied much more on textbooks primarily because she thought that that's what she was supposed to do -- other teachers in the county all taught from the same book. She recalls, “They [textbooks] were probably my security blanket when I first started teaching because I felt like I was on task with all the other fourth grade teachers in the county.”

Presently, students in her class have three books for the area of language arts alone -a reading book, a spelling book, and a grammar book - which is a costly endeavor for the school district. In a response that is perhaps one of the most radical departures from the other participants in this study, she states:

...we could get away from this and just have a social studies book and everything could be based on your social studies. You have your reading 
comprehension and your vocabulary skills and then you could teach the grammar of the lessons for that so I don't think it is necessary to spend so much money on textbooks.

From Linda's point of view, she believes grades are very important to students and likewise, believes that grades function as the main motivator. Linda did not share her present system of assessment but does share a memory that creates mixed feelings, which seems to be the result of the subjectiveness of the grading process -- years ago, the elementary report card was based on a three-tier scale of "improving, is improved, and needs to improve.....it was awful because I could have done a report card on one day and then two days later they would have gotten a completely different grade. It just depended on the mood I was in...” In retrospect, she admits embarrassment over the inability to be objective. Additionally, she explains that for parents this was especially difficult to understand because anything less than 'improving' was equated with an 'F.' But, realistically, she asks, "Who doesn't need to improve?” 


\section{Section Two Summary:}

\section{In-Service Teachers Understandings Related to Main Research Questions}

- The Classroom Setting As...

Comfortable

Attractive and colorful

Personalized space

Rich in technology and computers

Isolated, enclosed

- Meaningful Experiences As...

Relationships with students and interns

Freedom of expression

Respectful and caring

“Cultural Literacy”

Contextualized

Struggle and success

- $\quad$ Teaching and Learning As...

Collaborative

Social and active

Chaotic

Thematic

Grades

Alternative assessment

Lesson plans and IGO’s 
Teacher guides and students take over...

Less textbooks 


\section{Section III: The Lived Experiences of College Faculty}

The three college faculty members who participated in the study are employed by the respective University and teach at various levels in the 5-year teacher-education program. "Kathy” instructed $3^{\text {rd }}$ year students (“Tutors”) in the program; “Jim” taught a professional seminar course during the semester of student teaching and a methods course prior to student teaching; and, "Mike" instructed courses that students could take either one or two semesters prior to student teaching. Each faculty member had his/her specific area of concentration, none of which teach the same course. Each faculty participant had prior teaching experience before attaining their current position, not only at the college level, but in the elementary or secondary grades, as well; some also taught courses while in graduate school as a graduate teaching assistant.

Prior to introducing the college faculty, I am including a personal entry. In this entry, I have two concerns and the concerns are evidence of the two 'hats' I wear in this study. First, as qualitative researcher, I have doubts about my choice of participants and struggle to make amends with that decision. Second, as a 'teacher,' my eyes are opened to the reality that not everyone approaches the act of teaching in ways that are in alignment with my personal beliefs. I do not believe that this is ignorance, but perhaps a naïve perspective that is symbolic of the near-sighted experiences of which my 'lifeworld’ revolved around.

\section{Personal Journal Entry:}

Met with Jim, Mike, and Kathy -- each have done one interview each. I have concerns about Jim. He has not been the best of participants - not easy to work with. He comes across as making sure that you always know that he knows more than you do and he makes you feel as if every single minute you spend with him is time taking away from his other duties. He did not 
bother to read over the abstract I gave him explaining the study so when I verbally explained it to him, he seemed to immediately have a sense of urgency of time.

As eloquently as he spoke about the field of education and his training, not once did I get the feeling that he really cared about his students. I only say this because not once did I ever feel like he cared about my needs with this study. He never really looked at me during the interview. He also commented that he did not think that I would be able to collect all my data by the end of the semester. Sometimes I think that professors forget what it's like to be a student. I felt like he didn't give me any respect. I felt like a kid who could barely get in a word edge wise and when I did talk I couldn't seem to talk fast enough for his time frame. Then, he says that he doesn't understand - that's because he doesn't take time to listen. His behaviors spoke much louder than his words on this day. I feel that he was a good choice for the study but I don't think he is going to be as easy to work with. I have my doubts about him (Sayers, March, 2001).

\section{Post-Script to Journal Entry:}

In Jim’s Narrative (see Narrative \#8), I attempted to set aside our personality differences and write as objectively and free from bias as possible. The reader may detect a 'gap' or some inconsistencies between my 'not-so-positive' introduction of Jim (in the above personal journal entry) and wonder how it was possible Jim was depicted in such a positive light in Narrative \#8.

Jim was an animated individual whose experiences and story-telling provided myself, as the researcher, with valuable tales and at times, brought a comical air to the sometimes 
seriousness of educational affairs. While the personality differences were apparent in the beginning, I cannot discount the contribution that Jim made to this research study. 


\section{Meet the College Faculty}

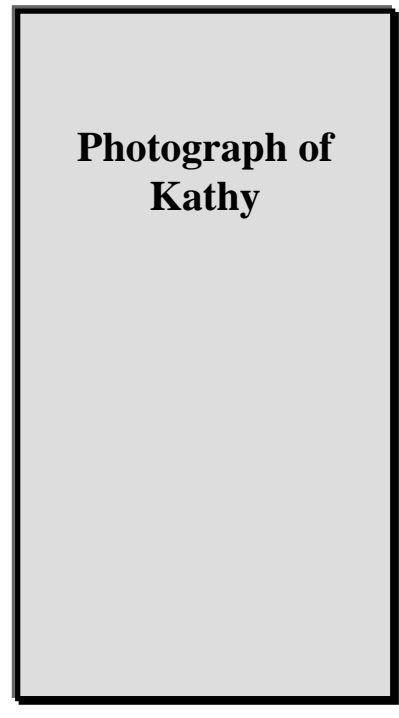

"Kathy"

Age: 40

Years teaching: 15

Degree: Ph.D. in

Curriculum and Instruction with a specialization in Language and Literacy Studies

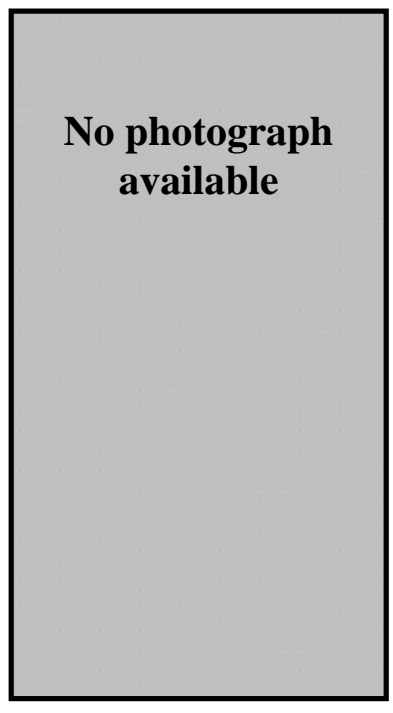

"Jim"

Age: 40

Years teaching: 19

Degree: Ph.D. in

Science Education

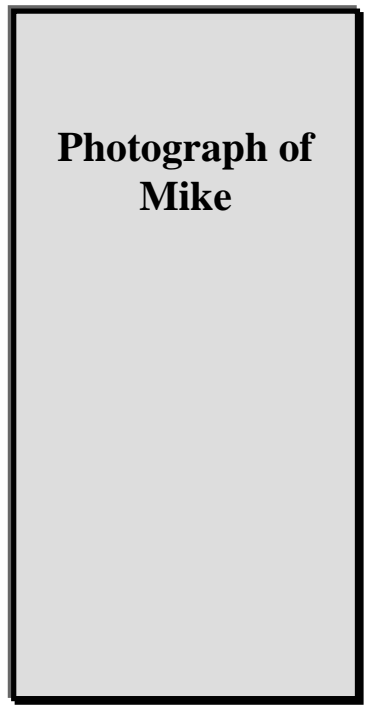

"Mike"

Age: 32

Years teaching: 10

Degree: Ph.D. in

Educational

Psychology with a specialization in

psychology 


\section{Narrative VII: The Lived Experiences of Kathy}

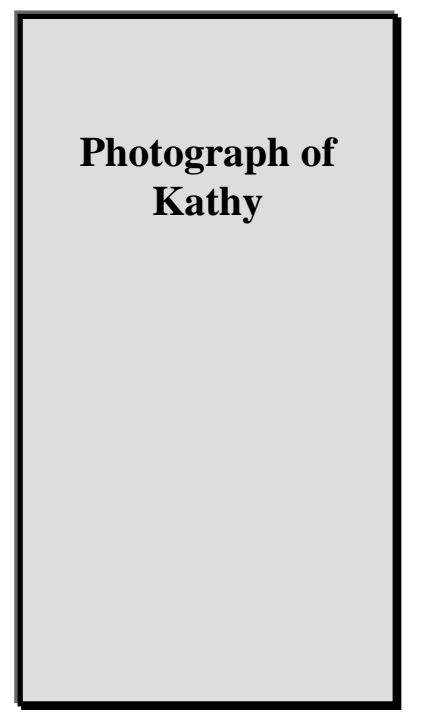

I've always loved school, but from my earliest memories of school I was repeatedly told that I talked too much, and so from the earliest report card it said, 'Kathy talks too much. Kathy would do better work if she didn't talk as much. Kathy needs to concentrate more on her work...' School was a very social place for me, and [I was] very involved in extracurricular activities, and doing my work. I was never the brightest person but I was always a good worker and agreeable so going to school was never hard (Kathy, spring 2001).

During the first semester of my doctoral work, Kathy was an instructor of a professional seminar course that focused on professional development topics that doctoral students should be concerned with but often times left unspoken in the mix of other courses, such as, finding and writing grants, exploring research opportunities, and writing conference proposals, etc. When she entered the room the first night of class, I appreciated her youth, her confidence as a woman in field that is often dominated by men, and her mid-west accent. She was different from the other instructors I had. However, it later came to be known that we were more alike than different -- we both have backgrounds in exercise physiology, health and physical education, and have worked in earnest to overcome speech impediments. She worked to overcome what she calls, “forward tongue” which affects the distinct sound of "Th's" and "Sh's" and I have worked to overcome a stuttering problem which at times, still plagues me today. For these reasons, I feel the closest to Kathy out of all of the participants. 
During the course of this study, I learned about Kathy’s background growing up in Oklahoma and later on, moving to Texas as a young woman where she took one of her first teaching positions in an Alternative Remedial Program working with children who had been retained at least two years in the school system. She painfully shared some of her memories of that experience and questions the lack of judgment shown by administrators when hiring teachers, such as herself, for this position, "Why put your weakest, least knowledgeable teachers in your most challenging situations with the kids who have the greatest needs? I was in way over my head.” Kathy acknowledges that to meet the needs of her students, she had to "rise to the occasion," and did so through professional development workshops, staff development workshops, books, the advice of others, and membership in professional organizations. She later admits, “That's probably the most powerful memory and influence on my teaching today.”

In Kathy's educational philosophy statement, there are traces of these past experiences, which influence the types of relationships she seeks to foster with students in the teachereducation program, and likewise, she demonstrates an understanding of social nature of teaching and learning:

I believe language mediates learning and that all learning is social; thus, my teaching represents a constructivist philosophical stance. I learn as I aid others in learning through social interaction. In this way, knowledge is negotiated and is shared. Consequently, I treat students as knowledgeable, interested learners with whom I can work to increase their knowledge as well as my knowledge. This translates to treating the undergraduate pre-service teachers as less experienced colleagues and the graduate students as differently experienced 
colleagues - colleagues who are interested in teaching and in children, and who are interested in becoming effective teachers of the language arts. Because I think of students as less-experienced colleagues or differently-experienced colleagues, I respect their knowledge and the complexity of their lives. I work to structure my courses and the assignments in ways that honor the knowledge they bring to the courses. I work toward relevancy in the assignments, calling the students' attention to the rationale behind each assignment and connecting that rationale, that assignment to furthering the students' goals of becoming effective teachers of the language arts and of children.

The teaching strategies I use also reflect my philosophical stance. I model; I facilitate; I scaffold; I collaborate; I share. I give freely of my knowledge without claiming to be a 'fount of all knowledge.' Together, the students and I work to build a community of learners as we read, write, and reflect on our own teaching and the teaching of others. The courses I teach are structured to allow for large group discussion of focus topics, small group or partner work, independent and collaborative reading/writing during workshop periods, and independent teaching experiences as well as collaborative teaching experiences with elementary children and with colleagues.

\section{Classroom Setting}

I think that you should have beautiful grounds. I think there should be gardens so that science projects and health projects and art projects and social studies projects could be going on...You need windows. It's ok for kids to look out the window. I think all classes 
should be small. Elementary classes should be below 20 and in high school and college should be below 12 (Kathy, Spring 2001).

Because professors in higher education do not have 'home' classrooms, such as those in the elementary or secondary grades, much of what is shared in the proceeding discussion is reflective of Kathy's thoughts and memories of past experiences as a classroom teacher, the present classrooms in which her courses take place, and an ideal vision for the classroom.

“Large rooms without desks. Large rooms with tables...I wouldn’t have desks if my life depended on it,” Kathy states without hesitation, as we begin discussing the ideal classroom setting in the elementary grades. Kathy's present classroom at the university is the 'sterile' classroom that many of the pre-service teachers referred to in disapproval and what Kathy will personally describe as, “...just a nightmare to teach people how to teach kids in.”

A glimpse of the crowded classroom atmosphere in which Kathy's teaches one of her courses during 2001. (Photographed by Kathy)
The classrooms that Kathy teaches in typically consists of rows of desks, a chalkboard, and overhead projector, and depending upon the day, may (or may not) have windows with off-white pull down shades. The color of the walls matches the color of the window shades and there is

overhead fluorescent lighting. Due to the size limitations of the room along with the number of students and desks in the room, Kathy's teaching is restricted to the front of the room where she appears 'trapped' between the first row of students and the chalkboard. During one of my observation visits, I counted 23 students, all women, and noticed a small sign on the wall that indicated the maximum capacity allowed in the classroom was 35 students as denoted by the number of desks. Further taking away from the available space in the room, is a resource cart 
Kathy has brought along, full of reading materials and other resources, to share with students. Most days, she has the cart.

The issue of having a classroom 'without desks' seems to be a product of some of her current frustrations and a result of earlier learning experiences as a child. Kathy recalls that as a student, her last name translated into her consistently being in the front row which, in retrospect, she is critical of because it advantages certain students over others:

...the random occurrence that my last name is A-B made me in almost in every class in every year first row, first seat, first to do almost everything, and that's a kind of powerful opportunity -- opportunities that other kids didn’t have just because of the placement of their name in the alphabet...

Now, as a teacher, she reminds her students of the advantages (or disadvantages) some students will have, that is, if they structure their classroom as such.

One of the main reasons that students should sit at tables is because, "they need space to socialize and work in groups.” Kathy understands that socializing and communicating with others is an important aspect of learning, not only learning about the subject area, but learning about one another's culture and beliefs. She believes that her students are at a disadvantage because $98 \%$ are white, European-American and conveys this message to her students, “...how unfortunate we don’t have a more

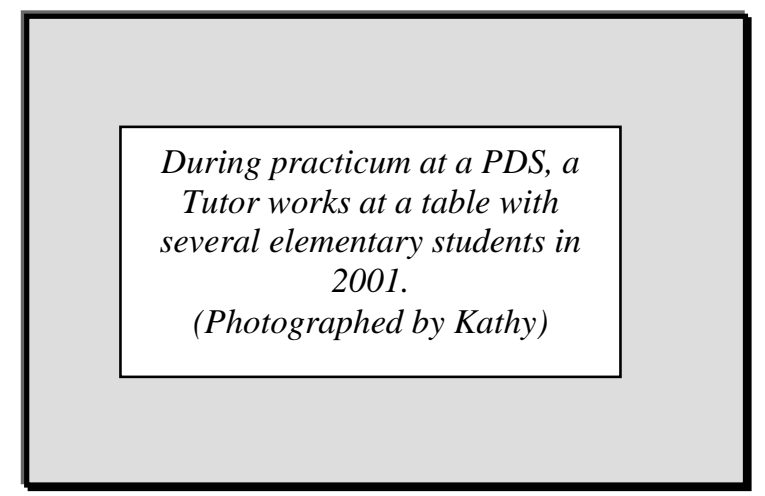
racially diverse mix because we're not learning about the perspectives of other people...” During one of my observation visits, I noted that a woman in her class identified herself as 
Dominican Republican and later, Kathy will share with me that there have been very few students of color in her classes.

Ideally the elementary classroom should include, in addition to tables, carpeted areas, and tiled areas for "all the slop that I would have or would be doing.” Kathy will continue to 'rattle off' characteristics of the elementary classroom at such a high pace that I am thankful for the tape recorder during the interview:

I'd have windows. I'd have lots of plants. I'd have animals. I'd have a lot of things that could stimulate conversation, writing, lots and lots of books, music....fabulous grounds so that you could be outside doing things - a garden. I would want a vegetable and flower garden. I would want playground equipment, space for kids to run...I would want in my classroom computers, at least one for every three children. I would want to have my own personal computer and I would want all of the computer to have Internet hookup....

Interestingly enough, her ideas about the 'inside and outside’ setting at the elementary level will follow through at all levels - that is, to the secondary grades and higher education. With the exception that at the secondary level, block scheduling should be implemented because the content demands greater in-depth study, "You need longer periods of time to explore things.” Likewise, due to the level of inquiry and investigation, she believes that at least one computer should be made available for every student.

In a teacher-education program in higher education, she specifically advocates for classrooms to resemble the set up of the elementary classroom, that is, complete with chalkboards, computers, bulletin boards, felt boards, mini-libraries, so “...they [the students] could see what it means to be an elementary school teacher.” But, she also speculates that the 
advantage that students gain in this simulated classroom atmosphere, could translate into her teaching, as well, "I'd be a better teacher that way..."

In Kathy’s present classroom not only are students learning about literacy and language, but it is also a place where they discuss some of the challenges the Tutors are met with during their practicum. It is Kathy’s intention to, "set up a classroom community that is safe and open and accepting,” which is especially important if they recognize that collectively and professionally, they offer much more to each other than Kathy could alone. Similarly, one of the aspects Kathy finds most satisfying about teaching is, "knowing that what I am doing is likely to have influence on what will happen in classrooms later on.”

\section{Meaningful Experiences}

I work to find out about them [the students], to talk with students, to pay attention to the things that they say and the things that they write and then to try to support them in the areas that they're having difficulty. I pride myself in being available to my students... I think one of my strengths is that I take the time to get to know the student, know who they are as learners in my class, and also as who they are as people outside of class (Kathy, spring 2001).

One of the main messages echoed in Kathy's words, is her desire to create relationships with students for the main purpose of allowing her to best meet the needs of students and in turn, she believes, students can be successful. Kathy used the term, “successful” countless times and in one of the interviews, I interjected, that's a relative term, thereby prompting her to further clarify, "To be successful is to have a deep understanding of the content of literacy studies and an array of instructional approaches to meet the individual needs of students.” From this, it becomes apparent that Kathy attempts to "model for them how to be humane to 
students," and as a teacher, she takes this to heart because too many students become "exasperated" when success is not followed by earnest effort. In this case, teachers must forgoe typical strategies of teaching, and, "teach kids ways of helping themselves...teach strategies towards independence,” which can only be transgressed through types of relationships that are genuinely based on concern and compassion.

Kathy shared several memories from her girlhood that she personally describes as "painful memories," about her frustration as a student who did poorly on spelling despite studying and asking for additional help. "I remember going out in the first round of the spelling bee in third grade on the word 'button'...my mother and my brother were always so good at spelling and neither could understand why I was not as good.” Another spelling-related story, this time from high school, entailed reviewing spelling words with friends at lunch time in preparation of an afternoon spelling test, “I can remember on Friday’s, the spelling test, at lunch time going over spelling words, and then an hour later, still not making a $100 \ldots .$. and there's numbers of time that I would write and write and write and try to get in the groove....” For Kathy, she admits that there is a lesson learned, "it has helped me in working with novice teachers...”

Some of the ways that Kathy attends to building relationships with students are attempts to open conversation in class about current practicum experiences. Part of her role as a teacher with Tutors is to "problem-solve crises" and one strategy she feels that has been exceptionally effective is relating stories of personal teaching experiences. What she finds is as she opens herself to students, they feel comfortable in doing the same. As boundaries melt away between distinct student and teacher roles, less formal relationships begin. The less formal feel of the classroom tends to legitimize relationships in a way that Kathy cannot 
adequately articulate except, "Humans take interest in one another when they get a sense of where we are from.”

Other day-to-day strategies are making students aware that due dates of assignments are flexible, that is, if they let her know in advance; an 'open' door policy before and after class; second chances to re-submit work because "there are times when the students might not do their best work”; being sensitive to illness or personal crisis, but, “I can’t be sensitive if you don't let me know”; and, being aware that some students can’t tolerate a lot of feedback on papers due to low confidence in their writing abilities.

Out of frustration, she says that one of the drawbacks of maintaining and ensuring student success is time; that is, time on her behalf, which cuts into other professional duties and responsibilities, and time on the students half where the greatest rewards come from devoting themselves to projects over extended periods of time. Creating this type of atmosphere, where she truly must practice what she practices, entails "listening, speaking, reading, and writing in every single lesson" and unless time is somehow 'recovered,' "it will be a barrier that is if we are going to be doing things that are more meaningful.”

One of Kathy’s first teaching positions was at an Alternative Remedial Program in San Antonio, Texas with a group of students who had been retained for at least two years. It was a multi-age classroom with children of severe behavioral and learning problems. As a young, inexperienced teacher she was frustrated working with a group of students that she knew so little about, some of which she blames on herself and the teacher-education program she attended. She remembers, “All the kids were different than I - they were all Hispanic - so I had issues, not about diversity but I was not as knowledgeable about the Hispanic culture and I certainly wasn't knowledgeable about what the norms of life in San Antonio.” 
Now, in her present classroom, it is especially important to address race, class, and gender issues and she does this purposefully from two perspectives - (1) personally -- that is, within the personal lives of her students and (2) professionally -- how will her students as future teachers, address these issues within their classrooms? From the personal perspective, "there are gender implications in the classroom" which lead to conversations about research on boys in the classroom versus girls in the classroom, which she finds especially interesting and timely because, “almost all of my students are female although, I occasionally have a male.”

During practicum at a PDS, a

Tutor exposes elementary students to the American Eskimo culture through books and art in 2001.

(Photographed by Kathy)
Students are asked to contribute stories of their own lives and in return, Kathy tells them stories of her experiences teaching and growing up. Professionally, they discuss ways that these issues can be incorporated in

the classroom in age appropriate and culturally sensitive ways. As a literacy and language specialist, books are one medium to introduce issues of race and gender to students, but the other issue that the classroom teacher must come to understand is that one's values are closely related to socioeconomic status. For example, she asks her students to consider various scenarios, such as:

...what does it mean really not to have supplies and not to be able to contribute to the supplies in the classroom and how important it is not to be angry at the kids because their parents aren't sending materials [back]....if you have an older child who is responsible for younger siblings in the afternoon and the evening and then you're angry at that child for not completing his or her homework or reading assignment. 
More importantly, how will future teachers put aside judgment, put aside their values, to educate children that come to the classroom with a set of values, not reflective of a culture similar to theirs?

\section{Teaching and Learning}

And so trying to help pre-service teachers or novice teachers, recognize that their joy in learning is going to influence their students' joy in learning. I think it's important for me to demonstrate my joy in learning and my commitment and enthusiasm to my content (Kathy, Spring 2001).

“Research shows that a teacher's level of interest and enthusiasm is related to students' level of interest and enthusiasm,” Kathy explains, as we talk about her thoughts on teaching and learning. Aside from the noted characteristics of teachers in research, in general, Kathy has always associated learning with favorable memories. For instance, she says, "Learning is a luxury....I have always loved school....going to school was never hard...,” and it seems that it is Kathy's intention to instill this same love of learning in her students or still yet, reawaken them to the joy of learning. More importantly, teachers should love what they teach and welcome students into a "learning community, into a really loving, learning community."

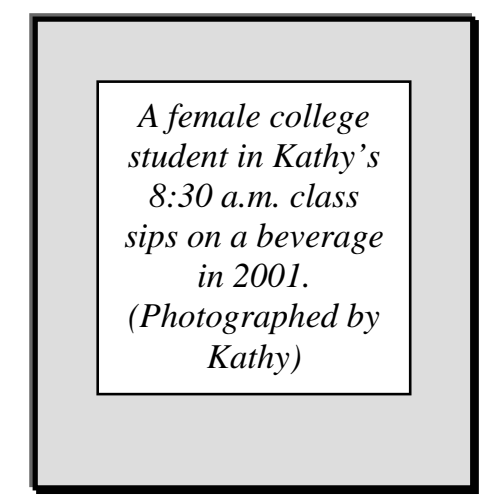

Judging by some of the events I observed during my visits, Kathy’s enthusiasm towards her students and joy for learning are evidenced in small ways - she greets students with a smile for an 8:30 am class, opens class with 'show and tell' time which prompts students to talk about recent literature finds and

discuss practicum experiences, interjects bits of humor and levity into discussions, and occasionally provides drinks and snacks. At a larger class level, she attempts to establish a non- 
hierarchical structure by acknowledging, "You are a teacher. I am a teacher. I happen to more knowledgeable in certain areas. You are more knowledgeable in certain areas. We are here to learn.” Within a learning community, Kathy acknowledges that group members need to feel a sense of belonging, if they are to contribute to the group process. For Kathy, 'membership in the group' is especially important and is the topic of discussion from a memory she recalls from graduate school, "In the research team, I was never treated like I was anything different. I was one of the group and that's one of the most powerful events of my learning...I was learning just as fast and hard as I could.”

Some of what has created the 'teacher within’ Kathy can be understood as a reflection of her experiences as a student and teacher. There are negative experiences and positive experiences to speak of, but in either case, have influenced her teaching today. More specifically, she credits particular teachers who's teaching styles resonated positively or negatively, which has led to her preferring certain strategies over others, her personal interests, and current research. The final influence on her teaching is the students:

I'm a better teacher when I get lots of feedback from students. If I have a very verbal, gregarious group, I'm a better teacher. If I have a quiet, shy group who aren't particularly interested in literacy, I'm not as good as a teacher. It's harder to reach them, it's harder to stay up.

Kathy's planning for courses takes into consideration many factors: the standards of the college and other professional organizations related to teacher-education and literacy; the knowledge and information students will need when they are teachers; the focus of the course; prior student knowledge, and current sequence of courses students are completing. In the event, there are students "who are so fabulous and display knowledge of basic literacy concepts 
significantly higher than the other students, my job with them is to try to push them further.” She incorporates into her planning, opportunities for students to participate in outside of class programs and projects, allowing them to step into leadership roles, and then returning to class as “...the voice of experience.”

Current literature, research, and textbooks also play a role in Kathy’s planning. As a teacher of literacy, she must stay current in the field of children's literature, as well as, college level materials for pre-service teachers. "Textbooks do not dictate the curriculum but there are weekly readings that I make from the textbooks that I select for class...in higher education it is critical that our students read...” During one of my observation visits, I make note of themes of a few children's literature books on her cart - one about the Far East, another about Africa, and another on Yiddish traditions. The book about Africa (I fail to record the title) is a fable about why mosquitoes buzz in people’s ears. Kathy instructs students that this book is good for 'sequencing' lessons and the word "mosquito is a tough word to spell...it is a Spanish word and does not follow the letter sounds.” The authors of the book are a, "biracial couple -- the wife is of European descent and the husband is of African-American descent.” From the course syllabi, I observe that Kathy requires students to purchase three texts: Literacy Beginnings (2000), Phonological Awareness and Primary Phonics (2000), and An Observation Survey of Early Literacy Achievements (1993).

Class assignments for this particular course

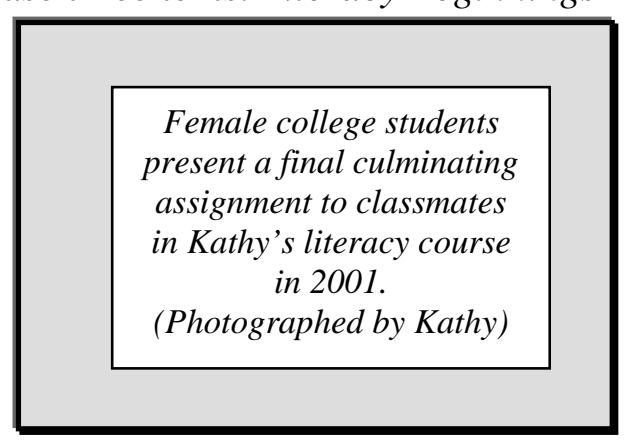
are of a varied nature - from the course syllabi students are expected to create a high quality audio-cassette recording of a children's book; present a mini-teaching; create a child’s book; establish through professional communication with class members; and perform a case study. 
In these assignments, Kathy's views learning as a process of talking, writing, and listening; participating in an atmosphere where taking risks and posing questions are acceptable; and, providing opportunities for students to "wrestle with ideas but not aggressively with one another.”

Grades are assigned according to an established scale listed on the course syllabus, but the issue of grades is an especially sensitive topic for Kathy, which may not be known judging by the straight-forwardness of the scale on the syllabus, and only, became apparent as we discussed them during the interviews. Throughout the course of the interviews, the topic of grades emerged on numerous occasions and Kathy's expresses a deeply felt concern over the role of grades in the teaching and learning process, a role, which she believes is detrimental to education in general. She outwardly communicates these ideas and nonetheless, understands that there are others who will not be in agreement with her. In the following dialogue, I have pieced together many of these instances:

Grades really stink...Being required to assign grades for student’s work and assign an overall grade for student performance is really dissatisfying...I'm certainly supportive of providing substantial feedback but when forced to translate that performance into some judgment letter grade, I really dislike that...If I were the queen of education I would not be assigning grades...It would be a pass-fail or a satisfactory-not satisfactory option....I think grades interfere with learning. Grades reflect whether people are attending regularly, they're prompt, if they've done extra credit, if they turn things in on time or if the don’t...they show dedication, commitment and personal development....Grades are not highly related to knowledge...Students are 
more concerned about accomplishing some grade than they are in learning material. I think that's a part of schooling. I think we've done it to ourselves. 


\section{Narrative VIII: The Lived Experiences of Jim}

(No photographs available in this section)

'I really need for you to teach this, Jim.'

'Joe, I really can't do it because $I^{\prime} m$ being pulled in all these

different directions.'

'Ok, let me see if I can find someone else, Jim.'

He came back to me and said, 'Look you're the only person who can teach this class.'

So here I am out there alone trying desperately to sort out what it is that needs to be done...I ended up being very lecture and very theoretical...It was disastrous experience...I was out there all alone, no one to talk to, no dialogue... that continues to haunt me...it's this specter I can't seem to put to rest... (Jim, Spring 2001).

Jim is a professor in the 5-year teacher-education program with an extensive background in science and science education. His love for science began as an undergraduate and quickly faded after several disappointing semesters of "abstract chemistry labs.” As his interest waned, so did his grades. After having a scholarship repealed, Jim attended a geology class taught by the father of a friend, which he personally describes as a turning point in his academic career and a rejuvenating moment, “...I really loved it...that sort of turned things around quite a bit.” Now, at 40 years old, he has been teaching in a science related field for about the 20 years at some capacity, be it, in the public schools or in higher education, and has published articles in refereed journals, received grants, presented at national conferences, and is currently the director of a project which aims to bring students from the Arts and Sciences, 
and Engineering to the field of education. In addition to his professional responsibilities, he is a husband and father.

He has taught numerous courses in the field of science -- geology, oceanography, mineralology, biology, physical science, earth science, and chemistry - and some of his most rewarding moments as a teacher have been, “when students go beyond what I can do personally, not so much I in terms of the product they generate, but to see an extension of myself in my students...they own it [ideas and projects]...And, they say, 'wow, this is pretty cool."” On the other hand, he finds himself especially frustrated when students lack motivation and "expect to be spoon-fed or expect to not do things independently, but be told exactly what to do and never go beyond that." Some of this frustration is merely the result of a 'plate' that is extremely full where time is at a premium.

The issue of time and change over time is a recurring theme in Jim’s discussion. One such instance is witnessed in Jim’s introductory piece. He was in graduate school and was asked to teach a course, which he initially turned down to rather focus his energies on his dissertation. After a second offer, he accepted but, in retrospect, speaks of his teachings with sorrow and regret, “I haven’t had such a bad teaching experience ever. I know it was bad. I wasn’t able to dedicate the time, I didn’t have my philosophy of teaching sorted out...” Even though this memory still haunts him, he does have a firmly established teaching philosophy today, which he succinctly recites:

...if there's something important enough to learn then I'd better find a way of conveying that and evaluating those means that I choose...education is an iterative process, teaching and learning play off of each other. If learning is the 
ultimate goal, then that's the directive force behind everything....if learning does not occur, I haven’t been teaching.

What sets Jim apart from the other participants is his brutal honesty and colorful stories which I am inclined to believe is a part of his teaching, as well. I was personally able to relate to Jim’s experiences through his animated storytelling. In the proceeding narrative, there are numerous metaphors wrapped into an interesting blend with teaching and sociological theories, and epistemological assumptions.

\section{Classroom Setting}

Teachers own their classroom in a sense and they close the door, and when they close the door they have little controllable area, this sort of control-oriented approach...I like the concept of open school...where you've got to create autonomy...you give them the general guidelines, cut them loose, and let them run with it. Now, they'll run with it down the halls, they'll run with it at home (Jim, spring 2001).

"You might go into those elementary classrooms and see all the wonderful colors and posters and things on the wall and it's all a very happy, bright place....so the sweetness and light, the color of the pretty pictures and everything are just that - it’s window dressing,” Jim explains, as we talk about the classroom setting. Contrary to the other participants, Jim strays away from discussing the physical features of the classroom setting and focuses more on how the atmosphere of classroom is driven by issues of control, that is, teacher control, “...the literature on motivation goes back to teachers tend to be very controlling and what they end up with are students that are looking for controls.” In Jim’s opinion, what one sees upon entering an elementary classroom are "illusory” effects that overshadow the real underlying issues of 
control. Because Jim's ideas about teaching and learning are deeply aligned with students becoming independent, free thinkers, he conceptually frames his classroom setting around "open and autonomous areas where students learn to take risks and engage with the subject."

In this ideal environment, Jim believes students need to take command of their learning; it must be a place where learning is turned over to the student and the way to do that is to "trick them into believing that they're in charge of their learning, that they're in charge of the situation.” He further elaborates on this concept, “...they have to have an environment where questioning and dialogue is allowed. They have to be able to question the teacher. They have to be able to question the situation. They have to be able to interrogate what it is they're doing...”

Students also need to be free from the rigid structure so often is a part of a student's plan of study. One way to do this is to provide students with options and choices in their plan of study. At the high school level, Jim believes that "no more than two-thirds of their schedule in a given your should be required core courses. The rest should be electives...by the time they get to high school, they have an idea of who they are so you've got to give them an opportunity to refine that.” Jim echoes similar sentiments about the higher education, “...there should be a minimal number of required courses, a maximum number of different options.”

Logistically, he understands to create this type of student, the classroom setting must be open "to a lot of exchange," thereby making noise level a concern, and for many teachers, noise is a sign of "student's being out of control and teachers unable to control." Another large issue at play here, he explains, is people are not ready for this type of environment and further expands his argument to include issues of societal (un)readiness. Jim speculates that the level of readiness (or non-level of readiness) fall backs to professional development and leadership issues at the local, state, and national level, where teachers and administrators are, "simply not 
ready for technical and developmental progress.” Another aspect to his argument is, if leaders of education dictate progress, how do they determine people's state of readiness? Jim attempts to answer my mental question before I could ask it through re-telling the story from a science fiction novel, Pavane, which I am unfamiliar with:

On the eve of the invasion of the Spanish Armada, Queen Elizabeth I is assassinated and the Reformation grinds to a halt...the progress of technological development in Catholic Europe has been altered as well. So people try to apply knowledge to situations but as soon as they invent something new, the Church seizes it. The Church suppresses it or hides it, takes it away....the last chapter is kind of bizarre and breaks stride but basically, the Church wasn’t really suppressing this, the Church was holding onto this knowledge until such time as people were ready for it. That they were too immature at the time the technology became available to use it without destroying either themselves or the environment...

\section{Meaningful Experiences}

I had this professor when I was in my master's program...this old guy was a fossil himself, and he sat down at the beginning of class, and opened a file folder for the course, all the notes that he had generated over the years...he read the first page, then the second page. He kept reading pages until the end of the period, put a little paper clip at the page he stopped at, closed the file. Next class, he had that file, opened it to where the paperclip was, and started reading again...(Jim, spring 2001). 
One of the over-riding themes that emerged from Jim's conversations, related to meaningful classroom experiences, is the need to always relate the topics of the classroom to the lives of students even, "if that means going outside the formal curriculum for relevance," and incumbent upon this, is dialogue and engagement between the teacher, student, and object. In this particular section, Jim speaks to this from two perspectives - as a student and teacher.

In the above scenario, Jim is especially displeased with the instructor's teaching style and continues the story, “...in the back of his mind, I’m sure he didn’t care if you learned it or not...he wasn’t interested in dialogue.” What this teacher lacked in communication skills, is what Jim now believes is so valuable that he repeatedly emphasizes the need to always contextualize the content area to the students' lives and tells many stories to make his point. When connections are made, Jim asserts, value, or "genuine-ness" is discovered. He describes an experience as a student where such 'genuine-ness' was revealed, “...the instructor had the ability to tie the content into something real in the real world. Some real contact...without some personal value added to it, it doesn't work for me.” The other characteristic that Jim attributes to these types of experiences is engaging students with the object and less with the instructor, “...the instructor wasn’t lecturing us...didn’t dump on us - we were engaged more with the experience than we were with the instructor.”

One such story that epitomizes many of the above characteristics of communicating, genuineness, and engagement, comes from Jim's days as an undergraduate student, which I have entitled, “Justifying Your Existence.” Jim introduces this memory with, “...did I tell you about my history professor in the park at night?” and further, preludes the story with, “...this type of thing would never happen these days...” I am intrigued. 
This guy was about 75 years old...one of the best teachers I've ever seen. He was giving a lecture about Aristotle. His lectures were always engaging but there was this guy that had fallen asleep in the front row of class. All of a sudden, the professor starts talking about his sailboat how he loves going out on the lake on summer afternoon...then, he reaches into his pocket and pulls out this great big lock blade pocket-knife, the really heavy blade that every good sailor needs. He's got the blade out and he goes right up to the guy who was half asleep and says, 'Tell me why I shouldn’t kill you right now?' Of course, the kid wakes up and says, 'Because I'm a nice guy?' And the professor says, 'That's not good enough.' The guy got real worried but it was all part of the lesson of justifying your existence. I don’t know if that guy could justify his existence but it helped me to think about the process of justifying what I do. From Jim's days as a teacher, some of his most meaningful moments where when he would take students or teacher-groups on fieldtrips in the North Carolina mountains to explore non-operational mica mines. During the day long field trips, he witnessed students participating in pleasurable learning activities which he describes here:

...I'd take a group up there to see their eyes widen, their horizons expanded. Very, very satisfying...I know they learned something. I know I hit the nail on the head. I can see it in their eyes. I can hear it in their actions...

The other main theme that emerged from our conversations related to meaningful classroom experiences is addressing issues of diversity and more specifically, the underrepresentation of people of color and women in science. Jim admits that his background is such 
that, "I do not by any stretch of the imagination consider myself having a multicultural background but I do have an appreciation for marginalized populations in science.”

As I combed over the transcripts, there were several accounts that Jim spoke of which demonstrates an understanding of diversity issues and how he, in a practical sort of way, goes about bringing awareness of these issues to his students. One episode I have entitled, "The Tortilla Theory,” and the other, "Look and Listen.” The Tortilla Theory is what Jim calls, “a shoot from the hip sociological theory,” that provides an understanding of the one's community when "official numbers" are not available. Look and Listen offers suggestions for teachers to understand the broader context of students' lives.

\section{The Tortilla Theory}

- Postulate \#1 - When grocery shopping, pay attention to the different varieties of tortilla shells. "Go to any grocery store and look at the variety of tortilla shells. You might find corn tortillas, flat corn, wheat, whole wheat, ...big ones, little ones...all different shapes and sizes.”

- Postulate \#2 - Be aware that grocers stock shells to cater to specific demographic groups in the community:

...there was a large grocery store, 'Ingles,' that's Spanish for English...I was there at about 11:30 at night getting Pedialite for my son. I was the only English speaking person in that store at the time. The people running the stores aren't stupid. They had so many varieties for a reason.

\section{Look and Listen}

- Postulate \#1 -- When taking students on a field trip, pay attention to what they are saying and pay attention to when they are not talking: 
We got up a 6:00 to drive three hours into the mountains for a field trip. I think there was one White fellow and the rest were African-American. They asked if they could play some music. They were playing music and talking, and when we would stop, they'd be talking to kids from other schools. And then we got into this one town, and they all got really quiet and I said, ‘you guys OK back there?' No reply. I said it again. Still silence. Then the spokesperson for the group said, 'Don’t see too many black folks up here do you?' Then it hit me, the kids will tell you if you listen.

\section{Teaching and Learning}

If you don't like evaluation then education is the wrong business for you. It really and truly is [continual self-examination] because you have to go through this process of constant evaluation to see if what you're intending to happen is in fact happening. And if it's not happening, then it's not just a situation of 'it's just those kids,' Maybe it's something you're doing (Jim, spring 2001).

Leaning back in his office chair, Jim reflects on some of the teaching and learning experiences that have impacted his life:

...in first grade, I learned to tie my shoes...in second grade, the teacher had absolutely no control and I didn’t learn crap...in third grade, we went on a field trip to Chinatown...in fourth grade, we read 'Charlotte’s Web.' Everybody made fun of me after that because I cried. I got all emotional about the story... Amazingly, Jim is able to tell an account for all but three years of his public school experiences and recall the events in the classroom with great detail. Such as, ..."she was a mean battle-axed kind of teacher,” or “my German teacher brought in his accordion very 
Friday and sang songs in German.” But, Jim will be the first to admit, that today’s teacher needs to re-examine traditional teaching methods and acknowledge that there are many problems with the existing school system, and the problems cannot be solely blamed on students. A closer examination may instead reveal that the problems are due to inadequately meeting the needs of students and linked to insufficient teaching strategies that no longer 'work' in this rapidly changing technological world. Ideally, Jim believes, "instruction should be matched to the capacities of students in a much more mindful way.” He further expresses this sentiment with frustration:

We have a school system that took us 100 years to perfect, and it doesn't work anymore. And when they say, 'Oh, yes, schools are failing,' schools are failing because the methods the schools are using are not appropriate to the population any more...going back to 'chalk and talk' is the wrong direction folks!

Coming back to examine the role of the teacher, Jim states, “...to create the conditions that will allow students to learn, and own those tools for dealing with and shaping reality.” Embedded within this message, there is also a sense that, not only can students be active participants in shaping reality, but teachers can, too. Likewise, education should not only be the medium to provide tools for the changing times but also has the means to shape reality. How might teachers and learners begin to do this?

During our time together, Jim introduces me to the ideas of Joseph Schwab and much of Jim's philosophy towards teaching is based on Schwab’s ideas in The Teaching of Sciences Enquiry. Jim explains that a large portion of Schwab’s philosophy challenges current practices of schooling, which he believes, promotes an atmosphere of "the rhetoric of conclusions." That is, “...as a student, it doesn’t matter what you think. All the thinking’s already been done and 
here are the conclusions that you have to have.” Schwab challenges the lack of professional dialogue between teachers and students, which feeds into the status quo of learners and at this point, even teachers stay 'locked’ into the status quo. Jim emphatically claims, “....we do anything but enquiry.”

Schwab proposed that four components be taken into consideration to 'break out' of the current situation: content, role of the teacher, role of student, and building context. Of the four components, Jim admits that 'context' is the most difficult, yet the most fascinating aspect for him in his teaching:

Context would be anything that's connected to teaching and learning or organizing...it might be something that supports your teaching or student learning...like grant writing, getting instructional materials, evaluating textbooks, field trips, professional organization, and professional journals that speak to teachers....it's the part that really makes your job enjoyable. A role of the teacher, if one is to follow Schwab's model is to push for connection, and personalize and contextualize learning to the student's life. Jim describes some of what he does in alignment with Schwab's model:

You have to come up with ways for them [the student] to be a little bit uncomfortable...this is the stuff they talk about with assimilation and accommodation...I try to create these situations where you live it, you experience it, it's forcing you to go into a direction you might not go on your own...when schemata changes, that's where learning takes place...it's like the 'Field of Dreams' build it and they will come.

As a teacher, Jim finds some of his most satisfying moments are when: 
...the mindset changes from that of a student to that of a professional...to hear them say, this has changed my life; this has change my point of view on science; or my point of view somehow; its broadened my world. I mean, that's the essence of the learning experience.

In these moments, Jim likens his role to that of a master craftsman or tour guide where the students are on some journey with him as an apprentice or journeyman.

Much of Jim's actual planning for courses revolve around Schwab’s principles and he pays special attention to building context to meet the needs of students. He reviews his syllabus from years past, revises assignments, and periodically 'checks-in' with students “to assess where do they want to go from here?” All of which he says is very time intensive. He also relies on the standards set forth by the college as part of maintaining NCATE accreditation and the NSTA standards for science educators.

One of the most time consuming activities of his teaching responsibilities is reading papers and writing comments. "It takes me a long time to read papers. I hate grading papers but in the end I realize that it's important for me to do that because that's an opportunity for dialogue.”

Most assignments in his courses, “are not prescriptive," even though he does offer guidelines. From a course focused on professional development for pre-service teachers, students are required to create a "Coordinated and Thematic Module." The following is a set of guidelines accompanying the Thematic Module assignment, as stated in the course syllabus:

(1) Well defined content theme with supporting rationale.

(2) Evidence of coordination of the four science content areas within the theme. 
(3) Explicit reference to Science Instructional Goals and Objectives and relationship to relevant Benchmarks.

(4) At least four activities per grade level described for teaching the module with complete references.

(5) Clear and complete class presentation.

Grades are an area of concern with Jim, which he closely associates with student motivation. He mentions that his dissertation was on an aspect of motivation but this topic came to fruition following situation where, out of necessity, he had to figure out a way to motivate students. As a young classroom teacher, Jim had two periods of students, where in one class $35 \%$ were at the "D" or "F" level and in the other period, $40 \%$ were receiving similar grades. The principal was aware of the situation and inquired into Jim's assessment plan. Able to justify the grades of students, the principal still was not satisfied and told Jim, "Well, you just have to motivate them.” Today, Jim still believes that part of the teacher's role is to motivate students to learn but grades should not be the primary concern of students. Unfortunately, as much as teachers try to get away from this, students desperately cling to the idea that grades are a measurement of knowledge. Jim approaches grades as reflective of mastery. One story he tells that had a profound effect upon him and continues to influence his ideas on grades, is about a professor he worked with while in Georgia:

It was at about the midpoint of the class and a bunch of students came up to her and wanted to know what their grade was. She got really upset with them. She said, 'If one more person asks me what their grade is right now, I'm going to fail them on the spot.' She caught everyone's attention with that, and she said, 'I don't care what you're grades are. I care about your learning, and if you're 
doing what you need to, if you're engaging in learning experiences, and you're growing with them, then the grade will come.

This story ends, much like the "Field of Dreams - if you do it, if you live it, it will come." 


\section{Narrative IX: The Lived Experiences of Mike}

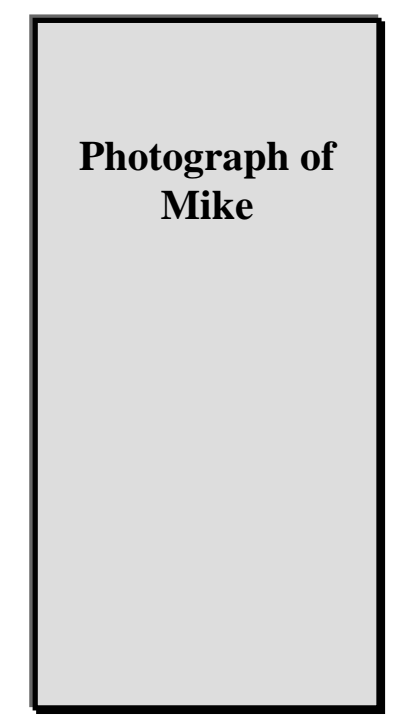

I grew up in Colorado...Spanish was a very popular second language, a lot of migrant workers from Mexico, a lot of my friends were Hispanic...I remember I had a sixth grade teacher that picked out a core of students to become leaders and I was not one of them. But, once the bell rang we were out on the playground and I was one of the leaders...I knew she had her 'pets'... g guess she wasn't very sensitive to multicultural things back then. But they were all white males...I think I was excluded because I was different, at least that's my interpretation of it (Mike, Spring 2001).

Mike is the youngest of the faculty members participating in the study and was fairly new to the University at the time of the study. Since completing the study, I was informed he has since moved on. But, what brought me to Mike was his fresh perspective towards the 5year teacher-education and his background in educational psychology. Furthermore, I believed that his background in educational psychology and statistics would offer a different kind of perspective unlike the other participants.

During the course of this study, I learned about Mike’s background growing up in Colorado, and later on, moving to Kansas where he attended a local community college. From there, his travels took him further east to attend a university in Tennessee where he obtained undergraduate and graduate degrees, and, eventually, finding his way to Mississippi State University for his doctoral program. As a doctoral student, he especially enjoyed the collegiality he shared with the other full time "cadre" of graduate students and he spoke fondly 
of the relationships he established with professors in and out of the classroom, "I played on an intramural softball team and we also had some faculty and that was very positive. It allowed me to see the faculty in a different light...it allowed me to see them as not such a serious person.”

Many of the contacts he made on the ball field enabled him to establish relationships that would further his professional development. He was a teaching assistant, research assistant, co-authored journal articles, and co-presented at conferences. One not-so-positive memory he recalled as a teaching assistant entailed the "instructor of record" repeatedly interrupting him during a lecture:

It was a big lecture [class] - human growth and development - I was getting some discussion going and I had the momentum built up and all of a sudden the professor jumps in and started giving other information. I sensed that the students really didn’t appreciate that...it become more frequent and broke up my flow of thought...

That situation was a "blow” to Mike's confidence and he confesses that the 'lesson learned' from this experience now enables him to practice patience and "sit back and wait until my teaching assistant is done.” He is curious if other participants in the study have had similar types of experiences and wonders out loud, “...have others taken something negative and turned it into a positive and now that they’ve done that, their current outlook on learning and education is also positive?” At that point in the study, I was unable to speculate, let alone, draw conclusions, which not surprisingly, led to Mike having questions about qualitative research and the methods by which I went about analyzing data. I did not get the sense that he was cynical or critical of the methods, just curious. In fact, later on he recalls a memory from 
graduate school where faculty members from two different departments arranged to have a philosophical debate over the legitimacy of qualitative versus quantitative methods. He did not indicate 'who won' or 'who lost' but does admit, “...professors that did quantitative studies had nothing to do with and completely disregarded qualitative methodology, and likewise, vice versa, so being a student I would have liked a chance to see both sides....I would have liked to learn more qualitative...”

Mike is the instructor for two sequential educational psychology courses to third year students in the 5-year teacher-education program. On the syllabus for one of the courses, he writes under the section entitled, Course Description, “This course covers the application of psychological principles to the educational process. Readings and lectures will focus on the areas of behavioral, social and cognitive learning and instructional theories, planning for instruction, motivation and learning, managing the learning environment, and assessment.” At first glance, this may appear insignificant, however, beside the course syllabus, rests Mike’s philosophy of education (which I have re-created in figure 5.1) and I notice stunning similarities in terminology and realize the close connections between his teaching and beliefs about education. One element that is missing, that has been common to the other preceding philosophy's of education, is mention of the student. Interestingly enough, Mike is the only individual in the study to construct his philosophy of education as a self-titled "pictorial" model. 


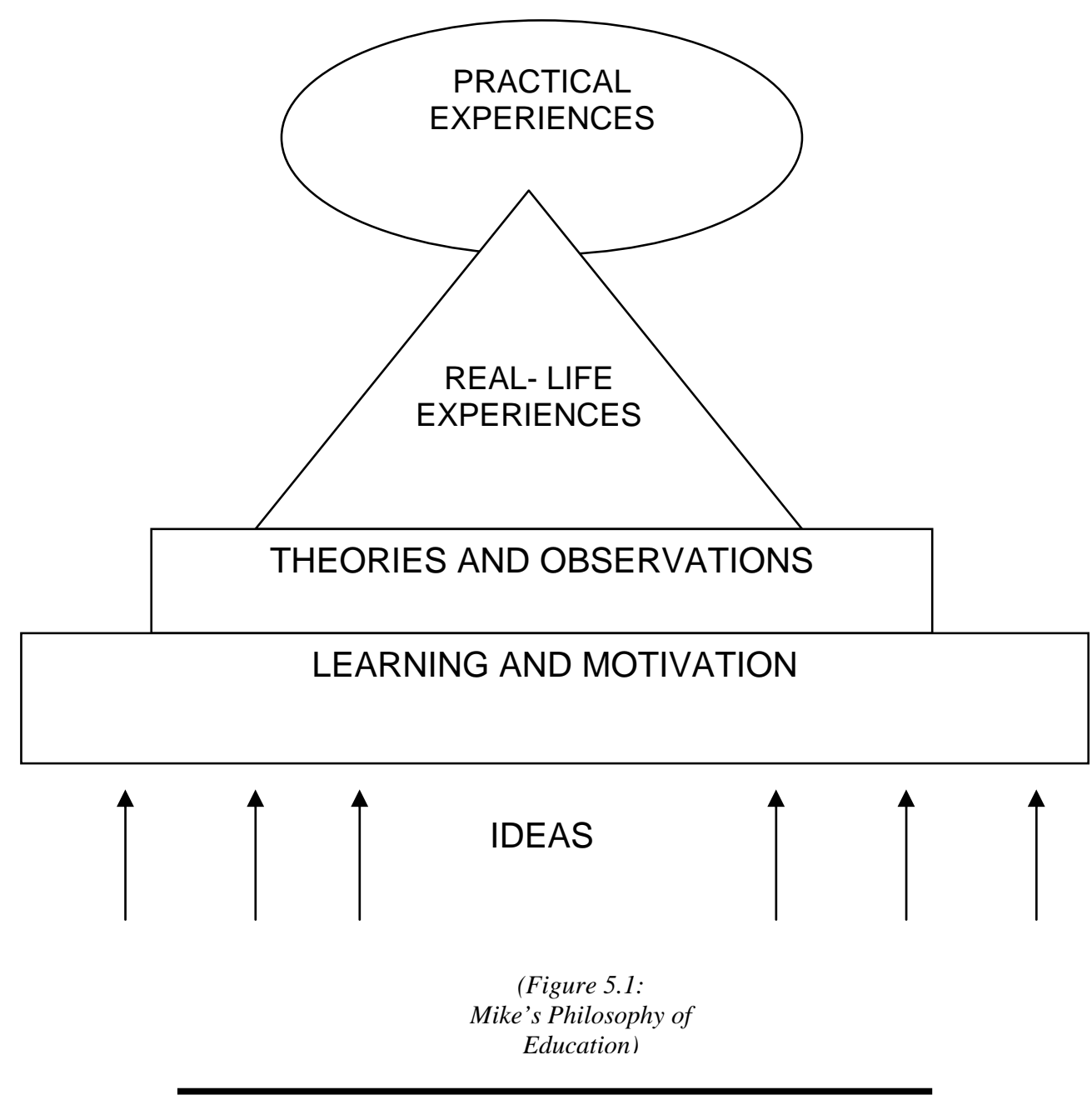

\section{Classroom Setting}

Every wall should have something on it. It showcases the students' work. So, the teachers are encouraged to kind of display their students' work with pride. I feel that's positive, it's motivational. I think students will try to perform better if they know it's going to be displayed. I think that's not based on any research. I don't think there's any harm in that (Mike, spring 2001). 
As Mike and I begin to discuss the characteristics of the ideal classroom at the elementary level, he echoes a similar sentiment shared by other participants in the study, "I would pick something...kind of lively and bright, cheery colors, not real bright, bright oranges on the walls but something that's friendly, peaceful.” In addition, pictures and "happy things” should adorn the walls, with "lots of room to move around in.” Upon further inquiry, Mike further elaborates and states that students need "room to move around in" within the classroom, as well as, other accessible areas such as a gymnasium, and outside, a playground with a safe surface, “not gravel or concrete but kinds of foam rubber surfaces, but I'm not sure if that's cost effective.” On the playground, he mentions students should have equipment and other structures in place for 'play,' “...hop-scotch, baskets, jungle gyms, see-saws, everything...that's an important part in the child's learning...important to get the creative juices going...”

From his boyhood, Mike shares a memory about a junior high school that he attended in Colorado. Based on his description, the school was large by any set of standards -- four wings (north, south, east, and west) that compartmentalized areas of study, such as the " math wing or science wing.” He remembers after lunch:

...going out and playing football or basketball or going to the gym if it was a rainy day and we had three gyms....the main gym, an auxiliary gym, and the girl's gym...the main gym had locker rooms and weight rooms...I don’t know why they had a separate girl's gym.

During our discussion, Mike often refers to this set up of the school but does not feel that the environment was ideal, only "helpful to the student.” 
His ideas about the classroom setting of the secondary grades resembles some of what he shared about his junior high experiences and later recognizes this, "It's going to be extremely biased based on my experiences and it may not be the best for everybody.” He believes that secondary grades should have "more structure” than the elementary grades and compartmentalized by hallways, “the hallway’s has all the humanities and languages, and another wing could have music and the fine arts...accommodate the arts to really excel.” High school students should have lockers available to them, and an area for socializing and casual conversation, “maybe some kind of central area where there’s snack machines, where students feel comfortable and spend time together.”

Pointing to the important role that technology plays in a student’s learning, Mike stresses the need for schools to have available "state of the art technology...computer jacks in all the classrooms, the auditorium would have a great sound system, and media drop-down screens....”

The actual schedule of the secondary school day is questionable. When he was growing up, he remembers having seven periods a day and is aware that many school districts are now switching over to block scheduling but is unsure of its benefits, especially as it relates to student learning and attention span:

My niece is in high school. They have an hour and twenty minute blocks...I've read some research that shows there's certain benefits but I'm not convinced that it is best for her attention span; besides teachers need to come up with lectures and activities for this entire time.

One of his main concerns related to the classroom setting in higher education is campus safety and the physical 'health’ of buildings. Where he currently teaches, many evening classes 
end at 10 p.m. and he believes more lighting should be installed in parking areas; however, his main concerns are for female students, "I worry...I see single women here at night and they have to walk to their cars...I even offer to walk them to their cars...” The other aspect he draws attention to is how the physical 'health' of the building affects the physical health of individuals, "just simple things like the air we breathe and the asbestos in the building...those are areas every school can improve on.”

Thinking about his current classroom, Mike believes greater thoughtfulness should be put into the layout of the classroom, especially since layout influences the aesthetic appeal and overall “feel for learning.” A remedy, he suggests, is for planners to consult with teachers. For

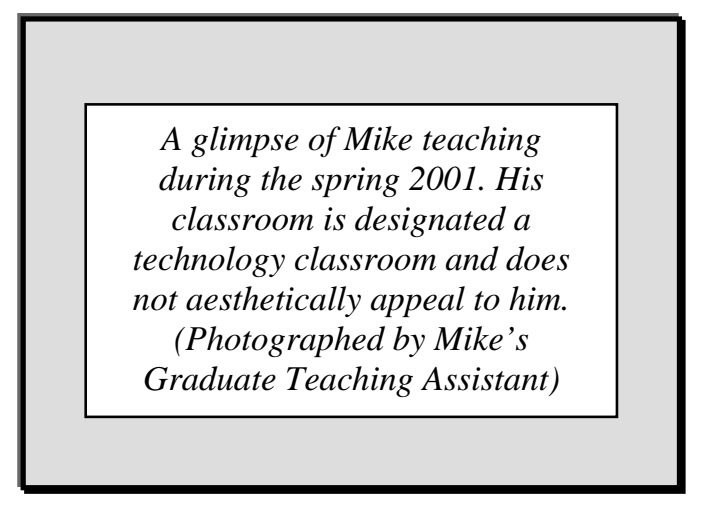
instance, the door of his present classroom is adjacent to the teaching 'space' and in the event students are late for class, they interrupt, not only his train of thought as they walk by him, but also distract the other students. Additionally, the glare of the overhead fluorescent lighting affects student's abilities to see the whiteboard, located at the front of the room. In his current classroom (which is designated a technology classroom), "wiring is up the back wall and hooks to everything up front,” which he does not find aesthetically pleasing.

During one of my observation visits, I note that there were 22 students in attendance 18 women and four men. The room is dimly lit and the walls are bare. Desks are arranged in rows and during class, Mike resides mainly up front between the desks and the whiteboard with the exception of when students are in groups, he moves around to supervise progress. One final note I make about this room is it is very warm. This is something Mike mentioned during the 
interviews and a feature that he wishes he had more control over, “...it’s always hot...there just doesn't seem to be a way to manually cools things down.” The heat of the room makes me tired and when it is time to leave, I get a cool drink.

\section{Meaningful Experiences}

I think I learned a lot from my advisor, just a lot of ways to interact with students, before, during, and even after class. I try to maintain a level of professional relationship, but also letting them know that you're a person. So, you use a lot of humor, I think, in good taste (Mike, spring 2001).

There are two main themes that emerged from my time spent with Mike related to meaningful classroom experiences - developing relationships with students and other professionals, and sensitivity to issues of diversity. Both of these themes emerged very early on and at times, 'over-lapped.' That is, being sensitive to issues of diversity can come about through exposure and interactions with individuals, leading to an understanding and tolerance of differences. And, without exposure or interactions, the need to be sensitive to issues of diversity may not come about.

From his earliest memories Mike tells stories about the types of relationships he shared with fellow classmates and instructors. As a young man, he was very active in sports teams and the team atmosphere fostered a sense belonging to a group. His love for sports led him, as an adult, to a coaching position that was obtained while teaching high school. He talked about the type of relationships he had with his student-athletes, as being one where he expected more out of them in the classroom and on the ball field. More importantly, there is a sense that the kind of relationship between 'the coach and the athlete' carried over into the classroom setting and academic lives of the athletes, “...I actually expected more out of them in the classroom...good 
examples as far as being a good role model, being respectful to all the other teachers, and being responsible by turning their homework in..."

During graduate school, he was part of another 'team' or cohort of graduate students that regularly took classes together. After class, it was a common occurrence for several of them to meet in a casual atmosphere and study, “we'd go get something to eat and go back to the office and have a little study session, debriefing, working at some of the formulas and applications and statistics...that was very satisfying.” Mike’s 'team’ depended upon one another, not only for learning and studying, but to provide a nurturing atmosphere where one's survival depended upon the strength of the whole, granting a shared sense of responsibility. Some of his most meaningful relationships with professors had its origins, not in the classroom, but through interactions while participating on an intramural softball team: I played on the softball team and we also had some faculty and that was very positive. It allowed me to see the faculty in a different light...I referred to them as ‘Dr. So and so’ and on the field, that doesn’t apply...call me ‘Craig’ or call me 'Dan.'

The less serious atmosphere encouraged 'less serious talk,' which ironically, also provided a 'doorway' to talk about more formal matters such as research interests. The relationships from the 'field,' led to Mike gaining the confidence of faculty. He was a called upon to assist in “certain types of analyses, so they'd pull me in on a project and I'd be glad to help out.” What Mike gained in these types of relationships was mutual respect, mentoring, and opportunities for professional development, which he now, in turn, attempts to pass on to his graduate teaching assistant and student advisees. 
As a professor, Mike finds satisfaction "helping students with either their program of study or course work, sharing examples that I have been exposed to or even my own work with students, having them draw interest to

Mike seated with students. He prides himself for creating relationships with students. He believes relationships strengthen his teaching and their learning. (Photographed by Mike's Graduate Teaching Assistant)

either research or teaching.” What takes away from building relationships is "nonverbalization.” This is especially problematic with the undergraduates, some of which Mike attributes to the large class sizes. Large numbers of students prevent him from personally knowing individuals. "If it’s small, I've always observed that they were more apt to speak up and verbalize and kind of give you cues to pick up on what their needs might be...”

In his teaching, Mike relies upon students to share their personal experiences, so that he can connect the subject matter with their own lives, “I say 'think back when you're in high school or some of the problems that you observed or remember.' I try to get into their past experiences and use those as examples in the classroom to try to apply some of the theories." One particular story that Mike recalls from his first semester at the University was a class session where the topic of discussion was bi-lingual, multi-lingual classrooms, and transitional classrooms. As he was attempting to convey the necessity of having this knowledge as a wellprepared teacher, the "proverbial nay-sayer" in class interjected, "Why do we have to learn this? Everyone in West Virginia speaks English?” Mike admits that his first reaction was disbelief at the student's ignorance. What ensued, surprised him, to say the least - students came to his defense and took on the discussion themselves. The discussion included legal ramifications, the changing U.S. population demographics, and being familiar with diversity issues if one does move and teach in another state. Mike reflected on the situation and 
rationalized the student's ignorance as stemming from living in an area where diversity is, for the most part, non-existent and therefore, the 'lack of diversity' does not create a need to be aware of these issues. This experience is one that Mike relayed to a University Diversity Task Force meeting, where he is a committee member, and it is a similar one shared by others in attendance.

Mike believes that 'creating a need to be sensitive to issues of diversity' could be as simple as randomly assigning lockers to students at the high school level. His belief is that if lockers assignments are randomly assigned "students would kind of get to know each other a little more so...than if I just hung out with all my friends and you hung out with all your friends.” By virtue of random assignment, students are exposed (due to the close proximity of the lockers) to students they may not have had contact with, that is, if they self-selected locker assignments. He acknowledged that cliques “will happen regardless,” but moving to random assignment of lockers can help move individuals towards awareness of diversity issues.

\section{Teaching and Learning}

I knew I wanted to be a teacher from a young age. I went into education because of my high school English teacher. I really respected her. She was real short lady, but very powerful. She was a good motivator, so I kind of thought it might be neat to be a teacher (Mike, spring 2001).

As a young man in high school, Mike began considering the field of education for his profession but did not 'commit' to the field until later on in college. Even though he did not enter into the field of English, he does give credit to his high school English teacher who greatly influenced him. As his interest grew in the teaching profession, he made a conscious decision to "pay attention to teachers," in regards to teaching style and desirable characteristics, 
and began to formulate an idea of "what makes a good teacher." He paid attention to, "attitudes, behaviors, and the way they react to certain situations, personality, and, the level of enthusiasm that they use when they teach.” While the majority of his 'learning experiences' were positive, he considers negative learning experiences just as valuable. A story he shared related to this is about a professor who taught one of his first educational psychology courses, “I had a terrible, terrible professor....but, I loved the material...I couldn't wait to go back to my room and start reading...I started thinking about the professor and how everything I wanted to do was going to be directly opposite of how she did it.”

Today, Mike approaches his role as a teacher in two ways: to prepare future researchers in the field of educational psychology and to prepare pre-service teachers in the teachereducation program to understand motivational techniques in the classroom. Accordingly, he says, “...provide students with information necessary to be competent researchers,” which he directs towards graduate students,” and “...to help my students learn and be successful learners," which he directs towards the undergraduates. To follow through on this, he realizes that he must "help students utilize their abilities and potential in class but also outside of class. It means I keep learning also. It means satisfaction. It means frustration. It means planning...”

Mike believes that the key component to good teaching is preparation, but this realization did not come without first experiencing what is was like to not be prepared. Mike recalls a story during his first teaching assignment at a high school which he admits to "never wanting to do that again...” while thinking about his lack of preparation. Now, Mike’s planning for courses is much different. There are several factors he takes into consideration for his dayto-day planning with the main guiding factor being his area of expertise, that is, content knowledge,“... how what I know might benefit the student.” From there, he proceeds to create a 
“mental organizer” of information and outlines related class activities. Another factor for consideration is based on student needs, which he will describe as, "background and learning styles... what kind of input do they want... what is it that they would like to get out of the course.” Elaborating on student needs, Mike also attempts to be aware of students' physical, intellectual, professional, emotional, and motivational needs; for instance, he takes into account if a student needs to sit closer to the front of the room due to hearing problems or incorporating humor to motivate them. He admits it is easier to meet their physical needs than the others because these are things, “I can pick up on real quickly.” Interestingly, Mike is also keen to pick up on the "personality" of groups of students from class to class and further tailors his preparation for groups that are "traditional or clinical or more open-minded.” A minor guiding principle in his planning is the objectives set forth by the college and the Collaborative for preservice teachers. He is required to include, "a multicultural, technology, and special needs strand" in all his courses, and does so on a regular basis. PowerPoint presentations and overhead transparencies are useful to convey information and also helpful to visual learners. During one of my observation visits, he utilized overhead transparencies and they appeared to be from a publisher resource packet, judging by their professional design and appearance.

At the undergraduate and graduate level, textbooks are required, “they’re pretty much the foundation," but Mike often supplements the text with journal articles. He explains that the texts provide students with basic information and teaching scenarios, and he personally draws upon the text for introducing ideas and the accompanying activities.

Mike approaches the role of grades in his courses somewhat different from the other participants in the study - grades are information for the student and for the teacher. While the other participants expressed frustration over grades and the demands put upon them from 
administrators, Mike is very succinct and unbothered. For students, he believes, "grades are student motivators...extrinsic motivators....” For teachers, "grades let me know where the students stand...if they're getting concepts, and the things we're talking about.” Grades represent the objective part of learning in his classroom.

Judging by an observation visit to one of his classes where evaluation and assessment was a lengthy topic of discussion, Mike placed emphasis on discerning student learning through performance or behavioral measures. I note that he introduced students to Bloom's Taxonomy and during another visit, Mike’s students presented assessment plans for a selected grade level via an 8-10 slide PowerPoint presentation with other classmates. I noted the following line of questioning - Mike is directing these questions towards the students:

Why do we assess?

How do you know when your students have learned something?

Are there ways to gauge student performance?

How will you lessen the $2^{\text {nd }}$ graders test anxiety?

Why impose time limits on test?

What is your definition of achievement?

Do portfolios really show what students know? 


\section{Section III Summary:}

\section{College Faculty Understandings Related to Main Research Questions}

- $\quad$ The Classroom Setting As...

Conceptually 'open’

Health and safety

Space to move

Rich in technology

Aesthetically appealing

Social

Inside/outside

- $\quad$ Meaningful Experiences As...

Critical pedagogy

Relationships with students

Success

Finding joy

Contextualized

Recovering time

- $\quad$ Teaching and Learning As...

Co-learning and community of learners

Teaching and learning and learning and teaching

There's grades and there's "Field of Dreams"

Theory into practice

Social Reconstruction 
Accommodation and assimilation

Texts are valuable resources 


\section{Chapter 6: Emerging Themes and Discoveries}

\section{Introduction}

In this concluding chapter, the ideas and experiences of the participants are compiled to reveal emerging themes and patterns related to the main research questions, and are followed by a discussion on the identified themes to determine where teachers have 'arrived' in terms of thought and practice. William Pinar (2004) calls this present historical moment in education a "waking nightmare” for public education in light of NCLB and subsequent funding concerns. According to Pinar (2004), the NCLB Act has 'misconstructed' public education into a business of testing-taking factories, putting creativity and individuality at-risk for the teacher, student, and teacher-educator. And, because standardized testing is the mainstay of determining academic achievement and teacher accountability, public educators are 'bound' or 'held hostage' to modern era assessment methods. Not to be forgotten, in institutions of teachereducation, accredited by the National Council for Accreditation of Teacher Education (NCATE), they, too, are now held responsible and must show evidence of teachereffectiveness. In the following account, Pinar (2004) has recorded a speech given by a NCATE Senior Vice President at a conference in 2000, as testament to this:

...Donna Gollnick explained to the assembled professors of education that the new NCATE standards focus on 'how and what' teacher candidates learn, not on what they have been taught. Gollnick warned those of us in the audience that NCATE accreditation examiners will be asking faculty, 'How can you document that what your unit does is efficient and effective? NCATE requires evidence... (p. 211) 
With these 'modern' structures bearing down on teachers at all levels, including the teachers in this study, where do teachers find themselves in thought and practice? Pinar (2004) personally refers to these structures (discussed above) as "anti-intellectualistic," but because the bottom line in education, as in business is funding, the issue of concern appears not as much of an epistemological issue, but axiological. It was revealed that the teachers in this study are anything but 'anti-intellectualized,' at least, conceptually, but are held hostage by structures.

\section{Problem Statement}

The American public school system has not kept up with changing societal views and still remains crudely positivist. The root of the educational problem lies in the epistemological assumptions of mind and then, the translation of the epistemological assumptions in classroom teaching and learning practices.

\section{Emerging Themes and Discoveries Related to Research Questions}

In chapter five, section summaries were provided for the pre-service teachers, in-service teachers, and college faculty, and related to the main research questions of the study. Themes were based on an emergent, inductive design and reflective of conceptual understandings and actual lived events. The themes represent a phenomenological blending of conceptual ideals with personal and professional experiences of the participants. In this particular section, further patterns are identified using a cross-case analysis.

Research Question \#1: What understandings do pre-service teachers, host teachers, and college faculty have about the kind of classroom setting that best contributes to teaching and learning?

\section{Themes and Discoveries for Research Question One}

Theme 1: Classroom setting as colorful, bright, and cheery. 
This sentiment was expressed by many of the participants to describe the physical features of classrooms at all levels, e.g., elementary, secondary, and higher education, and included a felt-sense in that, the colors promoted a 'cheery' disposition; that is, if the classroom was colorful and bright, students would be 'cheery.' In addition, it was proposed that student work and artwork should be hung on walls to promote a sense of pride in one's work. These physical features were common in many elementary education classroom today but not in secondary and higher education. The participants were inclined to believe that the same features in secondary and higher education classrooms would be beneficial to student learning. In higher education, the 'lack' of color was especially displeasing, but the other concern expressed by the pre-service teachers and college faculty was that the current classroom environment did not model best practices.

Theme 2: Classroom setting as nurturing and comfortable.

A commonly expressed idea was that a nurturing and comfortable classroom setting enabled students to participate in activities where taking risks and experimentation was integral to the learning process. The felt sense of a nurturing environment was somewhat equated to the 'feel' that someone would have at home when one is surrounded by loved ones or being surrounded by items that one would have at home. This type of setting would engender a feeling of safety, that is, to try things that one would not ordinarily do unless a safety net was put in place. The nature of children was typically viewed as experimental and this type of setting would be conducive to the nature of the child.

Another aspect related to this theme was being physically comfortable. Participants recognized that this type of setting would work 'with' (not against) the nature of learners. Many participants in the study shared moments when students (and sometimes themselves) were 
participating in activities on carpeted floors, sitting in chairs with legs resting on other chairs, sitting on tables, and laying on the floor.

Theme 3: Classroom setting as rich in technology and other resources.

Participants regularly spoke of technology and technological equipment in the classroom and participants who viewed themselves as technologically savvy believed that technology was an especially valuable teaching tool. Participants regularly spoke of having high-end computers (and other technological equipment) available, if not in the classroom, then in an adjacent computer lab for students. Computers connected students with related subject matter and other materials, with other students, and enhanced teaching methods for teachers. Other materials and resources included immediate access to items for hands-on learning activities, i.e., books, manipulatives, flashcards, maps, art supplies, to supplement other teaching strategies.

Theme 4: Classroom setting as public comes in and students go out.

Pre-service teachers and in-service teachers routinely spoke about the 'public in the public schools.' This occurred through several means. Parents and other community members were believed to be integral to providing students with services and opportunities that would be otherwise unavailable to them. Parents and other community members provided learning opportunities in the form of 'guest readers,' career presentations, family picnics, and assisted in fluoride treatments, as well as, provided mentoring opportunities for students.

Student learning not only took place within the confines of the school but when possible, students would 'go out.' The participants indicated that students seemed to appreciate the freedom of leaving the classroom while still being engaged in 'formal' learning activities in 
an 'informal' environment. Other outside activities included fieldtrips to local attractions and picnics on school grounds.

College faculty spoke of the importance of pre-service teachers leaving the University setting for practicum experiences to inculcate pre-service teachers into the life of the school. Theme 5: Classroom setting as conceptually and physically open.

Most participants described a classroom setting that provided students with an open learning space or a personal learning space, and a setting that enhanced a felt-sense of conceptual openness. Learning activities were often described involving group activities and it was further suggested that the classroom environment should allow for students to gather in formal and informal areas, e.g., round tables or the coatroom. In contrast, participants also recognized that some students needed individual space to work alone and/or in a quiet environment. There should also be a felt-sense that the classroom environment is conceptually open to inquiry, free thinking and questioning, dialoguing with others, and important matters in students' lives. The construction of a conceptually open classroom relied on a teacher who is also conceptually open which is significant to set the tone in this type of atmosphere.

\section{Response to Research Question One Themes:}

In response to the emergent themes of research question one, there are three issues I will address. First, the understandings that participants held towards the classroom setting that best contributes to teaching and learning was by all means, a conceptual and physical reality for the majority of individuals in the study. Most of the participants were very fortunate to teach in settings that were rich in resources and likewise, fortunate to have educational opportunities that afforded them the luxury to attend college. Based on this, most of the themes related to question one, falls back to a set of class values, specifically, middle-to-upper class; however, 
problematic to this discovery is that this is not always the same set of values or ideals held by students of less-privileged families. Nonetheless, most of the participants attended schools with these characteristics and teach at schools with these characteristics.

My second concern is related to the issue of money or funding. While I can appreciate the many features of the classroom setting described by the participants, the possibility for these circumstances to exist relies mainly on monies derived by local and state taxes. Some teachers do receive grant monies, which does compensate the small budgets teachers are provided, but the expertise and knowledge needed to complete grant applications, denies this possibility for countless others. Without such, these opportunities and resources do not exist.

The third concern is related directly to the problem statement of the study. The type of classroom setting described by the participants of the study, reveal epistemology assumptions about the nature of learning. The construction of knowledge is contingent upon what a student sees in his/her immediate surroundings, what they can touch and feel, and interactive opportunities and dialogue with self and others. This represents at a conceptual level an active epistemology but at a practical level, it is one, which I more often than not, did not witness. Research Question \#2: What understandings do pre-service teachers, host teachers, and college faculty have about the kind of educational experiences that are meaningful? 


\section{Themes and Discoveries for Research Question Two}

Theme 1: Meaningful experiences as memorable and contextualized to self and program of study.
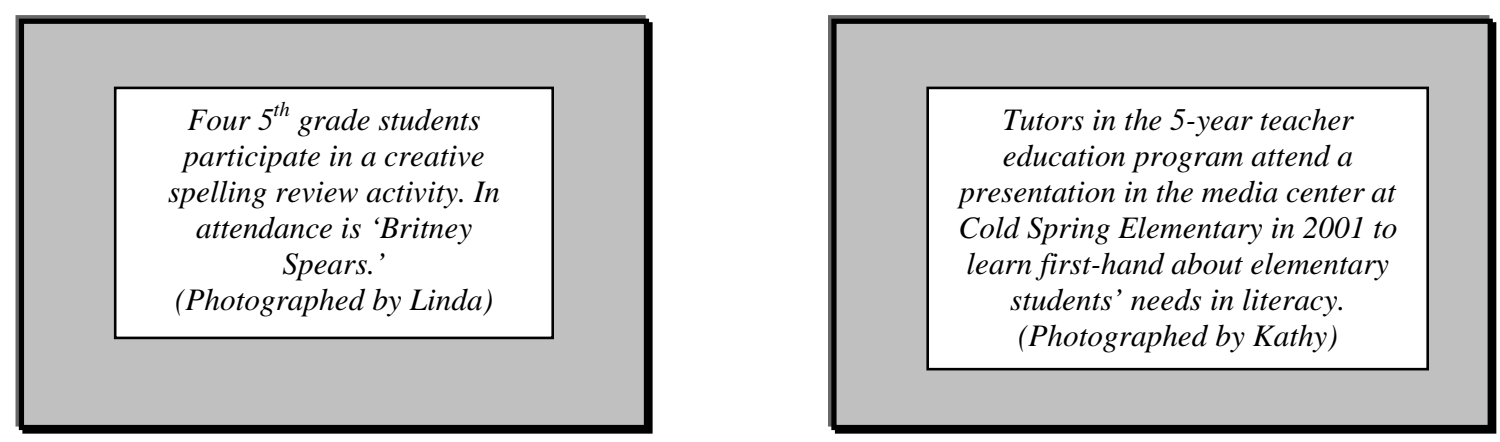

In a rather interesting find, the revealing of meaningful classroom experiences was repeatedly related through 'memorable experiences' and consistent with phenomenological principles. Memorable experiences were either seen in a positive or negative light (even shocking at times) and continued to influence present teaching and learning practices. The actual event impacted the life of the participant in such a way that when the memory was 'released,' it elicited strong emotions and feelings. Participants remarked: "It made me feel good.” "I was bored.” "I got excited.”

These educational experiences had defining characteristics - participants were 'learning' but in non-traditional ways and in non-traditional classroom settings which came to be revealed in hindsight. There were instances where the individual was 'thrown' into a different role, i.e., co-learner or teacher, or when the subject area for study became a live encounter. At these times, activities occurred in typical and non-typical classroom settings and also involved some form of social engagement with others. 
Theme 2: Meaningful experiences as respectful, caring relationships and mentoring opportunities.
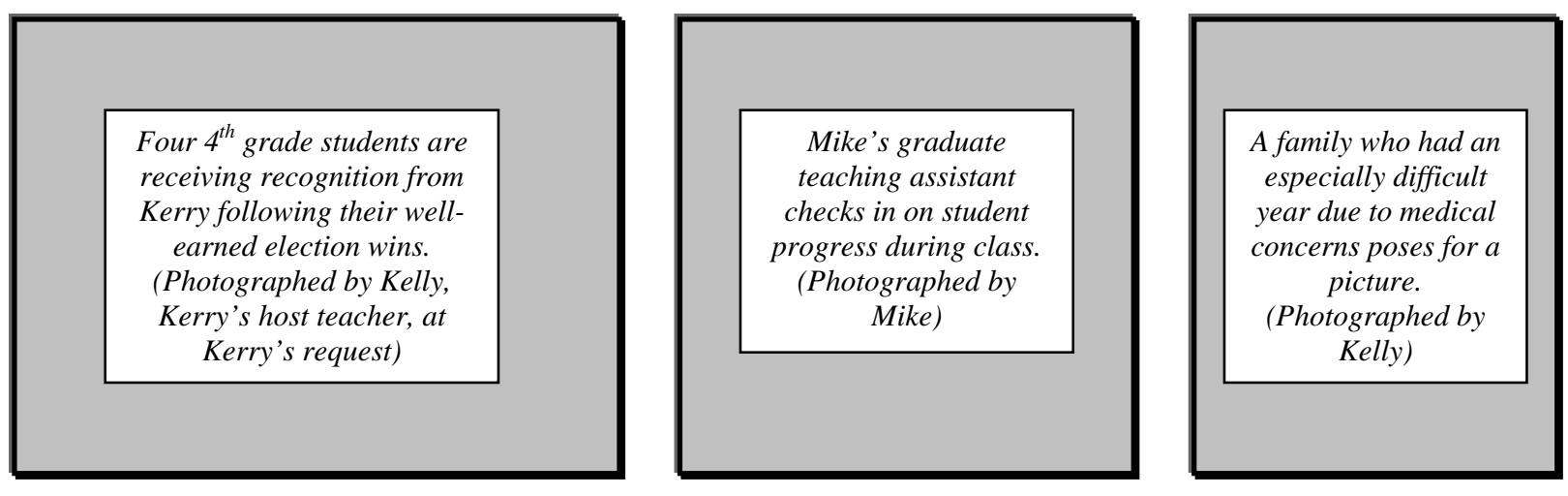

Creating personal relationships with students was cited as meaningful and satisfying to the majority of the participants. In order to best meet students' needs, participants in the study relied on formal and informal communications (i.e., in class and out of class communications) with students. Participants emphasized the importance of students making them aware of the events in their lives so they could best accommodate students, e.g., extended deadlines or oneon-one study sessions. When relationships were formed based on genuine concern for the other, both teachers and students tended to benefit. Participants indicated that when open lines of communicated were established, they gained insight into the personal lives and emotional states of students. This was cited as an important factor because participants connected learning with one's emotional and mental states, and connected best teaching practices with knowing the needs of the student. Teachers used a variety of means to 'get to know students better' and often referred back to items of interest with the intention that students would sense that teachers cared because they attempted to link personal interests with learning. If students believed that 
teachers cared, it goes without saying, that students put forth greater effort in classroom activities to continue to support the relationship.

When students entered into a teacher's life, the effect outwardly appeared less obvious because most of the participants recognized that they are in roles of authority and did not publicly reveal to students some of their more private feelings and thoughts. Students also needed opportunities to enter into relationships with other students. Such mentoring opportunities encouraged students to 'step out' of the student role and 'step in' to the role of confidant or leader.

Theme 3: Meaningful experiences as freedom of expression and freedom to choose.
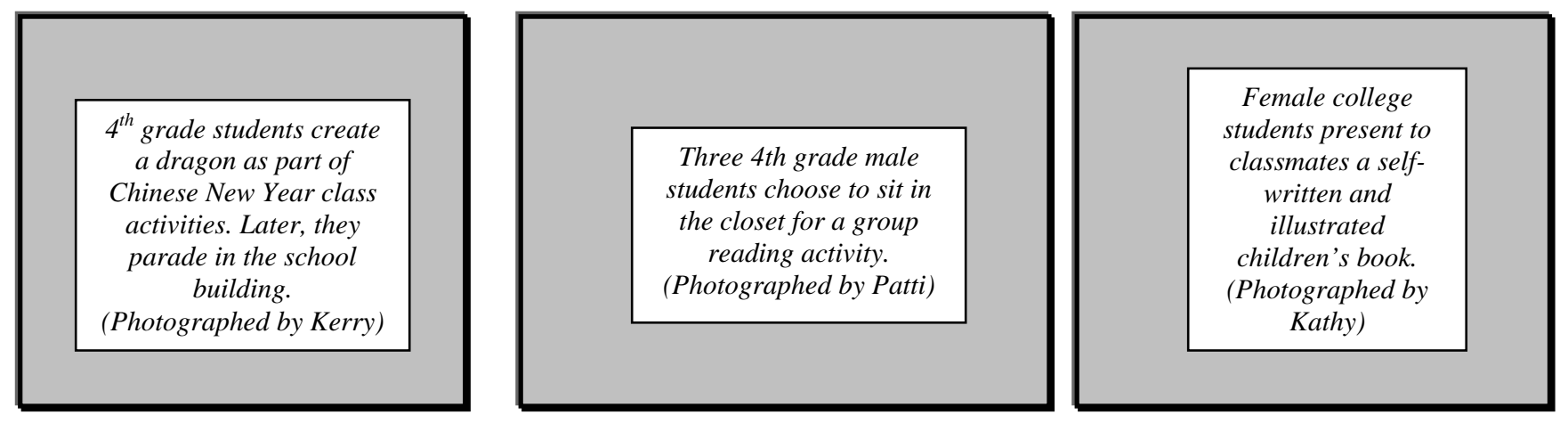

Participants in the study valued freedom of expression and freedom to choose in the classroom but acknowledged that it is the teacher's responsibility to set the parameters (or guidelines) before setting students 'loose.' Setting the boundaries meant that teachers needed to consider age and developmentally appropriate activities while at the same time, creating situations where students would be independent and free from 'step-like' directions. Participants stated that these types of activities meant more planning on their behalf but admitted that once activities started, students would 'run with it.' Participants also admitted that during these types of activities, the classroom appeared somewhat chaotic, i.e., above average noise and movement, and that they needed to mentally and physically be flexible with their 
original plans. When students were engaged in activities where they were free to express understandings, often times it entailed art-ful creations, creative dramatics, and in the process, invoked 'thinking and doing' qualities. The other aspect to this is when students were given freedom (in whatever capacity), participants noted that students were happier.

Participants also voiced personal displeasure for 'lack' of choice especially in the areas pertaining to program of study, daily classroom scheduling, and mandated testing/evaluation procedures. Participants strongly and critically reacted to these areas of concern as if to say these concerns detracted from best practices.

Theme 4: Meaningful experiences as exposure to diversity and critical pedagogy.

There were two levels of awareness of diversity issues revealed by participants in the study. First, there was awareness that diversity in the classroom does exist in terms of student's cultural heritage and individualized learning styles, e.g., multiple intelligences, differentiated instruction, and learning styles. But, in these cases, issues of diversity were viewed as "not a problem” and teachers bought into ‘mainstream’ cultural literacy practices, i.e., E.D. Hirsh’s ideas. At this level of awareness, participants emphasized the concept of respect or respecting individual differences. This summarizes the view primarily held by the in-service teachers.

The other level of awareness of diversity issues was dependent upon need and personal experiences. Pre-service teachers and college faculty members shared personal accounts where either they had personally been targets of 'cultural illiteracy' or they were involved in prior events that ethically inspired them to become more knowledgeable about a particular group of students they were teaching. Pre-service teachers and college faculty both spoke about events and conversations in their current classroom to shed light on these concerns. I would be inclined to describe their kind of teaching as 'critical pedagogy.' In these cases, participants 
believed that exposing students to their personal history could best approach the issues of relevance. Furthermore, because many students at the University do not 'see' diversity and doubt the usefulness of such information, participants felt the best way to make these issues 'come to life' is through sharing personal stories.

Theme 5: Meaningful experiences as struggle and success.
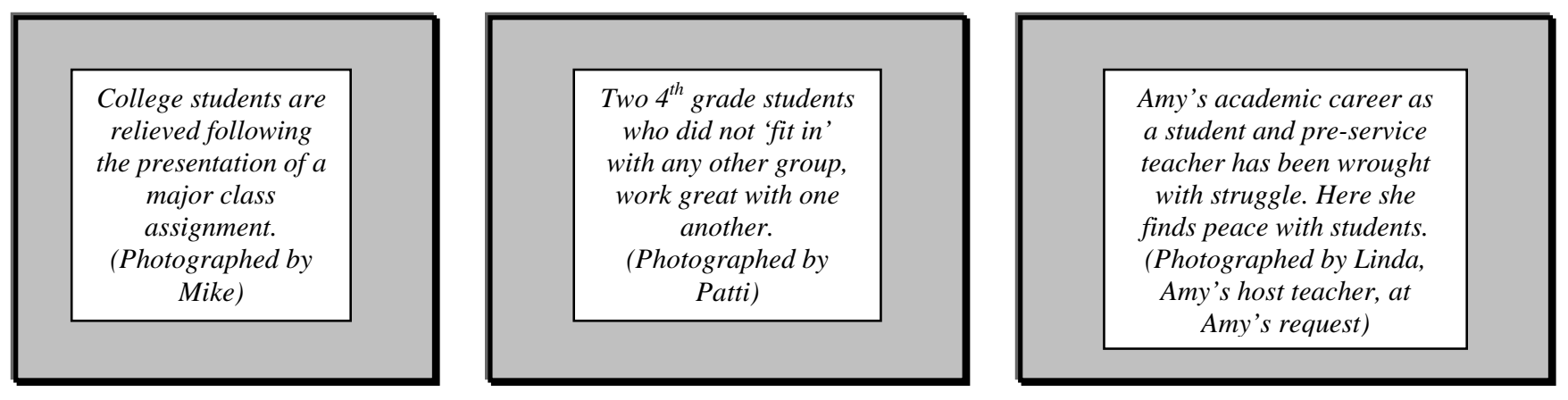

Overcoming struggle and achieving success was valued by participants in the study. Success was defined as mentally or emotionally overcoming difficulties, finding solutions to personal and professional challenges, or transcending above what one ever thought imaginable about his/her capabilities. In this study, participants spoke about personal struggles, the effect the struggles had on their personal growth, and about some of the struggles they had witnessed of their students.

Time was one key aspect that factored into this theme -- the longer the struggle, the greater the perceived success. Many of the participants acknowledged that they had, in general, experienced success in some facet in their lives, e.g., graduate school, and some of their most satisfying moments came when the struggle was so great that the pending outcome seemed improbable. As teachers, most of the participants articulated that they had been witness to struggling students or they struggled as teachers to help students learn. Through repeated problem-solving and trial-and-error, participants found solutions to classroom struggles. 
However, when participants did struggle and not find success in their role as teachers, i.e., attempting to help students with high needs, they personally expressed uncertainty or disbelief over the situation.

\section{Response to Research Question Two Themes:}

In response to the emergent themes of research question two, there are several issues I wish to address, one which is especially confounding. The understandings that participants held towards the kind of educational experiences that were meaningful were experiences they had personally experienced as either a student or teacher and they were also experiences that stirred feelings in them at a deeper emotional level. Participants shared stories that impacted them in negative and positive ways and furthermore, indicated that these past experiences continue to influence their decisions. Also, the 'living' of the experience was not separate from the 'feeling' of the experience. This is consistent with Merleau-Ponty's work highlighted in chapter two -- the experience is experienced in its entirety, not from separate, isolated angles (MerleauPonty, 1962). What is perceived as meaningful comes to be known in ways that intermingles the many dimensions of being and escapes dualities - the object with the subject; the head with the heart; and, the body with the mind. These experiences are judged or selected as meaningful due to the strength or intensity of the interaction experienced.

Another issue for discussion is related to the nature of relationships. When teachers were perceived as caring, students were more interested in learning and maintaining the relationship. But, does that mean that caring teachers are better teachers? A better question here might be what are the characteristics and qualities of caring relationships? What enables some student-teacher relationships to flourish while others never take root? In general, every participant in this study addressed the types of relationships they desired to build with students 
and conceptually, this represents an understanding of the importance of teacher-student relationships for teaching and learning. However, I doubt if building these types of relationships with all students is humanly impossible and therefore, these understandings are purely reflective of the relationships the most impacted participants or of the type of ideal relationship with students.

The final issue for discussion is related to understandings of freedom. There was an interesting connection between freedom and meaningful classroom experiences. At various levels, pre-service teachers, in-service teachers, and college faculty, offered thoughts about the lack of freedom in academic studies and the daily school schedule and much of what was spoken, came to light as ‘negative’ freedoms. Pre-service teachers are ‘locked into’ a plan of study with little variation and public school children, are at the will of the teacher to determine the activities of the classroom. While freedom of expression and freedom to choose were main themes in this section, the freedoms that did come about occurred at a small-scale level (i.e., at in the classroom) and were not a part of the larger institutional structures, which is where most of the controls exist and also is where the participants directed most of their criticism.

Research Question \#3: What understandings do pre-service teachers, host teachers, and college faculty have about teaching and learning?

\section{Themes and Discoveries for Research Question Three}

Theme 1: Teaching and learning as learning and teaching.

Participants in the study viewed teaching and learning as connected activities. When they spoke about the activities of teaching, the activities of learning were mentioned in conjunction, as if to say that one does not occur without the other, which is reminiscent of Thorndike’s ideas. During observational visits, I witnessed traditional teaching, e.g., direct- 
instructional methods, and at other times, it was difficult to ascertain if teaching or learning in the traditional sense based on the amount of activity. Most participants in the study relied on an assortment of teaching strategies, e.g., direct- instruction, cooperative learning, thematic projects, creative dramatics, etc., and did not advocate one method over the other.

Conceptually, student learning was regarded as a process that occurred over a period of time, as the acquisition of skills necessary in preparation of adult life, thematic, and had the potential to make students feel uncomfortable, similar to Piaget’s accommodation/assimilation theory. For the most part, I did not witness this nor did the assessment/evaluation practices represent this. Theme 2: Teaching and learning as collaborative community.

Participants in the study viewed collaboration from three perspectives -for professional development, the exchange of ideas, and, social development. As teachers, the participants felt it was of importance to turn to colleagues for support and encouragement. In the type of classroom setting that many of the pre-service and in-service teachers taught in, the atmosphere was such that they could regularly and casually observe and talk with one another. The atmosphere fostered a sense of connection with colleagues and furthered communication between teachers inside and outside of school. Many of the participants felt that professional development workshops and conferences were important to bring new ideas into the classroom and important to keep up with changing ideas and research in education.

For students, a collaborative community in the classroom was symbolic of the type of professional environment they could expect in the future. Also, in a collaborative community, teachers and students became co-learners. Additionally, the participants expressed that collaborative communities were not a physical environment but a felt-sense of place where members came together as equals. One's knowledge was not any less valuable than the others 
in this setting and collaboration was especially important for student learning, teacher teaching, and the whole of education.

\section{Theme 3: Teaching and learning as 'Field of Dreams.'}

In the movie, Field of Dreams, Kevin Costner’s character has a premonition, "Build it and they will come,” referring to the construction of a baseball field for legendary baseball greats who have passed on. As much as Costner's family and community doubt his efforts, he builds the field and waits, despite continuing criticism and financial bankruptcy. The baseball players do 'come' and play ball, but in the beginning, only Costner's character can see the 'players' and in the beginning, only he can see the excitement he has generated in building the ball field. In this study, participants viewed grades not as a measure of what one knows but as effort, mastery, performance, and reflection of change over time. However, for this to come to fruition, teachers must build the 'field' for students to play in. Most of the participants in the study expressed positive beliefs towards student success, and felt strongly that in order for students to succeed, that the 'field' must provide students with a variety of playing positions. Likewise, if one playing position is not favorable for the student, then the position should be changed until they find a place where they can be successful. The participants expressed joy in seeing their students do well and it was also recognized that some students do not do well in school.

Theme 4: Teaching and learning as thematic and alternative assessment.

Most of the participants in the study believed that teaching should be done thematically, across the content areas, and provide students with alternative forms of assessment. Part of the rationale for this approach is based on the idea that 'life is not separated into units of study' and neither should the classroom. For example, participants integrated reading with multicultural 
studies, creative dramatics with history, and chocolate with geography. However, the college faculty in this study did have specific areas of specialization and taught courses specific to their field of study in the teacher-education program. Alternative forms of assessment included portfolios, rubrics, reflective learning logs, presentations, and individual and group long-term projects.

Theme 5: Teaching and learning as lesson plans and IGO's.

The pre-service and in-service teachers relied upon lesson plans that directly tied teaching and learning in the state's IGO's. This was required of them by the school. College faculty were not required to prepare lesson plans but in their courses, students were preparing lesson plans or studying the construction of behavioral objectives based on Bloom's Taxonomy.

Theme 6: Teaching and learning as flexible and life-long.

Participants of the study were of the belief that the demands and uncertainties of teaching entailed teachers and learners to be flexible. Participants in the study acknowledged that teachers do more than 'just teach’ on a daily basis. Participants viewed their roles as multiple and continuing to change as the needs of children continue to change, and demanded that they were attentive to students needs. At times, the participants wondered whether the act of teaching was seen as a priority in light of the other responsibilities and expectations placed upon them. Participants also acknowledged that students needed to be flexible and accommodating within the classroom. Participants referred to specific examples where students sat side-by-side to students of special needs and students of backgrounds unlike themselves in inclusion classrooms. Most of the participants indicated that teachers should be committed to life-long learning and attempted to instill this notion in their students, as well. Learning from 
colleagues and students through formal and informal means -- workshops, conferences, professional memberships, informal conversations - was cited as a mechanism to life-long learning. Learning from students was another avenue. Fieldtrips offered opportunities for students to feel like they could talk to teachers and where the defining role of teacher and student was less clear. In this sense, life-long learning was broadly defined. Likewise, several participants noted that due to a rapidly changing society, they felt that a commitment to lifelong learning would assist them in better meeting the needs of students.

\section{Theme 7: Teaching and learning as text, less-text and valuable-text.}

The participants in the study tended to view textbooks in three ways - texts as useful, texts as increasingly less and less important, and texts as a necessary tool for learning. The preservice teachers relied on textbooks more than the in-service teachers; whereas, in-service teachers recognized the reliance on books of young teachers and tended to 'pull away' from books once the scope and sequence of the content area was mastered. In higher education, college faculty believed that books were critical to learning and valuable to staying current on research developments, but indicated that rarely did they teach directly from the text and put the responsibility of learning the material on the shoulders of the student. The participants also noted that textbooks and other supplemental material supplied by textbook publishers provided teaching strategies and additional ideas for special needs learners.

\section{Response to Research Question Three Themes:}

In response to the emergent themes of research question three, there are several issues I wish to address. The general understandings that participants held towards teaching and learning were approached with pride and optimism especially in respect to how they viewed their roles as teachers. The majority of the participants articulated an understanding of the 
significant role they played in students' learning. More often than not, participants believed that every student could find success. I question the idyllic or 'Polyann-ish’ nature of this and am critical to the idea that a teacher's effort is matched by a student's effort, and doubt that a positive correlation could adequately describe the associations humans have with one another. Also, participants realized that often times, students were very dependent upon teachers for learning and more specifically, grades. By the same token, participants also expected students to 'grow into' free-thinkers, who eventually needed to take initiative for their own learning, creating quite a mental quandary. I am reminded here of a sentiment expressed by Maxine Greene, 'does the process of education make us free or un-free?' The point at which the student breaks away from the teacher was not clear but what is, due to the demands placed upon teachers, teachers are unable to humanly meet every child's need.

In addition, based on my classroom observation notes, there were discrepancies in teacher action and teach thought. For instance, in some classrooms I observed, there was direct instruction taking place the entire time, and students and teacher followed the textbook wordfor-word. But, I want to recognize that the 'observer-effect' may have had something to do with this and likewise, I understand as teachers, there are many theories and strategies in the 'teaching toolbox' and it suffices to say, that one instructional method is not the one best way, all the time. There are appropriate times for direction instruction as there are for other methods.

Another inconsistency in thought versus action was seen in the types of assessment and evaluation procedures. In general, participants acknowledged learning as action-oriented and occurring through reflective processes over time. But, in the actual events of the classroom, which I witnessed or participants spoke of, all students were regularly tested, given the 
identical evaluation instrument, and expected to uniformly participate in teacher-driven practices.

One final issue I wish to address is the predominance of lesson plans in classrooms. For the most part, the format of the lesson plan has remained unchanged over the last 50 years, and is still one of the chief foci in methods courses and a major concern for school administrators to determine teacher effectiveness and student learning. Interestingly enough, the participants in this study understand the importance of lesson plans to administrators - that is, 'putting something down on paper' - but, once seasoned, veteran teachers are in the classroom, creative activities and discussions ensue. Unlike the seasoned teachers (who are also tenured), young inservice teachers coming into the field are more concerned about test scores and keeping their jobs.

\section{Discussion of Modernism and Post-Modernism Epistemological Assumptions of Mind}

\section{Related to Problem Statement}

"Teachers beware of the lesson plan." Mary Aswell Doll (2000, p. 36)

So, where is it that teachers find themselves today as society is in the midst of a cultural revolution? I concur with Pinar - teachers are in a waking nightmare and Mary Aswell Doll warns educators of the pending dangers when politics rule classroom activities and shape the teacher's identity. The one aspect of teaching, more specifically, the lesson plan, and likewise, its connection to state standards and assessment measures, is the over-riding influence that dictates what happens in the classroom. The lesson plan very much so represents the modern approach to teaching and learning, and is deeply tied into modern epistemological assumptions of mind, namely that of the philosophy of the behaviorism. Furthermore, not only are students' 
test score results tied into state and national funding, so is the perceived effectiveness of teachers -- a still yet, modern assumption of mind. If students do not perform well on tests, the public and state administrators blame the classroom teacher so much so that jobs are jeopardized. On test day, not only are students nervous, but teachers are as well. The seriousness of this cannot be discounted nor can the pressures teachers face be ignored - there are ethical and social-cultural ramifications here.

Conceptually, the teachers in the study do reveal post-modern epistemological assumptions, therefore, leading to a tension between thought and practice. The participants demonstrated high intent towards constructivist practices but in actuality, the intent was negated by the low application of theory. In the problem statement, I speculated that the crisis in education was due to modern epistemological assumptions of mind and how these assumptions translated into classroom teaching practices, and at the conclusion of this study, I reject that statement. The crisis in education is one of an axiological nature; that is, about what is valued. However, this value statement is that of an 'invisible' order within a larger public institution that teachers rarely 'see.' The teachers in this study valued: teaching and learning activities that are contextualized to their program of study; building relationships; freedom of expression and choice; diversity and critical pedagogy; and, struggle and success. State and national educational administrators value: standardized testing, efficiency in measurement, competition, and uniform approaches to assessment - all of which is some shape and form, revert back to monetary issues and the values associated with living in a capitalistic society. The crisis is in the antithetical expectations placed upon teachers that do not coincide with what is valuable to them. 
What this has produced is the 'waking nightmare.' Teachers teach in a physical plane that is not in alignment with their conceptual understandings of teaching, leading to what Parker Palmer (1998) describes as living a life divided; that is, where one’s identity and integrity are mismatched or not in alignment. In this study, the intent of what one does is not congruent with the behavior of one's teaching. The contemporary teacher's public image is really no different than that at the turn of the $20^{\text {th }}$ century with the exception that there is a new term - the 'factory supervisor' is now called the 'corporate manager' (Pinar, 2000). In this 'new' model, teachers are oppressed by the invisible structures of the state and federal departments of education and are likewise, the oppressors of students. Marx spoke of the pending dangers of the exploitation of 'workers' years ago when systems become so highly structured that the economic conditions dictate human action and in this case, alienating teachers from his/her work. The outcome is loss of creative freedoms or de-intellectualization for teachers. One might even go so far as to say that the culture of the school 'neuters' teachers intellectually and this somehow purposefully prevents teachers from taking greater stance to change the status quo of the profession. Additionally, in many ways the apathy expressed by teachers is by the same token the identical kind of apathy too often expressed by students.

At this juncture, teachers seem to have uncritically accepted their position within the system. Kincheloe et. al. (2000, p. 251) claims, "Thinking is always a major strategy in the cultural battle," and how might teachers be prepared or empowered to regain their identity and integrity and stop living a life divided? How might programs of teacher-education create reflective practitioners?

Kincheloe, et.al. (2000, p. 251) offer eleven suggestions in response to these critical issues and I believe that discussion and dialogue about these issues must begin in teacher- 
education programs. Teacher-education programs that revolved around a social justice framework would set the stage for developing empowered teachers:

(1) Empowered teachers understand the purposes of education and work to reform schools so they accomplish such purposes; (2) Empowered teachers appreciate the centrality of knowledge production in their pedagogy: The collision of student-teacher experiences with information derived from the disciplines produces knowledge in the classroom; (3) Empowered teachers make use of that knowledge and those understandings that have heretofore been devalued and excluded; (4) Empowered teachers model and teach postformal thinking; (5) Empowered teachers cooperate with school and community and facilitate cooperation between them; (6) Empowered teachers build learning networks between schools and communities that make use of recent developments and innovations in communications technologies; (7) Empowered teachers become researchers and teach their students sophisticated methods of inquiry; (8) Empowered teachers encourage schools to support their continued learning; (9) Empowered teachers recognize the inability of modern-positivist teaching methods to explain the current world of schooling; (10) Empowered teachers invent new and appropriate modes of assessment; and, (11) Empowered teachers recognize how power shapes them, their students and the everyday schooling context.

Another approach for preparing teachers for the demands of the classroom is the topic Donald Schon (1987) addressed in Educating the Reflective Practitioner. Schon claims that his book is for anyone concerned with education and reflective practice and since my concern is 
that teachers have become alienated from their work and, not only need to be empowered, but reflective as well; Schon's ideas can also serve today’s teacher well. Schon identified the challenges facing teachers, "Shall he [sic] remain on the high ground where he can solve relatively unimportant problems according to prevailing stands of rigor, or shall he descend to the swamp of important problems and nonrigorous inquiry?” The inconsistency between practice and ideas of teachers was problematic and prompted Schon to design a program based on artistry to overcome this 'gap.' The program is based on the following ideas (Schon, 1987, p. 13): (1) Inherent in the practice of the professionals we recognize as unusually competent is a core of artistry; (2) Artistry is an exercise of intelligence, a kind of knowing though different in crucial respects from our standard model of professional knowledge; and, (3) In the terrain of professional practice, applied science and research-based technique occupy a critically important though limited territory, bounded on several sides by artistry - the art of problem solving, the art of implementation, and an art of improvisation. According to Schon, an arts based teacher-education program can close the gap between theory and practice. Others who follow in Schon's foot-steps and advocate for teacher-education programs to promote reflective practitioners are Elliot Eisner (1998) who speaks directly about educational connoisseurship; Robert Tremmel (1993) who advocates for the introduction of non-Western ways of thinking; and, Carol Rodgers (2002) who experiments with ways that teachers can 'slow down' and be more attentive to their students needs and their personal needs.

Personally, this research study has informed and impacted my teaching in several ways. During the research and writing of the study, I regularly shared many of these ideas with my students as situations presented themselves in class discussions. Likewise, when other professional obligations take me out into the community, I also speak about these issues. And 
because my teaching and my research are deeply tied into my identity, it is my personal agenda to make others critically aware of the injustices that support and reproduce the status quo in classrooms. Admittedly, I know many do not want to 'hear' what I have to say or will deny the prospect of truth in my words and it is probably these individuals who are in most 'need' of this message. In the college department I teach in, we honor a commitment to social justice issues and for the most part, I know my colleagues 'get it' but my concerns rest with the students in the teacher-education program because the impact they can make on their students is greater, based on numbers alone.

\section{Implications of Research Findings for Teacher-Education Programs}

This qualitative study involved a small number of individuals connected to a 5-year teacher-education program at various levels and can serve as a resource to others in teachereducation programs. What follows are the implications of the research findings for teachereducation programs and are in alignment with the emergent themes related to research question two.

1. Early introduction to the classroom through volunteer experiences or formal field experiences.

2. Increase the number of required special education courses and offer special education courses at various levels in a teacher-education program.

3. Provide pre-service teachers and in-service teachers opportunities for team-teaching. 4. Increase emphasis on professional development experiences. Publicize conferences, workshops, and professional organizations. 
5. Create mentoring experiences between college faculty and pre-service teachers; pre-service teachers with more experienced pre-service teachers, “student advocates”; and, pre-service teachers with in-service teachers, "site-based liaison.”

6. On-site methods courses taught by team of instructors from university and school site.

7. Incorporate courses on learning theory specifically related to motivational issues.

8. Grant freedom and flexibility of course selections in program of study for pre-service teachers.

9. Greater attention to multicultural and diversity issues with emphasis on critical pedagogy.

10. Develop a curriculum framework for teacher-education based on the themes of this study. Recommendations for Future Research

This study generates the following questions and ideas for future research in teachereducation programs. It is recommended that:

1. A similar type of study be conducted at other institutions of the same size and smaller institutions having teacher-education programs.

2. A similar type of study be conducted at other institutions that have PDS collaboratives in place.

3. A similar type of study be conducted at institutions offering a 4-year teacher education program.

4. A similar type of study be conducted at institutions offering a Master's Degree (or 2-year) teacher education program.

5. A year-long (one calendar school year) study be conducted with pre-service teachers, inservice teachers, and college faculty of a similar nature. 
6. A study be conducted with teachers to explore the 'gap' between conceptual understandings held towards teaching and learning that are incongruent with the behaviors related to teaching and learning.

7. A study be conducted to determine teachers' perceptions of their status and power within the school and community.

8. A similar type of study be conducted with teachers based on ontological assumptions and derive a conceptual teacher-education program based on these assumptions.

9. A study be conducted with pre-service teachers who have had practicum experiences in schools where the student population is racially diverse with pre-service teachers who have had experiences in schools where the student population is racially homogeneous.

10. A study be conducted with in-service teachers who teach at schools where the student population is racially diverse with in-service teachers who teach at schools where the student population is racially homogenous. 


\section{References}

Adelman, L. (2003) Race: The Power of an Illusion, Episode 1 [video series from PBS]

Allison, C. B. (1995). Teacher's Litany: Present and Past Essays for Teachers in the History of Education.

A New Vision for Teacher Education at West Virginia University -- Report of the Participants of Partners for Progress: A Collaborative Project for Educational Improvement in West Virginia, June 12, 1992.

Apple, M. W. (1990). Ideology and the Curriculum (2 ${ }^{\text {nd }}$ Ed.). New York: Routledge.

Audi, R. (ed.) (1999), The Cambridge Dictionary of Philosophy ( $2^{\text {nd }}$ ed.). Cambridge, UK: Cambridge University Press.

Ayers, W. (1996). Doing Philosophy: Maxine Greene and the Pedagogy of Possibility. In C. Kridel, R.V. Bullough, P. Shaker (Eds.) Teachers and Mentors: Profiles of Distinguished TwentiethCentury Professors of Education. New York: Garland.

Ayers, W. (2001). To Teach: The Journey of a Teacher ( $2^{\text {nd }}$ Ed.). New York: Teachers College Press.

Baker, B. (2002). Values and practice: History teaching 1971-2001. Cambridge Journal of Education 32(1), 61.

Ball, M. \& Smith, G. (1992). Analyzing Visual Data. Newbury Park: Sage.

Bateson, M. C. (1994). Peripheral Visions: Learning Along the Way. New York: Harper Collins.

Barthes, R. (1977) Image-Music-Text. New York: Hill and Wang.

Barthes, R. (1981) Camera Lucida. New York: Hill and Wang.

Belenky, M., Clinchy, B., Goldberger, N., Tarule, J. (1986). Women's Ways of Knowing: The Development of Self, Voice, and Mind. United States: Basic Books.

Benedum Foundation (2000) Better Teachers, Better Schools: The Benedum Collaborative Model of Teacher Education at West Virginia University. A report from the Claude Worthington Benedum Foundation.

Berger, J. (1980) About Looking. New York: Pantheon.

Beyer, L. \& Apple, M. (1988) The Curriculum: Problems, Politics, and Possibilities. Albany, NY: SUNY Press.

Bierstedt, R. (1974). The Social Order. New York: McGraw-Hill.

Bleakley, A. (2000, October). Adrift without a life belt: Reflective self-assessment in a post-modern age. Teaching in Higher Education 5(4), 405. 
Bolotin, P. J., \& Burnaford, G. E., (Eds). (2001). Images of School Teachers in America (2 ${ }^{\text {nd }}$ Ed.). Mahwah, NJ: Lawrence Erlbaum Associates.

Borgman, A. (2000, Winter). Society in the Postmodern Era. The Washington Quarterly 23 (1), 189200.

Brandt, R. (2000). Education in a New Era. Alexandria, VA: ASCD.

Brown, R. (1992) Max Van Manen and pedagogical human science research. In Understanding Curriculum as Phenomenological and Deconstructed Text 1, 44. New York: Teachers College Press.

Bruner, J. (1987). Making Sense. London: Methuen.

Bruner, J. (1990). Acts of Meaning. Cambridge, MA: Harvard University Press.

Buber, M. (1970) I and Thou. New York: Simon and Schuster.

Burrup, P. (1960). Teacher and the Public School System. New York: Harpers \& Brothers.

Capra, F. (1982). The Turning Point. Toronto: Bantam Books.

Capra, F. (1996) The Web of Life. New York: Anchor Books, Doubleday.

Clark, E. (1997). Designing and Implementing an Integrated Curriculum. Brandon, VT: Holistic Education Press.

Collazos, C. A., Guerrero, L. A., \& Pino, J. A. (2003). Knowledge Construction Awareness. Journal of Student Centered Learning 1 (2), 77-86.

Collins, P. (1970) Some philosophical reflections on teaching and learning. Teachers College Record 71(3), 413-421.

Conklin, K. (1970) The aesthetics of knowing and teaching. Teachers College Record 72(2), 257.

Colorado Department of Education (2003, July). The 4 Day School Week. Retrieved August, 2003, from Colorado Department of Education Web site: http://www.cde.state.co.us/cdeedserv/download/pdf/4dayweek.pdf.

Cortes, C. (1999, May). The Accelerating Change of American Diversity. The School Administrator, 12-14.

Cushner, K. McClelland, A., Safford, P. (2003). Human Diversity in Education: An Integrative Approach $\left(4^{\text {th }}\right.$ Ed.). Boston: McGraw-Hill.

Darling-Hammond, L. (ed.) (1994) Developing professional development schools: Early lessons, challenges, and promises. In Professional Development Schools: Schools for Developing a Profession (pp. 1-27). New York: Teachers College Press. 
Davis, B. (1999) Thinking otherwise and hearing differently. In W. Pinar (ed.) Contempoary Curriculum Discourses: Twenty Years of JCT (volume 70 of Counterpoint Series) New York: Peter Lang (original work published in 1995).

Denzin, N. K., Lincoln, Y.S. (Eds.). (2002). The Handbook of Qualitative Research (2 ${ }^{\text {nd }}$ Ed.). Thousand Oaks: Sage.

Denzin, N.K.\& Lincoln, Y.S. (Eds.). (1998). Collecting and Interpreting Qualitative Materials. Thousand Oaks: Sage.

Dewey, J. (1935) Art as Experience. Minton, Balch and Company.

Dewey, J. (1944/1916). Democracy and Education. New York: Macmillan.

Dewey, J. (1958). Experience and Nature. New York: Dover Publications.

Doll, M. A. (2000). Like Letters in Running Water: A Mythopoetics of Curriculum. Mahwah, NJ: Lawrence Erlbaum Associates.

Doll, W. (1993). A Post-Modern Perspective On Curriculum. New York: Teachers College Press.

Doll, W.\& Gough, N. (Eds.). (2002). Curriculum Visions. New York: Peter Lang.

Dondis, D. (1973). A Primer of Visual Literacy. Cambridge, MA: The MIT Press.

Doyle, W. (1989) Themes in teacher education research. In W. R. Houston (ed.) Handbook of Research on Teacher Education. New York: MacMillan.

Dreeben, R. (ed.) (1970) The Nature of Teaching. Glenview, IL: Scott Foresman.

Dreeben, R. (2002). On What is Learned in School. Reading, MA: Addison-Wesley.

Eisner, E. W. (1998). The Kinds of Schools We Need. Portsmouth, NH: Heinemann.

Ellis, C. \& Bochner, A.(1996) Composing Ethnography: Alternative Forms of Qualitative Writing. Walnut Creek, CA: AltaMira Press.

Entwistle, N (1997). Reconstituting approaches to learning: A response to Webb. Higher Education, 33, 213-218.

Epstein-Jannai, M. (2001) A place for the teacher: Some remarks about teaching and learning. Educational Theory 51(2), 221-241.

Fleener, J. (2002). Curriculum Dynamics: Recreating Heart. New York: Peter Lang.

Frank, G. (1985) Becoming the other: Empathy and biographical interpretation. Biography 8(3), 189.

Frank, R. (1969) The Americans. New York: Grossman.

Fraser, J. (1992) Preparing teachers for democratic schools: The Holmes and Carnegie Reports five years later - a critical reflection. Teachers College Record 94(1), 7. 
Freire, P. (1993) Pedagogy of the Oppressed. New York: Continuum.

Fresch, E. (2004). Connecting Children With Children: Motivation for Inquiry and Civic Participation. Portsmouth, NH: Heinemann.

Gardner, H. (1993) Multiple Intelligences: The Theory in Practice. New York: Basic Books.

Garfield, C., Spring, C., \& Cahill, S. (1998) Wisdom Circles. New York: Hyperion.

Gideonse, H. (1986) Guiding images for teaching and teacher education. In T. Lasley The Dynamics of Change in Teacher Education (volume 1 pp. 187-196). Washington, D.C.: AACTE.

Giorgi, A (1997) The theory, practice, and evaluation of the phenomenological method as a qualitative research procedure. Journal of Phenomenological Psychology 28(2), 235.

Giroux, H. (1992) Border Crossings. New York: Routledge.

Giroux, H., \& Purpel, D. (Eds.). (1983). The Hidden Curriculum and Moral Education: Deception or Discovery? Berkeley, CA: McCutchan.

Glaser, B. \& Strauss, A. (1965) The Discovery of Grounded Theory: Strategies for Qualitative Research. Chicago, IL: Aldine.

Goodall, H.L. (2000). Writing the New Ethnography. Walnut Creek: AltaMira Press.

Goodlad, J. (1984). A Place Called School: Prospects for the Future. United States: Institute for the Development of Educational Activities.

Goodlad, J., Soder, R., \& Sirotnik, K. (eds.) Places Where Teachers Are Taught. San Francisco: JosseyBass.

Grant, C. \& Sleeter, C. (1999). Turning on Learning: Five Approaches For Multicultural Teaching Plans For Race, Class, Gender and Disability $\left(2^{\text {nd }}\right.$ Ed. $)$. New York: John Wiley \& Sons.

Greene, T. (1971). The Activities of Teaching. New York: McGraw-Hill.

Greene, M. (1973). Teacher as Stranger: Educational Philosophy For the Modern Age. Belmont, CA: Wadsworth Publishing.

Greene, M. (1978). Landscapes of Learning. New York: Teachers College Press.

Greene, M. (1993, February). The passions of pluralism: Multiculturalism and the expanding community. Educational Researcher 22 (1), 17.

Griffin, D. R. (1992). Ecological Literacy: Education and the Transition to a Postmodern World. Albany, NY: SUNY Press.

Grumet, M. (1989, January-February). Generations: Reconceptualist curriculum theory and teacher education. Journal of Teacher Education 40 (1), 13-17. 
Harper, D. (1998) An argument for visual sociology. In Jon Prosser (ed.) Image Based Research: A Sourcebook for Qualitative Researchers. (pp. 24-41) Great Britain: Routledge Falmer.

Harper, D. (spring 1988) Visual sociology: Expanding sociological vision. The American Sociologist, 54.

Hodgkinson, H. (December 2000/January 2001) Educational demographics: What teachers should know. Educational Leadership 58 (4) 6-11.

Holmes Group (1990) Tomorrow's Schools: Principles for the Design of Professional Development Schools, An Executive Summary. East Lansing, MI.

hooks, B. (1994) Teaching to Transgress. New York: Routledge.

Jackson, P. W. (1986). The Practice of Teaching. New York: Teachers College Press.

Jacobs, D. T. (2002, Spring). Spirituality in education: A matter of significance for American Indian cultures. Paths of Learning 12, 16.

Jardine, D. W. (2000). Under the Tough Old Stars: Ecopedagogical Essays. Brandon, VT: Foundation for Educational Renewal.

Jensen, E. (1998). Teaching With The Brain In Mind. Alexandria, VA: ASCD.

Joseph, P.B., Bravmann, S.L., Windschitl, M.A., Mikel, E.R., Green, N.S., (2000). Cultures of Curriculum. Mahwah, NJ: Lawrence Erlbaum.

Joyce, B.\& Weil, M. (1996). Models of Teaching (5 ${ }^{\text {th }}$ Ed.). Boston: Allyn and Bacon.

Kersey, K. (1983). Sensitive Parenting. Washington, D.C.: Acropolis.

Kessler, R. (2000). The Soul of Education. Alexandria, VA: ASCD.

Kessler, R. (2002, spring). Nourishing the inner life in schools. Paths of Learning 12, 27.

Kincheloe, J., Slattery, P., Steinberg, S. (2000). Contextualizing Teaching: Introduction to Education and Educational Foundations. New York: Addison Wesley Longman.

Kirk, D. \& Macdonald, D. (2001) Teacher voice and ownership of curriculum change. Journal of Curriculum Studies 33(5), 551-567.

Kockelmans, J. (ed.) (1967) Phenomenology: The Philosophy of Edmund Husserl. Garden City, NY: Doubleday.

Kozol, J. (1996). Amazing Grace. New York: HarperCollins.

Kuhn, T. (1962). The Structure of Scientific Revolutions. Chicago: University of Chicago Press.

Lakoff, G., Johnson, M. (1980). Metaphors We Live By. Chicago: The University of Chicago Press. 
Lasley, T. J., Matczynski, T. J., \& Rowley, J. B. (2002). Instructional Models: Strategies For Teaching in a Diverse Society $\left(2^{\text {nd }}\right.$ Ed.). Australia: Wadsworth Group.

Leonard, G. (1968/1987). Education and Ecstasy. Berkeley, CA: North Atlantic Books.

Lucas, C. (1997) Teacher Education in America: Reform Agendas for the Twenty-First Century. New York: St. Martin’s Press.

Maturana, H., Varela, F. (1998). The Tree of Knowledge: The Biological Roots of Human Understanding (Rev. Ed.). Boston: Shambhala.

Matusov, E. (2001) Intersubjectivity as a way of informing teaching design for a community of learners classroom. Teaching and Teacher Education 17, 383-402.

McCaleb, S. P. (1994). Building Communities of Learners: A Collaboration among Teachers, Students, Families, and Community. New York: St. Martin's Press.

McLaren, P. (1997) Revolutionary Multiculturalism: Pedagogy of Dissent for the New Millennium. Boulder, CO: Westview Press.

McDermott, J. (ed.) (1967) The Writings of William James. Chicago: The University of Chicago Press.

McIntosh, P. (1990, Winter). White Privilege: Unpacking the Invisible Knapsack. Independent School, 49 (2), 31-36.

McLaren, P. (1997). Revolutionary Multiculturalism: Pedagogy of Dissent for the New Millenium. Boulder, CO: Westview Press.

Merleau-Ponty, M. (1962) Phenomenology of Perception. New York: Humanities Press.

Merleau-Ponty, M. (James Edie, ed) (1964) Primacy of Perception. Northwestern University Press.

Messaris, P. (1994). Visual Literacy: Image, Mind \& Reality. Boulder, CO: Westview Press.

Miller, J. (2002). Learning from a spiritual perspective. In E. O'Sullivan, A. Morrell, \& M. A. O'Connor (Eds.) Expanding the Boundaries of Transformative Learning: Essays on Theory and Praxis. New York: Palgrave.

Miller, J. P. (2000). Education and the Soul: Toward a Spiritual Curriculum. Albany, NY: SUNY Press.

Miller, R (1997). What are Schools For? Holistic Education in American Culture. Brandon, VT: Holistic Education Press.

Miller, R. (Ed.). (2000). Creating Learning Communities. Brandon, VT: The Foundation for Educational Renewal.

Mills, C.W. (1959) The Sociological Imagination. London: Oxford University Press.

Mirzoeff, N. (1998). The Visual Culture Reader. London: Routledge.

Molnar, A., Morales, J. (2000, October). Commercialism@schools. Educational Leadership 58(2), 39. 
Mooney, R. (1975). The researcher himself. In W. Pinar (Ed.), The Reconceptualists (pp. 175-207). Berkeley, CA: McCutchan.

Moran, D. (2000). Introduction to Phenomenology. London: Routledge.

Moustakas, C. (1994). Phenomenological Research Methods. Thousand Oaks: Sage.

Nava, R. G. (2001). Holistic Education: Pedagogy of Universal Love (M. N. Ríos \& G. S. Miller, Trans.). Brandon, VT: Foundation for Educational Renewal.

Neil, A. S. (1960). Summerhill: A Radical Approach to Child Rearing. New York: Hart.

Neito, S. (2004). Affirming Diversity: The Sociopolitical Context of Multicultural Education (4 ${ }^{\text {th }}$ Ed.). Boston: Pearson.

No Child Left Behind Act, PL 107-110. Retrieved from the U.S. Department of Education website: http://www.ed.gov/policy/elsec/leg/esea02/index.html.

O’Brien, L. (2000) Engaged pedagogy. Childhood Education (Annual Theme 2000), 283.

Orfield, G. \& Frankenberg, E. (2004) Where are we now? Teaching Tolerance 25, 57.

Paige, R. (2002). Meeting the Highly Qualified Teachers Challenge. Retrieved July 29, 2002 from the U.S Department Of Education Web site: http://www.ed.gov/PressReleases/062002/06112002.html

Patton, M. Q. (1990). Qualitative Evaluation and Research Methods. Newbury Park, CA: Sage.

Perkins, D. (1999) The many faces of constructivism. Educational Leadership 57(3), 6.

Perkinson, H. (1999). Teachers Without Goals. New York: McGraw-Hill.

Palmer, P. (1998). The Courage To Teach. San Francisco: Jossey-Bass Publishers.

Phenix, P. (1964). Realms of Meaning. New York: McGraw-Hill.

Pinar, W. F. (1999). Contemporary Curriculum Discourses: Twenty Years of JCT. New York: Peter Lang.

Pinar, W. F. (2004) What is Curriculum Theory? Mahwah, NY: Lawrence Erhlbaum.

Pinar,W., Reynolds, W., Slattery, P., \& Taubman, P. (1995). Understanding Curriculum: An Introduction to the Study of Historical and Contemporary Curriculum Discourse. New York: Peter Lang.

Prosser, J. (1998) Image-Based Research: A Sourcebook for Qualitative Researchers. London: Routledge.

Prosser, J. The Moral Maze of Image Ethics. Retrieved January 17, 2003 from http://education.leeds.ac.uk./ edu-jdp/image/moral maze.html. 
Putnam, R. (2000). Bowling Alone. New York: Simon \& Schuster.

Reason, P. (1988). Human Inquiry in Action. London: Sage.

Reason, P. (1994) Participation in Human Inquiry. London: Sage.

Reiss, M.\& Tunnicliffe, S. D. (2001, Summer). What sorts of worlds do we live in nowadays? Journal of Biological Edcation 35(3), 125.

Rodgers, C. (2002) Seeing student learning: Teacher change and the role of reflection. Harvard Educational Review 72(2), 230.

Rogers E.M. (1983) Diffusion of Innovations ( $3^{\text {rd }}$ ed.) New York: Free Press.

Rousemaniere, K. (2001). Questioning the visual in the history of education. History of Education 30 (2), 109-116.

Rugg, H. (1955). Social Foundations of Education. New York: Prentice-Hall.

Russell, P. (1983) The Global Brain. Los Angeles: Tarcher.

Russell, P. (1998) Waking Up In Time: Finding Inner Peaces in Times of Accelerating Change. San Rafeal, CA: Origin Press.

Scherer, M. (2002) Perspectives. Educational Leadership 60(1), 5.

Schon, D. (1987) Educating the Reflective Practitioner. San Francisco: Jossey-Bass.

Schubert, W. (1989, January-February). Reconceptualizing and the matter of paradigms. Journal of Teacher Education 40 (1), 28-32.

Schubert, W. (1993, fall) Towards lives worth living: A basis for integrating curriculum. Educational Horizons, 25-30.

Schubert, W. (1995) Towards lives worth living and sharing: Historical perspective on curriculum coherence. In J. Beane (ed.) Toward a Coherent Curriculum. Alexandria, VA: ASCD.

Schubert, W. H., Schubert, A. L., Thomas, T., Carroll, W. (2002). Curriculum Books: The First Hundred Years ( $2^{\text {nd }}$ Ed.). New York: Peter Lang.

Searle, J. (1983) Intentionality. Cambridge, UK: Cambridge University Press.

Simon, K. (2002, September). The blue blood is bad, right? Educational Leadership 60(1), 24.

Shaker, P. \& Kridel, C. (1989) The return to experience: A reconceptualist call. Teacher Education 40(1), 2.

Slattery, P. (1995). Curriculum Development in a Postmodern Era. New York: Garland. 
Slattery, P. \& Rapp, D. (2003). Ethics and Foundations of Education: Teaching Convictions in a Postmodern World. Boston: Allyn and Bacon.

Sloan, D. (1983). Insight-Imagination: The Emancipation of Thought and the Modern World. Westport, CT: Greenwood Publishing Group.

Sloan, D. (Ed.).(1979). Education and Values. New York: Teachers College Press.

Sokolowski, R. (2000) Introduction to Phenomenology. United States: Cambridge University Press. Spiegelberg, H. (1975) Doing Phenomenology. The Hague: Martinus Nijhoff.

Tacey, D. (2002). Student Spirituality and Educational Authority. International Journal of Children's Spirituality 7(2), 171.

Tanner, D., Tanner, L. (1990). History of the School Curriculum. New York: Macmillan.

Terren, E. (2002). Post modern attitudes: A challenge to democratic education. European Journal of Education 37 (2), 161-177.

The National Commission on Excellence in Education. (1983, April). A Nation at Risk: The Imperative for Educational Reform. Retrieved from the U.S Department of Education Web site: http://www.goalline.org/Goal\%20Line/NatAtRisk.htm.

Tierney, W. \& Lincoln, Y. (eds.) (1997) Representation and the Text: Re-framing the Narrative Voice. Albany, NY: SUNY Press.

Toffler, A. (1970) Future Shock. New York: Random House.

Tomlinson, C. A. (2002, September). Invitations to learn. Educational Leadership 60 (1), 7.

Tozer, S. E., Violas, P. C., \& Senese, G.(2002). School and Society: Historical and Contemporary Perspectives ( $4^{\text {th }}$ Ed.). Boston: McGraw-Hill.

Trachtenberg, A. (1989) Reading American Photographs: Images as History Mathew Brady to Walker Evans. New York: Hill and Wang.

Tremmel, R. (1993) Zen and the art of reflective practice in teacher education. Harvard Educational Review 63(4), 434.

Tyack, D., et. al. (2001). School: The Story of American Public Education. Boston: Beacon Press.

Urban, W., Wagoner, J. (2000). American Education: A History (2 ${ }^{\text {nd }}$ Edition). Boston: McGraw-Hill.

U.S. Census Bureau. U.S. Statistics in Brief - Population by Race and Hispanic Origin. Retrieved March 30, 2004 from http://www.census.rog/statab/www/poprace.html.

Van Manen, M. (1990) Researching Lived Experience: Human Science for an Action Sensitive Pedagogy. Albany, NY: SUNY Press.

Van Manen, M. (1997, August) From meaning to method. Qualitative Health Research 7(3), 345. 
Verduin, J. (ed.) 1967) Conceptual Models in Teacher Education. Washington, D.C.: AACTE.

Weber, R. (winter, 1986). The Search for Unity. Institute of Noetic Science Review, 17.

Westbrook, R. (1991) John Dewey and American Democracy. Ithaca, NY: Cornell University Press.

Wilber, K. (1998). The Marriage of Sense and Soul: Integrating Science and Religion. New York: Random House.

Willoughby, B. (2004, Spring). An American Legacy. Teaching Tolerance (25), 40-48.

Winston, B. (1998) The camera never lies: The partiality of photographic evidence. In Jon Prosser (ed.) Image Based Research: A Sourcebook for Qualitative Researchers. (pp. 60-68) Great Britain: Routledge Falmer.

Wolff, R. (2002). Self-Reflection: An Essential Quality for Phenomenological Researchers. In S.B. Merriam (Ed.), Qualitative Research in Practice: Examples for Discussion and Analys. San Francisco: Jossey-Bass.

Wolfson, B. (1977). A phenomenological perspective on curriculum and learning. Association for Supervision and Curriculum Development 1, 81-89.

Yolen, J. (1992). Encounter. Orlando, FL: Harcourt.

Zeichner, K. Melnick, S., \& Gomez, M. (eds.) (1996) Currents of Reform in Preservice Teacher Education. NewYork: Teachers College Press.

Zusne, L. (1970) The Visual Perception of Form. New York: Academic Press. 